HANS-DIETER VON FRIELING - MICHAEL MIESSNER - ROBIN MARLOW

\title{
WOHNRAUM ATLAS GÖTTINGEN
}

WOHNUNGSVERSORGUNG UND WOHNUNGSPOLITIK IN GÖTTINGEN SEIT 2010

\section{FAKTEN - ANALYSEN - PERSPEKTIVEN}

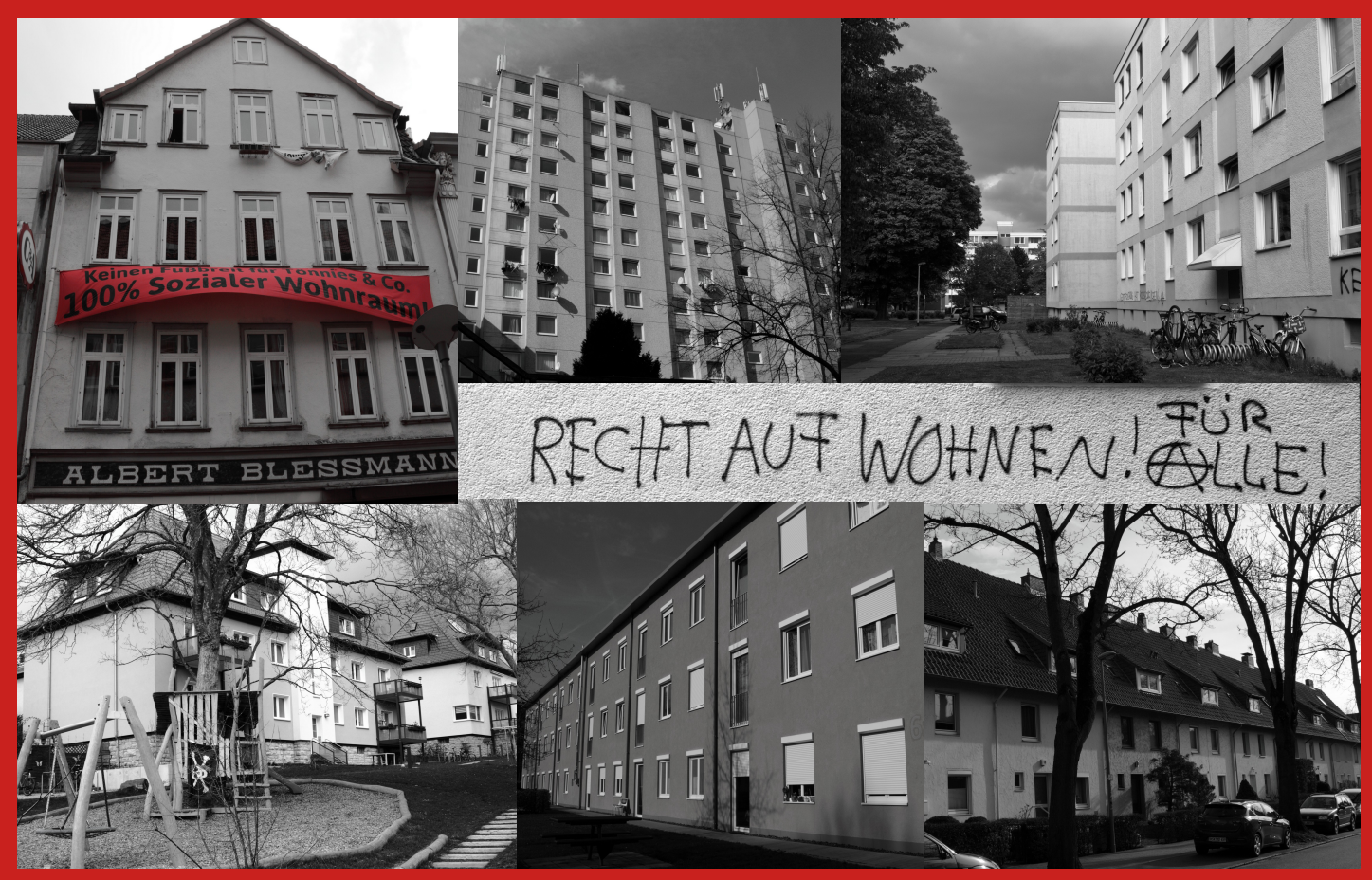

Göttingen 2020 


\section{Inhaltsverzeichnis}

I Wohnungsmarkt Göttingen.............................................................................. 10

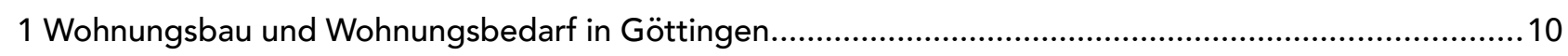

2 Mietenwahnsinn und die Verknappung günstigen Wohnraums............................................................. 12

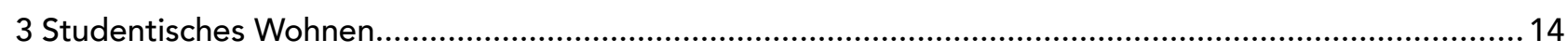

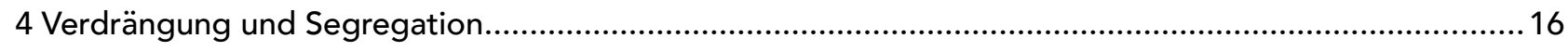

II Neoliberale Wohnungspolitik................................................................. 18

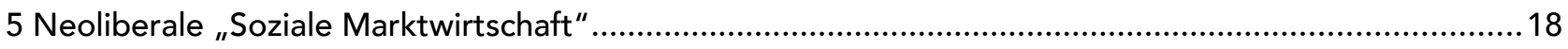

III Immobilienunternehmen und ihre Praktiken....................................................20

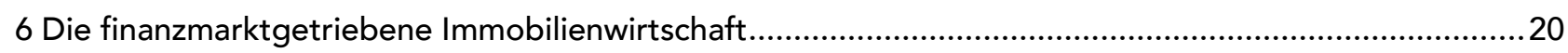

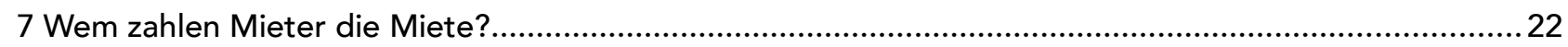

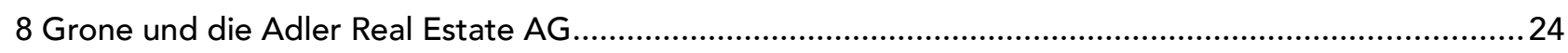

9 IWF - Bodenspekulation, Stadtplanung und Projektentwickler...........................................................26

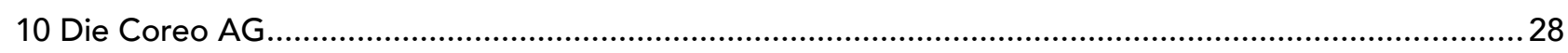

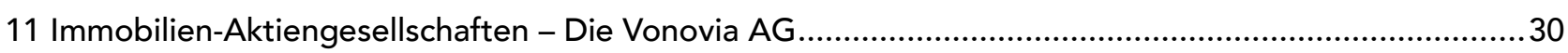

12 Jenseits von Aktiengesellschaften: Bassil Group - Wertgrund GmbH - Gruppe Kurth.........................32

IV Kommunale Wohnungspolitik........................................................ 36

14 Vom sozialen Wohnungsbau zur sozialen Wohnraumförderung (1).......................................................36

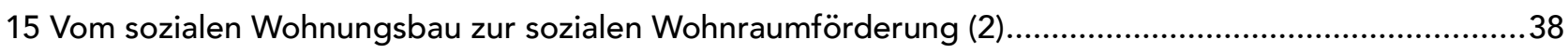

16 Kommunale Wohnungspolitik In der Zwickmühle?................................................................................ 40

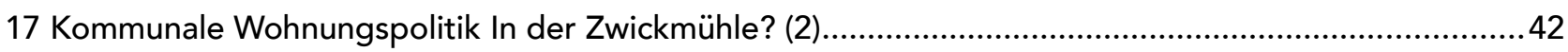

18 Bündnis und Kommunales Handlungs-konzept für bezahlbaren Wohnraum...........................................4

V Bodenpreise und ihre Effekte...................................................................46

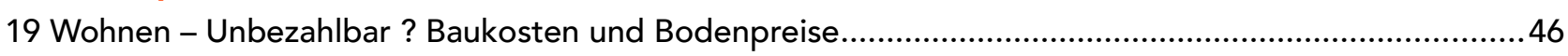

20 Wohnen - Unbezahlbar? Mietbelastung und Einkommensentwicklung...............................................48

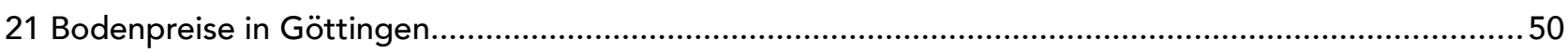

22 Bodenpolitik der Stadt - Kommunaler Grundbesitz und Bauleitplanung..............................................52

VI Proteste..................................................................................... 54

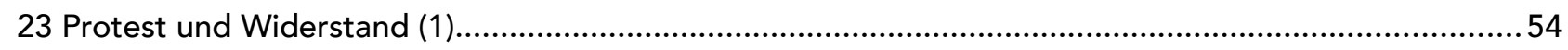

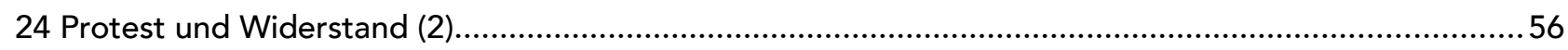

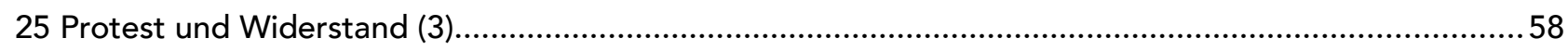

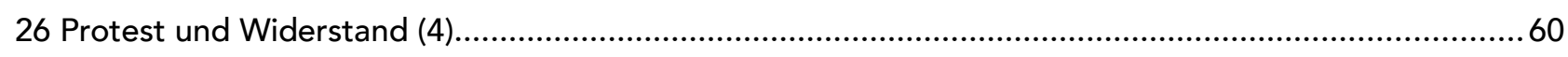

VII Eine grundlegend neue Wohnungspolitik ist notwendig................................64

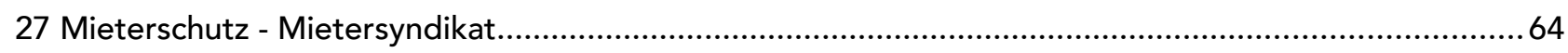

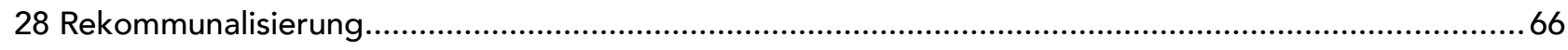

29 Neue Gemeinnützigkeit - Landeswohnungsbaugesellschaft.........................................................68

30 Soziales Bodenrecht, Öffentliches Grundeigentum........................................................................70

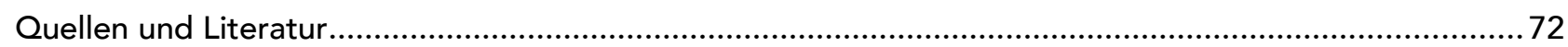




\section{Abbildungsverzeichnis}

Abb. 1: Standorte von Wohnungsunternehmen in Göttingen 2020..........................................9

Abb. 2: Entwicklung der Einwohner- und Haushaltszahlen in Göttingen seit 2000........................10

Abb. 3: Entwicklung der Haushalts- und Wohnungszahlen in Göttingen seit 2000.......................10

Abb. 4: Wohnungsneubau in Göttingen 2010-2017............................................................11

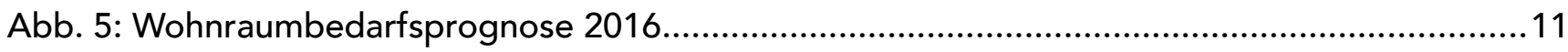

Abb. 6: Angebotsmieten in der Stadt Göttingen 2019........................................................12

Abb. 7: Entwicklung der Angebotsmietpreise in der Stadt Göttingen zwischen 2013 und 2019.....12

Abb. 8: Mietpreisentwicklung......................................................................................... 13

Abb. 9: Entwicklung der Zahl der Angebote nach Mietpreissegmenten in der Stadt Göttingen

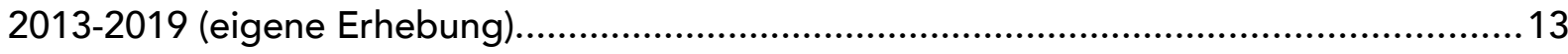

Abb. 10: "Campusglück" der BGP-Gruppe in Grone..................................................................14

Abb. 11: Entwicklung der Zahl der in Göttingen wohnhaften Studierenden (Quelle: Gösis)............14

Abb. 12: Goßlerstrasse 79 (Vermietung durch GöHV).........................................................15

Abb. 13: Fluktuationsrate nach Altersgruppen in der Stadt Göttingen im Jahr 2016...................15

Abb. 14: Entwicklung des Anteils verschiedener Bevölkerungsgruppen im Quartier „Theodor-

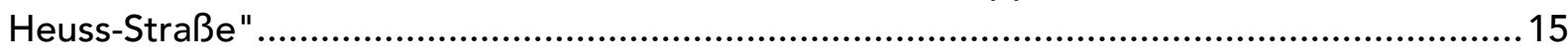

Abb. 15: Wohnungsannoncen im Immobilienportal immobilienscout24.de (20.02.2018)...............16

Abb. 16: Schematischer Überblick über die Verdrängungsprozesse in Göttingen..........................17

Abb. 17: Entwicklung des Anteils von Sozialleistungsempfänger^innen 2014 bis 2018 in den statistischen Bezirken

Abb. 18: Vergleich der Kosten der Objekt- und Subjektförderung des Bundes 1980-2014 (Holm et

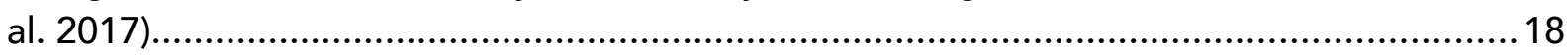

Abb. 19: Stationen der Wohnungspolitik seit 1990.................................................................19

Abb. 20: Schema der finanzmarktbasierten Immobilienwirtschaft..............................................21

Abb. 21: Aktionärs- und Unternehmensstruktur Vonovia (2019) ................................................23

Abb. 22: Aktionärs- und Unternehmensstruktur Adler Real Estate (2019).....................................23

Abb. 23: Grone „Mitte” (links) - Grone „Süd” (Violett: Gebiet des Bebauungsplans)....................24

Abb. 24: ARE: Mietenanstieg in Grone seit 2016...................................................................24

Abb. 25: Mietenanstieg in 'Top 20'-Städten...........................................................................24

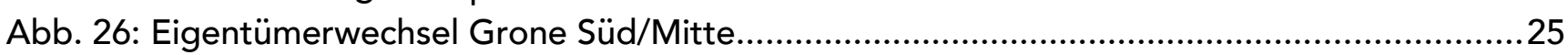

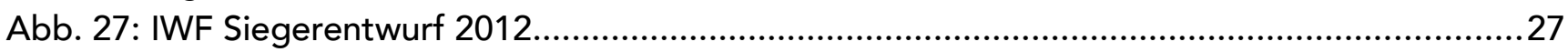

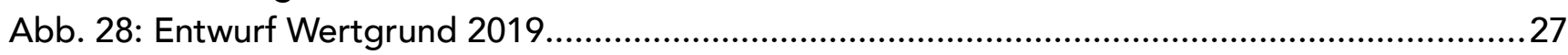

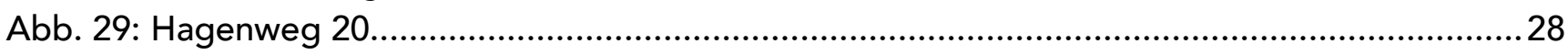

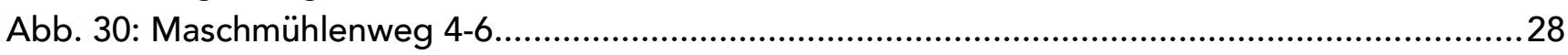

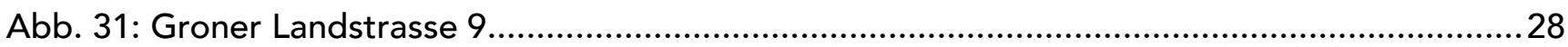

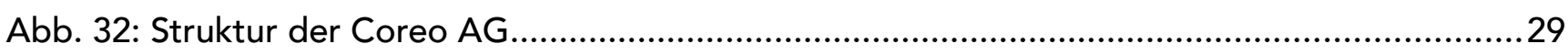

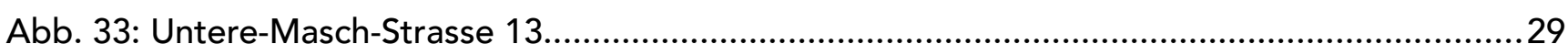

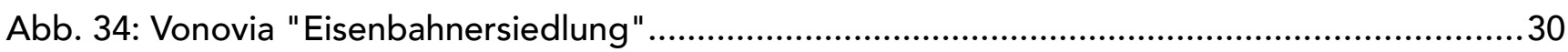

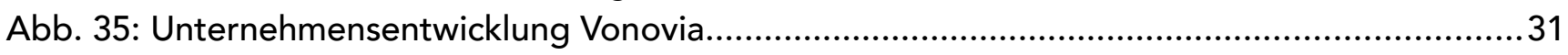

Abb. 36: Obere-Masch-Strasse 1 Zimmer + Bad, 20 qm, 17,25 Euro/m²...................................32

Abb. 37: Standorte von Vonovia und Adler Real Estate..............................................................34

Abb. 38: Standorte der Bassil Group (Vermietungsangebote) und der Coreo AG..........................35

Abb. 39: Verteilung der Sozialwohnungen in Göttingen 1994 und 2007......................................36

Abb. 40: Vermittlung von Sozialwohnungen 2008 - 2017 (Quelle: Gösis)......................................37

Abb. 41: Entwicklung der Zahl der Sozialwohnungen seit 1980................................................37 
Abb. 42: Änderungen im Sozialwohnungsbestand 2000-2017.................................................37

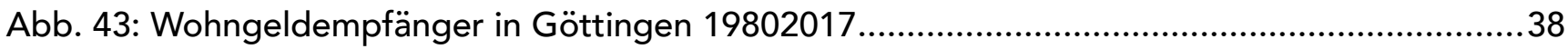

Abb. 44: Sozialwohnungsbewerber in Göttingen 2007-2018...................................................39

Abb. 45: Sozialwohnungen und Belegungsrechte in Göttingen 2000-2019................................39

Abb. 46: Bebaute und unbebaute städtische Flächen 2017 (orange $=$ Wohnbauland).....................40

Abb. 47: Aktivitäten des Rates der Stadt Göttingen 2012-2015..............................................41

Abb. 48: Aktivitäten des Rates der Stadt Göttingen 2016-2019..............................................43

Abb. 49: Instrumente des Kommunalen Handlungskonzeptes (nach Stadt Göttingen 2019)...........45

Abb. 50: Wohnraumbedarfsprognose (bezahlbar) (Stadt Göttingen 2018 nach GEWOS 2017).......45

Abb. 51: Finanzielle Förderinstrumente des KHK (nach Stadt Göttingen 2019)............................45

Abb. 52: Kosten im Wohnungsneubau (2016).......................................................................46

Abb. 53: Kostenentwicklung im Wohnungsbau seit 2000 (Quelle: Pestel Institut/ARGE 2018)......46

Abb. 54: Einfluss des Bodenpreises auf die Miethöhe (Modellrechnung)....................................47

Abb. 55: Mietbelastung in Deutschland 2018 (Junker 2018 ).....................................................48

Abb. 56: Einkommensentwicklung in Deutschland 1991-2014 (DIW 2018)...................................49

Abb. 57: Geschätzte Zahl der Haushalte mit geringem bzw. „mittlerem” Einkommen in Göttingen

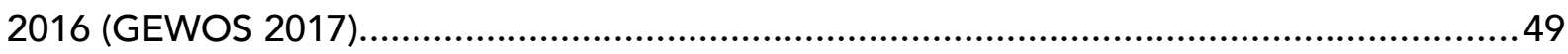

Abb. 58: Mietbelastungsquote in Deutschland 2018 (Destatis)...................................................49

Abb. 59: Entwicklung der Bodenrichtwerte 2009-2020............................................................50

Abb. 60: Boden- und Immobilienpreise in Göttingen seit 2000.................................................50

Abb. 61: Bodenrichtwerte in Göttingen 2018.....................................................................51

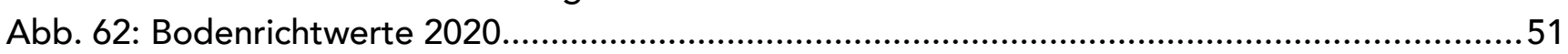

Abb. 63: Entwicklung von Wohnbauflächen (Stadt Göttingen 2019)..........................................53

Abb. 64: Wohn- und Baulandbedarf bis 2030 (FNP) - Planungsgrundlage..................................53

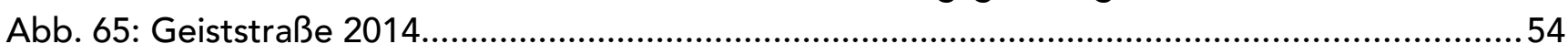

Abb. 66: Zeltlager Humboldtallee 9.Oktober 2014 ..................................................................55

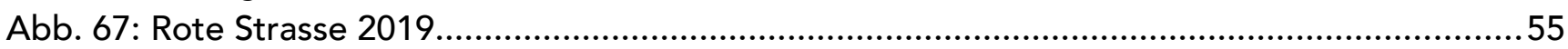

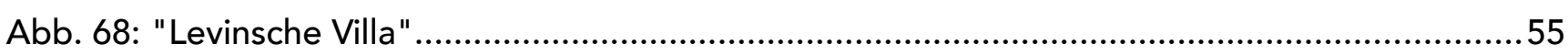

Abb. 69: Container - Ersatz für Bäder - Zimmermannstrasse Januar 2018...................................57

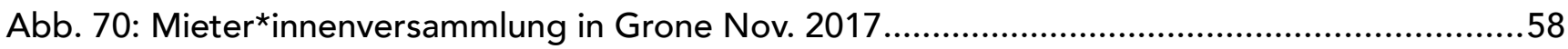

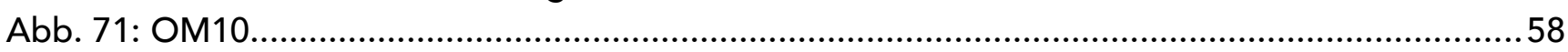

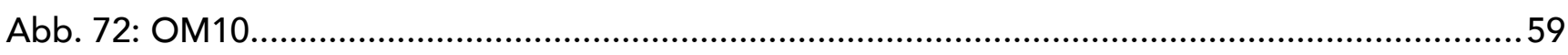

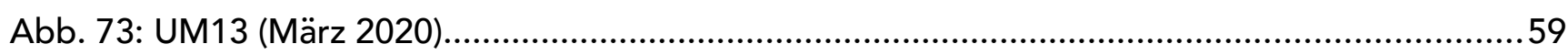

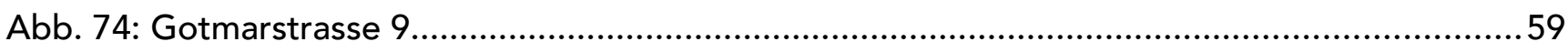

Abb. 75: Transparent der Groner Mieterini zur Demo: " Radtour durch das Miethaifischbecken"

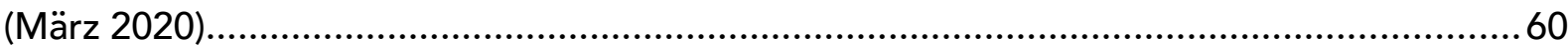

Abb. 76: Plakat des Göttinger Bündnis zum Housing Action Day 2020.....................................61

Abb. 77: Standorte öffentlicher und genossenschaftlicher Wohnungsunternehmen.....................63

Abb. 78: Modell des Mietshäuser Syndikats..............................................................................65

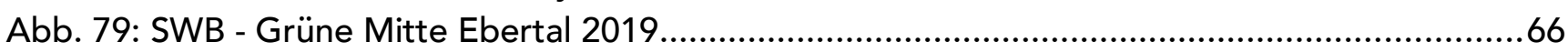

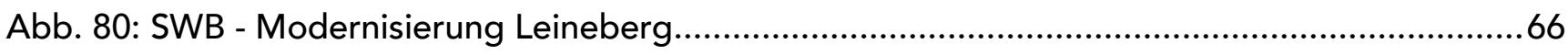

Abb. 81: Wohnungsgenossenschaft- Modernisierung Nonnenstieg............................................68

Abb. 82: Wohnungsgenossenschaft - Neubau Adam-von-Trott-Weg........................................68

Abb. 83: Vorschlag des DGB Niedersachsen für eine neue Wohnungspolitik (2019).....................69 


\section{Vorwort}

Die Wohnungsfrage ist - wieder einmal - zu einem sehr ernsten Problem geworden. Es fehlt in großem Umfang an bezahlbarem Wohnraum. Seit fast einem Jahrzehnt gibt es dementsprechend Mieter*innenproteste in zahlreichen Städten, auch in Göttingen.

Die Aufforderungen an politische Verantwortungsträger, sich konsequent für mehr sozialen Wohnungsbau einzusetzen, haben bisher zu keiner grundlegend neuen Ausrichtung der Wohnungspolitik geführt. Die Weichenstellungen zu einer neoliberal an marktwirtschaftlichen Grundsätzen orientierten Wohnungspolitik durch CDU, FDP, SPD und Grüne seit 1990 werden politisch nach wie vor verteidigt. Stimmen, die diese Politik in Frage stellen, werden im Diskurs hingegen kaum gehört. Seit 2002 haben die Kommunen mit der Übernahme der Kosten der Unterkunft für Transferleistungsempfänger*innen eine noch größere Verantwortung in der Sicherung der Wohnungsversorgung übertragen bekommen. Ihnen wurden jedoch weder mehr finanzielle Mittel und noch neue wirksame Instrumente zur Bewältigung dieser Aufgabe übertragen. Ihre finanziellen Möglichkeiten wurden nach der Finanzkrise mit der Schuldenbremse sogar weiter eingeschränkt - ausgerechnet in einem Moment, als das Wachstum in den großen Städten den Wohnungsbedarf deutlich vergrößerte. Die so hergestellten „angespannten Wohnungsmärkte” waren Immobilienspekulanten und finanzmarktgetriebenen Immobilienunternehmen sehr willkommene Gelegenheiten, Bodenpreise und Mieten zu steigern.

Der Atlas greift diese allgemeinen Entwicklungen auf und versucht die damit zusammenhängenden Fragen am Beispiel Göttingens zu beantworten:

Welche Folgen hatten die Reformen für die kommunale Wohnungsfrage?

Welche Auswirkungen hat eine marktwirtschaftlich organisierte Wohnungsversorgung?

Wie stellt sich die finanzgetriebene Immobilienmarktentwicklung auf lokaler Ebene dar?

Welche politischen Strategien wenden Kommunen angesichts dieser Entwicklungen an und welche Folgen hat dies für die Wohnungsfrage?

Dieser Atlas untersucht zur Beantwortung dieser Fragen die grundlegenden Entwicklungen des Göttinger Wohnungsmarktes. Der zweite Abschnitt widmet sich den Effekten neoliberaler Wohnungspolitik. In einem dritten Schritt stellt er die Auswirkungen investorengetriebener Wohnungsmarktentwicklung anhand von Beispielen großer Immobilienunternehmen wie Vonovia oder Adler Real Estate, aber auch lokaler Projektentwickler und Investoren dar. Viertens erläutert der Atlas verschiedene wohnungspolitische Strategien zum Umgang mit der Wohnungsfrage und macht deutlich, dass diese die Wohnungsfrage keinesfalls lösen. Fünftens wird diskutiert, welche Effekte die Bodenpreise auf die Miethöhe und die Bezahlbarkeit des Wohnens haben. Sechstens widmet sich der Atlas dem vielfältigen Widerstand gegen die Verschärfung der Wohnungsfrage in den vergangenen zehn Jahren. Abschließend umreißt er Diskussionen und Überlegungen, wie eine bessere, strukturell andere Wohnungspolitik und -wirtschaft gestaltet werden müsste und könnte, die ein „gutes Wohnen für alle” zuverlässig sicher stellt.

Dieser Atlas will den Widerstand und die strategischen Diskussionen mit Informationen, Analysen und Perspektiven unterstützen.

Wir danken Martin Ahlfeld für die Unterstützung in der Kartographie.

Göttingen und Dresden, im März 2020

Hans-Dieter von Frieling, Michael Mießner und Robin Marlow 



\section{Objekte großer Wohnungseigentümer im Stadtgebiet Göttingen}

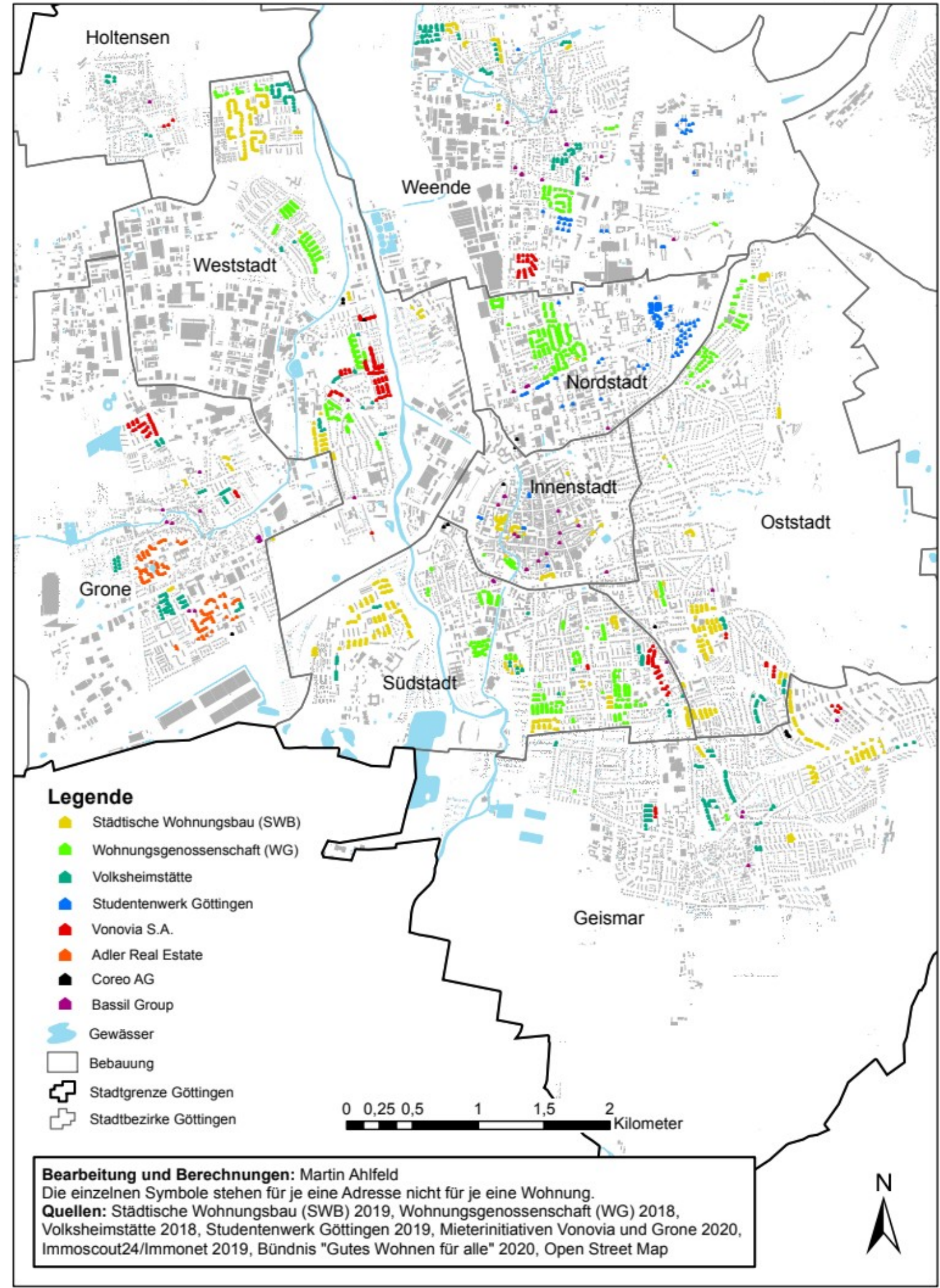

Abb. 1: Standorte von Wohnungsunternehmen in Göttingen 2020 


\section{Wohnungsmarkt Göttingen}

\section{WOHNUNGSBAU UND WOHNUNGSBEDARF IN GÖTTINGEN}

$\mathrm{S}$ eit dem Ende der 1990er Jahre ist der Neubau von Mietwohnungen in Göttingen - wie auch in der übrigen BRD - eingebrochen. Ein Jahrzehnt lang hat sich der Bestand an Mietwohnungen so gut wie gar nicht vergrößert. Das Statistische Amt der Stadt verzeichnet zwar für den Zeitraum 2000-2010 einen Zuwachs von knapp 1.400 neuen Wohnungen in Mehrfamilienhäusern (Gösis 060.01). Aber man weiß nicht, wie viele Wohnungen in der Zeit verloren gingen - durch Abriss, Umnutzung, o.ä. Abgänge sind seit 1995 genehmigungsfrei. So kann es sein, dass sich der Bestand an Mietwohnungen in dem Jahrzehnt 20002010 kaum verändert hat.

Bis 2010 bleibt auch die Einwohnerzahl Göttingens weitgehend stabil. Sie geht aufgrund sinkender Studentenzahlen sogar geringfügig zurück. Wie sich die

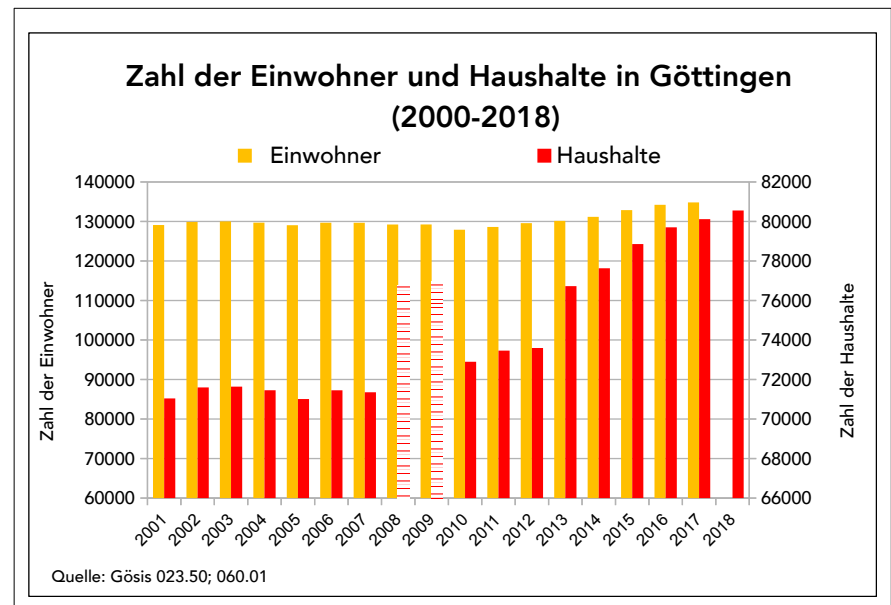

Abb. 2: Entwicklung der Einwohner- und Haushaltszahlen in Göttingen seit 2000

Zuwachs/Verlust an Wohnungen ${ }^{\star}$ ) und Haushalten in Göttingen (2000-2017)

Wohnungen in Ein-/Zweifamilienhäusern $\quad$ Wohnungen in Mehrfamilienhäusern घeränderung der Zahl der Haushalte

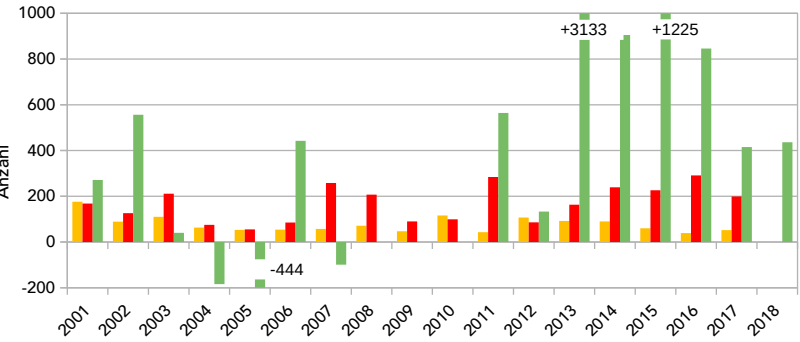
*) ohne Wohnungsabgänge (!) Fortschreibungszahlen, Quelle: Gösis 023.50; 060.01

Abb. 3: Entwicklung der Haushalts- und Wohnungszahlen in Göttingen seit 2000
Zahl der Haushalte in Göttingen, die wohnungsmarktrelevante Größe, seit 2000 entwickelt hat, ist nur näherungsweise bekannt; exakt vergleichbaren Zahlen liefert die amtliche Statistik nicht. (Gösis 060.00, 023.50)

Seit 2010/11 steigt die Zahl der (wohnberechtigten) Einwohner deutlich - von rd. 128.000 (2010) auf 135.299 (2018). Da der Zuwachs vor allem auf die wachsende Zahl von Studierenden zurückgeht, ist auch die Zahl der 1-Personen-Haushalte um rd. 8.000 angestiegen. Insgesamt wohnen in Göttingen jetzt 80.555 Haushalte (2018) gegenüber rd. 73.000 um 2010/11 (Gösis 023.50).

Der zusätzliche Bedarf an Mietwohnungen ist in den letzten Jahren deutlich größer geworden. Die Neubautätigkeit ist zwar auch gestiegen, aber die rd. 200 Mietwohnungen, die 2010-2017 durchschnittlich pro Jahr dazu gekommen sind, haben - wegen möglicher Abgänge - vergleichbaren Zahlen den Bestand wohl nur minimal vergrößert. ${ }^{1}$ Genaue Daten hat die Stadt nicht.

Ob es 2018 tatsächlich insgesamt 66.658 Wohnungen in Göttingen gibt, ist lediglich ein geschätzter Maximal- und nicht ein Realwert.

Schon 2013 weist die GEWOS in einem Gutachten für die Stadt auf einen Wohnungsmangel und die Gefahr steigender Mieten hin:

"Die Wohnungsmarktsituation in Göttingen hat sich in den vergangenen Jahren deutlich angespannt. Größere Leerstände finden sich stadtweit jedoch nur in privaten Problemimmobilien auf unterstem Ausstattungsniveau. Dieser Nachfrageüberhang führt zu einem insgesamt steigenden Mietniveau in Göttingen, insbesondere für kleine Wohnungen, auf die Studenten bevorzugt zurückgreifen. ${ }^{2}$

Einen sich kurzfristig verschärfenden Wohnungsmangel bei preisgünstigen Wohnungen, besonders für 1und 2-Personenhaushalte, prognostiziert das Gutachten, bevor die Zahl der Studierenden deutlich steigt. Insgesamt stellt die Modellrechnung der GEWOS für das Basisjahr 2011 einen Angebotsüberhang für Wohnungen in Mehrfamilienhäusern fest. Ein Neubau von Mietwohnungen, insgesamt 1.770 bis 2025, sei zur Bestandserhaltung (als Ersatzbauten und Fluktuationsreserve) notwendig. Grundlage dieser Schätzung ist die Prognose der Einwohnerentwicklung der 
Stadt von 2011. Laut dieser Prognose könnte die ,wohnungsmarktrelevante' Einwohnerzahl Göttingens bis 2025 um 2\% sinken, maximal vielleicht um 0,8\% steigen. Für den letzteren Fall wären nach GEWOS noch zusätzliche 910 Mietwohnungen bis 2025 erforderlich.

Doch die Einwohnerzahl Göttingens entwickelt sich anders als vorhergesagt. Seit 2010 steigt die Zahl der Studierenden um rd. 1.000 pro Jahr. 2017 sind rd. 8.000 Studierende mehr eingeschrieben als 2010. Die Bevölkerungsprognose von 2011 hat zwar auch einen Zuwachs bis 2013 errechnet, danach aber einen Rückgang oder höchstens Stagnation. Doch tatsächlich steigt die Einwohnerzahl seit 2011 ständig weiter und beträgt 2018 rd. 135.000. In einem erneuten Gutachten 2016 errechnet GEWOS nun schon für das Bezugsjahr 2014 einen Mangel von 700 Mietwohnungen. Das Gutachten sieht aufgrund wachsender Einwohner- und Haushaltszahlen jetzt einen Neubaubedarf von 2.800 Wohnungen bis 2020 und - unter der Annahme eines Einwohnerzuwachses von 3.000 Personen bis 2030 - einen Neubaubedarf von 4.600 (Miet)Wohnungen bis 2030. Plus einem Neubaubedarf von 1.600 Wohneinheiten in Ein-/Zweifamilienhäusern bis dahin.

Auch diese Annahmen und rechnerischen Größen sind mittlerweile überholt. Die für 2030 angenommene ,wohnungsmarktrelevante' Einwohnerzahl wird bereits 2018 erreicht. D.h. bis 2020 müssten laut dieser Modellrechnung nicht 2.800 neue Mietwohnungen gebaut worden sein, sondern 3.600 und bis 2030 dann weitere 1.000. Oder mehr, wenn die Einwohnerzahl weiter steigt. Die Zahl fertiggestellter Mietwohnungen liegt in den letzten Jahren gerade bei 200 bis 233 pro Jahr (dunkelrote Säule Abb. 3). Eine Menge, die nicht einmal im Jahr 2030 den im Modell geschätzten Bedarf erfüllen könnte. So ist Göttingen auch zu einem „angespannten Wohnungsmarkt" geworden. Die Mieten steigen. Es fehlt an bezahlbarem Wohnraum, verschärft dadurch, dass nicht rechtzeitig Ersatz für die absehbar wegfallenden Sozialwohnungen geschaffen wurde.

Die Stadtpolitik tut sich schwer, angemessen und zügig auf die Wechselfälle der Stadtentwicklung zu reagieren, Wechselfälle, welche Boom oder Rezession, Strukturwandel oder politische Beschlüsse wie z.B. über die Verkürzung der gymnasialen Schulzeit auslösen können. Die Wohnungsunternehmen, der "Markt", leisten nicht schnell genug die nötige Wohnungs"versorgung" dort, wo sie benötigt wird. Das hat auch damit zu tun, dass die Herstellung von Wohnungen, der Neubau, eine gewisse Zeit in Anspruch nimmt. Und es hat auch damit zu tun, dass die Investitio-
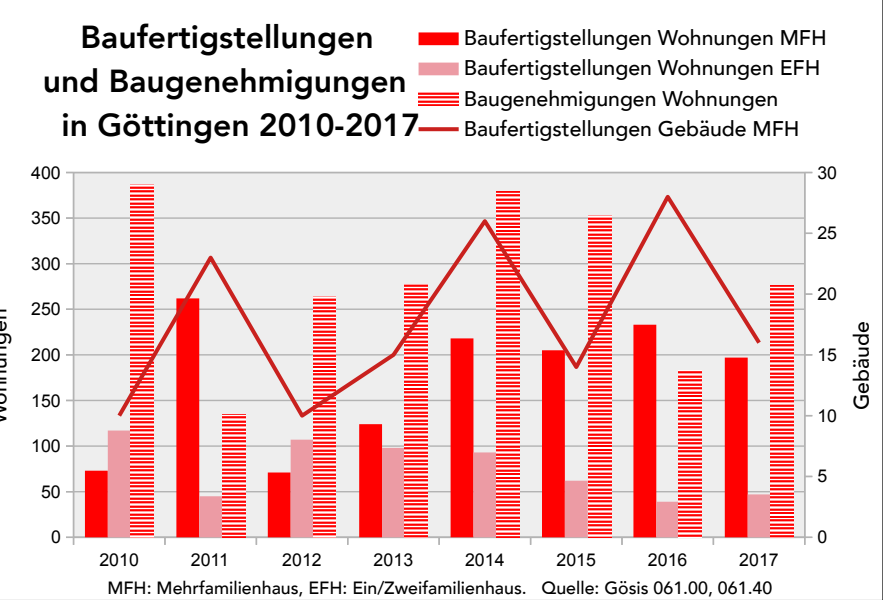

Abb. 4: Wohnungsneubau in Göttingen 2010-2017

nen einem anderen Zeitrhythmus folgen; sie sind in der Regel auf längeren Zeitraum hin ausgelegt. Ganz abgesehen davon, dass es vielleicht andere Regionen auf der Welt oder Wirtschaftsbereiche gibt, die lukrativer erscheinen für Investitionen. Wann, wo und wieviel in den Wohnungsneubau investiert wird, hängt von einer Kalkulation des "Investors" ab und nicht vom Bedarf an mehr Wohnungen. Dennoch wird gern die wenig hilfreiche Frage gestellt:

Ist es Politikversagen oder Marktversagen? Aber hat "der Markt" überhaupt die Aufgabe der Versorgung, der Befriedigung von Bedürfnissen? Verfolgt er nicht andere Zwecke und diese sehr erfolgreich? Und der Sozialstaat - hat er gegen seine verkündeten Ziele gehandelt? Hat er ein Versprechen gebrochen?

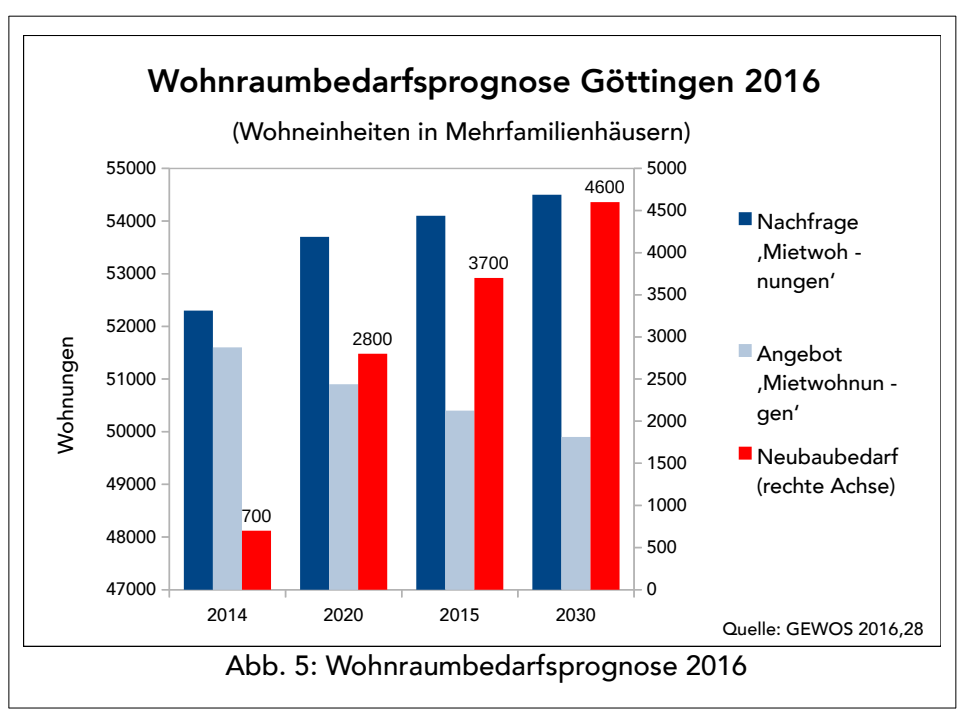




\section{MIETENWAHNSINN UND DIE VERKNAPPUNG GÜNSTIGEN WOHNRAUMS}

$\mathrm{D}$ er Mietenwahnsinn galt lange als ein Problem deutscher Metropolen, wie Berlin, Frankfurt am Main, München oder Hamburg. Mittlerweile ist er aber auch in deutschen Universitätsstädten wie Göttingen angekommen. Welche Entwicklungen den Göttinger Mietwohnungsmarkt kennzeichnen ist Gegenstand dieses Abschnittes.

Seit dem Jahr 2013 haben sich die von uns erhobenen Angebotsmieten $^{3}$ (Neuvertragsmieten) um über $28 \%$ von $8,00 € / \mathrm{m}^{2}$ auf mittlerweile $10,26 € / \mathrm{m}^{2}$ erhöht (vgl.

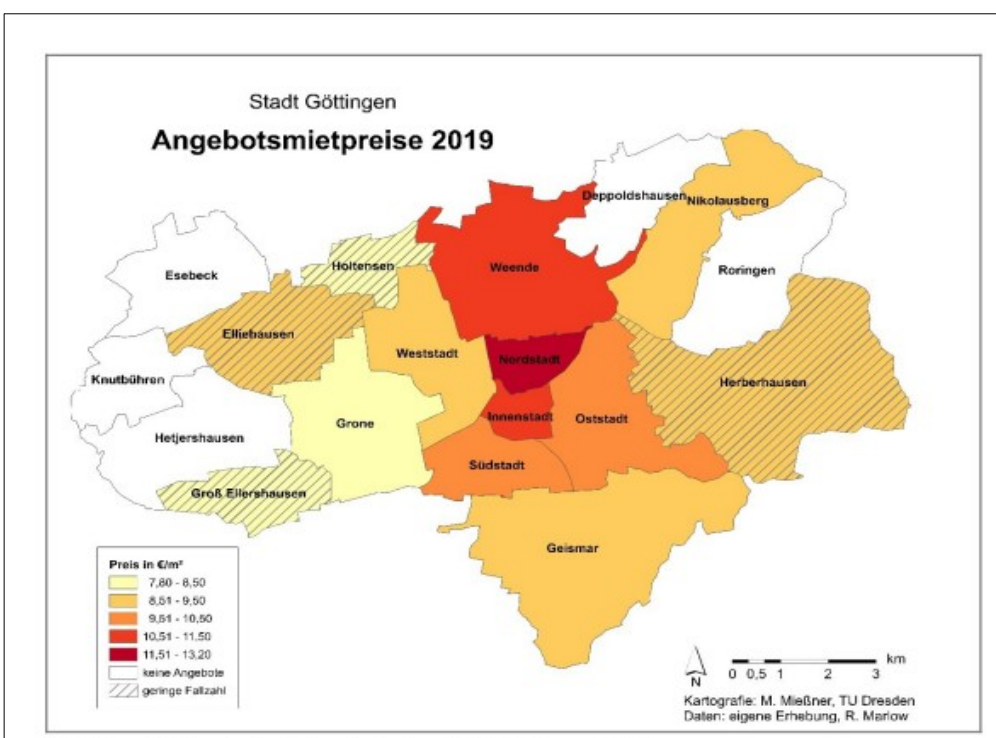

Abb. 6: Angebotsmieten in der Stadt Göttingen 2019

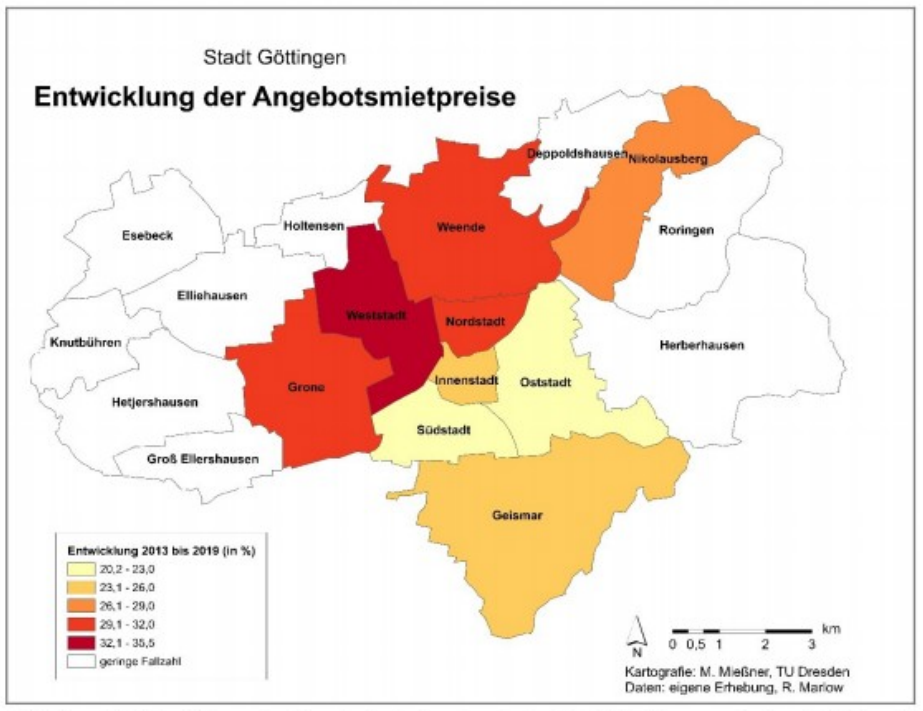

Abb. 7: Entwicklung der Angebotsmietpreise in der Stadt Göttingen zwischen 2013 und 2019
Abb. 7). Dabei sind die Mietpreise insbesondere bis 2016 stark angestiegen. Seitdem sind ausgehend von einem bereits hohen Niveau die Steigerungsraten geringer ausgefallen. Die Mietpreise in der Stadt sind dabei unterschiedlich hoch (vgl. Abb. 6). Es zeigt sich ein Keil von Nord nach Süd mit hohen Mietpreisen: Die höchsten Mieten weißt die Nordstadt mit über $13 € /$ $\mathrm{m}^{2}$ auf, gefolgt von Weende und der Innenstadt. Die Stadtteile Oststadt und Südstadt sind etwas günstiger, gefolgt von Geismar, der Weststadt und Nikolausberg.

Betrachtet man nicht nur die aktuelle Miethöhe, sondern auch die Mietpreisentwicklung zeigt sich ein anderes Bild (vgl. Abbildung 8). Die Stadtteile mit den höchsten Mieten waren in den ersten Jahren (bis 2017) durch besonders hohe Mietpreissteigerungen gekennzeichnet. Seitdem sind die Steigerungsraten - ausgehend von einem hohen Niveau - moderat gestiegen. Ganz anders verhält es sich in der Weststadt und in Grone. Hier waren die Steigerungsraten lange Zeit gering, diese Stadtteile weisen aber insbesondere seit 2017 sehr hohe Steigerungsraten auf. Hier sind deshalb die Mieten seit 2013 mit 31,1\% (Grone) bzw. 35,4 \% (Weststadt) mit Abstand am stärksten gestiegen. Damit folgen die Entwicklungen in diesen vormals sehr günstigen Stadtteilen einer allgemeinen Logik: In günstigen Beständen sind die Preissteigerungspotentiale und die so erzielbaren Renditen besonders hoch, weshalb die Immobilienbesitzer angesichts einer allgemein angespannten Versorgungslage auf dem Wohnungsmarkt hier hohe Mietpreissteigerungen durchsetzen.

Auffällig ist, dass einige wenige große Investoren die Marktentwicklung sehr stark beeinflussen und eine Trendsetterrolle einnehmen, sodass sich kleine Privatvermieter an den Preisentwicklungen in den Beständen dieser großen Investoren orientieren. So ist beispielsweise der durchschnittliche Angebotsmietpreis im Segment der Ein- und 1,5-Zimmer-Wohnungen in der Innenstadt 2019 im Vergleich zu 2018 drastisch angestiegen, während er in vielen anderen Stadtteilen konstant geblieben ist. Der Grund dafür ist, dass mehr als die Hälfte dieser Angebote in 
der Innenstadt von Anbietern kam, die insgesamt ihre Angebotsmieten in den letzten Jahren überdurchschnittlich stark gesteigert haben. Ein Beispiel hierfür ist die Bassil Immobiliengruppe. Das Unternehmen bietet Nettokaltmieten an, die 2019 um 112,1 \% (bei den Ein- und 1,5-Zimmer-Wohnungen) beziehungsweise $121,9 \%$ (bei den größeren Wohnungen) über den Mieten der Angebote von Bassil im Jahr 2016 lagen. Zum Vergleich: Die durchschnittlichen Steigerungsraten in der Gesamtstadt lagen in den Segmenten bei 4,4\% (Ein- und 1,5-Zimmerwohnungen) bzw. 7,6 \% (größere Wohnungen). Es gibt aber auch andere Anbieter mit relativ großen Beständen, deren Angebotsmieten im Verlauf der Jahre stark gestiegen sind. So ist etwa neben Beyes Immobilien und Vonovia die Göttinger Hausverwaltung (GöHv) zu nennen, die hauptsächlich Ein- und 1,5-Zimmer-Wohnungen verwaltet. In den Stadtteilen Nordtadt und Weende, in denen die GöHv große Bestände verwaltet, zeigt sich, dass die GöHv eine Trendsetterrolle einnimmt, indem sie zunächst die Angebotsmieten ihrer Ein- und 1,5-Zimmer-Wohnungen stark erhöhte, woraufhin andere Anbieter in den folgenden Jahren mit ihren Angebotsmieten nachzogen.

Angesichts dieser Entwicklungen spitzt sich die Wohnungsfrage auf dem Göttinger Mietwohnungsmarkt weiter zu. So schmilzt das günstige Mietpreissegment stark ab (vgl. Abbildung 9): Der Anteil an Wohnungen mit einer Angebotsmiete von unter $6,00 € / \mathrm{m}^{2}$ liegt mittlerweile nur noch bei 0,7\%. 2013 lag der Anteil noch bei $11,8 \%$. Ein- oder 1,5-Zimmer-Wohnungen sind gar zu einem Mietpreis von unter 7,00 €/m² nicht mehr zu bekommen. Insgesamt machen die Wohnungen von unter $7,00 € / \mathrm{m}^{2}$ nur noch $5,0 \%$ der Angebote aus, während 2013 noch über $29 \%$ dazu zählten. Wäh-

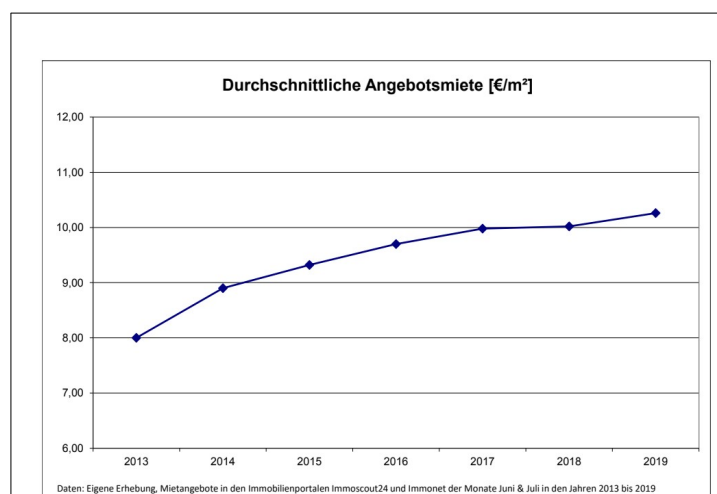

Abb. 8: Mietpreisentwicklung

renddessen haben 48,5\% der 2019 erhobenen Angebote Nettokaltmieten von $10,00 € / \mathrm{m}^{2}$ und mehr 2013 waren es nur $17,0 \%$. Dabei weitet sich vor allem das Segment über $14,00 € / \mathrm{m}^{2}$ in den letzten Jahren aus, das 2013 nur 0,5\% der Angebote ausmachte und 2019 schon fast jedes zehnte Angebot umfasst.

In den letzten Jahren ist also durch das freie Spiel des Marktes preiswerter günstiger Wohnraum systematisch vernichtet worden, so dass sich einkommensschwache Bevölkerungsgruppen auf dem Göttinger Wohnungsmarkt kaum noch mit Wohnraum versorgen können. Dies hat eine räumliche Entmischung sowie Verdrängung einkommensniedriger Bevölkerungsschichten aus der Stadt zur Folge (vgl. Kapitel 4).

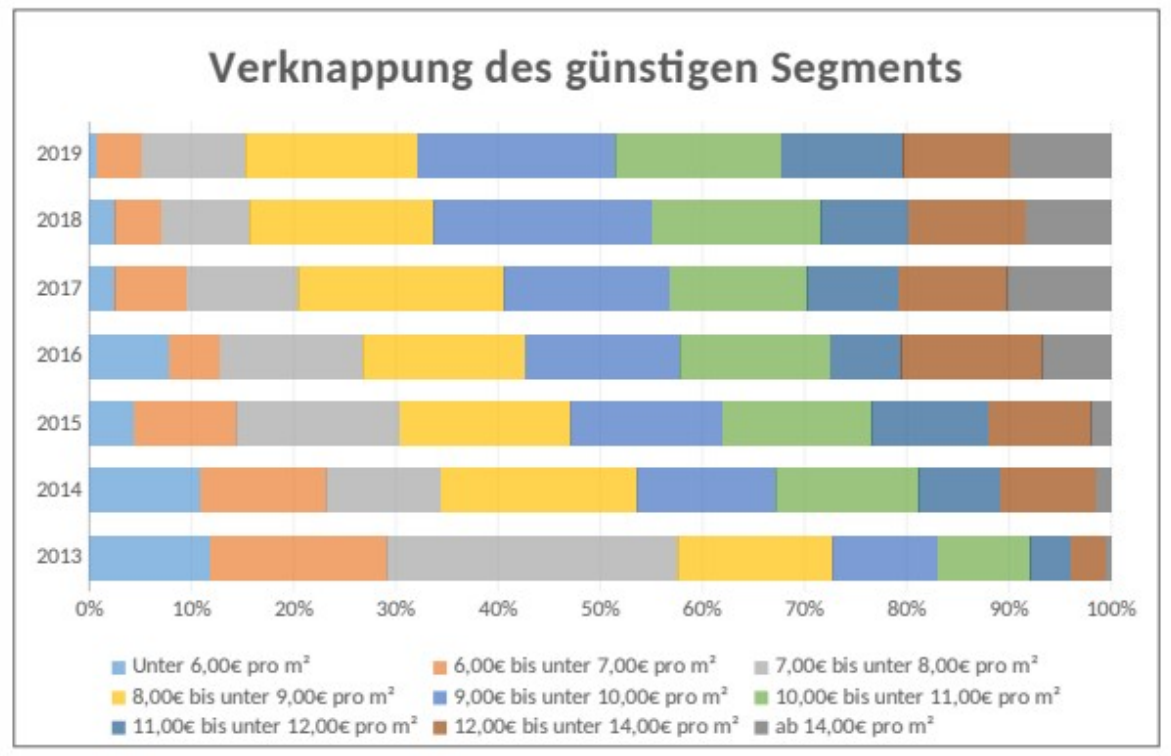

Abb. 9: Entwicklung der Zahl der Angebote nach Mietpreissegmenten in der Stadt Göttingen 2013-2019 (eigene Erhebung) 


\section{Wohnungsmarkt Göttingen}

\section{STUDENTISCHES WOHNEN}

n Göttingen haben die Georg-August-Universität sowie die beiden Fachhochschulen eine große Bedeutung für die städtische Entwicklung. Für den Wohnungsmarkt sind dabei die in der Stadt lebenden Studierenden besonders wichtig, weil sich für das studentische Wohnen ein eigener Markt entwickelt hat, der großen Einfluss auf den restlichen Wohnungsmarkt hat.

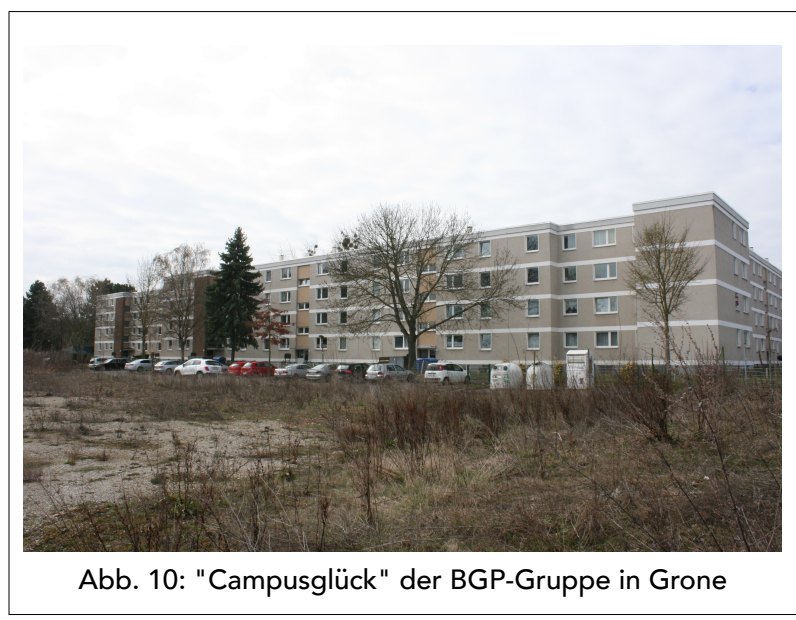

Die Zahl der in Göttingen wohnhaften Studierenden ist von $16.069 \mathrm{im}$ Jahr 2009 auf $21.329 \mathrm{im}$ Jahr 2018 angestiegen (vgl. Abbildung 11). Zusammen mit dem Fakt, dass die Göttinger Bevölkerung in den vergangenen Jahren hauptsächlich aufgrund des Zuwachses an Studierenden gewachsen ist, verweist dies auf die besondere Bedeutung, die Studierende auf dem Göttinger Wohnungsmarkt spielen. Aufgrund des besonders starken Zuzugs von Studierenden zu Beginn des Wintersemesters bemühen sich Studentenwerk und Stadtverwaltung seit einigen Jahren im Herbst darum,

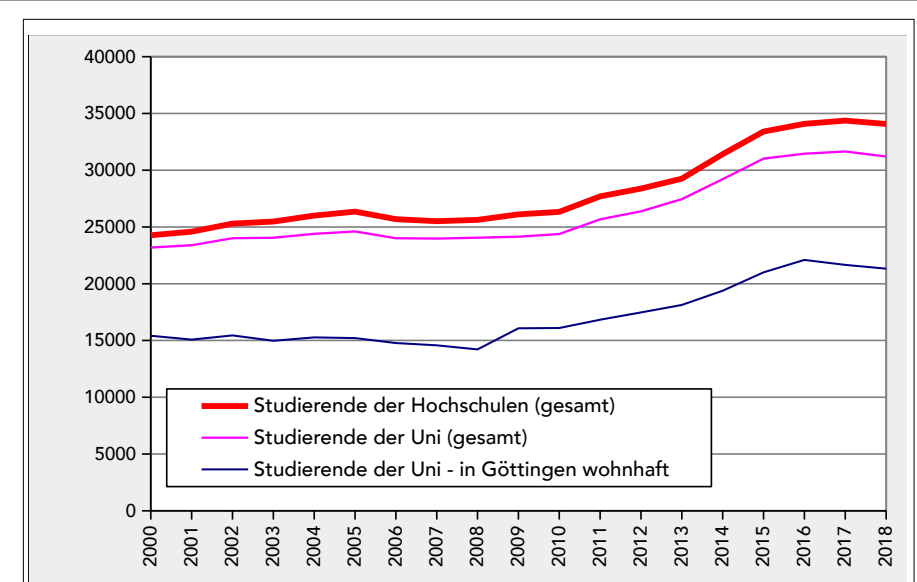

Abb. 11: Entwicklung der Zahl der in Göttingen wohnhaften Studierenden (Quelle: Gösis)
Wohnraum für Erstsemester bereitzustellen. Sie appellieren beispielsweise an die Bevölkerung Zimmer zur Untermiete zur Verfügung zu stellen oder mieten Hotelzimmer an und stellen diese Studierenden für kurze Zeit zur Verfügung. Im November 2014 richtete die studentische Wohnrauminitiative Göttingen zudem ein Zeltlager für Erstsemesterstudierende ein und machte damit auf den studentischen Wohnraummangel aufmerksam.

Insbesondere weil die Studierenden eine bedeutende Nachfragegruppe auf dem Göttinger Wohnungsmarkt darstellen, haben sich einige Vermieter auf das studentische Wohnen spezialisiert und ihre Investitions- und Vermietungsstrategien an studentische Wohneigenschaften angepasst. Zu nennen ist erstens, dass Vermieter und Investoren die aktuell hohe Nachfrage nach Wohnraum in der Stadt im Allgemeinen und im studentischen Wohnungssektor im Speziellen ausnutzen. So sind die Mieter angesichts der großen Konkurrenz gezwungen die Wohnung zu nehmen, die sie bekommen können. Gerade Studierende sind bereit, hohe Mietpreise zu zahlen, um überhaupt eine Unterkunft zu finden. Deshalb können Vermieter die Mietpreise mehr oder weniger diktieren und nutzen diese Machtposition zur Durchsetzung von Mietpreissteigerungen aus.

Zweitens herrscht unter studentischen Mietern eine hohe Fluktuation. Die Vermieter nutzen dies aus, um die Mietpreise beim Mieterwechsel zu erhöhen. Die Abbildung 13 zeigt, dass die Fluktuationsrate in der Altersgruppe der 18- bis 30-Jährigen mit $35 \%$ wesentlich höher ist als in den übrigen Altersgruppen, in denen sie bei $20 \%$ liegt oder darunter. Nach dem Auszug eines Mieters und dem Einzug eines neuen Mieters ist eine Mieterhöhung für den Vermieter wesentlich leichter durchsetzbar als in bestehenden Mietverhältnissen. Dabei werden die durch die Umzüge für den Vermieter entstehenden Verwaltungskosten durch den erhöhten Mietzins auf die Mieter abgewälzt. Dies treibt die Mieten im studentischen Wohnungssektor nochmals in die Höhe.

Aber nicht nur die Fluktuation ermöglicht die Durchsetzung hoher Mieten. Investoren setzen auch zunehmend auf kleine Wohnungen, um hohe Quadratmetermieten zu erzielen. So werden immer mehr Studierendenwohnheime mit einem überwiegenden Anteil an Einzimmerwohnungen gebaut. Dabei erlaubt es die geringe Wohnungsgröße den Vermietern, eine insgesamt 
noch erschwingliche Gesamtmiete zu fordern, während gleichzeitig die Quadratmetermiete besonders hoch ist. Beispielswiese lagen $70 \%$ der Angebote für Einzimmerwohnungen im Juni und Juli 2018 über dem durchschnittlichen Göttinger Angebotsmietpreis von $10,05 € / \mathrm{m}^{2}$. Einige Studierende können sich diese Mietpreise trotz der kleinen Wohnungsgrößen nicht leisten und weichen auf Wohngemeinschaften aus.

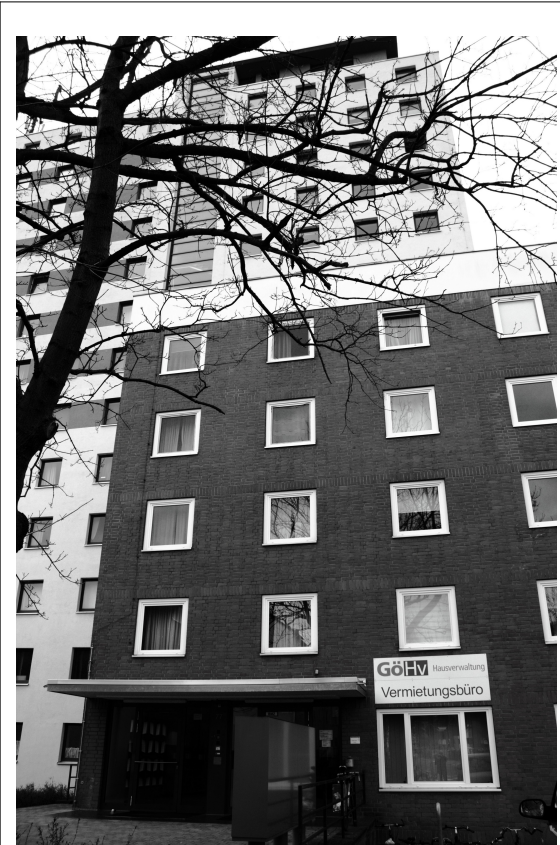

Abb. 12: Goßlerstrasse 79

(Vermietung durch GöHV)
Aber auch mit Wohngemeinschaften lässt sich ein gutes Geschäft machen. Das gemeinschaftliche Aufbringen der Miete ermöglicht es nämlich jedem einzelnen Studierenden günstiger zu wohnen, zugleich können Wohngemeinschaften höhere Mieten zahlen als andere Grup-

pen, die ebenfalls in Mehrzimmerwohnungen leben wollen, wie beispielsweise Familien. Deshalb bevorzugen Vermieter studentische Wohngemeinschaften gegenüber anderen Mietern. Außerdem gehen die Vermieter mittlerweile dazu über, alle Wohngemeinschaftsmitglieder in den Mietvertrag aufzunehmen.
Auf diese Weise sind bei eventuellen Mietrückständen alle Mieter (und nicht nur der Hauptmieter) haftbar, so dass das Ausfallrisiko gemindert wird. Da in diesem Fall bei jedem Auszug eines Wohngemeinschaftsmitgliedes der Vertrag neu aufgesetzt werden muss, können mit dem notwendigen Neuvertrag erneut Mieterhöhungen leichter durchgesetzt werden.

Aufgrund dieser guten Möglichkeiten zur Renditesteigerung im Segment des studentischen Wohnens treten zunehmend überregionale Investoren auf dem Göttinger Wohnungsmarkt auf. Beispielsweise hat sich die BGP-Gruppe mit dem „Campusglück"-Studierendenapartmentprojekt in Grone einge-

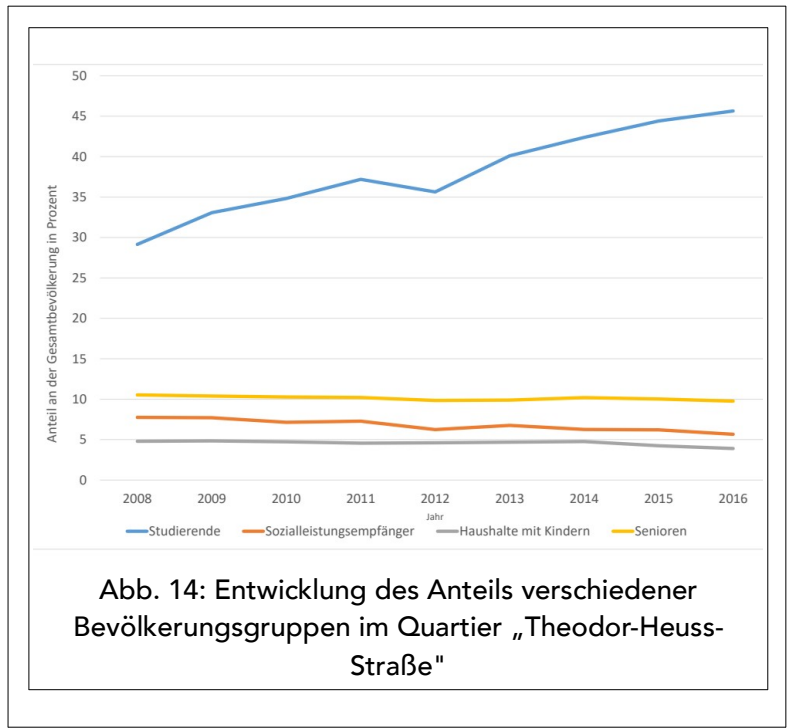

kauft. Das Unternehmen besitzt mehr als 15.000 Wohn- und Gewerbeeinheiten in deutschen Städten, darunter Studierendenapartments in Göttingen, Karlsruhe, Kiel, Köln und Münster. Die Göttinger Apartments werden mit einer "Rundum-sorglos-Komplettmiete" beworben. Die Mieten liegen zwischen 349 Euro und 549 Euro für ein Wohngemeinschaftszimmer. Dies ist im Göttinger Vergleich sehr teuer. Noch dazu ist das "Campusglück" ein vergleichsweise alter Plattenbau.

Im Segment des studentischen Wohnens sind Vermieter und Investoren angesichts der angespannten Situation auf dem Göttinger Wohnungsmarkt in der Lage hohe Mietpreise durchzusetzen. Aufgrund dieser aus Investorensicht günstigen Renditebedingungen mit studentischen Mietern, bevorzugen sie Studierende gegenüber anderen Bevölkerungsgruppen und treiben somit die zunehmende Segregation (vgl. Kapitel 4) in Göttingen voran.

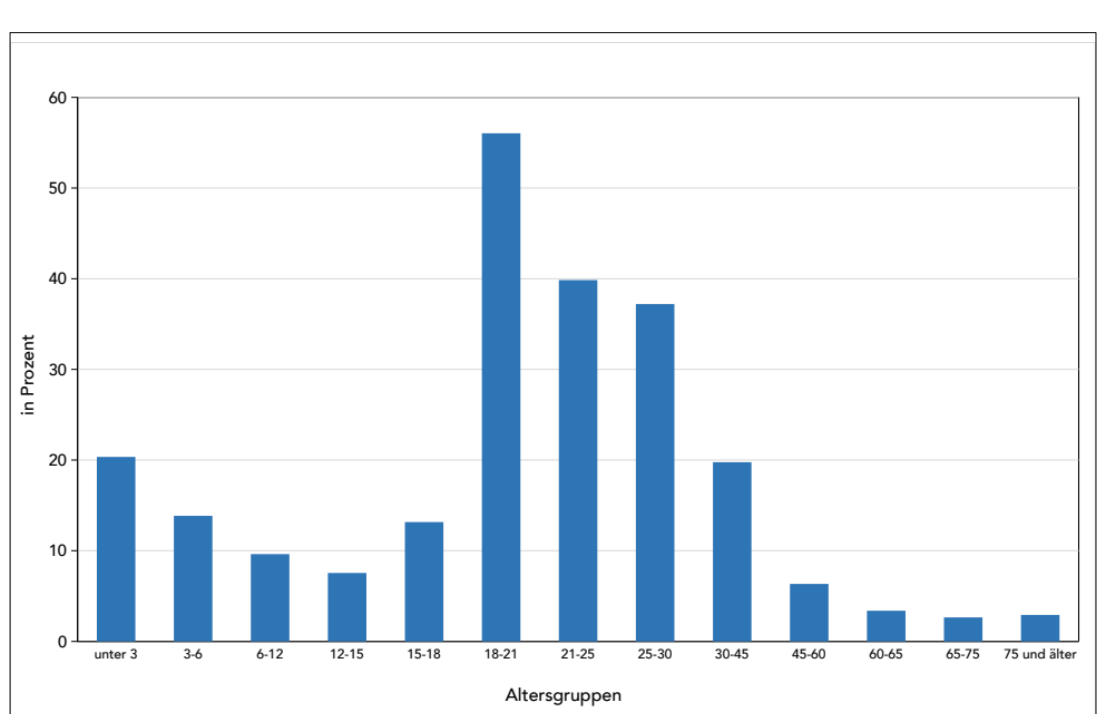

Abb. 13: Fluktuationsrate nach Altersgruppen in der Stadt Göttingen im Jahr 2016 


\section{Wohnungsmarkt Göttingen}

\section{VERDRÄNGUNG UND SEGREGATION}

$\mathrm{D}$ ie Mietpreissteigerungen (Kapitel 2) und die Konzentration der Investoren auf das studentische Wohnen (Kapitel 3) führen in Göttingen zu Segregation und Verdrängung. In diesem Abschnitt wird erläutert, wie diese Prozesse ablaufen.

Aufgrund der hohen Mietpreise, die im studentischen Wohnsektor erzielt werden können, sind Studierende eine ökonomisch interessante Mieterklientel. Sie sind deshalb auch eine der Hauptzielgruppen von Göttinger Vermietern. Deshalb findet man in Mietwohnungsangeboten häufig Hinweise wie "Studenten aufgepasst!" oder „Nur für Studenten!” (vgl. Abbildung 15).

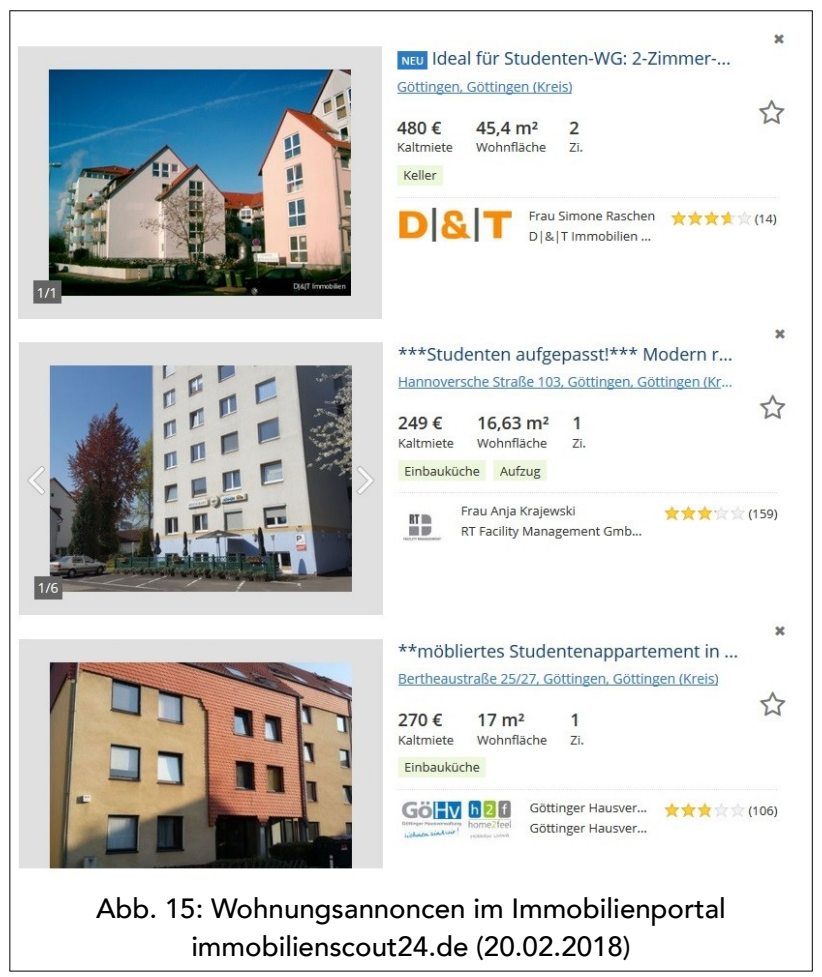

Die Vermieter streben außerdem eine homogene Bewohnerschaft in einzelnen Beständen an. Aus ihrer Sicht vermeidet dies Konflikte, die entstehen können, wenn verschiedene soziale Gruppen in einem Haus wohnen. Diese Präferenz für eine homogene Bewohnerschaft im Zusammenspiel mit den Vorteilen, die Studierende aus Vermieter*innensicht haben, führen dazu, dass andere Bevölkerungsgruppen noch größere Probleme haben, im Göttinger Stadtgebiet eine angemessene Wohnung zu finden. Besonders Transferleistungsempfänger, kinderreiche Familien und Menschen mit Migrationshintergrund sind bei der Wohnungssuche benachteiligt. Ihnen gegenüber herrschen unter den Vermietern Vorurteile, die zum Teil rassistischen
Ursprungs sind und manchmal an sozialdarwinistische Ideologien erinnern.

Auf diese Weise kommt es zu Verdrängungsprozessen von sozio-ökonomisch schwächeren Bewohnergruppen, die auf die Renditestrategien der Vermieter*innen zurückzuführen sind. Ein Beispiel für eine solche Verdrängung ist das Weender Quartier "Theodor-HeussStraße". Inzwischen leben mehr als 8 Prozent der in Göttingen wohnhaften Studierenden in diesem Quartier. Die Bevölkerung des Quartiers ist von 3.884 Einwohnern im Jahr 2008 auf 3.976 Einwohner 2016 angewachsen, während sich die Zahl der dort wohnenden Studierenden um mehr als 600 erhöhte. In diesem Zeitraum ist der Anteil der im Quartier lebenden Studierenden um mehr als 15 Prozent angewachsen, während der Anteil der Sozialleistungsempfänger*innen um über 2 Prozent, der Anteil der Haushalte mit Kindern sowie der Senioren um jeweils knapp 1 Prozent gesunken ist. Dies deutet darauf hin, dass durch den vermehrten Zuzug von Studierenden Sozialleistungsempfänger*innen und Familien, aber auch Senioren und andere Haushalte aus dem Quartier verdrängt werden.

Der einsetzende Verdrängungsprozess stellt sich wie in Abbildung 16 dargestellt dar: Mit der zunehmenden Zahl an Studierenden steigt auch der Nachfragedruck nach Wohnraum in der Stadt. Dieser ist im Segment der Drei- und Mehrzimmerwohnungen besonders groß, weil auf dieses nicht nur Studierende, sondern auch Transferleistungsempfänger*innen, kinderreiche Familien und Menschen mit Migrationshintergrund zugreifen. Die Vermieter*innen nutzen dies zur Durchsetzung ihrer Renditeinteressen aus und fordern hohe Mieten in diesem Segment. Sie bevorzugen Studierende als Mieter, weil diese die hohen Mieten für kleine 1Zimmer-Appartments oder auch für größere Wohnungen in Wohngemeinschaften erbringen können. Für viele andere Bevölkerungsgruppen werden diese Wohnungen jedoch immer unerschwinglicher; sie sind zunehmend gezwungen, an den Stadtrand auszuweichen.

Dies spiegelt sich in der Entwicklung der Sozialleistungsempfänger*innen in Göttingen. Ihr Anteil lag im Jahr 2014 bei 10 Prozent und ist bis ins Jahr 2018 auf 10,56 Prozent angewachsen. Die Abbildung 17 zeigt, dass sich der Anteil der Sozialleistungsempfänger*innen innerhalb der Stadt unterschiedlich entwickelt hat. In nahezu allen Quartieren deren Anteil an Sozialleistungsempfänger*innen an der Bevölkerung unter dem 


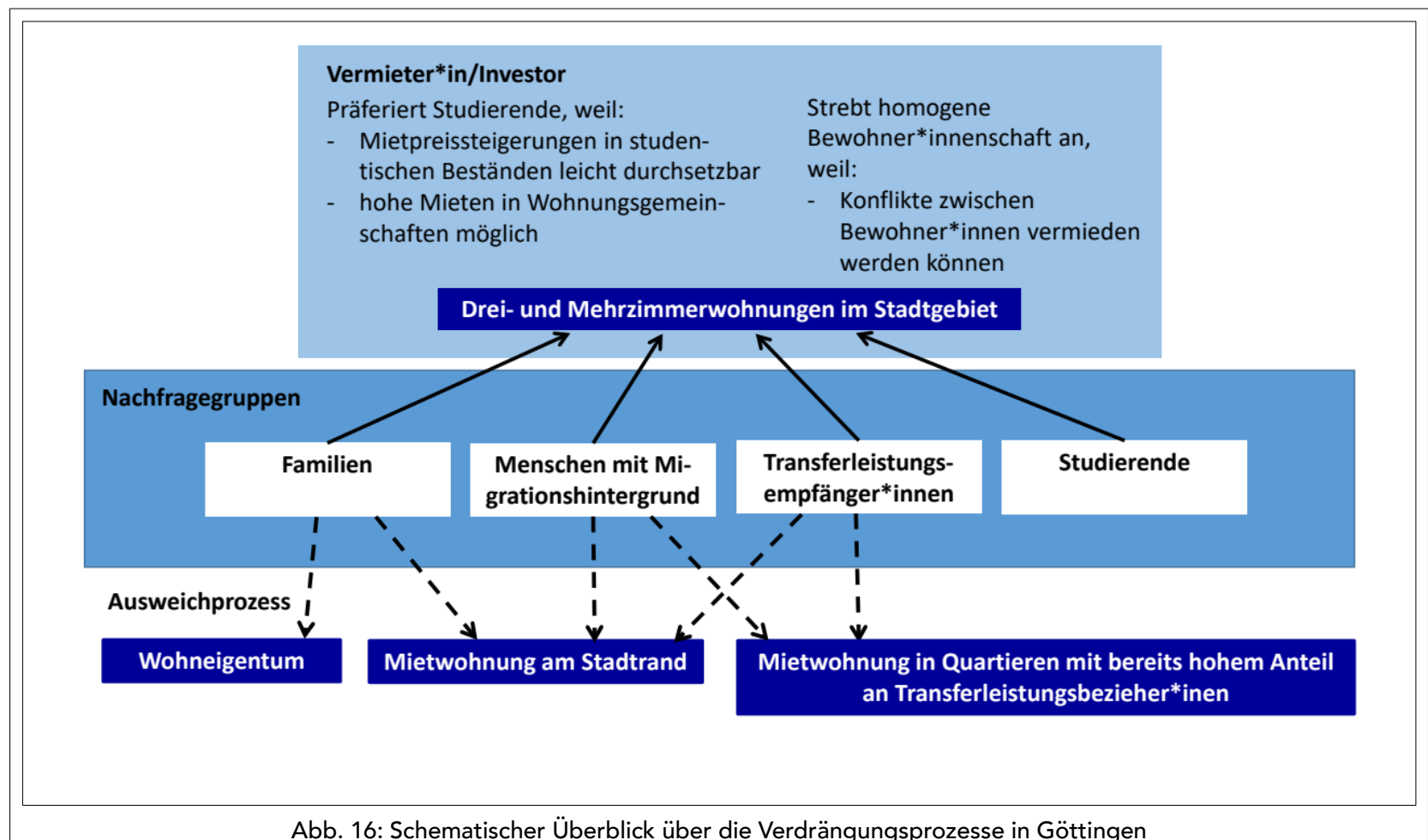

Abb. 16: Schematischer Überblick über die Verdrängungsprozesse in Göttingen

gesamtstädtischen Niveau von 10 Prozent lag, hat sich der Anteil der Sozialleistungsempfänger*innen verringert oder ist auf dem Niveau der gesamtstädtischen Entwicklung angestiegen. In fast allen Stadtteilen mit einem ohnehin überdurchschnittlichen Anteil an Sozialleistungsempfänger*innen ist dagegen der Anteil der Sozialleistungsempfänger*innen seit 2014 stärker als im gesamtstädtischen Durchschnitt angestiegen. Dies betrifft insbesondere Stadtteile in Grone und der Weststadt, aber zum Teil auch in Geismar.

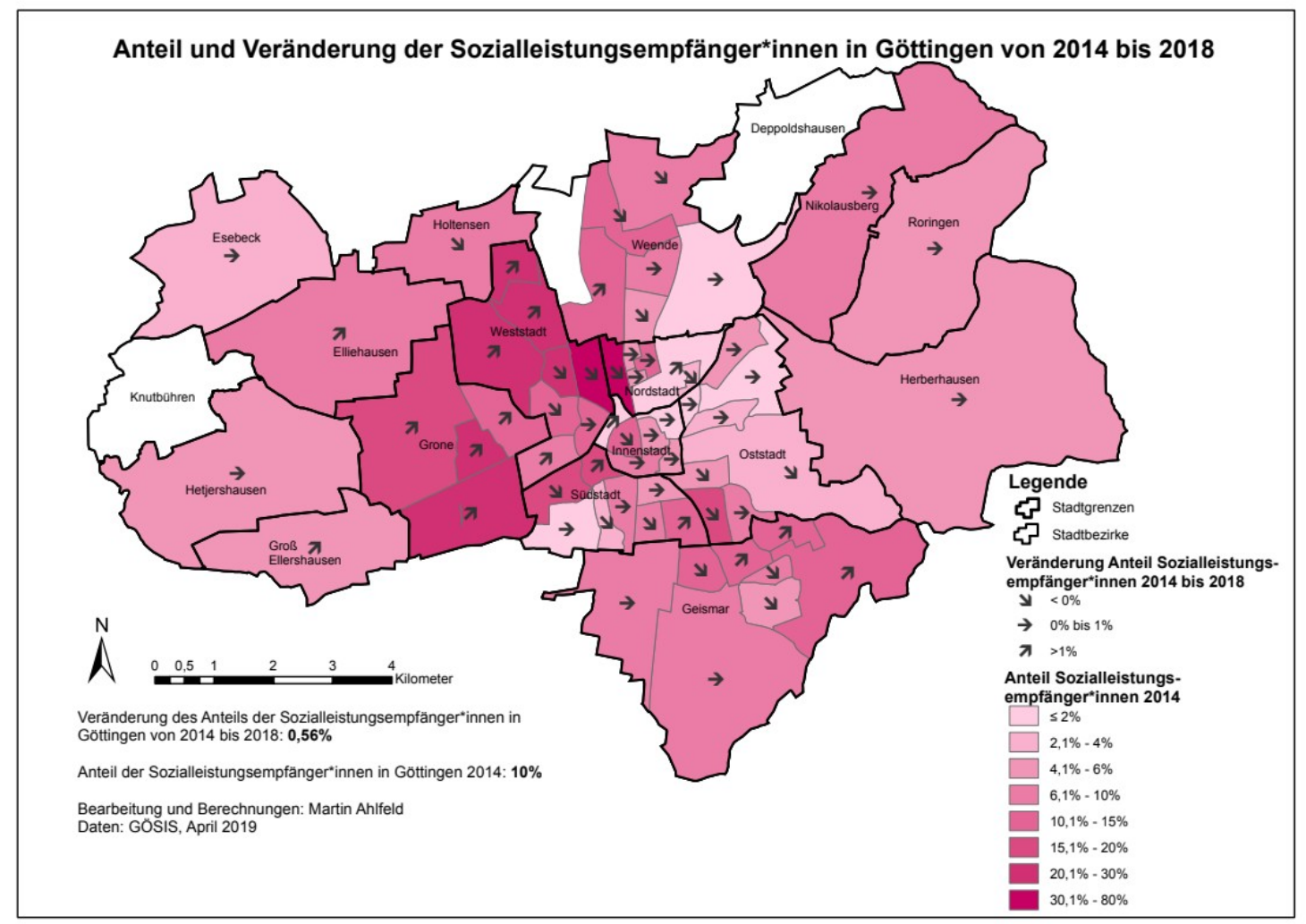

Abb. 17: Entwicklung des Anteils von Sozialleistungsempfänger*innen 2014 bis 2018 in den statistischen Bezirken 


\section{Neoliberale Wohnungspolitik}

\section{NEOLIBERALE „SOZIALE MARKTWIRTSCHAFT“}

ern der bundesdeutschen Wirtschaftspolitik in der Nachkriegszeit ist die "Soziale Marktwirtschaft". Über drei Jahrzehnte gehörten zu diesem ordoliberalen Programm staatliche Eingriffe in Märkte, um das Wirtschaftswachstum zu stützen. Der in den 1960er Jahren eingeführte Sozialwohnungsbau und der in den 1970er Jahren erweiterte Mieterschutz waren derartige Eingriffe. Sie haben dazu beigetragen, die Wohnungsnot in den Städten, wo Arbeitskräfte benötigt wurden, zu lindern, die Mieten zu dämpfen und für viele Menschen Wohnungen halbwegs bezahlbar zu machen.

Mit einem ganzen Bündel von Massnahmen - Gemeinnützigkeit, erhöhte Abschreibungen, direkten Subventionen wie Kreditverbilligungen / Darlehen, Zuschüssen, u.a. - regulierte die Regierung den Wohnungsmarkt, um Verstädterung, Wohnqualität und Lohnentwicklung wachstumsdienlich zu steuern.

Die Folge: Neue moderne Wohnungen - mit Zentralheizung, Bad, Balkon - wurden gebaut, ganze Stadtteile an den Stadträndern errichtet wie auf dem Leineberg, Holtenser Berg, in Grone. Die Konstruktion des Sozialwohnungsbaus als Objektförderung, d.h. Förderung des Wohnungsneubaus, führte zu steigenden staatlichen Ausgaben und verhinderte durch das Prinzip der Kostenmiete nicht den Anstieg der Sozialwoh- nungsmieten. Es kam in den 1970er Jahren zu heftigen Mieterprotesten gegen Mietwucher und Vertreibung durch Sanierung und Umwandlung von Miet- in Eigentumswohnungen, zu Hausbesetzungen und Häuserkämpfen. Dennoch hat die damalige Wohnungspolitik der "Sozialen Marktwirtschaft" für viele den guten Ruf des Sozialstaates gefestigt. Zumindest im Rückblick.

Mit der CDU/FDP-Regierung änderte sich in den 1980er Jahren die Wohnungspolitik. Staatliche Eingriffe in den Markt wurden zunehmend als hinderlich und falsch betrachtet. Eine neoliberale "Soziale Marktwirtschaft" wurde das herrschende wirtschaftspolitische Konzept. Ab den 1990er Jahren galt das für alle groBen Parteien, von der CSU bis zu den Grünen: Die freie Konkurrenz der Individuen auf dem Markt sei das beste Mittel, eine "kundengerechte" Versorgung zu gewährleisten - und die beste Förderung des Wirtschaftswachstums; für jene Teile der Gesellschaft, deren Einkommen zu gering ist, an diesem Wettbewerb teilnehmen zu können, soll ein staatlicher Zuschuss (Wohngeld) die Miet-Zahlungsfähigkeit ein wenig erhöhen und ihnen so eine Marktfähigkeit ermöglichen.

So wurde - in Ergänzung dazu, dass der Staat sich Schritt für Schritt aus dem Wohnungsmarkt zurückzog (Deregulierung) - die zu teure und angeblich nicht zielgenaue Objektförderung im Sozialen Wohnungsbau zur Subjektförderung umgewandelt. Die Begründungen z.B. „zu teuer" waren fragwürdig: Die Subjektförderung wurde viel teurer (s. Abbildung 18 ).

Was passierte? Gesetzliche Sonderregelungen wurden aufgehoben (Gemeinnützigkeit), Förderprogramme zurückgefahren oder eingestellt, der Sozialwohnungsbau umgewandelt in soziale Wohnraumförderung, Wohnungsbestände der öffentlichen Hand privatisiert, die Verwendung von Wohnimmobilien als Anlage- und Handelsobjekt des Finanzkapitals erleichtert. Die rot-grüne Regierung unter Schröder (SPD) beschleunigte in der ersten Hälfte der 2000er Jahre diese neoliberale "Ökonomisierung" im Bereich Wohnen wie auch in den Bereichen Bildung, Gesundheit, Arbeitsmarkt, Altersvorsorge, usw. Auf dem Wohnungsmarkt kam es zu erheblichen Umwälzungen. Große Wohnungsbestände wechselten immer wieder den Eigentümer, wenn sie die Renditeerwar- 


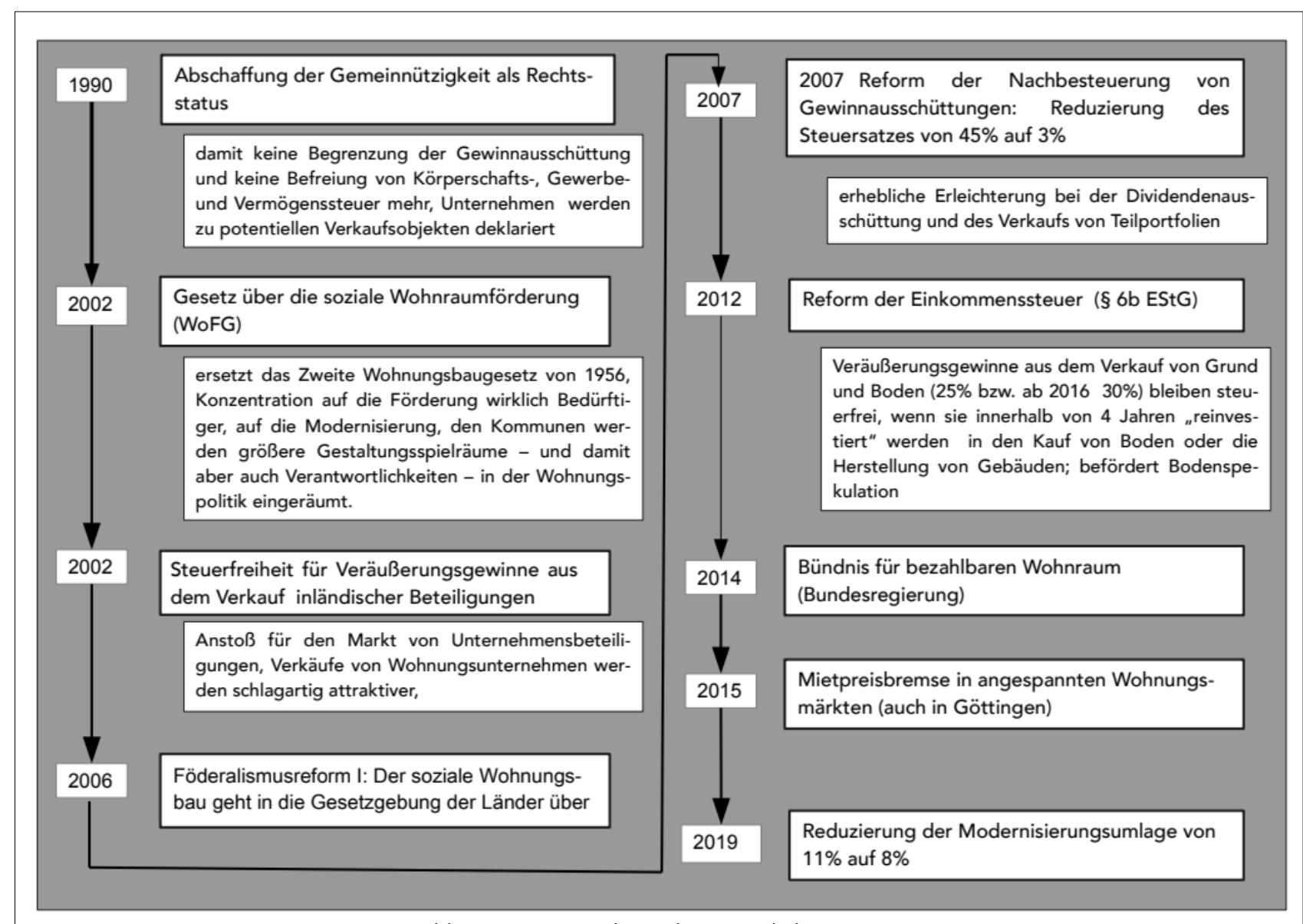

Abb. 19: Stationen der Wohnungspolitik seit 1990

tungen internationaler Kapitalgesellschaften nicht erfüllten. Oder auch, weil sie sich - in der Finanzkrise „nur" verspekuliert hatten. Der Mietwohnungsneubau sank auf den niedrigsten Stand der Nachkriegszeit.

Erst mit dem Aufschwung der deutschen Exportwirtschaft nach der Finanzkrise änderte sich die Situation. Durch die Niedrigzinspolitik existierte eine große Menge an Geldkapital, das dringend rentierliche Anlagemöglichkeiten suchte. Die günstige Wirtschaftsentwicklung konzentrierte immer mehr Arbeitskräfte in den großen Städten, die Metropolen wuchsen und damit auch dort die Nachfrage nach Wohnungen. Mieten und Immobilienspekulation stiegen rasant. Da die Agenda 2010-Politik zu einer starken Ausweitung des Niedriglohnsektors geführt hatte und die untersten Einkommensgruppen nicht vonm Wirtschaftsboom profitierten, sondern sogar Reallohnverluste hinnehmen mussten, wuchs die Wohnungsnot. Proteste gegen den "Mietenwahnsinn" breiteten sich seit 2011/12 aus. Die großen Städte sahen ihr wirtschaftliches Wachstum gefährdet, weil es zunehmend an „einfachen", gering entlohnten Arbeitskräften fehlte.

Doch die Politik reagierte nur widerwillig auf die Forderungen nach mehr sozialem Wohnungsbau, der seit 2006 Sache der Bundesländer war. Sie beharrte auf der Funktionsfähigkeit des (freien) Marktes und sah sich (finanziell) ohnmächtig in den selbst verordneten Sachzwängen. Sie drehte an diesen und jenen Stellschrauben (z.B. Innenverdichtung, Beschleunigung von Planungsverfahren, geringfügige Aufstockung der Fördermittel) und reagierte vor allem mit mehr symbolischen Maßnahmen wie dem „Bündnis für bezahlbarem Wohnraum" oder der Mietpreisbremse. Die Kommunen, vor allem die Städte, gerieten wohnungspolitisch unter Druck und suchten nach neuen Handlungsorientierungen und -mitteln wie z.B. Erhaltungs- oder Milieuschutzsatzung, Baurechtschaffungen, eigenen Förderprogrammen oder Mietendeckel. Den „Mietenwahnsinn" hat das bisher nicht beendet.

Eine grundlegende Abkehr von der neoliberalen Wohnungsmarktpolitik ist nicht in Sicht. 


\section{Immobilienunternehmen und ihre Praktiken}

\section{DIE FINANZMARKTGETRIEBENE IMMOBILIENWIRTSCHAFT}

$\mathrm{S}$ eit der Jahrtausendwende tummeln sich neue Akteure auf dem deutschen Wohnungsmarkt börsennotierte Aktiengesellschaften, Real Investment Trusts (REITS), Privat-Equity-Fonds. Derartige Unternehmen haben ein anderes Geschäftsinteresse als die "traditionellen" Immobilienunternehmen oder Privatvermieter. Der Unterschied ist: Sie sind kapitalmarktorientiert. Die Gewinne aus dem Immobiliengeschäft dienen ganz wesentlich noch einem weiteren, wichtigeren Geschäft.

\begin{tabular}{|c|c|c|c|c|c|}
\hline & $\begin{array}{l}\text { Wohneinheiten } \\
\text { Q3/2018 }\end{array}$ & $\begin{array}{l}\text { LTV } \\
\text { Q4/2017 }\end{array}$ & $\begin{array}{l}\text { LTV } \\
\text { Q3/ } 2018\end{array}$ & $\begin{array}{l}\text { Bonitätsrating } \\
\text { (S\&P) } 2018\end{array}$ & ICR \\
\hline Adler Real Estate & 62.004 & 64,5 & 66,3 & BB & 2,3 \\
\hline Vonovia & $363.446^{4)}$ & 43,9 & & BBB+ & 5,4 \\
\hline Deutsche Wohnen SE & 163.057 & 34,5 & 36,5 & A & \\
\hline LEG Immobilien & 130.170 & 42,7 & & & \\
\hline TAG Immobilien & 81.915 & 52,3 & 49,4 & $\mathrm{BBB}+$ / Baa3 & \\
\hline Grand City Properties & & 35 & & $\mathrm{BBB}+/ \mathrm{Baa} 1$ & 6,0 \\
\hline
\end{tabular}

Quelle: Geschäftsberichte der Unternehmen; Q = Quartal, S\&P = Standard\&Poor, LTV - ICR s. Text

„Ihr Hauptgeschäft besteht darin, einer internationalen Kundschaft von Finanzinvestoren Aktien und Anleihen anzubieten, die lukrativer oder sicherer erscheinen als die Anlagen der Konkurrenz, zum Beispiel Staatsanleihen. Aus den Zahlungsströmen der Mieten und der Kreditsicherheit, die das Immobilieneigentum bietet, lassen sich zahlreiche Finanzprodukte konstruieren. Diese Produkte können global bewertet, permanent gehandelt und in weitere abgeleitete $\mathrm{Fi}$ nanzprodukte verpackt werden. Viele der Aktionäre sind selbst Kapitalsammelstellen, die für die Finanzinteressen von Dritten agieren, zum Beispiel der berüchtigte Fondsverwalter Blackrock, der norwegische Staatsfonds oder große Privatstiftungen und Versicherungen. Um ihre Kund*innen bei der Stange zu halten und neue Anleger*innen zu gewinnen, müssen die gebotenen Renditen und Sicherheiten ständig verbessert werden." ${ }^{4}$

Wie geht das?

Es werden die Mieteinnahmen gesteigert, die Bewirtschaftungskosten gesenkt durch zentralisierte, immer stärker standardisierte und automatisierte Verfahren; es werden die Risiken gestreut, weniger profitable Portfolios verkauft, neue Wohnungsbestände dazu gekauft, vorhandene Bestände durch Nachverdichtung und/oder energetischer Modernisierung im Wert gesteigert und bei günstiger Gelegenheit an die Börse gebracht oder sonst wie verkauft.

Es werden Unternehmen gegründet, die international von Finanzinvestoren Kapital einsammeln zu dem Zweck, große Wohnungsbestände aufzukaufen und diese so zu bewirtschaften, dass die Kapitalgeber kurzfristig überdurchschnittliche, meist zweistellige Verzinsungen ihrer Investitionen erzielen können. Zu dieser Art der Bewirtschaftung gehören neben den genannten Strategien der Mieterhöhung und Senkung der Bewirtschaftungskosten auch der Einsatz spezieller Finanztechniken (z.B. Hebeleffekte) und von Anbeginn Strategien des Verkaufs, sobald sich eine lohnende Gelegenheit dazu für Teile oder des gesamten Port-

folios bietet.

Die Gewinne aus den aufgekauften Wohnungsunternehmen und deren Immobilien dienen zugleich als "Grundlage" und Sicherheit für weitere Geschäfte auf dem Finanzmarkt. Die Investoren, die für ihre Investition ein Schuldpapier vom Immobilienunternehmen erhalten haben - eine Aktie oder Anleihe - handeln mit diesen Schuldpapieren auf den internationalen meist außerbörslichen, also kaum regulierten Kapitalmärkten. Hohe Renditen im Wohnungsgeschäft, vertraglich zugesicherte Verzinsungen („Verbriefung")

LTV - Loan to Value: das Verhältnis der Summe der ausstehenden Kredite/ Anleihen zum Gesamtwert der Kreditsicherheiten - Je höher der Wert, desto größer das Risiko für die Gläubiger, im Insolvenzfall einen Teil ihres Kapitals zu verlieren.

ICR - Interest Cover ratio / Zinsdeckungsgrad: wie oft die laufenden Einnahmeüberschüsse (EBIT, operating profit) die ausstehenden Zinsen bedienen könnten, je höher, um so solider.

Bonitätsstufe - Einstufung der Kreditwürdigkeit durch Ratingagenturen (z.B. Standard\& Poor, Moody's). 


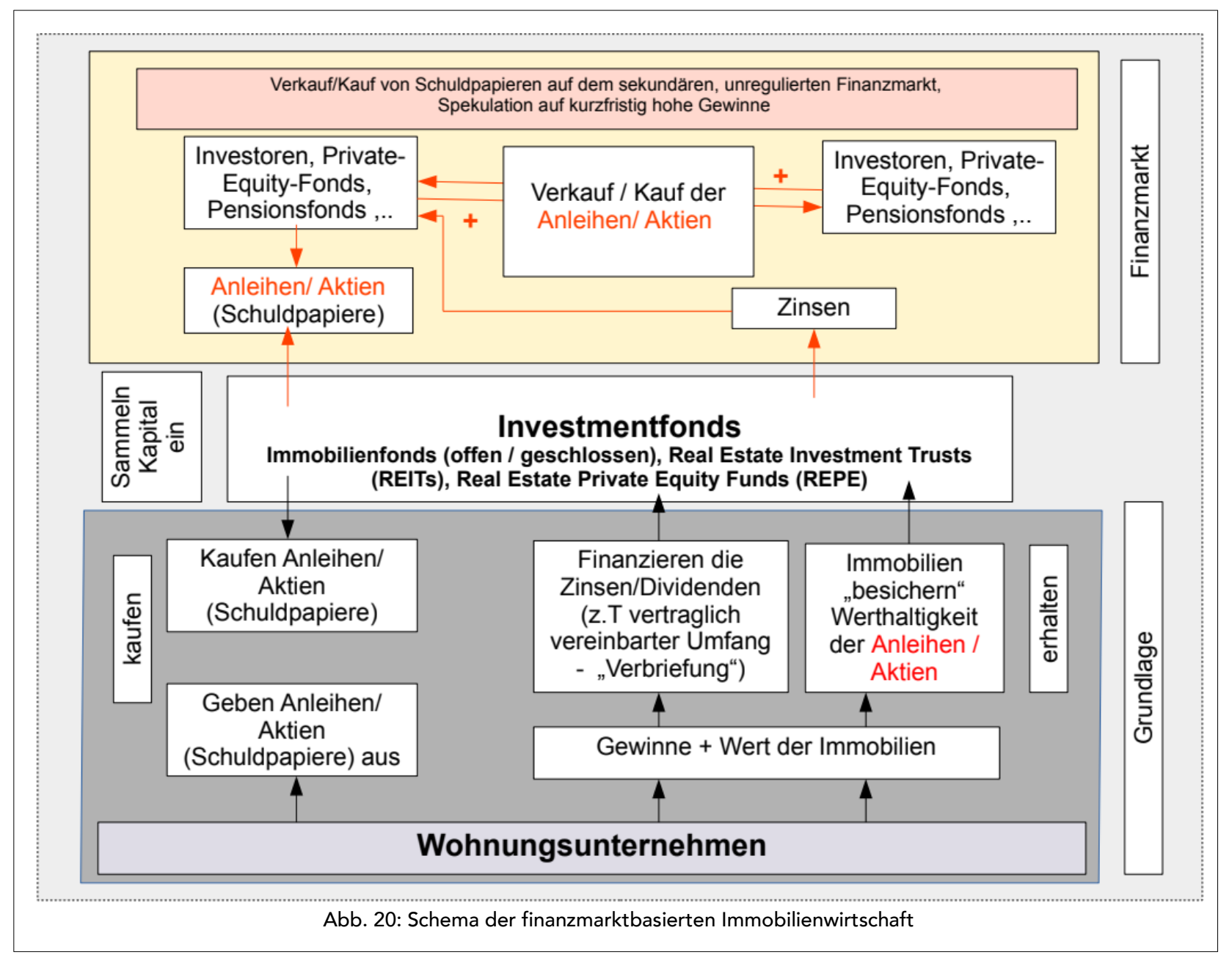

und Kreditsicherheit machen die Schuldpapiere "wertvoll" und ermöglichen im Handel weitere Gewinne. Die Strategie besteht darin, eine im Grund endlose Reihe von Schulden durch Immobilienvermögen zu "besichern". ${ }^{5}$ Eine hoch spekulative Strategie. Drohen Risiken können sie in „innovativen” Finanzprodukten verpackt und weiterhin gehandelt werden (Beispiele dazu bot die Subprime-Krise 2007).

Vor diesem Hintergrund sind die Immobilienunternehmen, beständig zu "beweisen", dass sie die Gewinne auch erzielen, dass ihr (wachsendes) Vermögen solide und werthaltig ist und ihre Schuldpapiere daher kreditwürdig sind. Die Unternehmen veröffentlichen daher auch mehrmals im Jahr bestimmte Risikokennziffern, die das belegen sollen.

Das jüngsten Finanzmonopoly von Adler Real Estate und Ado Properties: Im September 2019 übernimmt ARE die Ado Group, die grosse Wohnungsbestände in Berlin besitzt. Damit hat ARE an der luxemburgischen Muttergesellschaft Ado Properties S.A. einen Anteil von 33\%. ARE und Ado Properties S.A. wollen zusammen den Projektentwickler Consus übernehmen und so zum drittgrößten Immobilienkonzern in der BRD aufzusteigen. Im Januar 2020 startet Ado Properties S.A die Übernahme von ARE (Aktientausch), der Name
Adler Real Estate soll bleiben. Die Groß-Investoren bei Ado Properties kritisieren die möglich Herabstufung des Kreditratings. Die Ado Group (Berlin) hatte ein LTV von 21, ARE hingegen von 56. Nach einem Zusammenschluss mit Consus könnte der LTV-Wert gut 50 betragen mit der Folge, dass das Kreditrating von BBB- (Investmentgrade) auf $\mathrm{BB}+$ (spekulativ) fallen. ${ }^{6}$

Die Entwicklung solcher finanzmarktgetriebenen Immobilienunternehmen beginnt in Deutschland Ende der 1990er Jahre. Deregulierungen durch die Politik und die massiven Privatisierungstendenzen öffnen dem internationalen Finanzkapital den Zugang zum deutschen Immobilienmarkt. Vor allem seit 2003/04 werden us-amerikanische Hedgefonds wie Cerberus, Fortress oder Blackrock aktiv und seit der Finanzkrise 2007 auch vermehrt in den Steueroasen Luxemburg, Malta oder Irland angesiedelte Kapitalsammel-Gesellschaften. Mit den reichlich fließenden Krediten expandieren Aktiengesellschaften wie Deutsche Wohnen, Grand City Properties, Vonovia, LEG oder Adler Real Estate (ARE). 


\section{Immobilienunternehmen und ihre Praktiken}

\section{WEM ZAHLEN MIETER DIE MIETE?}

$\mathrm{M}$ iete bezeichnet im bürgerlichen Recht eine Geldzahlung, die zur zeitweisen Nutzung einer Sache ermächtigt, die sich in fremdem Eigentum befindet.

In der Wohnungs-Miete ist ein grundlegend widersprüchliches Verhältnis angelegt: Mieter*Innen sind am Wohnwert (zu einem bezahlbaren Preis) interessiert, für Vermieter ist eine Wohnung eine Kapitalanlage, die einen möglichst hohen, zumindest durchschnittlichen Zins auf das verliehene Kapital (die Wohnung) erzielt ${ }^{7}$. Diese gegensätzlichen Interessen führen immer wieder zu Protesten und zu politischer Organisierung.

In den letzten Jahren haben sich Protest und Widerstand vor allem gegen die Mieterhöhungsstrategien der großen Wohnungskonzerne gerichtet. ,Privatwirtschaftliche Unternehmen', zu denen Aktiengesellschaften zählen, sind mengenmäßig zwar nicht die größten Vermieter, $58 \%$ der Mietwohnungen in Deutschland (2018) gehören ,Privaten Kleinvermietern' und „nur” $15 \%$ den Unternehmen ${ }^{8}$. Aber die großen, börsennotierten Unternehmen haben erheblichen Einfluss auf die Entwicklung der Mieten.

\section{5\% der Miete für Dividenden \& Aktionäre}

Wem zahlt ein Mieter einer Immobilien-AG wie Deutsche Wohnen, Adler Real Estate, Coreo oder LEG die Miete eigentlich? Und wieviel?

Kritische Mieteraktionärinnen der Vonovia haben versucht, anhand der Geschäftsberichte zu berechnen, wie viel Vonovia-Mieter an die Aktionäre zahlen müssen. Die Vonovia hat seit 2014 Mietsteigerungen durchgesetzt, die weit über der Mietenentwicklung im Bundesgebiet liegen. ${ }^{9} 2018$ hat die Vonovia, der 25,1 Mio. qm Wohnfläche gehören, 746 Mio. $€$ an Dividenden ausgeschüttet. In einer Modellrechnung kommen die Kritischen Mieteraktionärinnen zum Ergebnis, dass Vonovia-Mieter 35,6\% ihrer Miete nur für Dividende zahlen. ${ }^{10}$ Dieses ist nur ein Beispiel, ein Wert für einen Konzern in einem bestimmten Jahr. Aber er gibt einen Hinweis darauf, wie viel der Miete an die Aktionäre umverteilt wird und nicht für Instandhaltung und Modernisierung zur Verfügung steht.

Wer sind diese Aktionäre?

Aktiengesellschaften sind keine Genossenschaften, die Überschüsse an ihre Mitglieder auszahlen oder Reserven für künftige Modernisierungen oder Neubauten anlegen. Wem Immobilien-AGs gehören, ist nicht einfach heraus zu finden. ${ }^{11}$ Auf den ersten Blick geben
Geschäftsberichte Auskunft. Doch dieser genügt nicht angesichts stark verschachtelteter Besitzstrukturen verschiedenster Rechtsformen, eingeschränkter Publizitätspflichten, Steueroasen usw.

\section{Zwei Beispiele: Adler Real Estate - Vonovia}

Den größten Anteil am Grundkapital hält bei beiden Unternehmen der "Streubesitz". Mit dem Begriff "Streubesitz" ist eine Vielzahl von Aktionären gemeint, die nur eine kleinen Anteil am Grundkapital besitzen und deren Aktien an der Börse frei gehandelt werden (Free Floater). Nur wenn der Aktienanteil eines einzelnen Aktionärs 5\% überschreitet, wird er gesondert aufgeführt (wie hier der Aktionär Bergander bei Adler Real Estate $(A R E)$ ). Entscheidenden Einfluss auf das Unternehmen und auf die Unternehmensstrategie haben aber die manchmal so genannten Ankeraktionäre. Das sind Pensions- und Investmentfonds, die ihr international eingesammeltes Vermögen langfristig anlegen und entsprechend auf das Immobilienunternehmen Einfluss nehmen. (Das bedeutet nicht, das sie an einer bestimmten Immobilien langfristig interessiert sind!).

Die Investmentfonds werden zwecks Steuervermeidung dort angesiedelt, wo Staaten ihnen eine günstige Rechtsform und niedrige Steuersätze anbieten - in „Steueroasen“ wie z.B. Luxemburg, Malta, Dublin. Die Fonds können ganz unterschiedlich konstruiert sein; sie können wie bei der Fairwater (ARE) Tochtergesellschaften haben oder Unternehmen wie etwa die Mirabella Malta Limited auf Malta mit dem Fondsmanagement beauftragen (INGrone 2019). Wer die Kapitalgeber der Investmentfonds sind - Versicherungen, Milliardäre, Stiftungen, Gesellschaften - bleibt in der Regel unbekannt. Das zeigt auch der Versuch der Zeitschrift Wirtschaftswoche 2015, die Eigentümer des für die ARE wichtigen Ankeraktionärs Mezzanine IX herauszufinden. Es gelang ihr nicht, zu klären, in welchem Umfang die Mezzanine IX dem Österreicher Cevdet Caner gehört, der zuvor ohne viel Eigenkapital ein groBes Immobilienimperium aufgelegt hatte, das 2008 mit der Insolvenz seines Unternehmens Level One, eine der größten deutschen Immobilienpleiten, endete.

Wem genau Mieter die Miete zahlen, bleibt bei Aktiengesellschaften und Fonds meist undurchsichtig. Nur in der wachsenden Ungleichverteilung von Vermögen zeigen sich Spuren. 


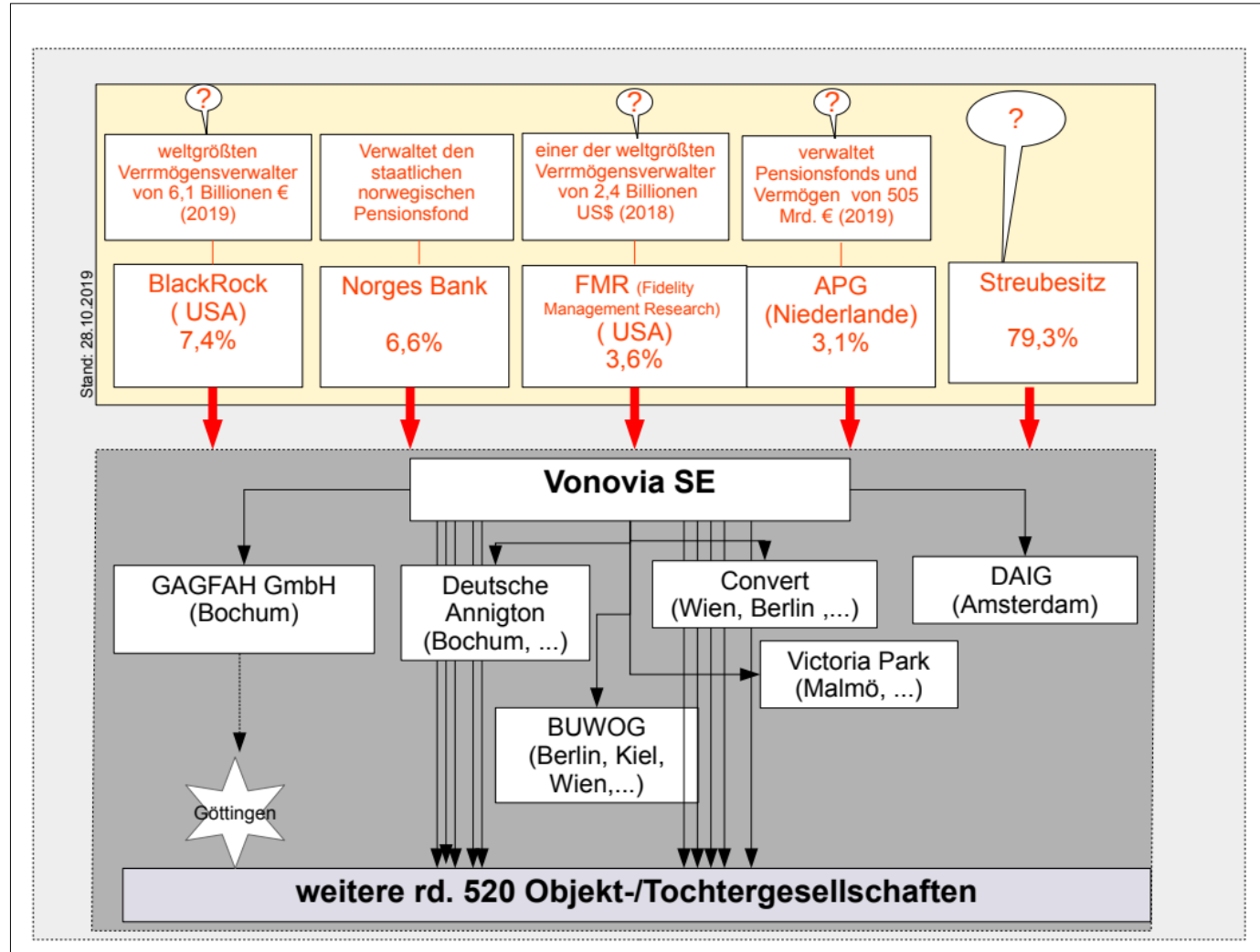

Abb. 21: Aktionärs- und Unternehmensstruktur Vonovia (2019)

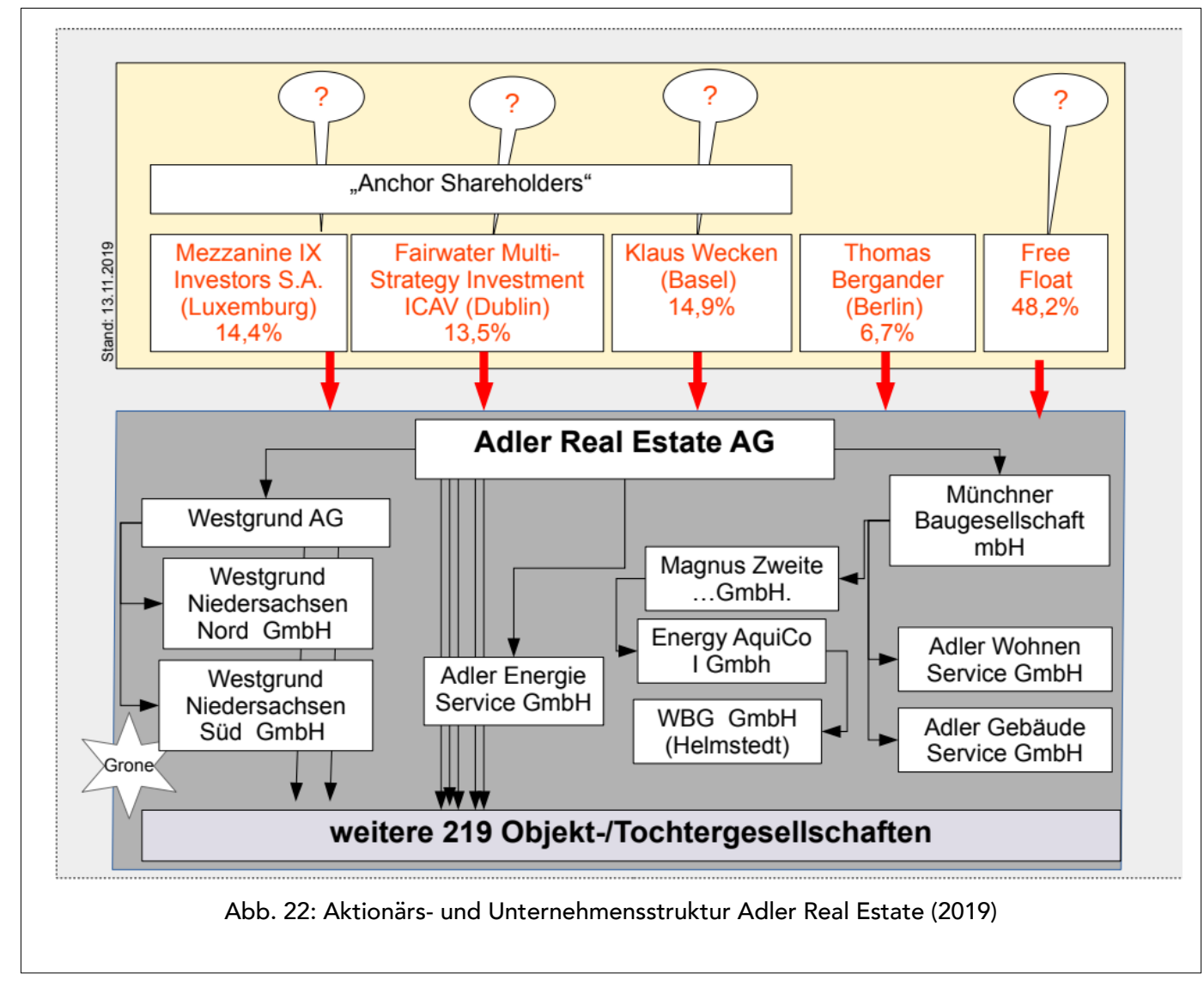




\section{Immobilienunternehmen und ihre Praktiken}

\section{GRONE UND DIE ADLER REAL ESTATE AG}

$\mathrm{D}$

as Wachstum der Stadt Göttingen in den 1960/70er Jahren hat den Ortsteil Grone massiv verändert. Es wurden ausgedehnte Wohnsiedlungen neu gebaut, insbesondere von der Neuen Heimat in Grone Süd und im Ortszentrum nördlich der Kasseler Landstrasse. Diese von der Neuen Heimat gebauten Wohnsiedlungen sind seit Anfang der 2000er Jahre zum Spekulationsobjekt finanzmarkt-
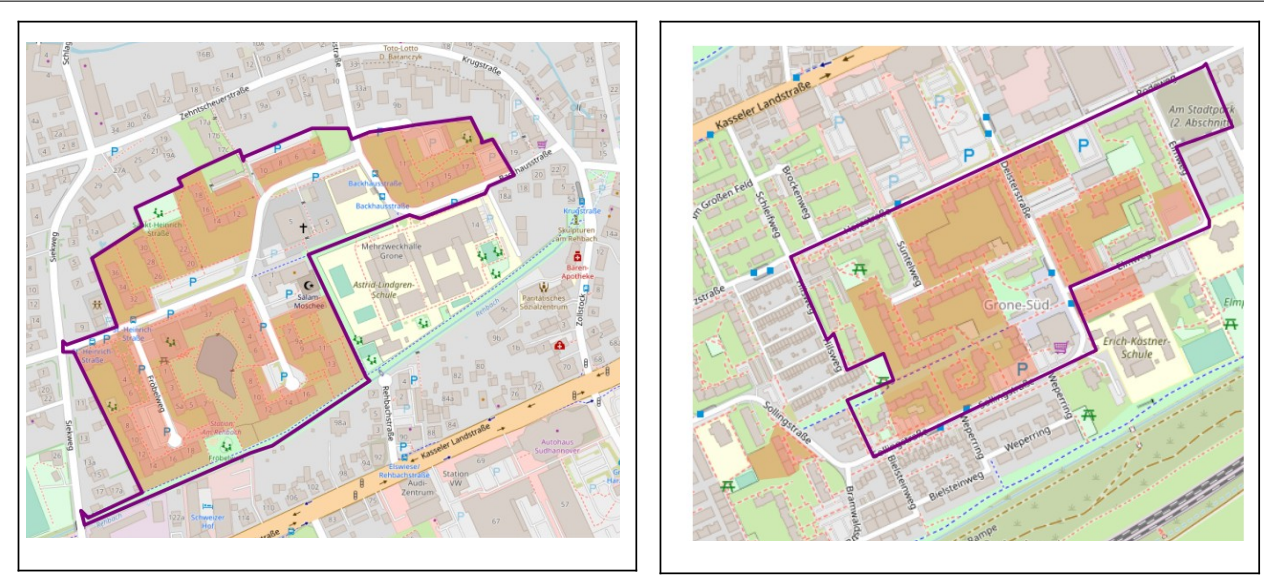

Abb. 23: Grone "Mitte” (links) - Grone "Süd” (Violett: Gebiet des Bebauungsplans) Nachverdichtung.

a) Mieterhöhungen
Grone, zu erhöhen - durch a) Erhöhung der Mieten, b) Senkung der Bewirtschaftungskosten und c) durch

Anfang 2017 erfolgte eine erste Welle der Mieterhöhung im Bestand, laufende Erhöhungen finden bei Neuvermietungen statt. Inzwischen ist die durchschnittliche Miete um rd. 25\% gegenüber 2015 gestiegen; die Mieter zahlen jetzt fast 2,5 Mio. $€$ Miete im Jahr mehr an ARE (+69\%) als 2015/16. Der Standort Göttingen ist für ARE lukrativ - sie hat hier die dritthöchste Mietsteigerung und die zweithöchste Durchschnittsmiete unter ihren "Top-Standorten" durchgesetzt. Und weitere deutliche Mieterhöhungen stehen bevor aufgrund der für 2020 angekündigten Modernisierungsmaßnahmen.

getriebener Unternehmen geworden. Seit dem Ver kauf an den Finanzinvestor Cerberus 2004 haben die Wohnungen in kurzen Abständen immer wieder den Eigentümer gewechselt. Bis sie 2015 (vorläufig) bei der Adler Real Estate AG (ARE) gelandet sind (ausführlich und Quellen in: INGrone 2019).

ARE: „Der Wert des Immobilienportfolios kann im Wesentlichen dadurch zunehmen, dass ein möglichst hoher und im Zeitverlauf stabiler Ertrag aus der Vermietung erzielt wird. Ziel des Asset-Managements ist es daher, Vermietungsstand und Mietniveau zu steigern und die Kostenstruktur zu optimieren." 12

Die Adler Real Estate AG hat zügig damit begonnen den Wert ihrer Finanzanlage, die 1.098 Wohnungen in-

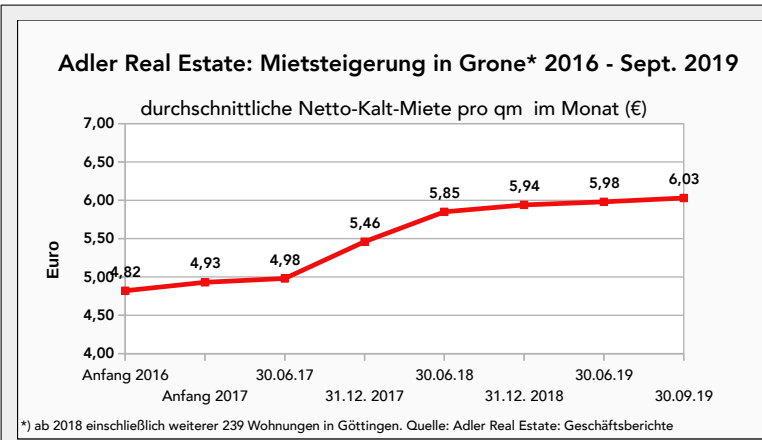

Abb. 24: ARE: Mietenanstieg in Grone seit 2016

\section{b) Bewirtschaftungskosten}

Auch bei der ARE gibt es - wie bei Vonovia, Deutsche Wohnen \& Co - immer wieder Beschwerden über falsche und und überhöhte Nebenkostenabrechnungen und mangelnde Instandhaltung (z.B. Wartung der sicherheitsrelevanten Brandschutzventile ${ }^{13}$ ). Die ARE dagegen ist stolz darauf, dass sie durch Insourcing die Vermietungs- und Bewirtschaftungskosten senken kann - durch ihr Tochterunternehmen Adler Wohnen Service $\mathrm{GmbH}$, Adler Gebäude Service $\mathrm{GmbH}$ und Adler Energie Service $\mathrm{GmbH}$.

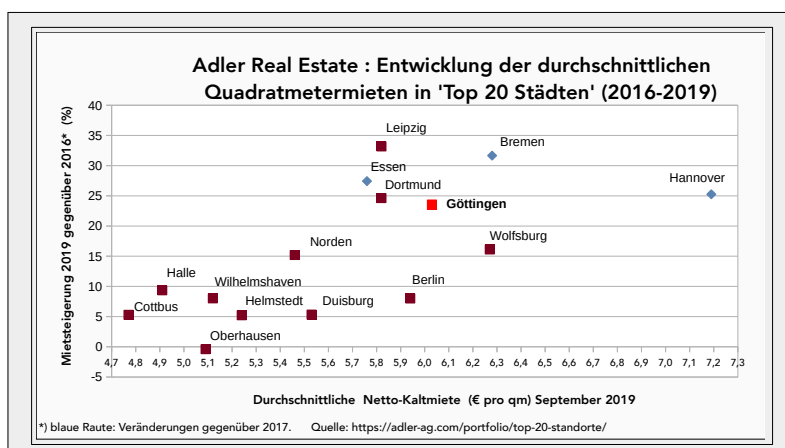

Abb. 25: Mietenanstieg in 'Top 20'-Städten 


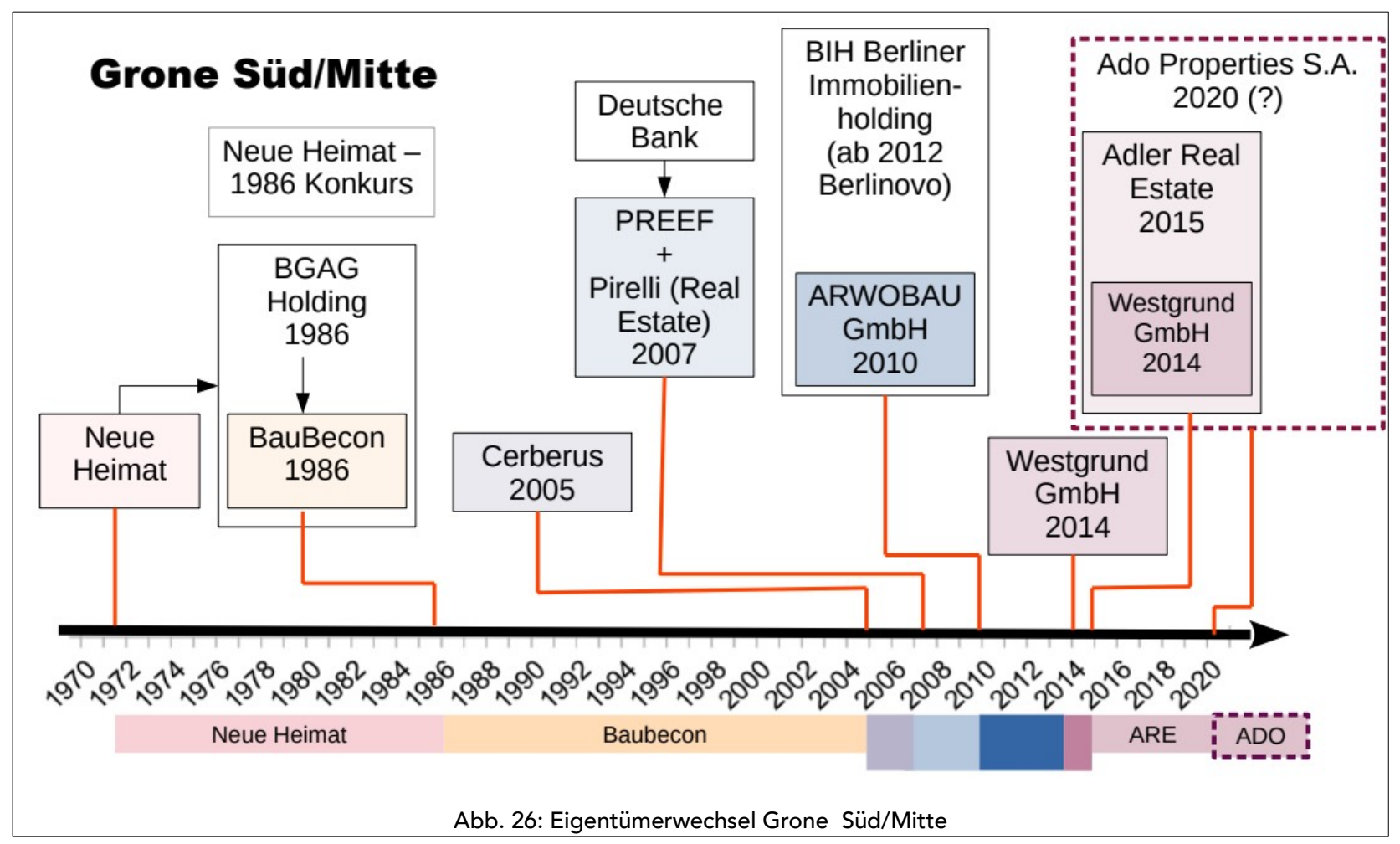

ARE: „Unsere neuen internen Property Management-Kompetenzen werden es uns ermöglichen, Mieten zu erhöhen und Leerstände kurzbis mittelfristig zu reduzieren, so dass das ADLER Property Management sich mit den Top-Performern der Branche messen kann. Wir haben 2017 viel Zeit in die Internalisierung des Property Management investiert". ${ }^{14}$

\section{c) Nachverdichtung}

Zentral für die ARE ist auch die Nachverdichtung. Die meisten Gebäude sollen durch ein Geschoss aufgestockt werden (s. Modell für Grone Süd). Rd. 177 neue Wohnungen sollen so entstehen. Die ARE hat sich intensiv bei der Stadtverwaltung, dem Rat der Stadt wie dem Ortsrat Grone bemüht, ihre Nachverdichtungspläne durch eine Bebauungsplanänderung zu sichern. Um Goodwill zu schaffen, ist sie dafür dem Göttinger

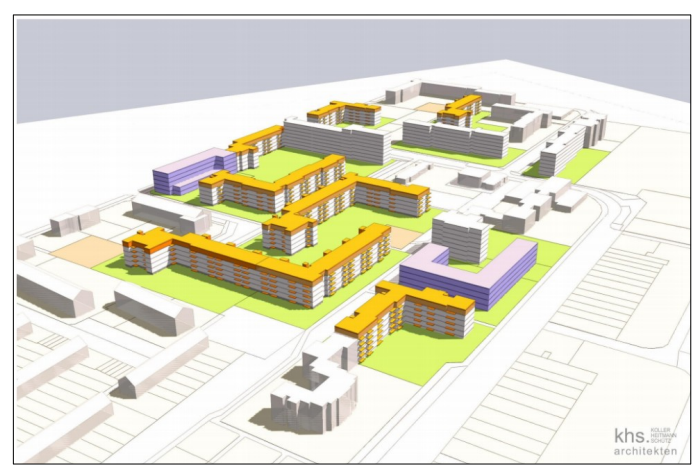

Bündnis für bezahlbares Wohnen beigetreten und hat in einem Städtebaulichen Vertrag Auflagen wie eine 45\%-Quote - $45 \%$ preisgünstige Wohnungen im Bestand (!) zu "schaffen”, d.h. zu bewahren - akzeptiert. Der Widerstand der Groner Mieterinitiative hat die Mieten steigernden ARE-Pläne zwar nicht verhindern, aber verzögern können. Das dämpft die Mietsteigerungen spürbar, weil inzwischen die Modernisierungsumlage von $11 \%$ auf $8 \%$ gesenkt wurde und Mieten innerhalb von 6 Jahren nur um maximal $3 € / \mathrm{m}^{2}$ bzw. bei niedrigen Mieten um maximal $2 € / \mathrm{m}^{2}$ erhöht werden dürfen (Kappungsgrenze). Im Frühjahr 2020 plant die ARE den Beginn der Modernisierung mit einem Volumen von 150 Mio. $€$, doppelt so viel wie 2017. Außendämmung, Balkonerweiterung und Fahrstühle lassen den inneren Zustand der 40 bis 50 Jahre alten Wohnungen (Bad, Heizung, sanitäre Einrichtungen) unberührt und holen die ausgebliebenen oder spärlichen Instandhaltungen nicht nach.

Für Unternehmen wie $A R E$ geht es auch um etwas anderes - um die Möglichkeit, einen höheren Wert der Immobilie berechnen zu können.

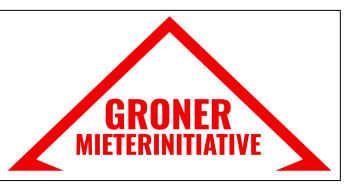
Steigende Markmieten sind zentrale Stellschrauben ${ }^{15}$ in den Wertermittlungsverfahren. Und die Wertsteigerung des (Immobilien)Vermögens ist das Signal an die Finanzmärkte, das zählt. 


\section{IWF - BODENSPEKULATION, STADTPLANUNG UND PROJEKTENTWICKLER}

rojektentwickler in der Immobilienwirtschaft sind Unternehmen mit ganz unterschiedlich definiertem Aufgabenfeld. Dies kann von der Grundstückssuche über die Entwicklung einer Konzeptionsidee für die bauliche Nutzung, der Projektkalkulation, der baurechtlichen Prüfung bis zum Grundstücksverkauf gehen. Manchmal verbirgt sich hinter einem Projektentwickler auch nur ein ganz normaler Immobilienspekulant.
Im Beispiel IWF hat der Projektentwickler EBR nach dem Grundstückskauf - in Zusammenarbeit mit der Stadt - eine Konzeption für ein verdichtetes Wohnquartier entwickeln lassen, damit auf eine Baurechtsänderung hin gearbeitet, so dass mit Hilfe der Stadtpolitik das Grundstück aufgewertet wird. Mit dieser rechtlichen Möglichkeit auf höhere Mieterträge ist eine Grundlage geschaffen für eine Spekulation auf einen

\begin{tabular}{|c|c|}
\hline $1959 / 60$ & $\begin{array}{l}\text { Bau des IWF - "Institut für den Wissenschaftlichen Film gemeinnützige GmbH, } \\
\text { Göttingen" (IWF) - (bis dahin landwirtschaftlich Fläche) }\end{array}$ \\
\hline Ende 2010 & $\begin{array}{l}\text { Schließung des IWF, Aufgabe des Standortes, (zu dem auch Kleingärten } \\
\text { gehören), die Stadt Göttingen zeigt Kaufinteresse }\end{array}$ \\
\hline Februar 2012 & Aufstellungsbeschluss für einen Bebauungsplan „Südlich Nonnenstieg” \\
\hline Frühjahr 2012 & $\begin{array}{l}\text { Rahmenvereinbarung zwischen IWF Wissen und Medien gGmbH, potenziellem } \\
\text { Entwicklungsträger und Stadt Göttingen, März bis Juli: städtebaulicher Wettbewerb } \\
\text { "Lebensquartier Nonnenstieg" bis Sommer } 2012\end{array}$ \\
\hline Mai 2012 & EBR Projektentwicklung GmbH gegründet, EBR überbietet Stadt-Angebot \\
\hline Sommer 2012 & $E B R$ kauft das 22.000 qm große Grundstück für etwa 5, 1 Mio. $€$ \\
\hline November 2012 & Gründung einer Bürgerinitiative, Kritik an den Plänen einer massiven Bebauung \\
\hline März 2013 & $\begin{array}{l}\text { „Neustart”， (leicht geänderte) Rahmenbedingungen vom Bauausschuss der Stadt } \\
\text { zustimmend beschlossen (Reduktion der Geschossflächenzahl (GFZ)) }\end{array}$ \\
\hline Juni/August 2013 & $\begin{array}{l}\text { Weiterhin Widerstand der Bürgerinitiative gegen massive Überbauung und für Erhalt des } \\
\text { kompletten Grünflächenbestandes, kontroverse Diskussionen, Bürgerversammlungen, } \\
\text { „Runder Tisch" - "eine weit über die gesetzlichen Anforderungen hinausgehende } \\
\text { Bürgerbeteiligung" (aus Sicht der Stadtverwaltung) }\end{array}$ \\
\hline November 2013 & $\begin{array}{l}\text { Diskussion des Rates über Auslegung des Bebauungsplans, nun GFZ von 0,95, EBR kritisier } \\
\text { "den massiven Eingriff in die Planungen des Investors" (die Reduzierung der ursprünglich } \\
\text { geplanten Wohnfläche um } 5.500 \text { qm) }\end{array}$ \\
\hline Nov./Dez. 2013 & Städtebaulichen Vertrag mit EBR "Gestaltungsvereinbarung ehemaliges IWF- Areal" \\
\hline $\begin{array}{l}\text { Februar - August/ } \\
\text { Oktober } 2014\end{array}$ & $\begin{array}{l}\text { Im Februar beschließt der Rat, den Bebauungsplan auszulegen, aus Verfahrensgründen ist } \\
\text { im Juli eine } 3 . \quad \text { Auslegung des Bebauungsplan Nr. } 242 \text { notwendig; } \\
\text { es gibt } 426 \text { Einwendungen („Bedenken“), die "sehr große Anzahl an eingereichten } \\
\text { Stellungnahmen bislang einzigartig” (so die Stadtverwaltung); alle bis auf eine werden } \\
\text { von der Stadt zurück gewiesen oder als bereits berücksichtig beschieden }\end{array}$ \\
\hline November 2014 & Vertagung des Bebauungsplans im Bauausschuss \\
\hline
\end{tabular}




\begin{tabular}{|c|c|}
\hline Okt. 2015 - Aug. 2018 & $\begin{array}{llll}\text { Nutzung als } & \text { Unterkunft } & \text { für } & \text { Geflüchtete, } \\
\text { Überarbeitung des Bebauungsplans } & & \end{array}$ \\
\hline September 2017 & $\begin{array}{l}\text { Städtebaulicher Vertrag der Stadt mit EBR ( } 30 \% \text { preisgünstige Wohnungen, Preisbin- } \\
\text { dung } 10 \text { Jahre, Bauantrag } 9 \text { Monate nach Rechtskraft des Bebauungsplans, Baufertig- } \\
\text { stellung innerhalb von } 24 \text { Monaten). Das Kleingartengelände "Am Rohns” (ursprünglich } \\
\text { Teil des IWF-Geländes) bleibt dauerhaft Kleingartengelände. }\end{array}$ \\
\hline Oktober 2017 & 4. Auslegung des (geänderten) Bebauungsplans \\
\hline März 2018 & $\begin{array}{l}\text { nach } 6 \text { Jahren stimmt der Rat der Stadt dem Bebauungsplan zu, im April erfolgt die } \\
\text { amtliche Bekanntmachung; es werden Anträge auf Normenkontrollverfahren gestellt }\end{array}$ \\
\hline August2018 & $\begin{array}{l}\text { EBR verkauft } 17.000 \mathrm{qm} \text { an Wertgrund Wohnpartner } 2 \mathrm{GmbH} \& \text { Co KG für rd. } 8 \text { Mio. } € \text {, } \\
\text { Steigerung des Bodenpreises um } 100 \% \text { in } 6 \text { Jahren (von } 232 € / \mathrm{qm} \text { auf } 470 € / \mathrm{qm} \text { ), } \\
\text { (30\%-Quote wird von Wertgrund übernommen, Vereinbarung über Fristen des Bauan- } \\
\text { trages wird in Frage gestellt) - "die Politik ist verstimmt" }\end{array}$ \\
\hline Januar 2019 & Bauvoranfrage der Wertgrund \\
\hline Februar 2019 & $\begin{array}{l}\text { neue Vereinbarung der Stadt mit Wertgrund (Bauantrag bis spätestens Februar 2020, } \\
\text { (Rechtskraft des Bebauungsplans vorausgesetzt) Im April präsentiert Wertgrund dem } \\
\text { Rat das Baukonzept (sieben 5-6 geschossige Wohnblöcke mit insgesamt } 210 \text { Mietwoh- } \\
\text { nungen und 150-160 Tiefgaragenstellplätze). }\end{array}$ \\
\hline Ab Oktober-2019 & Abriss der IWF-Gebäude \\
\hline
\end{tabular}

steigenden Bodenpreis. Den hat die EBR 2019 realisiert - eine sehr erfolgreiche Spekulation.

Dass Gewinne aus Planungen und öffentlichem Infrastrukturausbau nicht „abgeschöpft” werden, d.h. vor allem der Gesellschaft zu gute kommen, sondern der leistungslosen Bereicherung privater Grundeigentümer dienen, wird schon seit vielen Jahren kritisiert. Die Politik ändert dieses aber nicht. Die Kosten der Spekulation werden die zukünftigen Mieter zu tragen haben.

\section{Bodenpreis in 6 Jahren um $100 \%$ gestiegen}

Mitte August 2018 geht der größte Teil des IWF-Geländes an den Immobilienfonds WERTGRUND Wohnpartner $\mathrm{GmbH}$ aus München (siehe auch Kap. 12) Sie kauft das Grundstück für den von ihr 2016 aufgelegten

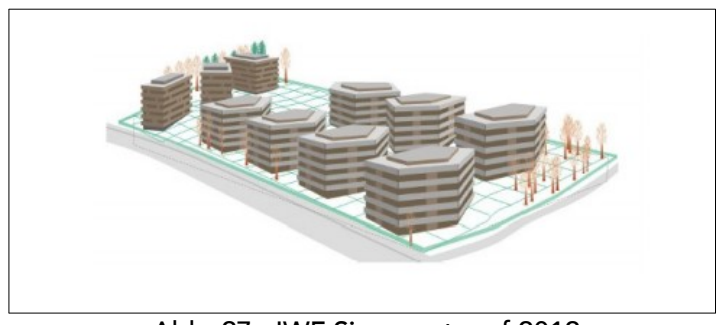

Abb. 27: IWF Siegerentwurf 2012 offenen Immobilienfonds "WERTGRUND Wohnen D2" und plant den Bau von etwa 210 Mietwohnungen, davon circa 70 geförderte und mietpreisreduzierte Wohnungen (30\%-Quote). Das bei der EBR verbliebene 5.000 qm große Gelände ist weiterhin ungenutzt seit 2012.

Die EBR Projektentwicklung $\mathrm{GmbH}$ wird wenige Monate vor dem IWF-Kauf, am 11.5.2012, von dem Geschäftsführer und - heute alleinigem - Gesellschafter Rafie Elizei sowie zwei weiteren im Immobiliengeschäft tätigen Österreichern (aus Wien bzw. Feldkirch) und zwei Bauunternehmern aus der Region Göttingen gegründet. Die EBR verfügt offenbar von Anbeginn an über größere Mengen Kapital bzw. Kredit und gute Beziehungen $^{16}$ und wird schnell erfolgreich mit Wohnungsbau (Geismarlandstrasse), dem Neubau der Sparkasse/Freigeist-Hotel und - dem IWF-Gelände.

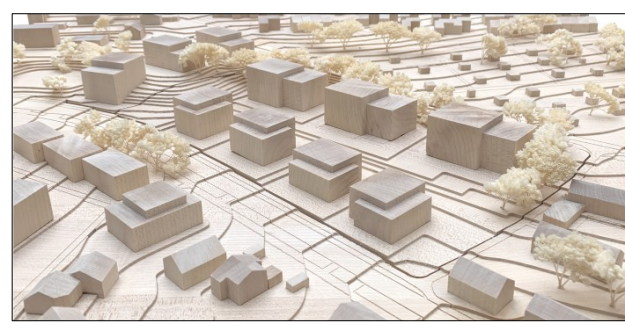

Abb. 28: Entwurf Wertgrund 2019 


\section{Immobilienunternehmen und ihre Praktiken}

\section{DIE COREO AG}

m April 2018 erwarb die in Frankfurt am Main ansässige börsennotierte Coreo AG durch einen so genannten Share Deal ein Portfolio aus 432 Mikroappartements in Göttingen und Umgebung. ${ }^{17}$ Dieser Kauf ist nicht nur ein weiteres Indiz, dass der Göttinger Wohnungsmarkt zunehmend finanzmarktgetrieben wird, sondern auch eine Gefahr für viele Menschen, die bisher noch günstig in der Stadt wohnen.

Neben Wohnungen in Wormeln, Katlenburg, Osterode und Clausthal-Zellerfeld sind Wohnungen in den Immobilien Groner Landstraße 9-9a, Maschmühlenweg 4-6, Untere-Masch-Straße 13, Hagenweg 20-20a, Sollingstraße 3, Am Weißen Steine 1a und Ruhstrathöhe 16$20 \mathrm{a}$ in den Besitz von Coreo übergegangen. ${ }^{18}$ Der Kaufpreis von 9,3 Mio. Euro ${ }^{19}$ würde theoretisch Mieten ermöglichen, die nach Kriterien der Stadt Göttingen für niedrige Einkommen bezahlbar wären. Coreo aber will das „erheblich[e] Wertsteigerungspotenzial" 20 ausschöpfen. Das bedeutet, dass in den von Coreo gekauften Beständen aufgrund der im Stadtgebiet Göttingen mittlerweile deutlich höheren Angebotsmieten eine Ertragslücke in den Coreo-Beständen besteht. Genau diese Lücke will Coreo schließen. Das Unternehmen möchte hierzu seinen Besitz auf fünf Standorte - wahrscheinlich in der Stadt Göttingen - konzentrieren. ${ }^{21}$ Am 16.07.2019 kündigte Coreo an, dass ein Viertel seiner Wohnungen (mehr als hundert) an einen institutionellen Investor übergehen würden - hierbei handelt es sich um Wohnungen in der Groner Landstraße 9-9a. ${ }^{22}$ Den Bewohner*innen dieser Wohnungen drohen Mieterhöhungen allein schon wegen der Kaufnebenkosten.

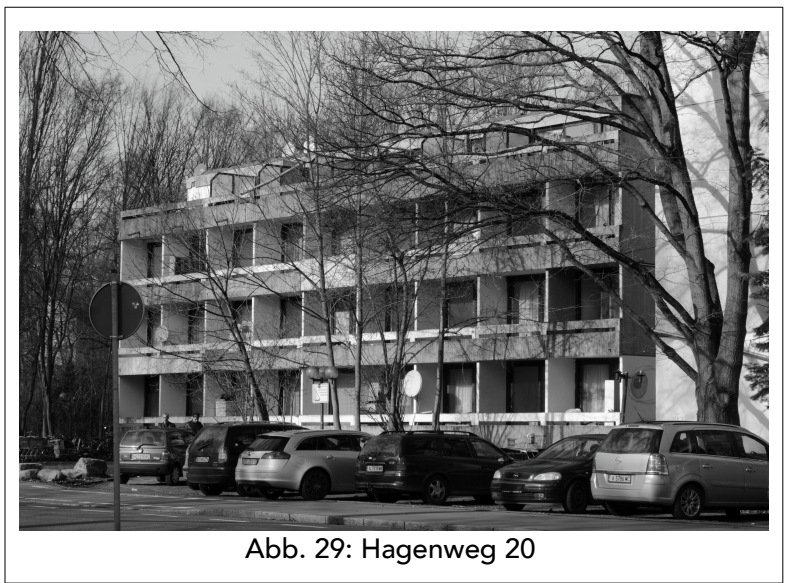

In der Untere-Masch-Straße 13 kam es zu Widerstand und Protest der Bewohner*innen und mit ihnen solidarischer Menschen. ${ }^{23}$ Nichtsdestotrotz hält das Unternehmen an seiner Strategie fest, das Gebäude inner- halb weniger Monate vollständig zu entmieten, die Mieter*innen aus ihrem bisherigen sozialen Umfeld in der Innenstadt in teils kaum zumutbare neue Wohnumfelder zu drängen und die Untere-Masch-Straße 13 in voraussichtlich erheblichem Maße aufzuwerten.

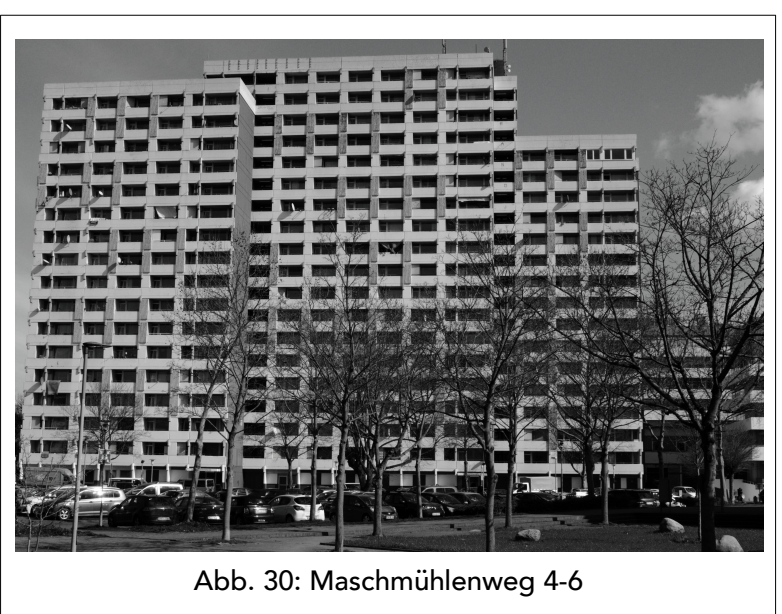

Die laufenden jährlichen Mieteinnahmen betrugen 2019 (bei einer Gesamtfläche von $13.754 \mathrm{~m}^{2}$ ) 1,2 Mio. Euro pro Jahr. ${ }^{24}$ Die durchschnittliche Nettokaltmiete pro Appartement betrug also 231 Euro pro Monat bzw. 7,27 Euro je Quadratmeter und Monat. Der Kaufpreis von 9,3 Mio. Euro könnte sich hiermit in weniger als acht Jahren amortisieren. Allerdings ist die aufzubringende Summe um einiges höher. Auf über die Hälfte des Kaufpreises sind Zinsen von 10 \% pro Jahr zu bezahlen. Um dies nachzuvollziehen, lohnt sich ein Blick auf den Zweck, die Struktur und die Strategie von Coreo.

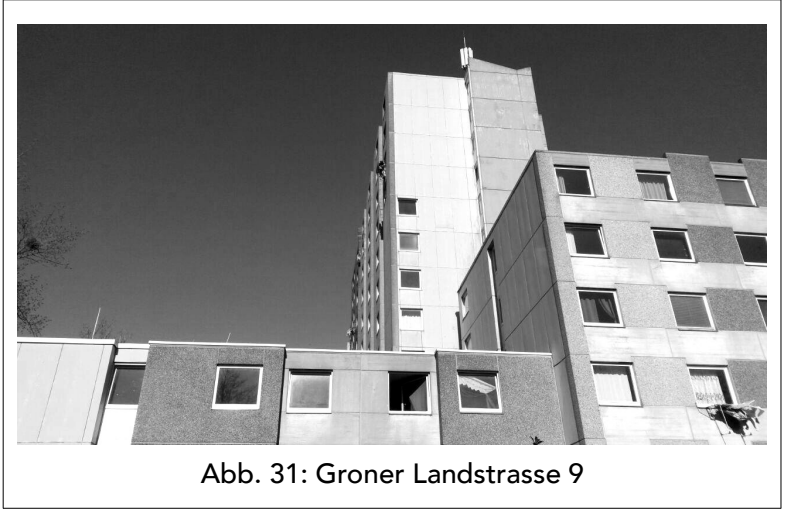

Die Coreo AG ist 2016 aus einem Beteiligungsunternehmen für Nanotechnologie hervorgegangen. Zwei Drittel der AG gehören in sich ständig ändernder Aufteilung Beteiligungsunternehmen von Christian Angermayer (London) und Bernd Förtsch (Kulmbach). Das letzte Drittel befindet sich im Streubesitz. ${ }^{25}$ Weder An- 
germeyer noch Förtsch sind auf Immobilien spezialisiert - sie nutzen das Unternehmen, um ihr überschüssiges Kapital lukrativ zu parken. Das Unternehmen ist gut vernetzt ${ }^{26}$ und hat einen auf dem Finanzmarkt und in Immobiliendingen erfahrenen Geschäftsführer. Bis 2022 (innerhalb von fünf Jahren) möchte es um $1000 \%$ wachsen. $^{27}$ 2017 ließ es Options- und Wandelanleihen mit einem Gesamtvolumen von 20 Mio. Euro an der Münchner Börse platzieren. ${ }^{28}$ Die Laufzeit beträgt fünf Jahre, der Zinssatz $10 \%$ per annum (zwei

Millionen Euro pro Jahr). Das Geld war schnell eingeworben. ${ }^{29}$ Dies kann ein Indiz dafür sein, dass Immobilien in deutschen B- und C-Lagen-Städten (auf die Coreo sich ausgerichtet hat) für internationales Kapital hoch interessant sind.

Die Wandelanleihen stellen Derivate dar. Sie können weiter gehandelt werden, während die Immobilien im Hintergrund als Sicherheit dienen. Solche Finanzprodukte können zur Überbewertung von Immobilien und zur Blasenbildung führen. Im Januar 2020 sollen - vorzeitig - sämtliche Wandelanleihen der Coreo AG zu-

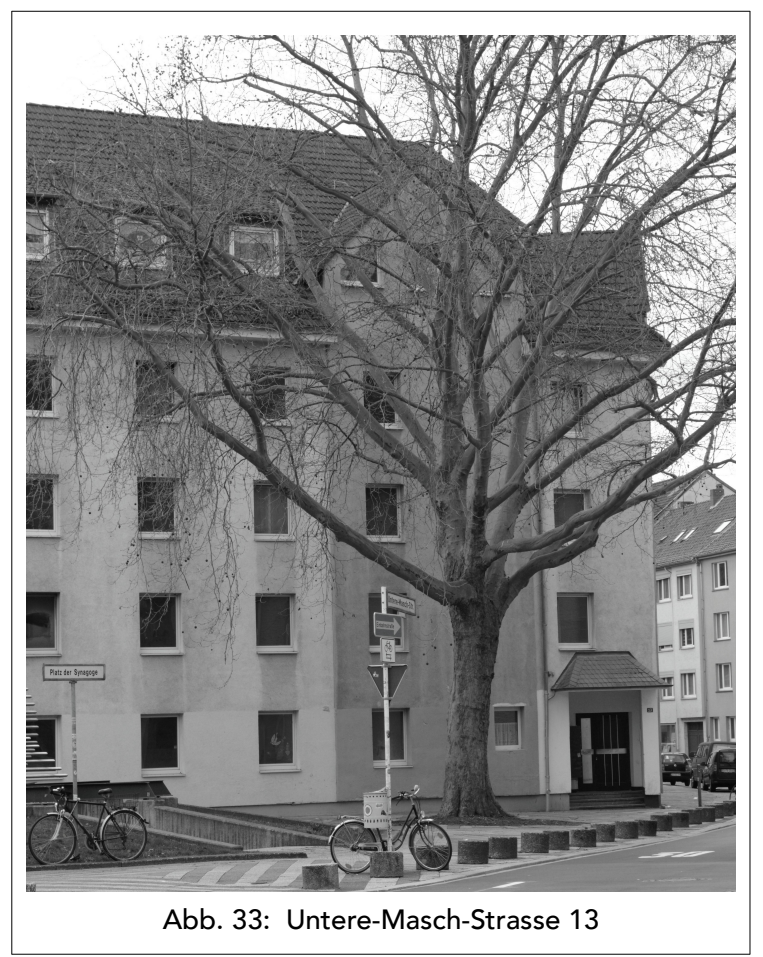

Abb. 32: Struktur der Coreo AG

rückgezahlt werden ${ }^{30}$, was einerseits auf dieser Ebene die Gefahr einer Blase abwendet, andererseits aber die Wertsteigerung der Immobilien zeigt. Das börsennotierte Unternehmen beschleunigt also Wertsteigerungs- und somit Verdrängungsprozesse.

Die auf den Finanzmarkt ausgerichtete Verzinsungslogik muss durch die Mieten finanziert werden. Das Göttinger Portfolio ist, wie fast jedes andere Portfolio der Coreo AG, im Besitz eines Tochterunternehmens, das sich sein Kapital von der AG leiht - zu einem Zinssatz von $10 \%$ per annum. Das Gesellschafterdarlehen der Coreo AG an die Coreo Göttingen Residential UG (haftungsbeschänkt) \& Co. KG beträgt 5.285.000 Euro (Stand: 26.11.2018). ${ }^{31}$ Bei einer Jahresnettokaltmiete von 1,2 Millionen Euro müssen entsprechend allein 528.500 Euro Zinsen an die Gesellschafterin gezahlt werden - gut $44 \%$ der Einnahmen, die aus den Mieten generiert werden. Es ist also davon auszugehen, dass die Mieten in den Beständen der Coreo Göttingen Residential beständig erhöht werden, allein schon um die hohen Zinsen an die Muttergesellschaft zahlen zu können. Eine Verdrängung der bisherigen Mieter*innen ist damit programmiert.

Die Coreo AG ist ein finanzmarktgetriebener Investor, dessen Präsenz in der Stadt zeigt, dass in Göttingen durch Sanierung, Verdrängung und massive Steigerung der Mieteinnahmen lukrative Renditen zu erzielen sind. Umsichtige Sozialpolitik sollte ein solches Vorgehen von vornherein verunmöglichen. 


\section{IMMOBILIEN-AKTIENGESELLSCHAFTEN - DIE VONOVIA AG}

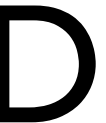

ie Vonovia SE, Deutschlands größter Vermieter, besitzt auch in Göttingen große Wohnungsbestände. Ihre 1.436 Wohnungen (2018) verteilen sich über das ganze Stadtgebiet mit Schwerpunkt Weststadt („Blümchenviertel") und Grone Nord ("Eisenbahnersiedlung"). Zu ihrem Wohnungsbestand ist Vonovia während der großen Privatisierungswelle Anfang der 2000er Jahre durch ihre Vorgängergesellschaften gekommen - die Deutsche Annington und die GAGFAH. Im Jahr 2000 übernimmt die von der britischen Private Equity-Gesellschaft gegründete Deutsche Annington die Eisenbahnerwohngesellschaften. Die Bundesversicherungsanstalt für Angestellte verkauft 2004 ihre GAGFAH an die Private

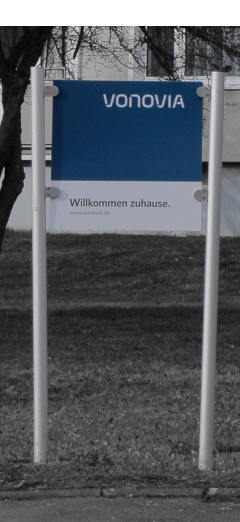

Equity-Gesellschaft Fortress. Beide Unternehmen, Deutsche Annington wie GAGFAH, stehen unter dem Druck der Investoren, hohe Renditen zu erwirtschaften. Die Folgen sind schlechter Service, geringe Instandhaltung, Mieterhöhungen und entsprechend negative Schlagzeilen in der Öffentlichkeit. Die Investoren ziehen sich zurück. Die Deutsche Annington wird 2013 an die Börse gebracht. 2015 kauft sie die GAG$F A H$ auf und nennt sich nun Vono-

via.

Die Expansionsstrategie des Immobilienkonzerns Aufkauf von Wohnungsunternehmen - ist bis heute geblieben und längst nicht mehr auf Deutschland beschränkt (Österreich, Schweden, Frankreich).

Als Aktiengesellschaft hat Vonovia - wenig überraschend - das oberste Ziel, Gewinn zu erwirtschaften und das Kapital ihrer Aktionäre zu vermehren durch Dividenden und Pflege des Aktienkurses. Die Mietwohnungen sind das Mittel: hohe Mieteinnahmen und geringe Kosten, das gilt auch hier. In der „Region Hannover" sind die Mieten 2015-2019 um rd. 14\% gestiegen, wobei dies auch mit Modernisierungen verbunden ist; unklar ist, ob die Wohnungen in Göttingen zur "Region Hannover" gezählt werden, also auch von den Steigerungen in dem (oder auch höherem) Mass betroffen sind.

Während die Umlage von Modernisierungskosten auf die Miete gesetzlich geregelt ist, gibt es bei Berechnung der Bewirtschaftungskosten „Gestaltungsmöglichkeiten", Gewinne zu steigern. Eine Strategie be- steht darin, die Bewirtschaftung Konzern eigenen Tochtergesellschaften

\section{Vonovia Wohnumfeld Service GmbH}

Vonovia Immobilien Service $\mathrm{GmbH}$

zu übertragen ("Insourcing") und an deren Gewinnen zu profitieren. Vonovia nutzt dies, wie zahlreiche Beschwerden von Mietern - auch in Göttingen - über gestiegene Nebenkosten zeigen.

Gleichzeitig ist Vonovia auffällig um ein besseres, positives Image bemüht. Sie distanziert sich von den (früheren) auf kurzfristig hohe Rendite spekulierenden Finanzinvestoren und gibt sich als ein Immobilienunternehmen mit langfristiger Strategie. Sie wolle ServiceQualität bieten, verweist auf überdurchschnittlich hohe Instandsetzungsraten und berichtet stolz von Mietern, die seit 13 Jahren bei Vonovia wohnen, und von Programmen, über 70jährige Mieter nicht durch Mieterhöhung zu verdrängen. In einigen Fällen kümmert sie sich um eine Quartiersentwicklung zur Erhöhung und Absicherung des Wohnwertes - vielleicht auch in Spekulation auf Gentrifizierung.

,Unsere Strategie ist langfristig, über Generationen hin zu behalten und Skaleneffekte und Effizienzen zu schaffen (kaufen \& halten), und die Strategie ist daher verschieden von der von finanziellen Investoren mit einem zeitlich begrenzten Investmenthorizont (kaufen\&verkaufen), 32

(Vonovia 2020: Investor Presentation January 2020, eigene Übersetzung.)

An dem Zweck, Gewinne zu erwirtschaften, ändert all das nichts. So werden die Investitionen in Modernisierung zurück gefahren, weil die Kürzung der Modernisierungsumlage auf $8 \%$ und der möglichen Mietensteigerung nicht mehr so rentierlich sind. Investitionen

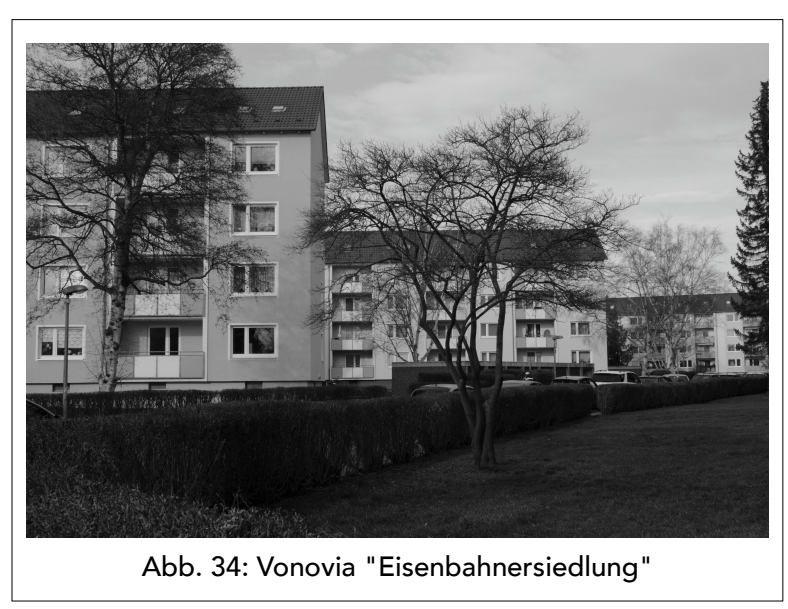




\section{Göttingen}

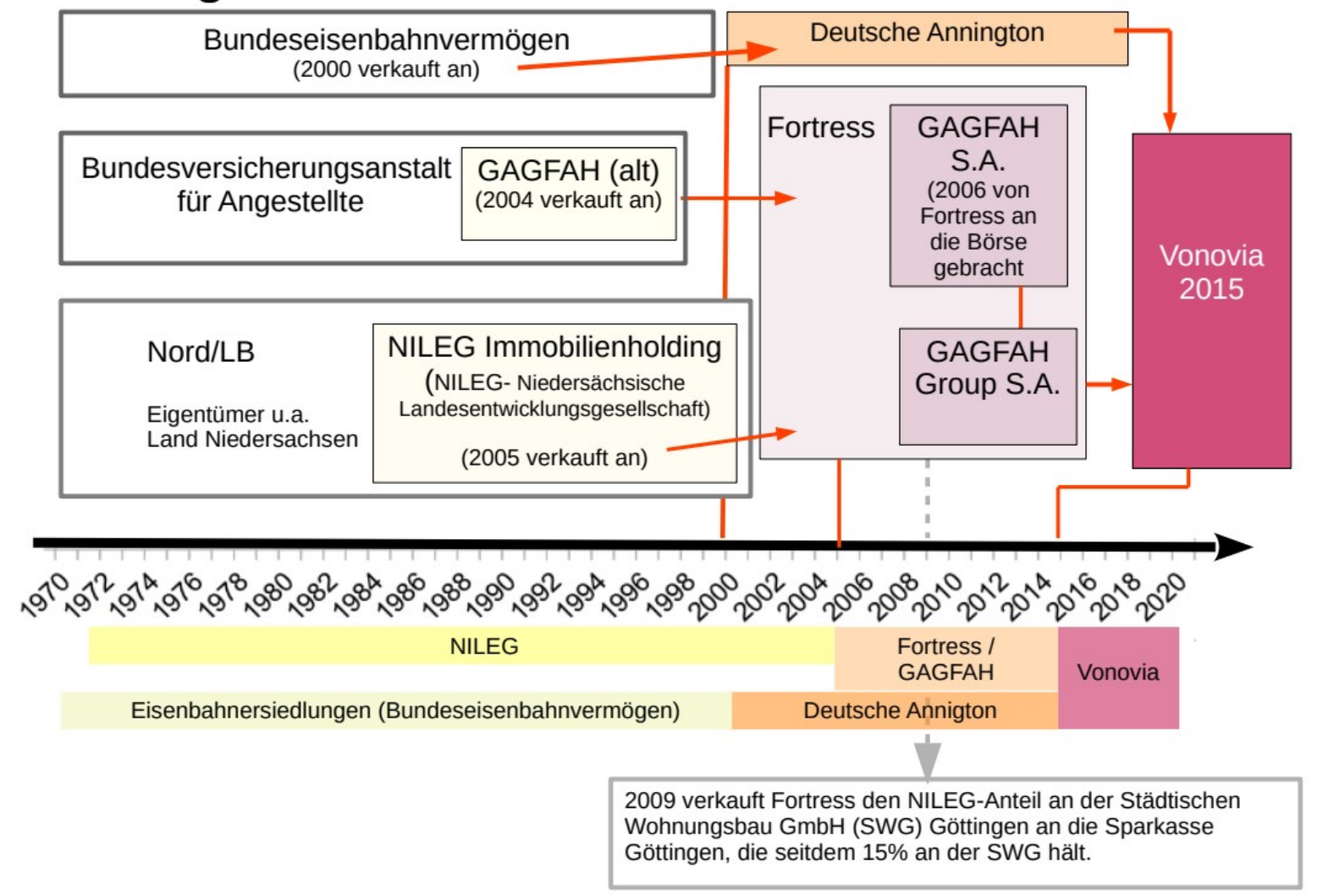

Abb. 35: Unternehmensentwicklung Vonovia

werden räumlich fein sortiert und auf "core regions" konzentriert - Schwarmstädte und andere Städte mit "hoher Dynamik". Göttingen wird offenbar dazu gerechnet.

Beschwerden über nicht nachvollziehbare, eklatant gestiegene Nebenkosten zeigen (auch) eine andere Praxis als die in den Hochglanzbroschüren für Aktionäre aufgeführten Absichten.

Auch in Göttingen gibt es Beschwerden über Vonovia. Betroffene Mieter haben sich deswegen schon 2016 in einer Mieterinitiative organisiert (s. Kap. 25). Im Februar 2020 rügt zudem der Göttinger Mieterverein öffentlich die Abrechnungspraxis der Vonovia als "unlauter" und „intransparent" - ein seltenes Vorgehen des Göttinger Mietervereins.

\section{Nebenkosten: Steigerung um bis $\mathrm{zu}+$ $370 \%$}

"So ist in einem Fall, den der Mieterverein zu beraten hat, die Position der Hauswartskosten von $794,88 €$ in 2015 auf 2.606,40 $€$ in 2016 und somit um 227,90\% gestiegen, der Winterdienst stieg von 651,24 $€$ im Jahr 2016 auf $2.732,22 €$ in 2017 und auf 3.100,09 $€$ in 2018 an. In der Zeit von 2016 zu 2018 ist somit eine Steigerung von $376,03 \%$ zu verzeichnen. Die Positionen Außenanlage, Rasenfläche, Hecken schnitt und Gehölzfläche (früher Pflege Außenanlagen) stieg in diesem Fall in der Zeit von 2015 bis einschließlich 2018 um 162,40 \% - und das, obwohl in einem der Jahre auf den Flächen rund um das betroffene Haus Materialien und Gerätschaften aufgrund durchgeführter Modernisierungsarbeiten standen und eine Gartenpflege nicht stattfinden konnte. Der Mieterverein Göttinnen e.V. rügt die Abrechnungspraxis als intransparent, das Verhalten der Vermieterin erscheine unlauter. Nicht nur, dass extrem steigende Kosten vom eigenen Unternehmensgeflecht generiert werden, die Vonovia versuche auch noch, diese Kosten als im Vergleich "unterdurchschnittlich" darzustellen Es ist zu befürchten, dass es hier weniger um die ordnungsgemäße Bewirtschaftung des Mietenbestands als vielmehr um die Generierung von Extraprofit zu Gunsten des Firmengeflechts der Vonovia geht." (aus der Pressemitteilung des Mietervereins Göttingen vom 17.2.2020)

Der Mieterverein ruft öffentlich zur "Mithilfe" auf.

„Willkommen zu Hause”.

(Vonovia-Schild vor ihren Wohnungen, sieh Bild oben) 


\section{JENSEITS VON AKTIENGESELLSCHAFTEN: BASSIL GROUP - WERTGRUND GMBH - GRUPPE KURTH}

$\mathrm{N}$ icht nur Aktiengesellschaften sind darauf bedacht, aus der Vermietung von Wohnungen eine möglichst hohe Rendite zu erziehen. Es gibt in der privaten Wohnungswirtschaft auch andere Unternehmen und Geschäftsmodelle, welche das Prinzip der Gewinnmaximierung verfolgen. Auch lokale Unternehmen wie z.B. die

\section{Bassil Group GmbH\&Co KG}

Die 2014 gegründete und in Rosdorf ansässige Firma ist im Göttinger Wohnungsmarkt sehr aktiv. Hinter diesem Unternehmen steht (als ,Komplentär') die Bassil $\mathrm{GmbH}$ Grundstücksverwaltung. Auf ihrer Homepage gibt die Bassil Group an, dass sie „über 900 Mieteinheiten" verfügt - in Göttingen und in benachbarten Gemeinden. Mit dieser Zahl an "Mieteinheiten" hat das Unternehmen innerhalb weniger Jahre eine GröBenordnungen erreicht, die an die Göttinger Bestände von Adler Real Estate oder Vonovia heran reicht.

Über Mietpreise, die Höhe von Mieteinnahmen, Gewinne oder andere betriebliche Kennzahlen ist öffentlich nichts zu erfahren. Aber die Immobilien-Anzeigen der Bassil Group sprechen eine deutliche Sprache. Ende Februar 202033: Mietpreise von 16 bis fast $18 € /$ $\mathrm{m}^{2}$ für Wohnungen in der Innenstadt (s. Abb. 35). Zu diesen Spitzenpreisen kommen in der Regel noch Kautionen von 1.000 bis $2.000 €$ hinzu. Die Wohnungen, meist in Altbauten, werden alle als renoviert beschrieben. Doch es handelt sich nicht um überdurchschnittlich gut ausgestattete. Die Bassil Group hat auch günstigere Wohnungen - für 9-10 $€ / \mathrm{m}^{2}$. Eine Auswertung von Immobilienanzeigen im Sommer 2019 hat jedoch gezeigt, dass die Bassil Group bei kleinen Wohnungen die höchsten Quadratmetermieten in Göttingen fordert (Miessner/Marlow 2019).

Der Wohnungsmarkt für Studierende gibt derartig hohe Mieten offensichtlich her, weil es an kleinen Wohnungen mangelt. Diese Situation ermöglicht es, so hohe Mieten durchzusetzen und vom Zustand und Zuschnitt her schwer vermietbare Wohnungen noch teuer zu vermieten. Studierende sind eine besonders geeignete Klientel (siehe Kapital 3). Weil sie nur für wenige Monate oder Jahre eine Unterkunft suchen, nehmen sie etliches in Kauf - z.B. unzureichende oder "sehr schlichte" Instandhaltung, "spezielle" Abrechnung der Kaution, "Wünsche”, sich im Konfliktfall nicht an den Mieterverein zu wenden.
Ob diese Praktiken immer legal sind, muss der Mieter arbeits-, kosten- und zeitaufwändig auf dem rechtlichen Weg klären lassen. Es ist eine privatrechtliche Sache, wobei die Grauzone groß ist, wessen Interessen schutzwür-

dig(er)

sind, die

des Mie-

ters oder

die des

Vermie-

ters/Eigen-

tümers.

Das Inter-

esse des

Vermie-

ters/Eigen- Abb. 36: Obere-Masch-Strasse 1 Zimmer + Bad, tümers, 20 qm, 17,25 Euro/m²

Gewinne zu machen, das Kapital zu vermehren, hat einen hohen rechtsstaatlichen Schutz und genießt eine hohe politisch-ökonomische Anerkennung. Das gilt im Grundsatz auch für die Tätigkeit der Bassil Group. Der Mieter, so die Auffassung vieler Ökonomen und Politiker, muss die hohen Mieten ja nicht akzeptieren. Er hat die Freiheit und - als "Konsument" - die Macht, den "Markt" zu beeinflussen, indem er woanders hinzieht (samt Arbeitsplatz und Uni?) oder auf Reisen, etc. verzichtet.

Der Geschäftsumfang der Bassil Group ist in Göttingen vielleicht relativ groß. Aber aus nationaler oder gar internationaler Perspektive ist die Kapitalgröße der Bassil Group eher bescheiden. In einer anderen Liga spielen Immobilienfonds wie die WERTGRUND $\mathrm{GmbH}$.

\section{Immobilienfonds Wertgrund}

Immobilienfonds sind Investmentfonds, die von Anlegern Kapital einsammeln, um es für diese durch bestimmte geschäftliche Tätigkeiten zu vermehren. Die Besonderheit besteht darin, dass das Vermögen des Fonds nicht in Effekten, also Aktien oder Anleihen, besteht, sondern in alternativen Werten (hier: Immobilien) - daher auch die Bezeichnung AIF - Alternativer Investmentfonds. WERTGRUND ist ein offener Immobilienfonds. Offen bedeutet, das Kapitalgeber Anteilsscheine erwerben können und - unter Wahrung bestimmter gesetzlicher Fristen - auch jederzeit wieder verkaufen können. Das eingebrachte Kapital wird von 
einer Kapitalverwaltungsgesellschaft verwaltet, während Kauf/Verkauf und Bewirtschaftung der Immobilien, das so genannte Asset Management, Aufgabe des Immobilienfonds ist. Ziel des Fonds ist die Erwirtschaftung einer überdurchschnittlichen Verzinsung. Da die Rendite aus den Mieterlösen und eventuell dem Verkauf von Immobilien bezahlt wird, handelt es sich bei dieser Kapitalanlage um eine Spekulation darauf, dass sich die kalkulierten und erhofften Mieten und Immobilienpreise zukünftig auch verwirklichen lassen. Das Risiko besteht darin, dass sich die Mieten nicht wie erhofft entwickeln.

Die WERTGRUND Wohnpartner GmbH hat 2018 das IWF-Grundstück für den von ihr 2016 aufgelegten offenen Immobilienfonds "WERTGRUND Wohnen D2" erworben und plant - ab 2020 - den Bau von etwa 210 Mietwohnungen.

Das 1992 gegründete Unternehmen Wertgrund war anfangs eine Vertriebsgesellschaft für Wohnimmobilien, wurde 2006 in eine Aktiengesellschaft umgewandelt und hat 2010 einen ersten offenen Immobilienfonds aufgelegt, den „WERTGRUND Wohnen D”, zusammen mit der Kapitalverwaltungsgesellschaft Pramerica Property Investment $\mathrm{GmbH}^{34}$, Tochtergesellschaft der PGIM Real Estate, die wiederum zur USamerikanischen Prudential Financial Inc. gehört. Die Anlagestrategie ist ausschließlich auf das „konservative und wertstabile Segment deutscher Bestandswohnimmobilien fokussiert", so Wertgrund. Anfang 2020 enthält das Portfolio rd. 2.000 Wohneinheiten in 13 Gebäuden in 6 Großstädten. Immer wieder werden Immobilien verkauft und neue dazu gekauft. Ein Anteilswert am Fonds hat sich nach eigenen Angaben der Wertgrund seit 2010 fast verdoppelt (berechnet als "BVI-Rendite").

Das Göttinger Projekt gehört in einen anderen Fonds, den "WERTGRUND Wohnen D2", der nur für institutionelle Anleger geöffnet ist (Mindestanlage $500.000 €$ ). Genauere Informationen über diesen Fonds gibt es nicht.

\section{Kapital im Überfluss schafft keine bezahlba- ren Wohnungen}

Offene Immobilienfonds gibt es seit rd. 60 Jahren. Jedoch "derzeit erlebt die Branche eines ihrer besten Jahre". Aufgrund der guten Verzinsung und der grossen Masse an Anlage suchendem Kapital ist die Nachfrage der Anleger gestiegen und „Fondsmanger müssen aufpassen dass sie nicht zu viel Geld einsammeln. Kapital, das nicht investiert werden kann, belastet die Rendite." (SZ 29.3.2020) Wertgrund und die zur Signal Iduna-Gruppe gehörende HANSAINVEST Han- seatische Investment-GmbH wollen diese Nachfrage nutzen und planen in einer Kooperation ein Wohnportfolio mit einem Volumen von zwei Milliarden Euro aufzubauen (ebd.)

Zu den Unternehmen mit größerem Wohnungsbestand gehört u.a. die in Göttingen ansässige

\section{Firmengruppe Kurth}

Die aus einem Geflecht von über einem Dutzend Unternehmen bestehende Firmengruppe besitzt in Göttingen neben gewerblich genutzten Immobilien auch eine größere Anzahl von Wohnhäusern - zwei größere Komplexe in Geismar (Auf dem Lohberg und Eisenacher Strasse) sowie etliche einzelne Objekte im Ostviertel, auf dem Klausberg und in Grone (insgesamt mindestens 50 Häuser). Über die genaue Anzahl der Wohnungen oder das Mietpreisniveau ist nichts bekannt. Es finden sich auch keine negativen Berichte über den Vermieter bezüglich falscher Nebenkostenabrechnungen, drastischer Mieterhöhungen, mangelnder Instandhaltung usw. Solche unauffälligen, „soliden" Vermieter und Immobilienunternehmen wird es in Göttingen noch weitere geben. Über die Renditen, die sie erzielen, ist ebenso wenig bekannt wie über ihren Einfluss auf den Göttinger Mietwohnungsmarkt. Dass sie keine roten Zahlen schreiben (und erwarten), darauf weisen Expansionspläne hin. Die Firmengruppe Kurth baut auch - in ganz anderen finanziellen Dimensionen - in Berlin.

\section{Bezahlbarer Wohnraum - Mietenwahnsinn}

Dass Mietwohnungen Mittel für ein profitables - nicht nur kostendeckendes - Geschäft sind, gilt als selbstverständlich. Es wird sogar als notwendige Bedingung gesehen, damit überhaupt Angebote für die ,Wohnungslosen' geschaffen werden. Unmut und Protest entsteht bei den Mietern, wenn die Wohnungen "unbezahlbar" werden, wenn die Voraussetzung für ein angenehmes Leben, die Wohnung, schon so viel kostet, das ein auch nur halbwegs angenehmes Leben dann gar nicht mehr möglich wird.

Wo diese Grenze zwischen „bezahlbaren Mieten” und "Mietenwahnsinn" verläuft, ist in keinem Ökonomie-Lehrbuch und in keinem Markt"mechanismus" festgeschrieben. Mieter müssen sie erkämpfen. 


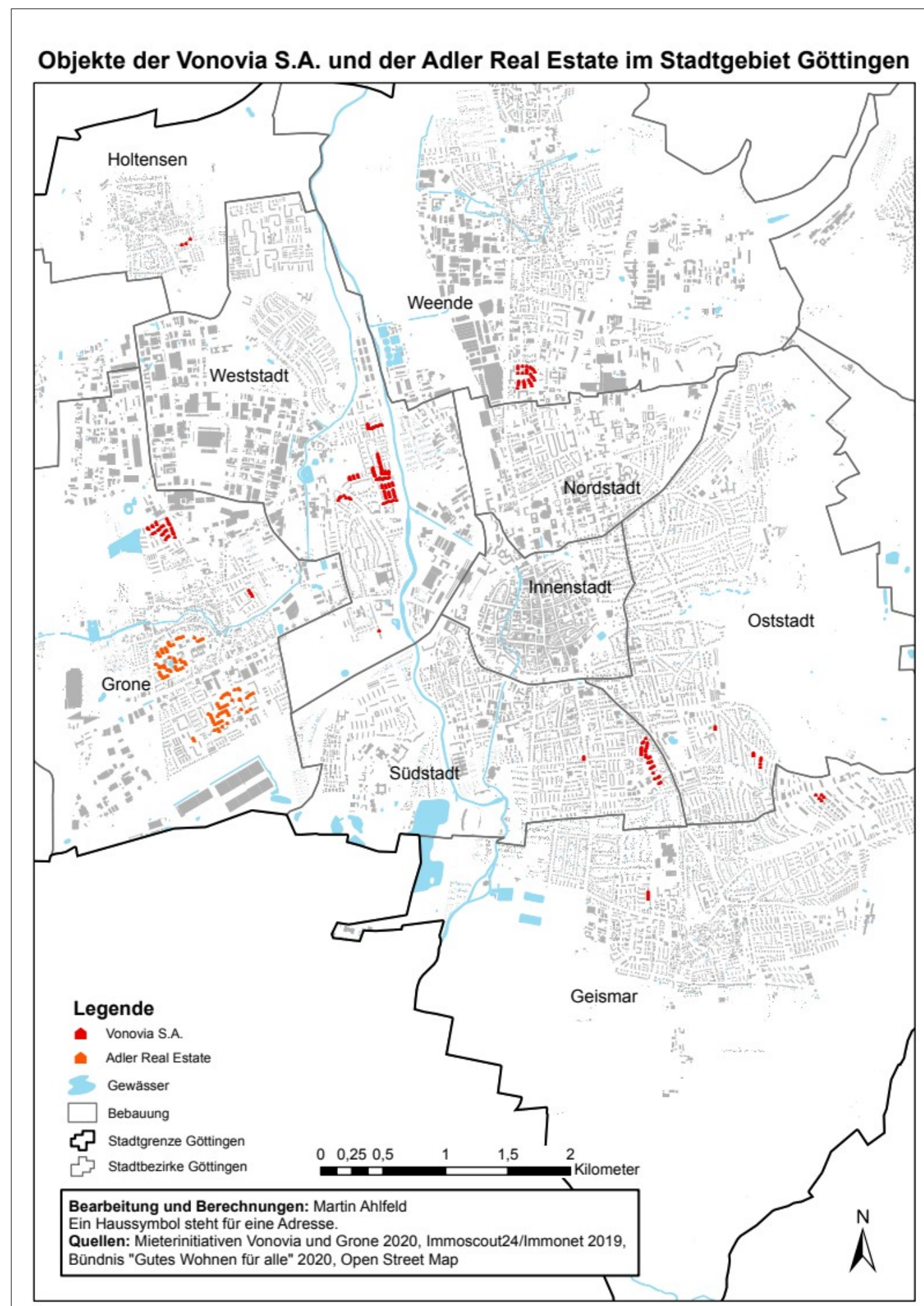

Abb. 37: Standorte von Vonovia und Adler Real Estate 


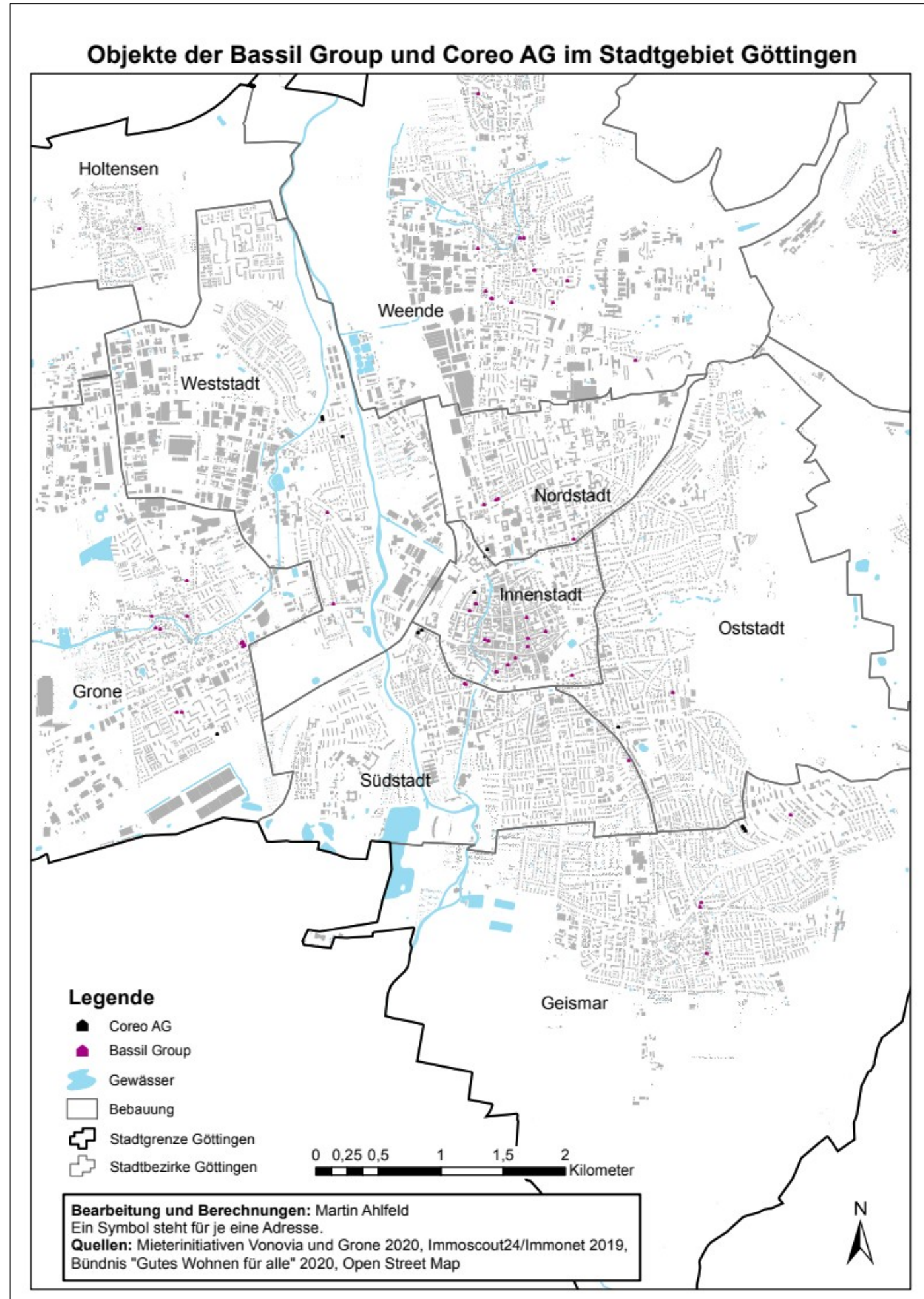

Abb. 38: Standorte der Bassil Group (Vermietungsangebote) und der Coreo AG 


\section{Kommunale Wohnungspolitik}

\section{VOM SOZIALEN WOHNUNGSBAU ZUR SOZIALEN WOHNRAUMFÖRDERUNG (1)}

A m 1.1.2002 tritt das Gesetz über die soziale Wohnraumförderung (WoFG) in Kraft. Damit endet im Kern die seit drei Jahrzehnten geführte Politik des Sozialwohnungsbaus. Die rot-grüne Bundesregierung setzt die neoliberale Wohnungspolitik der Kohl-Ära fort und erklärt angesichts der „unbestreitbar allgemein guten Versorgung mit Wohnraum" (Bodewig, s. Kasten) die staatliche Förderung von preisgebundenem Mietwohnungsneubau zu einem unnötigen, den Wohnungsmarkt behindernden Eingriff. Seitdem beschränkt sich die Wohnungspolitik - neben der Förderung von Modernisierung statt Neubauauf die finanzielle Unterstützung von Gruppen, die aus finanziellen Gründen nicht am Markt teilnehmen können: kinderreiche Familien, Menschen mit (zu) geringem Einkommen. Subjektförderung statt Objektförderung - mittels Wohngeld, Belegungsbindungen und eventuell auch Neubau in begrenztem Umfang. Die Umsetzung dieser Politik liegt jetzt im Wesentlichen in der Verantwortung der Kommunen, zu deren Aufgabe die Armenfürsorge ja traditionell gehört.

Die Wirkungen dieser neuen Wohnungspolitik sind in Göttingen deutlich an der Entwicklung der Sozialwohnungsbestände abzulesen.

Der Bestand an preisgebundenen Sozialwohnungen hat sich in Göttingen seit 1980 kontinuierlich verringert - bis 2002 halbiert. Seit 2002 sind weitere rd. 2.200 aus der Bindung gefallen und nur 191 sind neu hinzugekommen. So wird der Bestand an Sozialwohnungen 2020 auf rd. 1.080, also nur noch ein Viertel von dem im Jahr 2002, geschrumpft sein. Sozialwohnungen gibt es inzwischen in vielen Teilen der Stadt nicht mehr. Etwa die Hälfte der noch vorhandenen befindet sich auf dem Holtenser Berg. Weitere wichtige Standorte sind die Zietenterrassen, der Leineberg, Fahlbusch Straße (Weende) und die Neustadt (Innenstadt). 
Größter Anbieter von Sozialwohnungen in Göttingen - gut die Hälfteist die Städtische Wohnungsbau $\mathrm{GmbH}$ (SWB) mit rd. 1.200 Wohnungen (2017). Allerdings hat die sinkende Wirtschaftlichkeit des Sozialen (Neu)Wohnungsbaus aufgrund steigender Baukosten, aber gedeckelter Mieten auch bei der SWB dazu geführt, dass in den letzen Jahren der Anteil ihrer freifinanzierten Wohnungen in ihrem Bestand beständig gestiegen ist - von $55 \%$ (2008) auf knapp 62\% (2017). Zudem - so die SWB sind Kriterien, die zum Bezug einer Sozialwohnung berechtigen (Einkommens- und Wohnflächengrenze) öfter ein wenig erfreuliches Thema, da bei manchen Mietern Einkommen wie Haushaltsgröße häufiger schwanken und dann einen Umzug auslösen. Der Wegfall der Bindung sei nicht so ein großes Problem, weil das bei der SWB nicht automatisch zu einer drastischen Mieterhöhung führen würde (vgl. $\rightarrow$ Kap. 28).

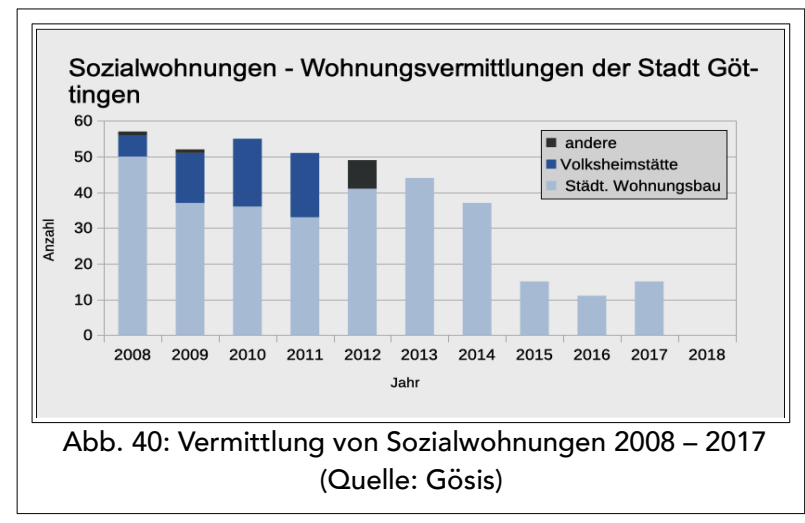

Immer weniger Sozialwohnungsbewerber können von der Stadt vermittelt werden. Seit 2015 ist die Zahl nochmals drastisch eingebrochen und mit 10 bis 15

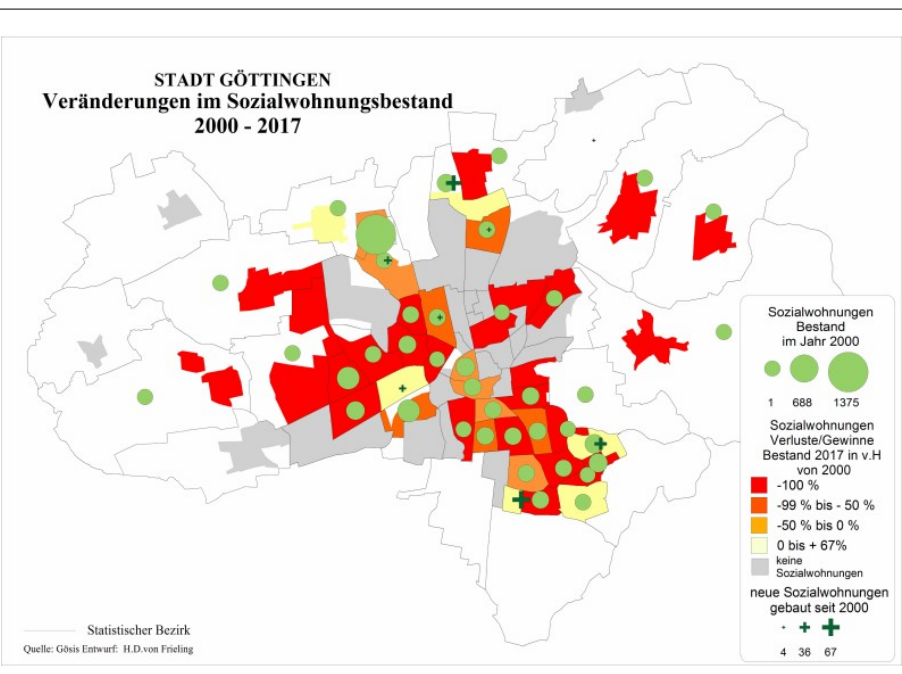

Abb. 42: Änderungen im Sozialwohnungsbestand 2000-2017

Fällen pro Jahr fast bedeutungslos (s. Abbildung 44). Seit 2013 werden Bewerber auch nur noch an die SWB vermittelt. Auch die Zahl der Bewerber um eine Sozialwohnung hatentgegen den Tendenzen auf dem Wohnungsmarkt und seinen steigenden Mietenseit 2015/16 stark abgenommen. Dies ist wohl eher eine Folge (der Nichtanpassung) der staatlichen Berechtigungskriterien. Denn kurioserweise entfällt in der Statistikbei steigenden Mietpreisenausgerechnet das Kriterium ,zu hohe Mieten' als Grund für Wohnungsnot und Berechtigung zu einer Sozialwohnung.

Diese Statistik spiegelt nicht die soziale Realität, sondern die Umgangsweise der (Agenda 2010-)Politik mit Armut wider. Auch die ansteigende Zahl akuter Obdachlosigkeit gibt keinen ausreichenden Hinweis auf den Umfang der Obdachlosigkeit in Göttingen, allenfalls auf deren Steigerung.

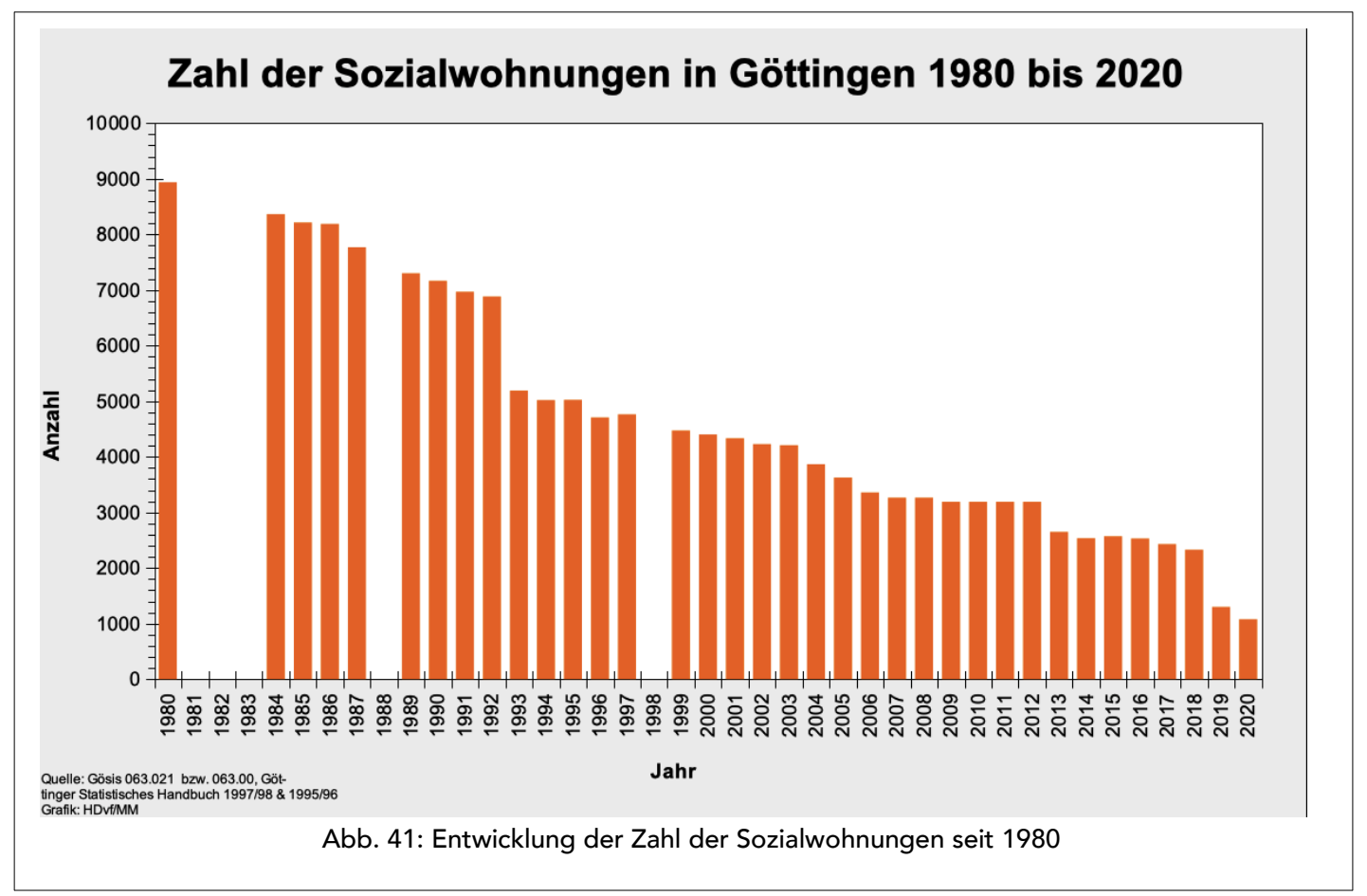




\section{VOM SOZIALEN WOHNUNGSBAU ZUR SOZIALEN WOHNRAUMFÖRDERUNG (2)}

$\mathrm{S}$ eit dem Rückzug aus dem Sozialwohnungsbau ist die Subjektförderung das zentrale Instrument der sozialen Wohnungspolitik. Was das für Mieter mit geringem Einkommen (aber oberhalb der Grundsicherung) bedeutet, zeigt sich beim Wohngeld.

"Zielgruppe sind künftig Haushalte mit geringem Einkommen, die sich aus eigener Kraft am Markt angebotene, ihren Wohnbedürfnissen entsprechende Wohnungen nicht leisten können, sowie Haushalte, die auf Grund der Zugehörigkeit zu bestimmten sozialen Gruppen oder wegen bestimmter persönlicher Merkmale auf Vorbehalte bei den Vermietern stoßen."

(Damaliger Bundesminister für Verkehr, Bau- und Wohnungswesen Kurt Bodewig (SPD) in: Wirtschaftsdienst 2001/III, S. 135-138.)

\section{Wohngeld}

Ein Mietkostenzuschuss zur Senkung der Mietbelastung muss jährlich neu beantragt werden. Weil eine festgelegte Einkommensgrenze nicht überschritten werden darf, findet eine eingehende Überprüfung des Einkommens statt. Ebenso darf die Miete eine zwar regional unterschiedliche, aber festgelegte Höhe nicht überschreiten. Beide Grenzen waren fixiert und wurden nach 2005 nur 2009 und 2016 angepasst. Die starren Grenzen hatten zur Folge, dass im Verlauf einer Periode die Zahl der Wohngeldberechtigten immer

\begin{abstract}
wieder stark abnahm, weil geringfügige nominale Lohn- (oder Renten-)erhöhungen den Wohngeldanspruch zunichte machten. Oder die steigenden Mieten führten zum Überschreiten der Obergrenze und damit zum Verlust des Anspruchs auf Wohngeld oder zumindest wieder zu einer deutlichen höheren Mietbelastung. Viele Wohngeldempfängerhaushalte rutschen so - trotz Erwerbseinkommen - in den Sozialleistungsbezug (Grundsicherung) bis zur nächsten Anpassung des Wohngeldes durch die Regierung. Erst 10 Jahre (!) nach In-Kraft-Treten der Hartz IV-Reformen hält die Bundesregierung es für angebracht, diese für Mieter mit geringem Einkommen stressige und unsichere Art sozialer Wohnungspolitik etwas zu korrigieren.
\end{abstract}

„Durch Einkommenssteigerungen, die nur die Inflationsrate ausgleichen wie auch durch inflationsbedingt steigende Preise und Mieten verliert das Wohngeld real an Wert. So können Haushalte aus dem Leistungsbezug fallen, obwohl ihre Wohnkostenbelastung gestiegen ist. "Am unteren Ende" wechseln Haushalte in die Grundsicherung für Arbeitsuchende bzw. in die Sozialhilfe, da dort die Regelsätze regelmäßig an die steigenden Bedarfe angepasst werden."

(Dt. Bundestag 2017: Wohngeld- und Mietenbericht 2016, BT-Drs 18/13120, S. 133; vgl. auch Wohngeld- und Mietenbericht 2018, S. 64f.)

Die wellenförmige Entwicklung der Zahl der Wohngeldempfänger in Göttingen gibt daher auch nicht die wechselnden Bedürfnislagen wieder. Sie ist vielmehr das Ergebnis, wie der Staat seinen Sozialstaat entsprechend seinen Interessen organisiert.

Ab 2005 werden Transferleistungsbezieher, die statt Wohngeld nun Unterkunftskosten (KdU) erstattet bekommen (2019 sind es 8.501 Haushalte), in einer anderen Statistik geführt $^{35}$. In Göttingen verringerte sich die Zahl der Wohngeldbezieher von 2005 auf 2009 und noch kräftiger, nämlich um rd. 50\%, von 2010 auf 2015. Nach der Anpassung 2016 steigt die Zahl leicht wieder. 


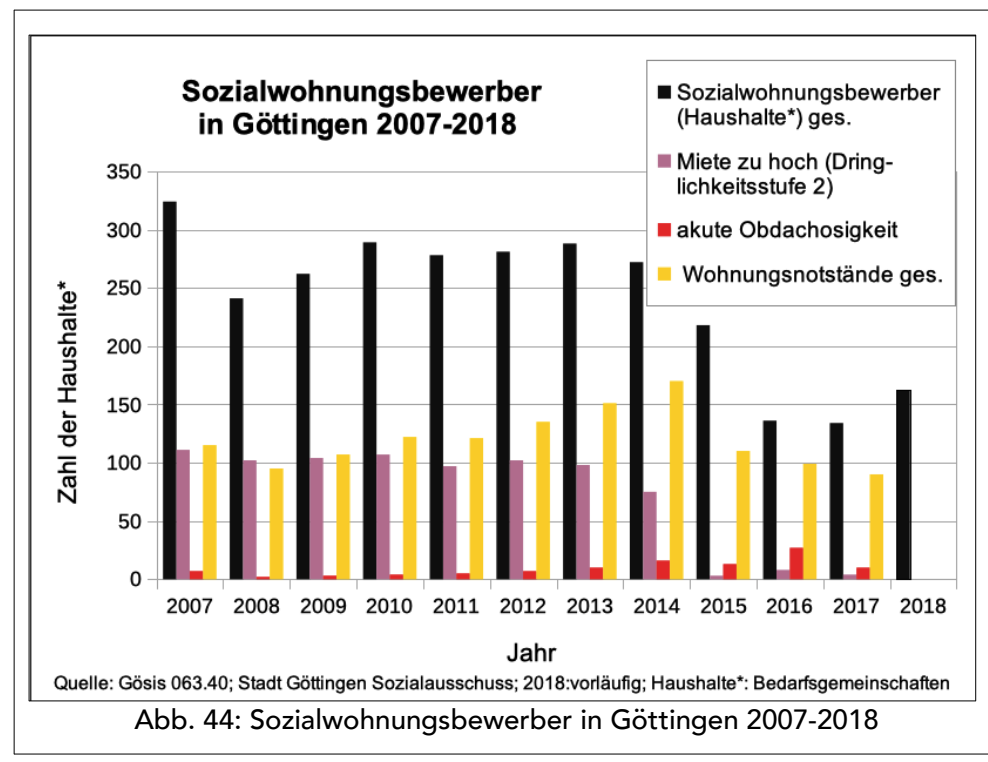

schlagen oder zu bestimmen und die Miethöhe zu deckeln, gewährt die Stadt dem Vermieter eine Entschädigung. Diese kann unterschiedlich sein und von einem Mietzuschuss bis zu Gewährung von (Bau)Rechten gehen. Das Instrument der Belegungsrechte gilt bei Politikern und in der Wohnungswirtschaft als zielgerichteter und (markt)gerechter als die ehemalige Objektförderung. Es gibt sie aber nicht ohne Gegenleistung (s. Kasten). Was es den Steuerzahler kostet und ob es funktioniert, wird kaum diskutiert. Das höhere Gewicht hat der freie Markt.

Die Stadt Göttingen versucht - im Handlungskonzept zur Schaffung und Sicherung von bezahlbarem Wohnraum (2018)Belegungsrechte über 10 Jahre durch einen (einmaligen) Mietzuschuss von rd. einem Euro pro Quadratmeter zu kaufen - für Haushalte mit "geringem" Einkommen und einer Mietpreisbindung nach §3 WoFG. Sie stellt 2019 allerdings fest, dass ihr Belegungsrechte „nur sehr zögerlich angeboten" werden. Die Menge ist weit entfernt von dem, was die Stadt für notwendig hält.

Menschen, die Leistungen aus SBG II oder SGB XII beziehen, erhalten kein Wohngeld, sondern beziehen Leistungen für Unterkunft und Heizung (KdU). Die KdU sind nicht Instrument sozialer Wohnungs- und Wohnraumförderpolitik, haben aber großen Einfluss auf das preisgünstige Segment des Wohnungsmarktes. Der Staat, d.h. die Kommunen bzw. Landkreise vor allem, übernehmen zwar die gesamten Kosten (bei Grundsicherung im Alter und Erwerbsminderung ersetzt seit 2014 der Bund die Kosten), allerdings gelten Obergrenzen hinsichtlich der Wohnungsfläche und der Miethöhe. Viele Kommunen/Landkreise versuchen diese Kosten, also die Obergrenzen, zu senken - trotz der sehr angespannten Lage im Segment der preisgünstigen Wohnungen. Der Landkreis Göttingen hat dies mit drei teuren Gutachten für ein „schlüssiges Konzept" durchzusetzen versucht; alle drei sind bisher juristisch gescheitert.

Die KdU-Leistungen haben erhebliche Auswirkungen auf die lokalen Wohnungsmärkte und die Versorgungsmöglichkeiten anderer Haushalte im preisgünstigen Wohnungsmarktsegment.

\section{Belegungsrechte}

Ein weiteres Instrument als „Ersatz" für den sozialen Wohnungsbau ist der Kauf von Belegungsrechten (\$26 WoFG). Für das Recht, einen Mieter vorzu-

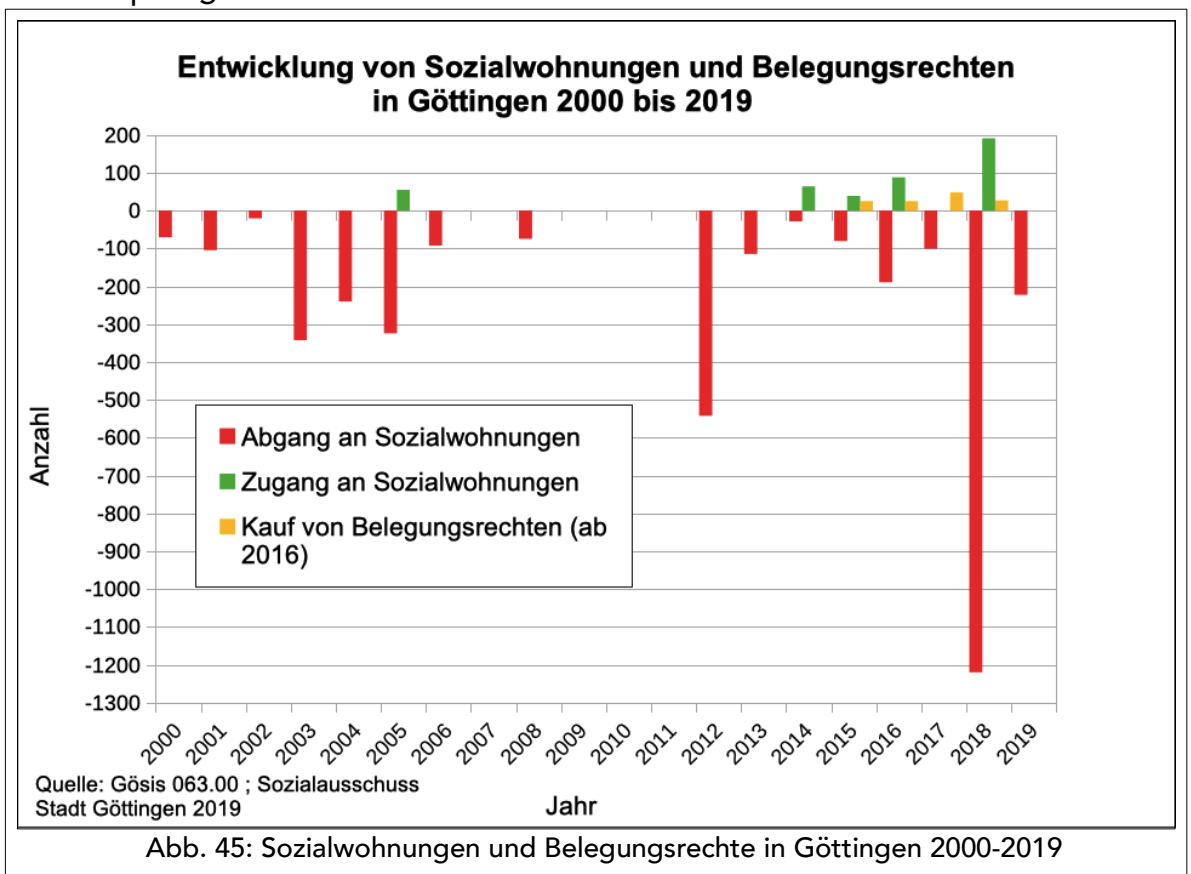




\section{Kommunale Wohnungspolitik}

\section{KOMMUNALE WOHNUNGSPOLITIK IN DER ZWICKMÜHLE?}

$\mathrm{n}$ der Wohnungsversorgung steht die Kommune von zwei Seiten unter Druck. Einerseits hat sie mehr Verantwortung erhalten, aber nicht mehr finanzielle Mittel, seitdem der Bund sich aus der Wohnungsbauförderung zunehmend zurückgezogen hat (2002 Wohnraumfördergesetz (WofG); 2006 Föderalismusreform). Zudem sind die Länder in der Wohnungspolitik weitgehend untätig geblieben und haben die Kommunen ab 2011 auch noch unter Entschuldungszwang gestellt. Der soziale Wohnungsbau ist aber abhängig von staatlichen Investitionen und Förderprogrammen.

Zum anderen richten sich Proteste und Forderungen nach mehr und bezahlbaren Wohnungen erst einmal an die Kommune und nicht an „Hannover" oder „Berlin”. Die in der Kommune regierenden Parteien müssen auf die Forderungen in irgendeiner Weise eingehen - sie akzeptieren, unterstützen, beschwichtigen, „übersehen" oder zurückweisen (was in der Wohnungsfrage schwierig ist) - ohne dabei ihre Bundes-/Landespartei ernsthaft zu kritisieren. Die Stadtregierung, die sie stellen, muss nicht nur mit vielfältigen Interessen und beschränktem Etat zurecht kommen, sondern auch noch etliche Bundesgesetze einhalten wie z.B. die zur Stadt- und Bauleitplanung.

Mit all diesen Schwierigkeiten und Widersprüchen hat die kommunale (Wohnungs)Politik zu kämpfen. Die öffentlich zugänglichen Rats- und Ausschussprotokolle der Stadt Göttingen dokumentieren das. Dass die Kommune dennoch dieses oder jenes in der Wohnungsversorgung erreicht hat, erscheint manchen lobens- und anerkennenswert. Doch man sollte nicht übersehen, wozu und von wem all diese Widersprüche eingerichtet worden sind.

Geht man die Protokolle der öffentlichen Rats- und Ausschusssitzungen durch, ergibt sich in der Frage der Wohnungsversorgung folgendes Bild:

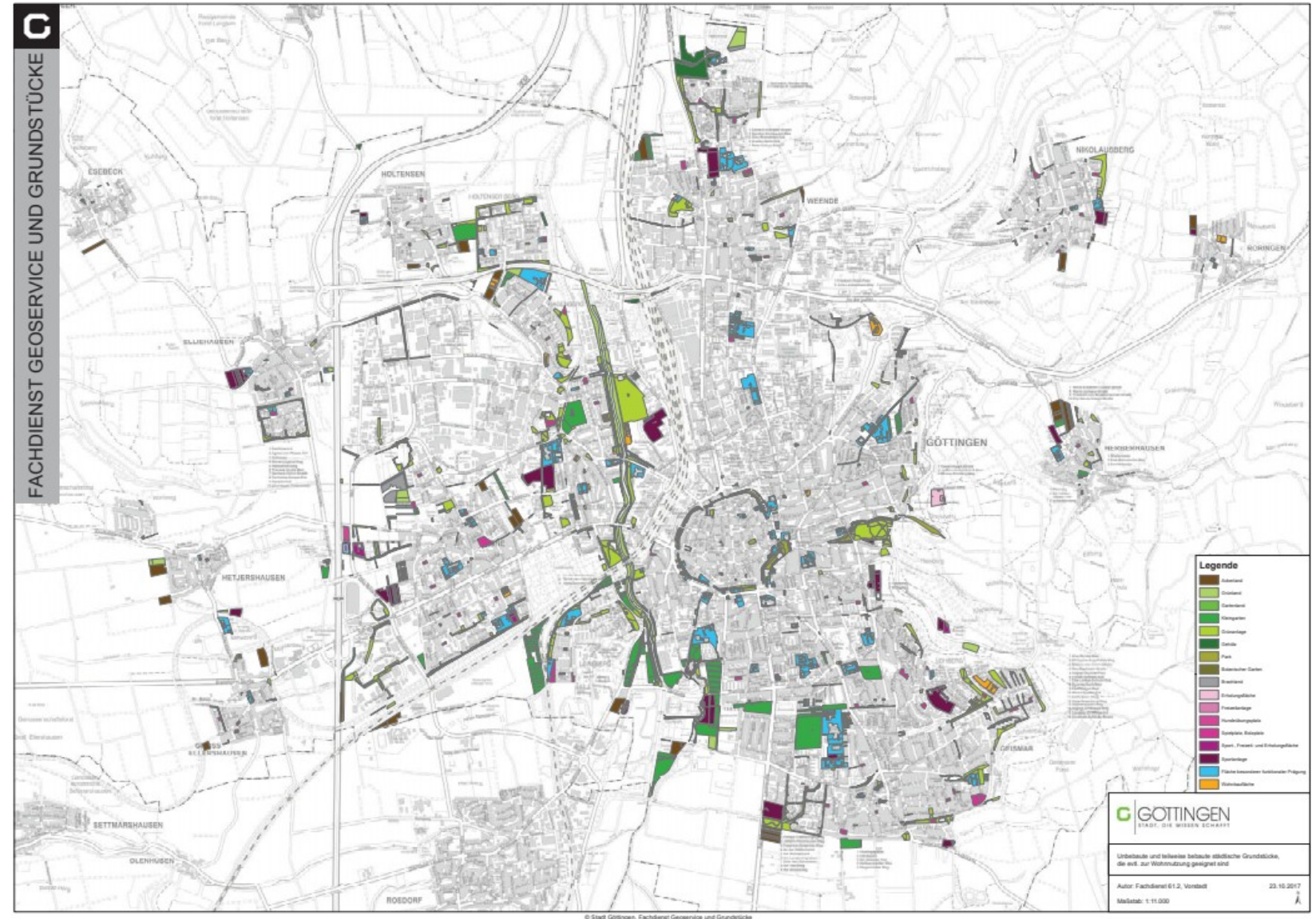

Abb. 46: Bebaute und unbebaute städtische Flächen 2017 (orange = Wohnbauland) 
1. Es gibt spätestens seit 2013 eine Fülle von Anträgen von fast allen Parteien im Rat (von FDP und CDU nur ausnahmsweise), mehr bezahlbaren Wohnraum zu schaffen. Über das Wie haben die Ratsfraktionen sehr verschiedenen Ansichten. Die Anträge konzentrieren sich vor allem auf den Herbst 2014, als die Wohnungsnot für Studierende so offensichtlich wurde, und auf das Jahr 2017. Das zeigt zumindest eines, dass die kommunale Politik das Problem der unzureichenden Wohnungsversorgung genau kannte.

2. Das Resultat all dieser Bemühungen seit über einem halben Jahrzehnt: Die Situation für nicht einkommensstarke Mieter hat sich nicht entspannt oder verbessert, eher im Gegenteil. Der Monitoringbericht 2019 der Stadt zu den Wirkungen des „Kommunalen Handlungskonzeptes" zeigt das deutlich. ( $\rightarrow$ Kap. 18).

3. Wie kommt es, dass noch immer und immer mehr bezahlbarer Wohnraum fehlt?

\section{1 Kommunaler Wohnungsbau}

Die Stadt hat über ihre Städtische Wohnungsbau GmbH (SWB) neue Wohnungen gebaut und bestehende modernisiert. Die SWB, der größte Wohnungseigentümer in Göttingen mit dem größten Bestand an Sozialwohnungen, hat in den letzten 8-10 Jahren auch neue Wohnungen gebaut. Sie hat nach eigenen Angaben sogar ihre Neubautätigkeit verdoppelt - auf durchschnittlich 40 neue Wohnungen pro Jahr, davon sind rd. $25 \%$ sozial geförderte. Doch diese Größenordnung ist weit entfernt von dem, was notwendig wäre. Aber eine stärkere Ausweitung des Neubaus hat die SWB in den letzten Jahren trotz der Krise und entsprechender Anträge im Rat stets abgelehnt ( $\rightarrow$ Kap. 28).

\subsection{Bauland: Bodenvorratspolitik}

Dieses Thema erscheint nur in Anträgen der GöLinke, die immer wieder fordern, städtische Immobilien nicht zu verkaufen. Die Stadtregierung widerspricht, u.a. mit dem Argument, der Entschuldungspakt zwinge sie zum Verkauf (zu Höchstpreisen). Nicht immer gelingt der Verkauf (z.B. Voigt-Realschule).

\subsection{Bauland: Schaffung durch Planung}

Es ist schwierig, über die öffentliche Protokolle herauszufinden, für wie viele Wohneinheiten wann Baurecht

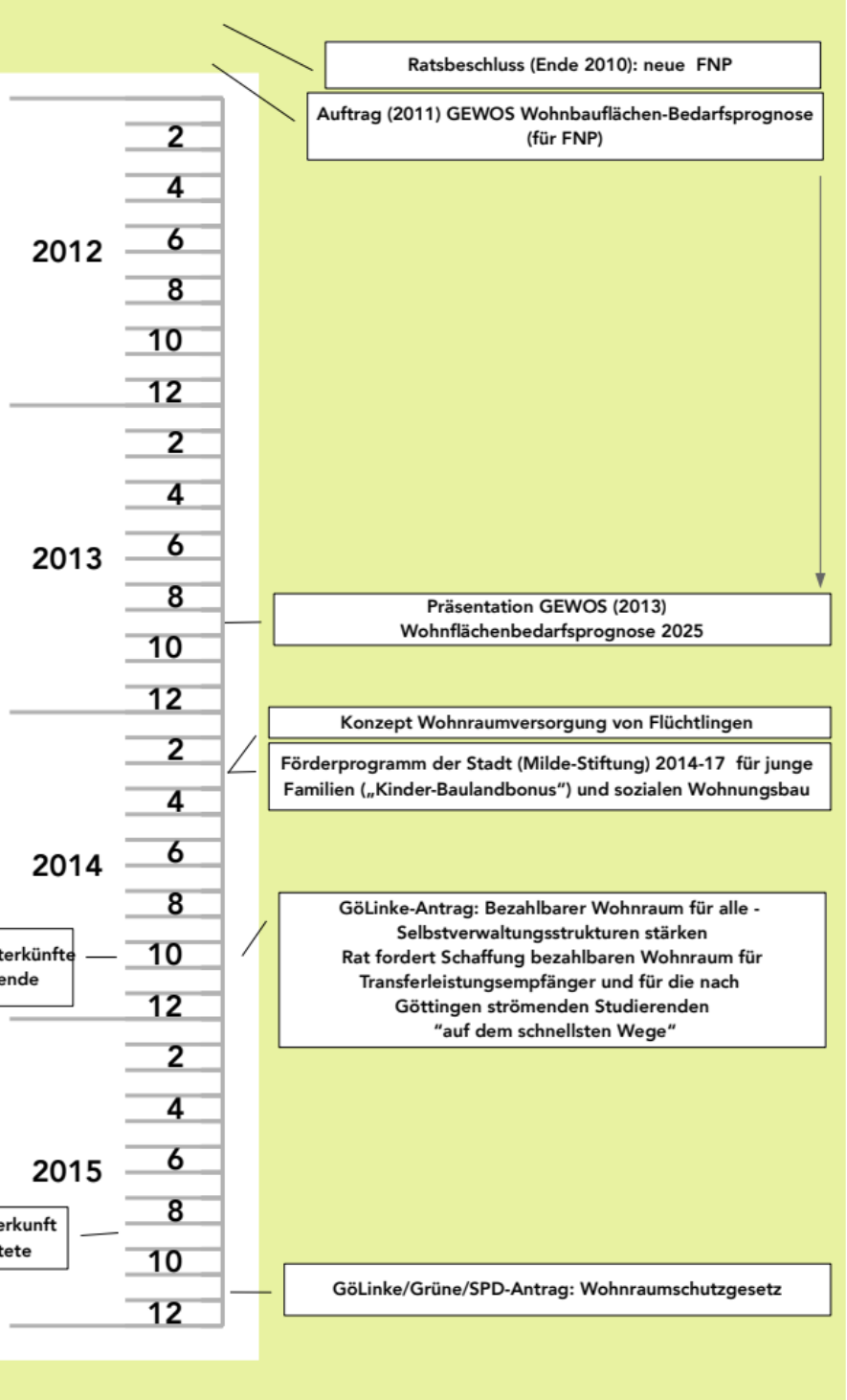

Abb. 47: Aktivitäten des Rates der Stadt Göttingen 2012-2015

geschaffen wurde. Doch in den Jahren 2010 bis 2016/17 gab es offenbar keine besondere Aktivitäten - trotz verschiedener Anträge aus dem Rat (ab 2014). Auf zwei Begründungen stösst man in den Protokollen:

\subsubsection{Personalmangel in der planenden Verwaltung?}

Seit 2011 klagt der Stadtbaurat, dass die "normalen”, laufenden Aufgaben nur noch mit zeitlichen Verzögerungen bewältigt werden könnten; die Politik der "Schwarzen Null” und der „Verschlankung” der Bürokratie lähme die Handlungsfähigkeit der Kommune, was sich besonders nachteilig beim neuen Flächennutzungsplan bemerkbar mache, dessen Fertigstellung verzögere sich um mindestens ein Jahr (beschlossen wurde er dann 2017 statt 2015). Erst zu Anfang 2017 erhielt das Planungsdezernat 6 neue Planstellen. 


\section{KOMMUNALE WOHNUNGSPOLITIK IN DER ZWICKMÜHLE? (2)}

\subsubsection{Planungsverfahren zu langsam?}

Immer wieder findet man in den Ratsprotokollen ungeduldige Fragen und Anträge an die Verwaltung, ,Bauland jetzt!' zu schaffen. Da die planende Verwaltung bei der Baurechtschaffung bestimmte gesetzliche Regeln einhalten und Vorschriften umsetzen muss, ist die Ausweitung eine Frage der personellen Kapazitäten und der planerischen Voraussetzungen.

Bebauungspläne, die Baurecht schaffen, leiten sich aus dem Flächennutzungsplan (FNP) ab. Ist ein Flächennutzungsplan veraltetet, weil er wie in Göttingen aus dem Jahr 1975 stammt, sind immer häufiger Änderungen des FNP erforderlich, damit ein Bebauungsplan entwickelt werden kann (s. Beispiel IWF). Ende 2010 beschließt der Rat, dass ein neuer FNP aufgestellt werden soll. Das ist ein aufwändiges und langwieriges Verfahren. Etwa 5 Jahre, so schätzt man damals, wird es dauern, bis er rechtskräftig wird. Bis dahin geht es vorrangig um solche Bebauungspläne, wo es konkrete Investitionsvorhaben gibt. Längerfristige Planungen sind sozusagen auf Eis gelegt, weil sie Bestandteil der Flächennutzungsplanung sind.

Doch nicht nur der Personalmangel in der planenden Verwaltung hat, wie erwähnt, zu einer großen Verzögerung in der Bearbeitung geführt. Vor 2014/15 gibt es scheinbar auch gar keine besondere Eile bei der Ausweisung von mehr Wohnbauland. Denn die für die Planungsziele relevanten Prognosen - vom eigenen Statistischen Amt (2011) wie von der GEWOS (2013) vermitteln, dass es ab 2016 gar keinen sonderlichen Wohnungsmangel mehr geben wird. Doch schon 2015 sieht sich die Stadt - und dann auch die GEWOSzu einer neuen Prognose und zu einer drastischen Änderung genötigt: mehr Wohnbauland ist dringend notwendig und möglichst schnell.

Hat die Göttinger Stadtplanung versagt, war sie zu langsam?

Wenn solch eine Kritik berechtigt ist, trifft sie die Stadtregierung, also die Politik und nicht die Verwaltung. Sie bleibt dennoch oberflächlich. Denn sie blendet strukturelle Veränderungen im Planungsverständnis vollständig aus, welche die Politik seit den 1980ern durchgesetzt hat. Gemeint ist der Rückbau einer Planung, die auf eine zukünftige, gesamtgesellschaftlich orientierte Entwicklung ausgerichtet ist.
Mitte der 1960er Jahre ist dafür einmal ein neues Instrument, die Entwicklungsplanung, eingeführt worden. Zu deren Instrumenten gehörten auch Methoden wie Prognose, Szenarien, Partizipation bis hin zu kybernetischen Modellen. Doch schon gut 10 Jahre später wurde sie auf das Abstellgleis geschoben zugunsten kurzfristiger Marktorientierung, deal-making, Privatisierung, Standortwettbewerb. Der Bedeutungsverlust räumlicher Planung in der neoliberalen Sozialen Marktwirtschaft spiegelt sich in Göttingen auch darin, dass der FNP über 30 Jahre nicht erneuert wurde. Für neoliberale Ökonomen und Politiker ist eine vorausschauende, umfassende, vorsorgende staatliche Planung ein zu starres Korsett, zu unflexibel, mehr eine Behinderung des "Marktes" und insofern eine Verhinderung der Versorgung durch den "Markt".

Sicherlich ist langfristige Planung schwierig. Wer kann schon zuverlässig vorhersagen, wie sich die Einwohnerzahl und das Wachstum der städtischen Wirtschaft entwickeln werden? Wann und wo boomt die Wirtschaft, wo kommt es zu Rezession oder "Strukturwandel"? Eine Ökonomie wie die Soziale Marktwirtschaft entwickelt sich "spontan”, anarchisch. Und entsprechend ist auch die Stadtentwicklung „unberechenbar". Doch folgt daraus, dass eine vorausschauende Planung überflüssig ist?

Wäre nicht gerade wegen der Unberechenbarkeit des "Marktes" eine Planung notwendig, die auch die anderen Interessen als die der "Investoren" berücksichtigt? Eine Planung, die Reserven - an Land und Infrastruktur - vorrätig hält, Reserven für unerwartet auftretenden zusätzlichen Bedarf (s. das Beispiel Ulm, Kap. 22) und Reserven sichert und aufrecht erhält für Situationen, in denen der Bedarf einmal schrumpft.

Doch diese Option kommt nicht in Betracht. (Stadt)Politik macht die (Stadt)Planung zum Anhängsel der Bewegungen des "Marktes". Und entsprechend werden Stadtplanung und Planer in Göttingen kritisiert. Die Änderungen der Strukturen und Aufgaben, denen die Planung unterworfen ist, sind nicht das Thema. Auch eklatante handwerkliche Fehler werden den Planern von keiner Ratsfraktion vorgeworfen, eher gibt es Lob und Dank. Aber schneller, unbürokratischer und geschmeidiger auf „Investoren“wünsche soll sie reagieren.

Das kurzfristige Effizienzdenken, dem sich seit Anfang der 1980er Jahre auch die Raum- und Stadtplanung 
zunehmend unterwerfen musste, ist ein typisches Kennzeichen neoliberaler Politik. Daseinsvorsorge und Sicherung des Allgemeinwohls wurden zu nachrangigen Zielen der Planung oder wurden umdefiniert in Standortwettbewerbspolitik.

4. Hat die kommunale Politik in Göttingen versagt? Oder steckt sie in einer Zwickmühle?

Alle Parteien bzw. Fraktionen im Rat wollen mehr bezahlbaren Wohnraum, oder haben zumindestwie die CDU und FDPnichts dagegen.

Aber, so hört man als Antwort auf kritische Fragen, die Ressourcen der Kommune seien begrenzt. Die zahlreichen Appelle des Rates an Land und Bund, mehr Mittel zur Verfügung zu stellen, seien weitgehend wirkungslos geblieben. Haushaltsrecht, Bauvorschriften und andere gesetzliche Regelungen hätte den Handlungsspielraum der Kommune weiter eingeengt. Dies ist nicht zu bestreiten.

Andererseits ist auffällig, wie gereizt die regierenden Parteien auf Proteste und wachsende Kritik reagieren und wie sie versuchen, durch mehr symbolische Maßnahmen wie dem Kommunalen Handlungskonzept oder einer Unterstützung für die Gründung von Mieterinitiativen die Glaubwürdigkeit ihres Engagements zu belegen und dafür Anerkennung und Zustimmung statt Kritik - erwarten.

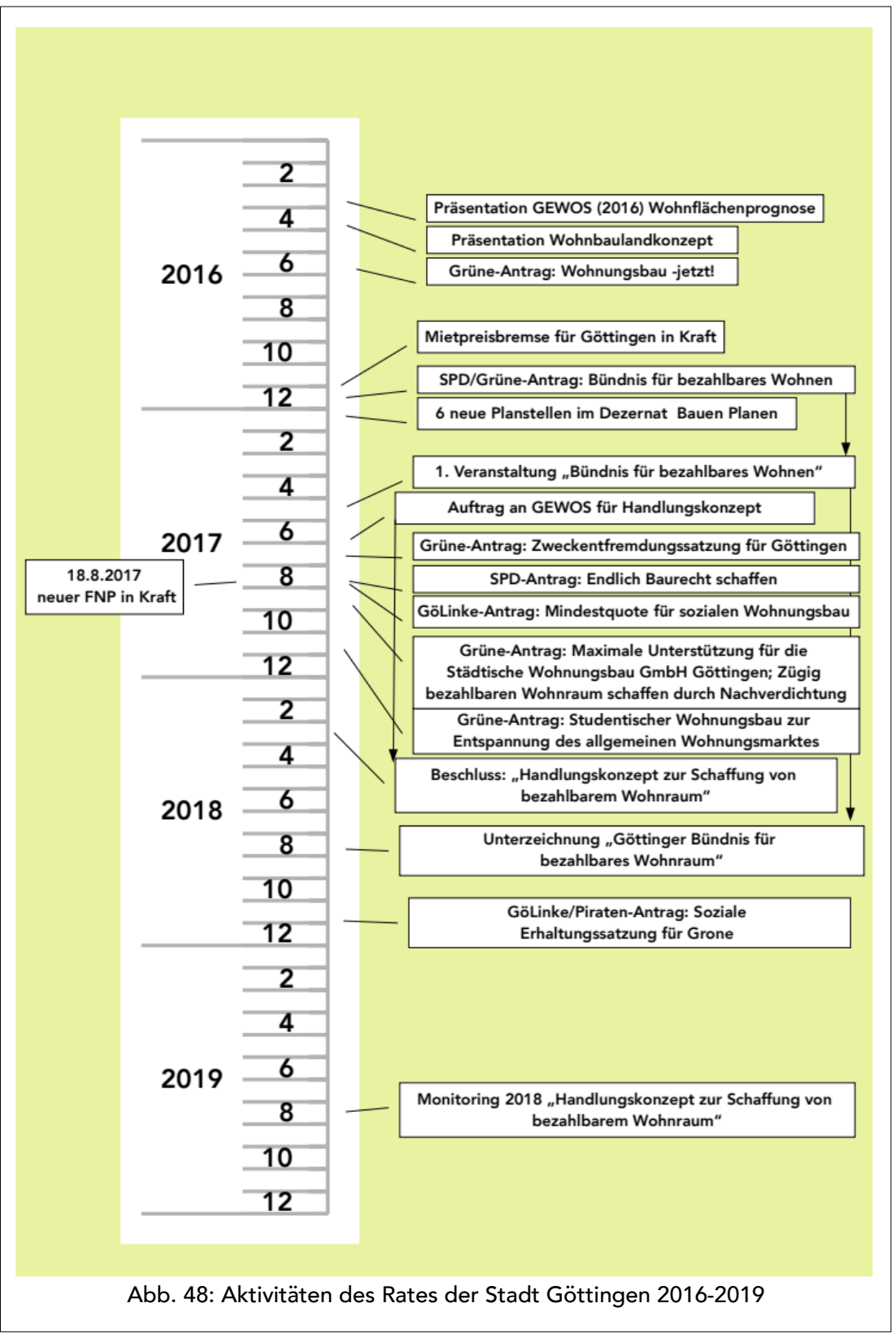

\section{Zwickmühlen und "Sachzwänge"}

In Diskussionen verweisen Vertreter der regierenden Parteien oftmals darauf hin, wie sehr ihnen die Hände gebunden seien. Sie beklagen die „Sachzwänge”. Von den Kritikern erwarten sie konstruktive Vorschläge für den Umgang mit den "Sachzwängen”. So etwas wie Mietpreisbremsen, Mietenspiegel. Auch Möglichkeiten, Paragraphen des BauGB zu nutzen oder kostengünstiger zu bauen, werden geduldig diskutiert. Doch die meisten Vorschläge schrumpfen oder scheitern an den „Sachzwängen"zu teuer, zu langwierig, rechtlich nicht möglich, nicht marktgerecht usw. Doch worin besteht der "Sachzwang" und woher kommt er? Ein "Sachzwang" ist kein naturgegebener oder von einer Sache ausgehender, sondern ein politisch gewollter und durchgesetzter, hinter dem sich bestimmte wirt schaftliche Interessen verbergen. In der Sozialen Marktwirtschaft bedeutet das: Ohne Profit gibt es keine Versorgung durch den „Markt”.

Steckt kommunales Handeln zwangsläufig in einer Zwickmühle und in welcher?

Offenbar. Einerseits soll sie die Widersprüche, die sich aus dem "Sachzwang Markt" ergeben, aushalten, regulieren, auffangen - Stichwort: Verwaltung der Armut. Andererseits soll, kann und will die kommunale Politik die Ursachen der Widersprüche aber nicht aufheben. 


\section{BÜNDNIS UND KOMMUNALES HANDLUNGS- KONZEPT FÜR BEZAHLBAREN WOHNRAUM}

Z u den wichtigsten Instrumenten der Stadt Göttingen, bezahlbaren Wohnraum zu schaffen, gehört das 2018 beschlossene „Kommunale Handlungskonzept". Dieses Konzept soll signalisieren, wie ernst die Stadt das Problem nimmt, und zeigen, dass sie dafür ihre Mittel umfassend und gebündelt einsetzt und um neue erweitert.

Im Dezember 2016, gut ein halbes Jahr nachdem die GEWOS einen deutlich erhöhten Wohnraumbedarf prognostiziert hat, beantragen SPD und Grüne im Rat, ein Bündnis für bezahlbaren Wohnraum einzurichten. Nach dem Vorbild von Hannover und Braunschweig soll solch ein Zusammenschluss „aus relevanten Akteu-

\section{Kommunales Handlungskonzept}

zur Schaffung und Sicherung von bezahlbarem Wohnraum

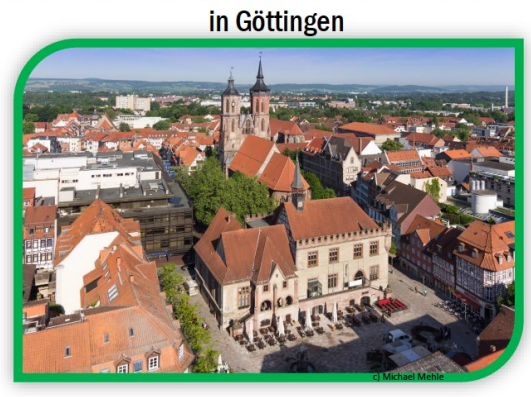

ren der Wohnungswirtschaft, der Verwaltung und der Fraktionen im Rat” dazu führen, „sich prozesshaft auf Ziele zur Stärkung des Wohnstandortes" zu verständigen und „in der Regel zu Selbstverpflichtungen aller Beteiligten im Rahmen eines Aktionsplanes" führen ${ }^{37}$. $\mathrm{Da}$ aus der Sicht der Antragsteller die öffentlichen Mittel und Instrumente nicht ausreichen, genügend sozialen und bezahlbaren Wohnraum zu erstellen, hofft man auf die Selbstverpflichtung der privaten Wohnungswirtschaft.

Im Mai 2017 findet das erste Bündnistreffen statt. Die Verwaltung beauftragt die GEWOS im Juli 2017 mit einem weiteren Gutachten zum Bedarf an bezahlbarem Wohnraum. Das liegt nach einem halbem Jahr vor. Im März 2018 präsentiert die Verwaltung ihr Kommunales Handlungskonzept, mit dem sie zugleich die zahlreichen Anträge der Fraktionen aus Sommer/Herbst 2017 für erledigt erklärt. Ende August 2018 wird das Bündnis für bezahlbaren Wohnraum feierlich unter- zeichnet. Göttingen hat ein Bündnis und einen Aktionsplan.

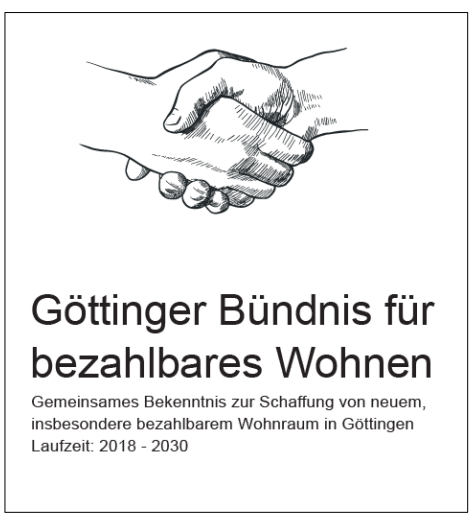

Aus dem Text des Bündnisabkommens:

„3.2 Die Beiträge \& Maßnahmen der Wohnungs- und Immobilienwirtschaft ab 2018 sind:

- Die Vertreterinnen und Vertreter der Wohnungsund Immobilienwirtschaft streben an, im Zeitraum bis 2030 insgesamt 5.000 neue Wohnungen zu schaffen. Durchschnittlich sind das etwa 420 Wohnungen je Kalenderjahr - unter der Voraussetzung des vorhandenen Baurechts und verfügbarer Flächen.

- Um vorgenanntes Ziel zu erreichen, erklären sich die Vertreterinnen und Vertreter der Wohnungs- und Immobilienwirtschaft dazu bereit, auch eigene Nachverdichtungspotentiale in Bestandsquartieren zu prüfen und nutzbar zu machen. Über das Ergebnis der Überprüfungen wird in der halbjährlichen Bündnissitzung berichtet. ....

\section{Die Schlussbestimmung}

Die Bündnispartnerinnen und -partner erklären ihre Bereitschaft, an der Verwirklichung der vorstehenden Ziele aktiv mitzuwirken. ...

Sollten sich die vorstehenden Rahmenbedingungen gravierend ändern oder die wirtschaftlich notwendigen Mittel des Unternehmens nicht zur Verfügung stehen, behalten sich die Bündnispartnerinnen und -partner vor, nach Analyse und Bewertung der Veränderungen das Bekenntnis jeweils neu zu formulieren und den verändernden Gegebenheiten anzupassen."

Dieses Bekenntnis haben u.a. unterschrieben: Vonovia, Adler Real Estate, EBR, Kurth, Cubus, Deltabau, Haus + Grund e.V.. Es schränkt die Freiheit der Immobilienunternehmen ja auch in keiner Weise ein. 
Was sieht der Aktionsplan, das "Kommunale Handlungskonzept zur Schaffung und Sicherung bezahlbaren Wohnraums in Göttingen" (KHK) vor? Zunächst stellt das KHK fest, wie groß der Bedarf an bezahlbaren Wohnungen ist. Es entnimmt die Zahlen den Modellrechnungen des GEWOS-Gutachtens $(2017)^{38}$. Das errechnet, dass 2016 schon 1.900 bezahlbare Wohnungen fehlten und „perspektivisch" bis 2030 zusätzlich weitere 2.000 fehlen werden - wachsende Altersarmut nicht eingerechnet. Wie die GEWOS zu diesen Zahlen kommt, ist an anderer Stelle ausführlich analysiert und kritisiert worden. $^{39}$

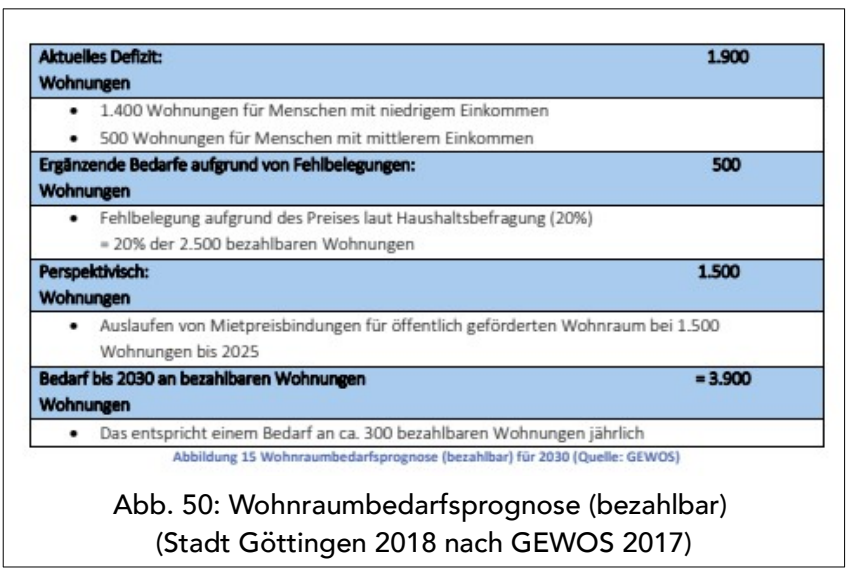

Aufgrund des aktuellen Fehlbedarfs und demnächst auslaufender Sozialbindungen werden bereits bis Ende 20203.100 mehr bezahlbare Wohnungen benötigt, wie die Stadt selbst feststellt.

Wie soll diese Herausforderung bewältigt werden? Die Stadt listet ein ganzes Bündel von Instrumenten auf:

1. 30\%-Quote: Unternehmen sollen sich bei Wohnungsneubauten (mit mehr als $12 \mathrm{WE}$ ) in Städtebaulichen Verträgen (und bei neu geschaffenem Baurecht) verpflichten, 30\% der Wohnungen im bezahlbaren Segment (im Sinne des NWoG) anzubieten.

2. Die Stadt legt für 5 Jahre ein weiteres Förderprogramm (3,5 Mio.) zur Schaffung von sozialem Wohnraum bzw. zum Ankauf von Belegungsrechten auf („Kommunale Anreizförderung”).

3. Einrichtung einer zentralen Beratungs- und Koordinierungsstelle für Wohnungsbauvorhaben und Teilnahme an einem Bundesforschungsprogramm „Wohnraumagentur".

4. Optimierung der Flächenverfügbarkeit über Stadtplanungsinstrumente, d.h. Schaffung von Planungsrecht, strategische Baulandentwicklung, soziales Baulandmanagement über Konzeptvergabe, u.a.

5. Baukostensenkung durch Änderung der Pkw-Stellplatzsatzung.

Halbjährlich will die Stadt über die erreichten Fortschritte berichten. In ihrem ersten Bericht im August

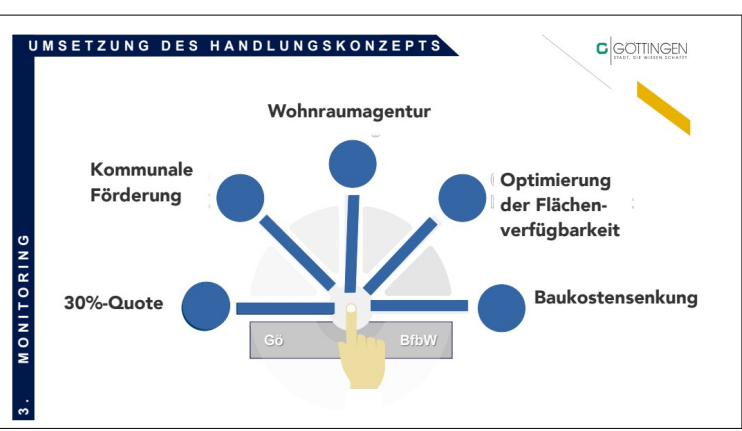

Abb. 49: Instrumente des Kommunalen Handlungskonzeptes (nach Stadt Göttingen 2019)

2018 stellt sie selbst „die begrenzte Wirksamkeit” des KHKs fest.

Es ist nicht annähernd erkennbar, dass der akute Fehlbedarf kurzfristig gedeckt werden kann. Die Stadt vertröstet daher auch immer auf das Jahr 2030.

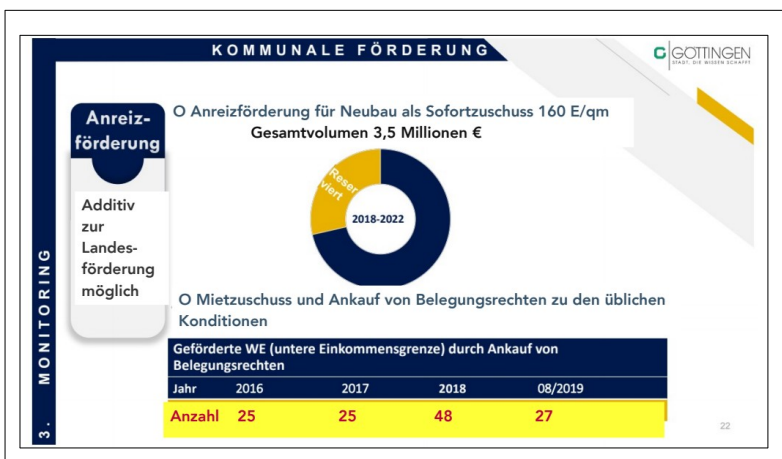

Abb. 51: Finanzielle Förderinstrumente des KHK (nach Stadt Göttingen 2019)

Die Instrumente schaffen nur Möglichkeiten. Ihre Verwirklichung hängt ab von den geschäftlichen Kalkulationen der Immobilienunternehmen. Und ist insofern auch unsicher. Die Stadt muss den Immobilienunternehmen schon etwas bieten, damit diese in Göttingen investieren (ausführliche Kritik in Frieling 2020).

Aber - nach außen, für die Öffentlichkeit, soll das Bild vermittelt werden: Die Stadt hat sich ernsthaft bemüht und angestrengt. Doch die "Sachzwänge" der Sozialen Marktwirtschaft setzen Grenzen. Eine Kritik am Kommunalen Handlungskonzept ist daher aus ihrer Sicht unangebracht (vgl. Göttinger Tageblatt vom 19.2.2020).

Mit dieser Argumentation schafft sich die Stadt eine Legitimation ihres Handelns und versucht Konflikte zu befrieden. 


\section{Bodenpreise und ihre Effekte}

\section{WOHNEN - UNBEZAHLBAR ? BAUKOSTEN UND BODENPREISE}

orderungen nach dem Neubau bezahlbarer Wohnungen werden meistens mit dem Hinweis zurück gewiesen, die aktuellen Bau- und Grundstückskosten würden das unmöglich machen, weil sie Mieten von über 10 oder $11 € / \mathrm{m}^{2}$ erfordern würden. Trotz des historisch niedrigen Zinsniveaus. Vor allem die drastisch gestiegenen Bodenpreise in den Metropolen und den meisten Großstädten werden für die Verteuerung des Wohnungsneubaus verantwortlich gemacht. Welchen Anteil an den Gesamtkosten haben sie und wie haben sich die Baukosten entwickelt?

Die Baukosten sind nach Arbeitsgemeinschaft für zeitgemäßes Bauen e.V (ARGE e.V.) seit dem Jahr 2000 bis 2017 um 55\% gestiegen. Ein Drittel dieses Preisanstiegs geht auf veränderte staatliche Vorschriften (vor allem zur Energieeinsparung 2009 und 2015) zurück. Rd. zwei Drittel macht der allgemeine Preisanstieg im Baugewerbe aus. Bis 2012 entwickelte er sich weitgehend parallel zur allgemeinen Inflation. Seitdem verläuft der Anstieg schneller - eine Folge des Baubooms der letzten Jahre.

Der Anteil der Bodenkosten an den Gesamtkosten lag nach Erhebungen der ARGE e.V und des Pestel Institutes in Großstädten in $50 \%$ der Fälle unter $18 \%$ (2016). Dies kann nur ein grober Hinweis sein. Denn der Anteilswert verändert sich mit dem Grad, wie intensiv ein Grundstück überbaut wird, und schwankt mit der innerstädti-

Abb. 52: Kosten im Wohnungsneubau (2016)

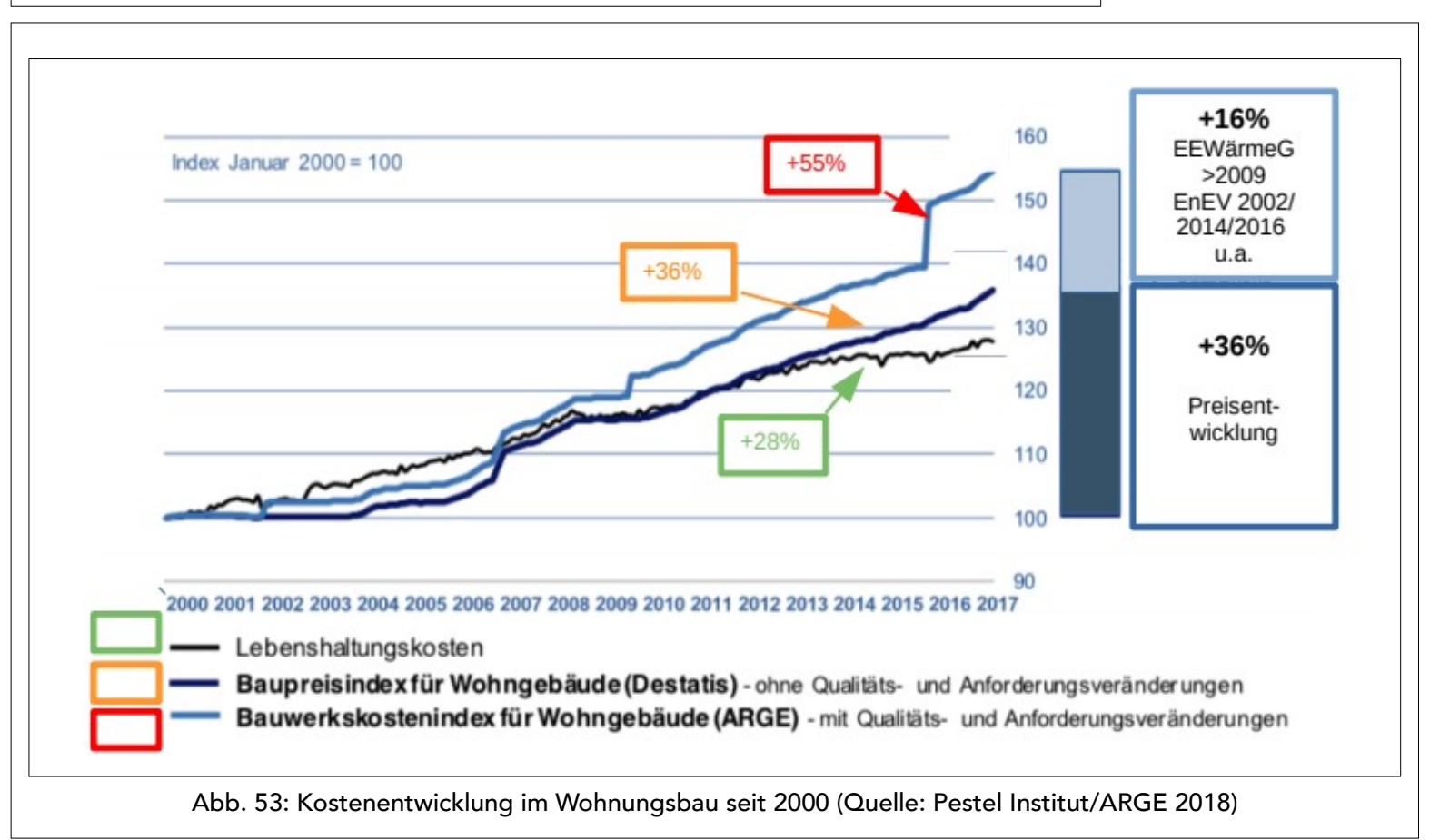


schen Lage und ihrem jeweiligen Bodenpreis. Die Prognos AG hat jüngst eine Modellrechnung aufgestellt, in der solche Faktoren berücksichtigt sind ${ }^{40}$.

Das Modell nimmt einen Neubau von 24 Wohnungen (2018) mit $1.582 \mathrm{~m}^{2}$ Wohnfläche an, Herstellungskosten $2.566 € / \mathrm{m}^{2}$ (Kostengruppen: 200 700). Finanzierung 20\% Eigenkapital, $80 \%$ Fremdkapital zu konstanter Verzinsung von $2 \%$ plus Tilgung $1 \%$. lineare Abschreibung von 1,25\% bzw. Nutzungsdauer 80 Jahre. Verwaltungskosten $285 € /$ Jahr/Wohnung, Instandhaltung konstant $8 € / \mathrm{m}^{2}$ Wohnfläche/ Jahr, angenommener Mietausfall 2\% der Jahresmiete. In der Überbauung des Grundstücks werden zwei Intensitäten angenommen: a) bei einer niedrigen Baudichte (Geschoßflächenzahl $(G F Z)=1$ ) werden $2.531 \mathrm{~m}^{2}$ Land benötigt, bei einer höheren Dichte (GFZ 2) nur $1.266 \mathrm{~m}^{2}$.

Die Modellrechnung zeigt, dass die Grundstückspreise zu deutlichen Aufschlägen in der Miete führen kann, und zwar je höher der Bodenpreis und je geringer die Baudichte ist. In den Metropolen (A-Standorte) bewirkt die Verdreifachung des Bodenpreises - von 450 auf $1.300 € / \mathrm{m}^{2}$ eine Mietsteigerung um 1,40 $€ / \mathrm{m}^{2}$ oder 14\% (GFZ 2, grüner Balken). In Städten mit angespannten Wohnungsmärkten (C-Standort), zu denen auch Göttingen gezählt wird, gibt es den gleichen Effekt, aber aufgrund der niedrigeren Bodenpreise deutlich abgeschwächt. Eine Verdreifachung des Bodenpreisesvon 140 auf $440 € / \mathrm{m}^{2}$ - führt zu einer um $5 \%=$ $0,50 € / \mathrm{m}^{2}$ höheren Miete (GFZ 2). Dass die Mietauf- schläge geringer sind als in den A-Standorten hat seinen Grund in der absoluten Höhe der Bodenpreise. Denn mit den steigenden Bodenkosten steigen auch die Gesamtkosten, damit die Kosten der Finanzierung und der Zeitraum, in dem sich die Investition amortisiert, und damit das Risiko, die erhoffte Rendite zu erwirtschaften. ${ }^{41}$

Die Modellrechnung zeigt auch, dass man unterscheiden muss, um welche Standortkategorie es sich handelt, welche Baudichte die Stadtplanung erlaubt - und welches Profitinteresse der Bauherr verfolgt (im Modell ist eine "verhaltene" Renditeerwartung des Bauherrn unterstellt). In der Modellrechnung liegt der Anteil der Grundstückskosten an den Gesamtkosten bei Standorten wie Göttingen zwischen 3\% und 21\% (GFZ 2 ), bei den A-Standort hingegen zwischen $12 \%$ und $46 \%$.

Sind steigende Bodenpreise und Bodenspekulation Ursache der steigenden Mieten?

Die Wirkung steigender Bodenpreise auf den Anstieg der Mieten muss man differenziert betrachten, wie die Modellrechnung zeigt. Und man muss auch jeweils kritisch prüfen, ob sich nicht auch gesteigerte Renditeerwartungen hinter dem Argument "die Bodenpreise sind Ursache der Verteuerung" verstecken.

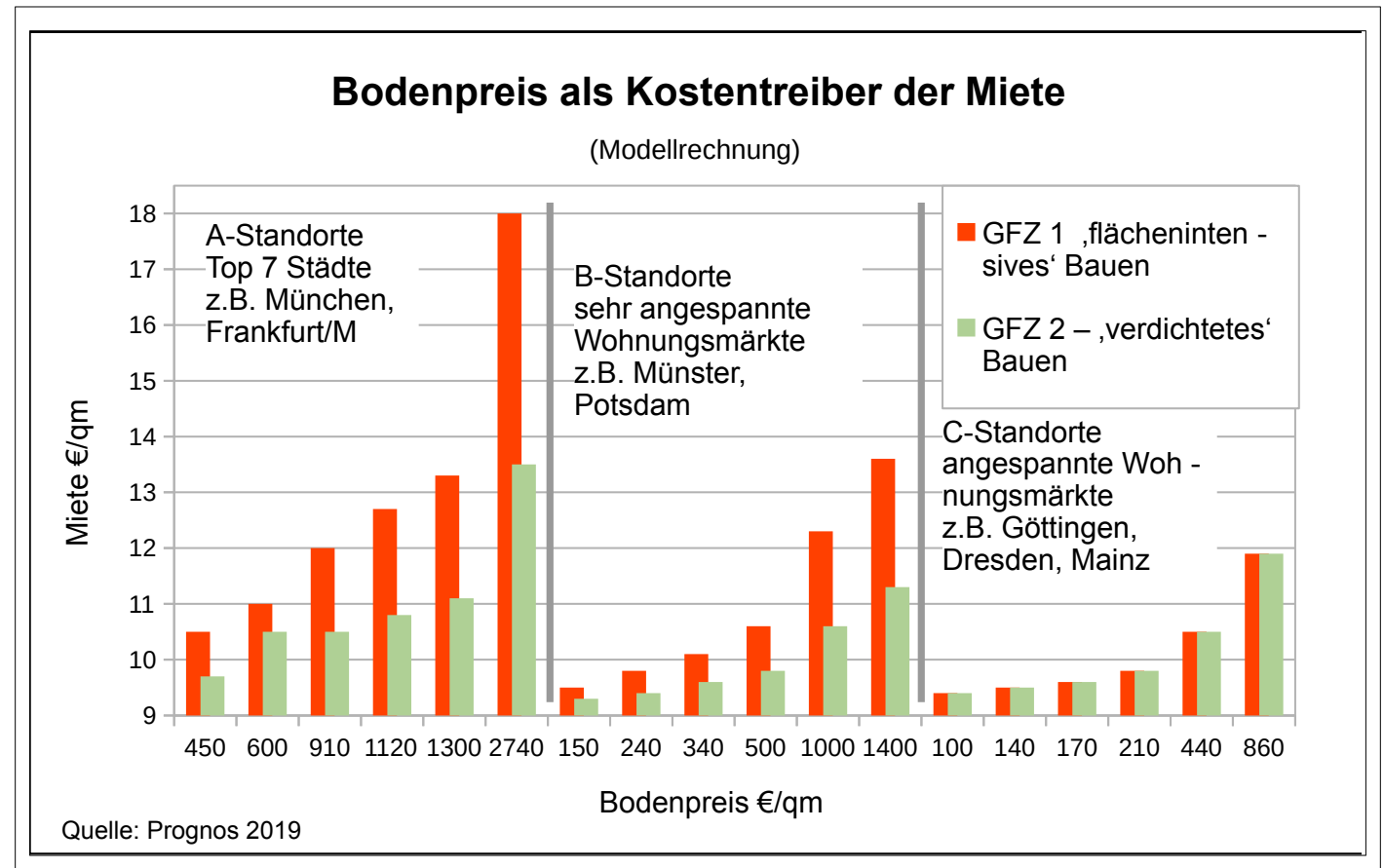

Abb. 54: Einfluss des Bodenpreises auf die Miethöhe (Modellrechnung) 


\section{WOHNEN - UNBEZAHLBAR? MIETBELASTUNG UND EINKOMMENSENTWICKLUNG}

$\mathrm{n}$ vielen Regionen Deutschlands, vor allem in den Metropolen und Universitätsstädten, sind die Mieten in den letzten Jahren stark gestiegen und für viele eigentlich unbezahlbar geworden. Eigentlich denn auf eine Wohnung kann niemand verzichten. So muss ein immer größer werdender Anteil des Einkommens für die Miete aufgewandt werden. Lag die Mietbelastung Mitte der 1960er Jahre für erwerbstätige Haushalte noch bei rd. $10 \%$ und für Rentnerhaushalte bei rd. $17 \%{ }^{42}$, ist sie heute doppelt bis dreifach so hoch. Es trifft vor allem Haushalte mit geringem Einkommen, Vollerwerbstätige im Niedriglohnsektor, Alleinerziehende, Senioren, Haushalte mit Migrationshintergrund. Ihre Mietbelastung liegt deutlich über dem BRD-Durchschnitt von 27,2\% (rote Linie in der Abb. 50). Von den 1-Personen-Haushalten hat fast jeder zweite eine Mietbelastung von 30\% und mehr (Abb. 53). Zu dieser Gruppe zählen auch Studierende. Besonders für diese Menschen fehlt es in den großen Städten, auch in Göttingen, an bezahlbarem Wohnraum.

Wann ist eine Wohnung bezahlbar? Die Bundesregierung will das nicht an einem festen Wert, einer Miethöhe oder Quadratmetermiete, festmachen. Das widerspricht ihrer Ansicht nach zu sehr der (Wahl-) Freiheit der Marktteilnehmer wie der (Wohnungs-)Eigentümer. Die Konsequenz daraus wäre, dass die Menschen deutlich höhere Einkommen benötigen, sich also tatkräftig für höhere Löhne und Renten einsetzen, damit sie auf den Mietwohnungsmärkten handlungsfähig sind.

Aber das ist ganz und gar nicht im Interesse der Politik. Im Gegenteil - zur Förderung der Wettbewerbsfähigkeit der deutschen Exportwirtschaft hat sie umfangreiche Maßnahmen zur Senkung bzw. Begrenzung des Lohnniveaus und Lebensstandards durchgesetzt: Einrichtung eines ausgedehnten Niedriglohnsektors, Hartz IV, Kostenüberwälzungen bei Kranken- und Altersversicherung auf die Versicherten, Schwächung der Gewerkschaften, usw. Die Folge: reale Einkommensverluste bei vielen Haushalten. Erst seit wenigen Jahren gibt es auch für mittlere und nicht nur für höhere Einkommensgruppen reale Einkommenszuwächse. Doch für die ärmsten $20 \%$ der Haushalte sinken die Einkommen - trotz der Transferleistungen. ${ }^{43}$

Das Problem Mietenwahnsinn, der Mangel an bezahlbarem Wohnraum ist nicht nur eine Folge der renditeorientierten Wohnungs- und Bauwirtschaft, sondern auch der von der Politik durchgesetzten Arbeitsmarktund Sozialpolitik. Um das Wirtschaftswachstum nicht

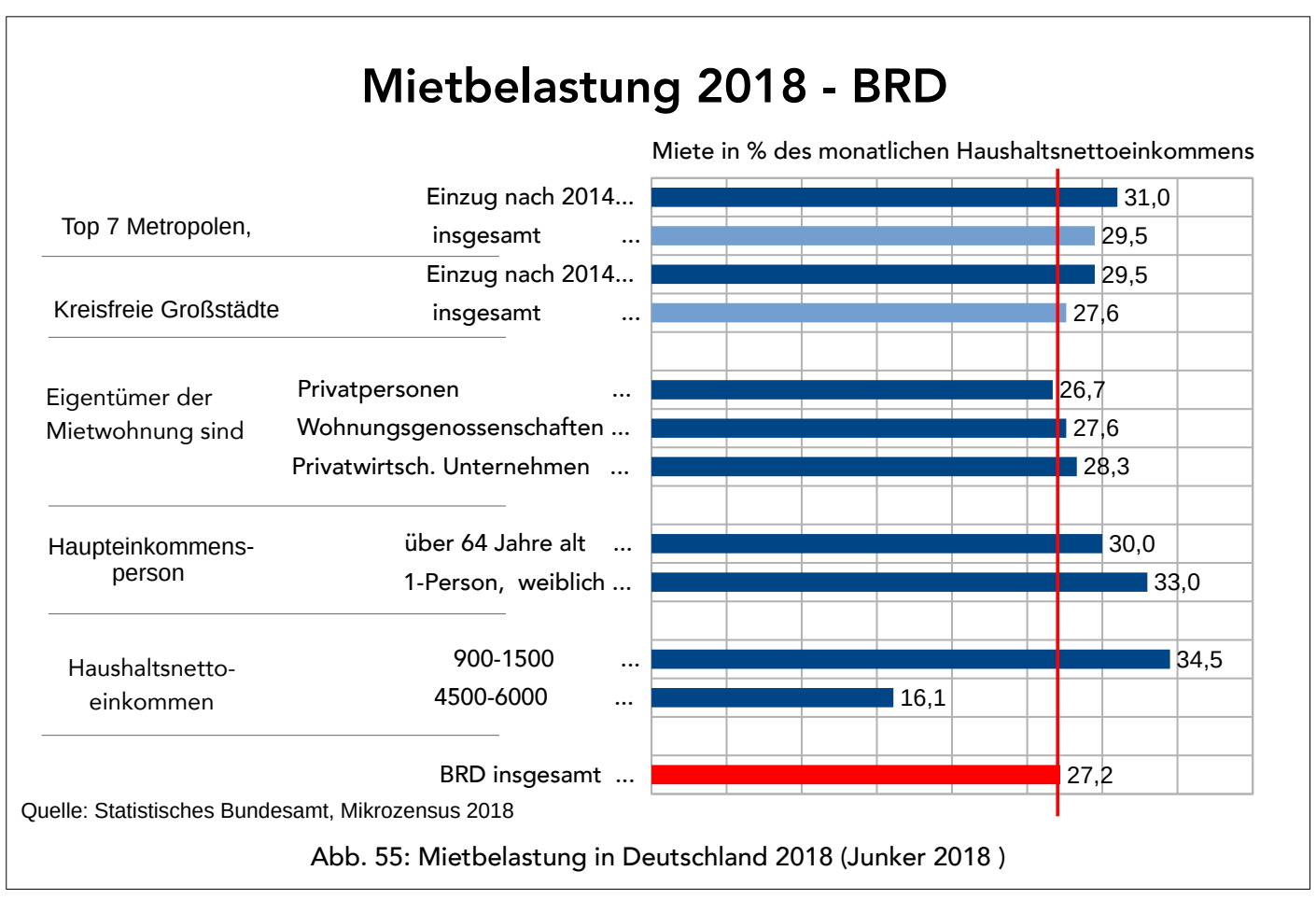




\section{Die Einkommen der Gruppen am unteren Ende der Verteilung sind seit 1991 gesunken}

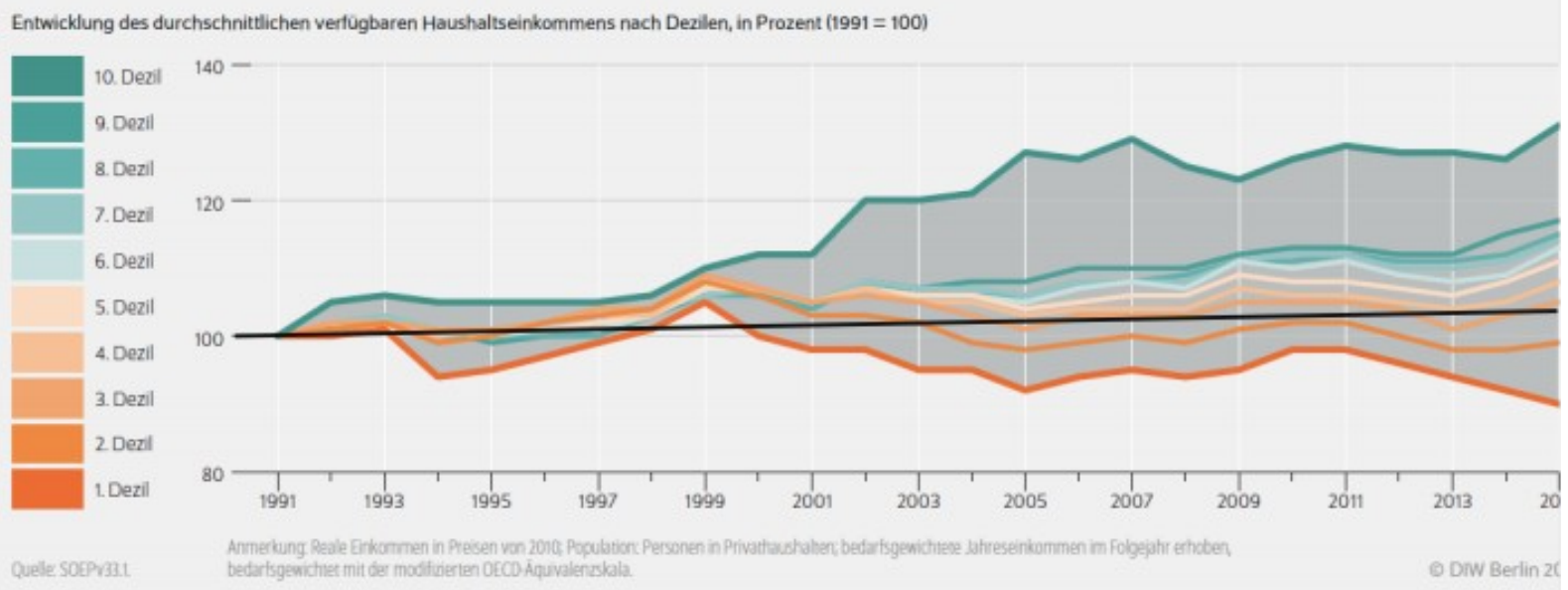

Abb. 56: Einkommensentwicklung in Deutschland 1991-2014 (DIW 2018)

zu gefährden, will die Regierung diese neoliberale Agenda 2010-Politik nicht aufgeben. Sie will aber auch nicht in großem Umfang durch Subventionen preisgünstigen Wohnraum ermöglichen, eine andere Bodenpolitik einführen oder leistungslose Bodenrenten kürzen. Stattdessen kreiert sie Bündnisse für bezahlbares Wohnen und bedauert die selbst geschaffenen Sachzwänge (Schuldenbremse, Baulandmangel, ,verschlankte' Planungsbürokratie).

Die Stadt Göttingen hat sich $2017^{44}$ in einem Gutachten zum zweiten Mal (davor 2013) berechnen lassen, dass es an bezahlbarem Wohnraum in der Stadt fehlt. Der Gutachter GEWOS kommt zu dem Ergebnis, dass 63\% (!) aller Göttinger Haushalte unter die Einkommensgrenzen des niedersächsischen Wohnraumfördergesetzes fallen, also nach den Kriterien der Politik bezahlbaren Wohnraum benötigen. Die Kriterien mögen nicht mehr aktuell sein und die geschätzten Zahlen be- dürftiger Haushalte zu niedrig ${ }^{45}$, dennoch zeigt es das Ausmaß, wie weit inzwischen Mietpreise und Haushaltseinkommen auseinander fallen. Und dennoch können Grundeigentümer ihr leistungsloses Renteneinkommen weiter steigern.

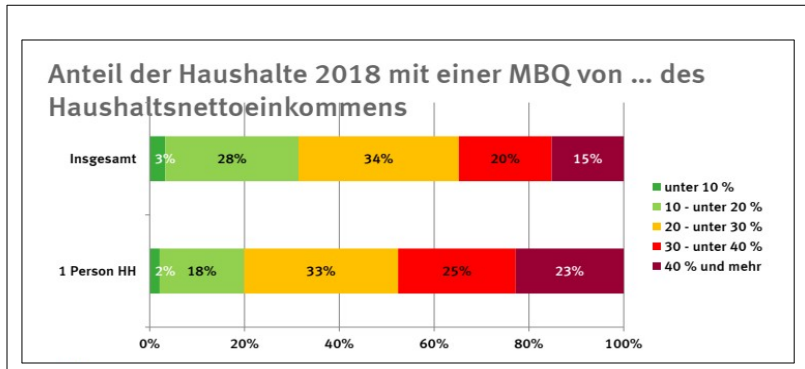

Abb. 58: Mietbelastungsquote in Deutschland 2018 (Destatis)

\begin{tabular}{|c|c|c|c|c|}
\hline \multirow{2}{*}{$\begin{array}{l}\text { Göttingen } \\
\text { Haushaltsgsröße }\end{array}$} & \multicolumn{2}{|c|}{ "geringe" Einkommen $(\S 3)$} & \multicolumn{2}{|c|}{${ }_{\text {„}}$ mittlere" Einkommen $(\S 5)$} \\
\hline & \begin{tabular}{|c|} 
(Jahres)Haus- \\
haltsnetto- \\
einkommen \\
(obere \\
Grenze)
\end{tabular} & \begin{tabular}{|c|} 
Mieter- \\
haushalte \\
2014
\end{tabular} & $\begin{array}{c}\text { (Jahres)Haus- } \\
\text { haltsnetto- } \\
\text { einkommen } \\
\text { (obere } \\
\text { Grenze) }\end{array}$ & $\begin{array}{c}\text { Mieter- } \\
\text { haushalte } \\
2014\end{array}$ \\
\hline 1 Person & 17000 & 17500 & 27200 & 6100 \\
\hline 2 Personen & 23000 & 6300 & 36800 & 5000 \\
\hline 3 Personen & 29000 & 1900 & 46400 & 1600 \\
\hline 4 u.mehr Personen & 38000 & 2500 & 60800 & 1200 \\
\hline
\end{tabular}

Einkommensgrenzen nach NWoFG § 3 und $\S 5$ (2014) 


\section{Bodenpreise und ihre Effekte}

\section{BODENPREISE IN GÖTTINGEN}

$\mathrm{n}$ der Diskussion um bezahlbaren Wohnraum und Wohnungsmangel gibt es viel Kritik an den Bodenpreisen, vor allem an gestiegenen Bodenpreisen.

"Die exorbitant gestiegenen Grundstückspreise sind der Hauptgrund, warum das Bauen und Wohnen so teuer geworden ist. ... Spekulationsgewinne muss die Bundesregierung endlich spürbar besteuern. Stattdessen lässt sie die Investoren leistungslos reich werden. Dabei steht im Grundgesetz: "Eigentum verpflichtet." (Süddeutsche Zeitung vom 21.7.2018)

Im Blick sind dabei vor allem die Metropolen wie München. Dort haben sich die Baulandpreise in wenigen Jahren, von 2010 bis 2018, verdreifacht und sind gegenüber 1985 um $600 \%$ gestiegen ${ }^{46}$. Inwieweit trifft das auch auf Göttingen zu?

Exakte Informationen darüber gibt es nicht, Kauf-/Verkaufspreise bleiben privat. Es gibt Kennziffern. Ein spezieller Gutachterausschuss entwickelt aus den tatsächlichen Kauf-/Verkaufsfällen und -preisen einen standardisierten Wert, den Bodenrichtwert. Der Bodenrichtwert (BRW) gibt den Preis für eine bestimmte
Kategorie von Land an, in der Regel für unbebautes (!), erschließungsfreies Wohnbauland.

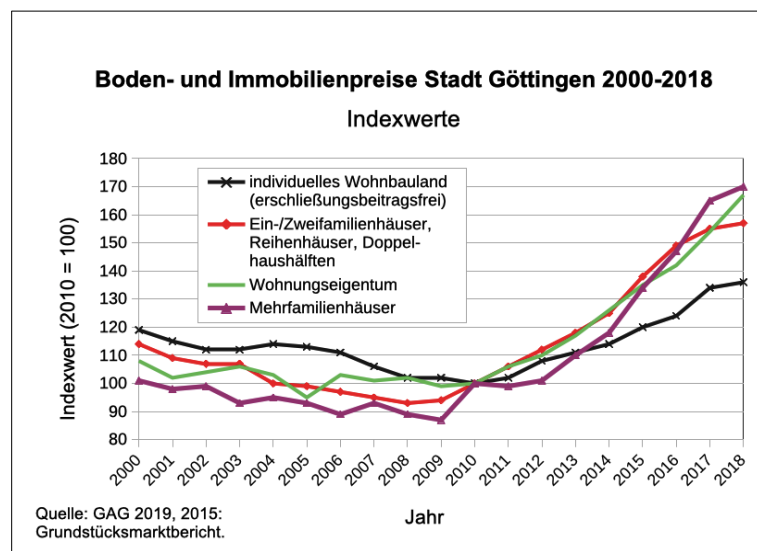

Abb. 60: Boden- und Immobilienpreise in Göttingen seit 2000

Auf der Grundlage einzelner Bodenrichtwerte konstruiert der Gutachterausschuss Bodenrichtwertzonen in der Stadt, Gebiete, in denen ein bestimmter BRW anzunehmen ist. Auch wenn ein BRW nur sehr bedingt etwas über tatsächlich gezahlte Bodenpreise aussagt,

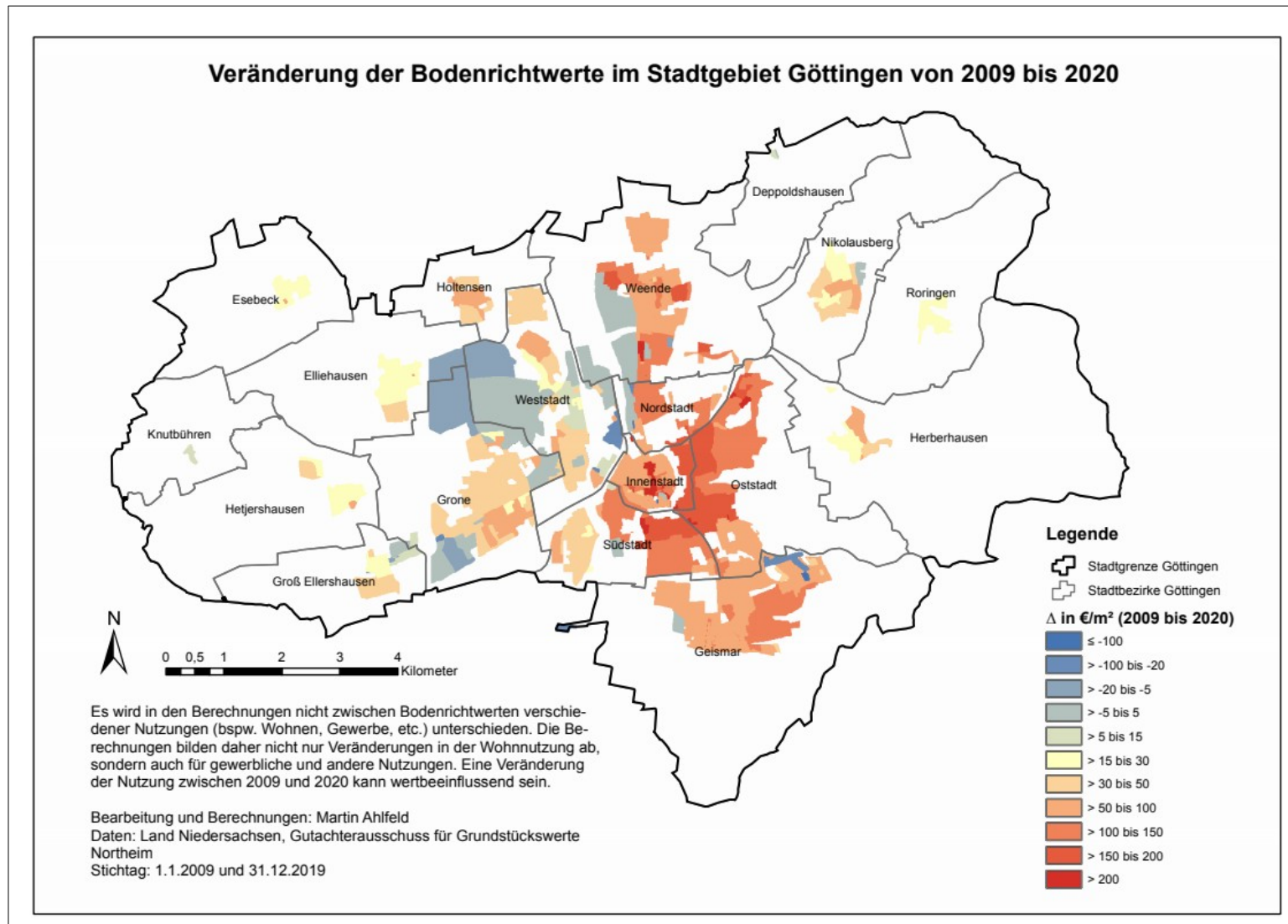

Abb. 59: Entwicklung der Bodenrichtwerte 2009-2020 
geben die räumlichen und zeitlichen Unterschiede doch aufschlußreiche Hinweise.

Im zeitlichen Ablauf zeigt sich, dass die Wohnbaulandpreise in Göttingen von der Jahrtausendwende bis 2010 gefallen sind ${ }^{47}$. Der Wohnungsneubau war in dem Jahrzehnt sehr gering, zudem gab es die Finanzkrise. Seit 2010 und vor allem seit 2015 steigen die Bodenrichtwerte stetig. 2018 liegt das Niveau um gut 33\% über dem von 2010. Viel stärker sind seit 2010 die Immobilienpreise gestiegen. Die für Eigentumswohnungen und Ein/Zweifamilienhäuser sind 2018 um rd. 60\% höher als 2010, die für Mehrfamilienhäuser sogar um rd. 70\%. Die wachsende Einwohnerzahl, die damit wachsende Wohnungsnachfrage und Durchsetzbarkeit von höheren Mieten ermunterte auch zu höheren Grundstücks- und Immobilienpreisen. Zudem trübten sich die Renditeaussichten in den Metropolen aufgrund der starken Preissteigerungen ein und das reichlich vorhandene Finanzkapital "entdeckte” kleinere Großstädte, so genannte B- und C-Standorte. ${ }^{48}$

Innerhalb der Stadt schwanken die Bodenrichtwerte stark. In den „Randlagen” ist der Boden nur halb so teuer wie im Ostviertel und z.Z. niedriger als in den benachbarten Gemeinden Rosdorf und Bovenden. Die Lage in der Stadtzu Arbeits- und Einkaufsstätten und zu Infrastruktureinrichtungen (Schulen, Kitas, usw.)sowie die Bewertung der Wohnqualität können Grundeigentümer zu Preisaufschlägen nutzen.

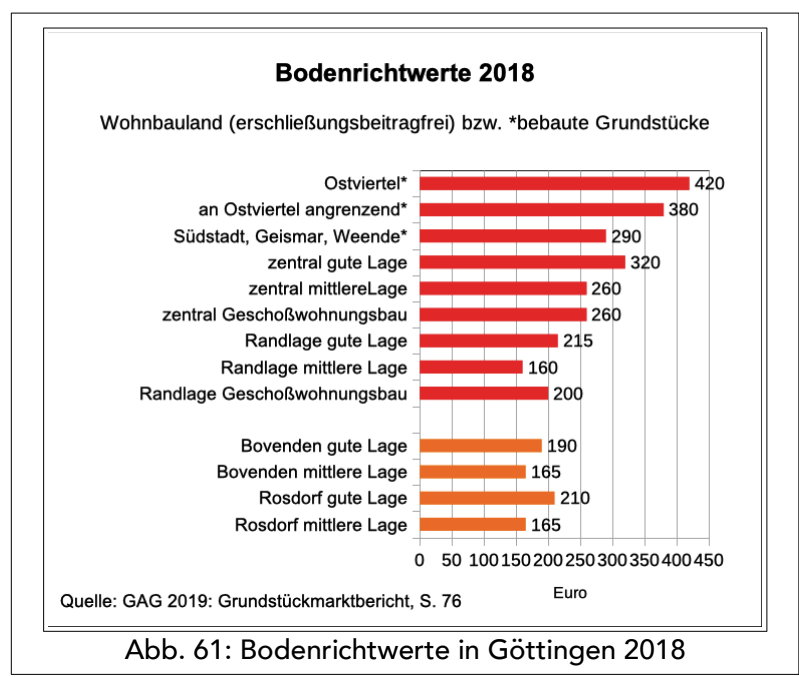

Neben der Lage steuert auch die Intensität der Flächennutzung den Preis. Ist Geschoßwohnungsbau möglich, steigt der BRW. Dies weist darauf hin, dass sich die Bodenpreise nicht völlig schwerelos nur aus Angebot und Nachfrage ergeben, sondern sich im Kern an den zu erzielenden Einnahmen orientieren. Die Bodenpreise hängen ab von der erhofften, möglichen Einnahmen aus Vermietung/Verpachtung. Diese Einnahmen, die Grundrente, werden behandelt als wären sie ein Zins auf ein gedachtes, fiktives Kapital. Diese bildet den Kern des Bodenpreises. Der Bodenpreis drückt die Größe dieses fiktiven Kapitals aus. Er ist eine Spekulation auf zukünftige Einnahmen.

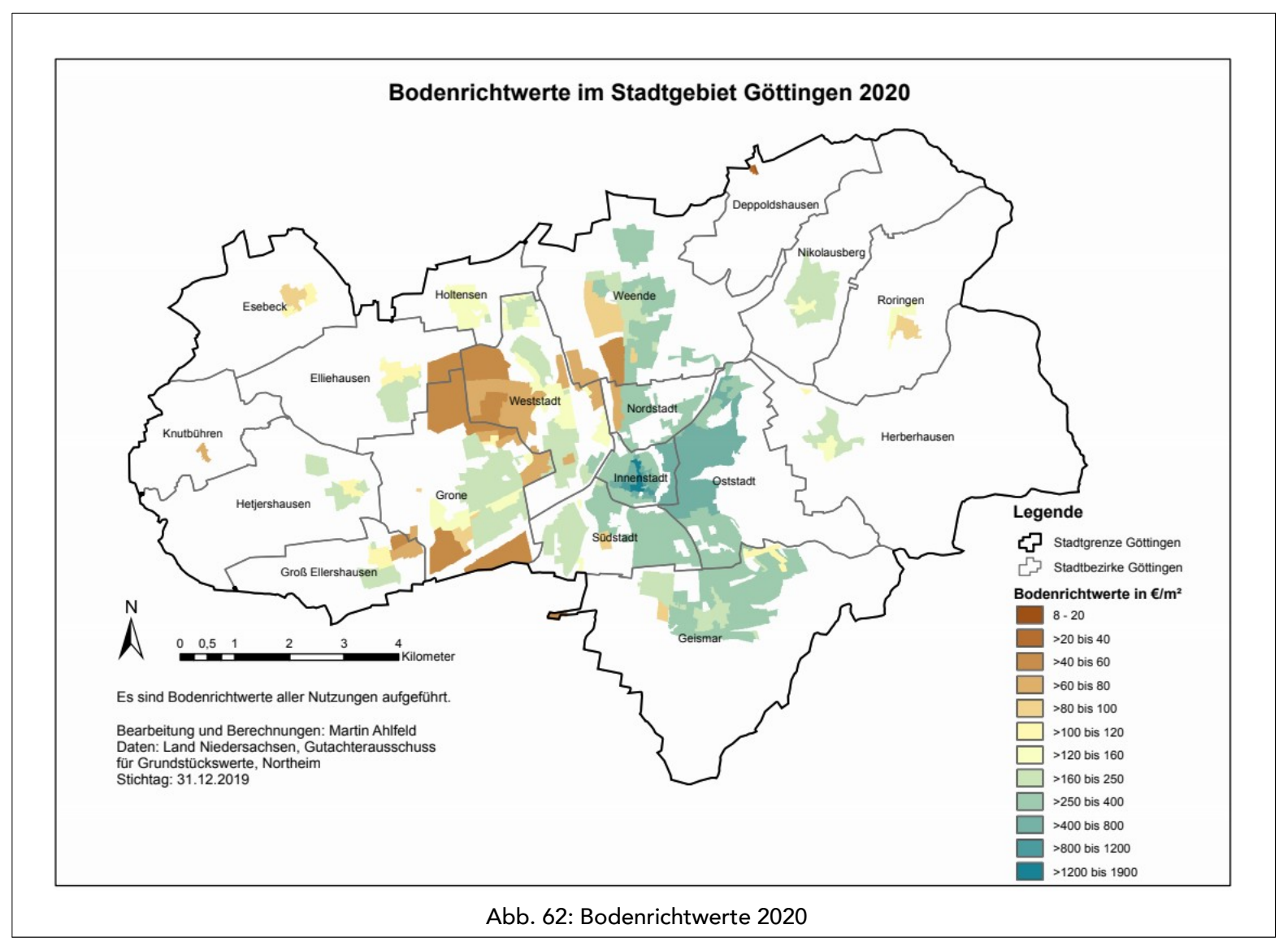




\section{BODENPOLITIK DER STADT - KOMMUNALER GRUNDBESITZ UND BAULEITPLANUNG}

$\mathrm{D}$ ie Gemeinde kann auf zwei Ebenen Einfluß nehmen auf die Nutzung von Grund und Boden: a) Sie wird selber Grundeigentümer und b) sie legt die Nutzungsmöglichkeit über Bebauungspläne fest.

\section{Grundbesitz der Stadt}

Vielfach wird in der Diskussion der Wohnungsfrage eine Kommunalisierung des Grund und Bodens gefordert. Damit hätte eine Gemeinde erheblich größere Möglichkeiten, die Stadtentwicklung gemeinwohlorientiert zu steuern. Aus neoliberaler Sicht ist das jedoch ein falscher, weil ineffektiver Weg. Der Staat, hier die Kommune, soll nur dort aktiv werden, wo der Markt „versagt", aber keine umfangreiche Bodenvorratspolitik betreiben.

\section{Ulm}

Beispiel einer innovativen Grundstückspolitik „Im Fokus der Ulmer Grundstückspolitik steht der Bevorratungsgedanke. Die Stadt Ulm kauft dabei gezielt und oftmals Jahre und Jahrzehnte im Voraus Flächen auf, um sie später zur Entwicklung von Gewerbe- und Wohngebieten einzusetzen. Neues Bauland wird nur ausgewiesen, wenn es sich im kommunalen Besitz befindet. So hat die Kommune immer das Erstnutzungsrecht. Sollte sie das Bauland an Dritte verkaufen, diktiert sie die Nutzungsbedingungen. Auf 30 Prozent der Flächen muss vergünstigter Wohnraum angeboten werden. Ein spekulativer Weiterverkauf ist ausgeschlossen. Denn sollte das Grundstück nicht mehr zum ursprünglichen Zweck verwendet werden, kann es nur an die Stadt Ulm verkauft werden - zu dem Preis, den es beim Kauf gekostet hatte. 4.500 Hektar werden derzeit so genutzt - das entspricht einem Drittel der Stadtfläche. 33 Millionen Euro investierte die Stadt Ulm im Jahr 2017 für den Ankauf neuer Grundstücke!" Quelle: Deutschlandfunk Kultur zit. nach DBG $2019^{49}$

Die Stadt verfügt über etlichen Grundbesitz. Der ist notwendig zur Erfüllung vieler öffentlicher Aufgaben für Straßen, Schulen, Entsorgungseinrichtungen, Grünanlagen, Friedhöfe. Die Stadt besitzt auch Flächen, die als Wohnbauland genutzt werden können und zu dem Zweck dann verkauft werden an die Städtische Wohnungsbau, die Genossenschaft oder an "Investoren". Wie die Stadt mit ihrem Grundbesitz und dem der Milde-Stiftung, über den die Stadt verfügen kann, verfährt - Verkauf, Kauf, Preise, Tauschgeschäfte - ist nicht transparent; es wird im Rat der Stadt nur in nicht-öffentlichen Sitzungen behandelt.

Die Klage über fehlendes Wohnbauland legt die Vermutung nahe, dass die Stadt dafür wenig Flächen vorrätig hält. Als Käufer unterliegt sie den kapitalkräftigeren "Investoren" wie im Fall IWF-Gelände oder Zimmermannstraße. Als Eigentümerin und Verkäuferin sieht sie sich haushaltsrechtlich gezwungen, zu erzielbaren Höchstpreisen zu verkaufen (z.B. Fridtjof-Nansen-Haus). Die Kommune handelt wie ein "normaler" Grundeigentümer. Für eine ausgedehnte Bodenvorratspolitik fehlen Geld, Haushaltsvorschriften - und oft auch der Wille. Die Instrumente Vorkaufsrecht und gar Enteignung sind tabuisiert. Eine soziale Wohnraumund Stadtentwicklungspolitik muss zwangsläufig darunter leiden.

\section{Städtische Planung}

Ein finanziell günstigeres Instrument ist die Bauleitplanung. Jede Art der Grundstücksnutzung braucht eine kommunale Genehmigung durch einen Bebauungsplan. Der gibt grundstücksgenau den verbindlichen, durch das BauGB geregelten Rahmen für Art und Intensität der Nutzung vor. Dem Bebauungsplan übergeordnet und vorausgesetzt ist der Flächennutzungsplan (FNP).

Wohnungsneubau benötigt Bauland mit Baurecht. Hat die Stadt Göttingen dafür ausreichend Vorsorge getroffen? Oder hat die "Verschlankung" der Verwaltung Kapazitätsengpässe geschaffen? Darauf wird in Kap. 16 näher eingegangen.

Welche Bedeutung der Baurechtschaffung und Planungspolitik jedoch zukommt, macht der Geschäftsbericht der Wohnungsgenossenschaft eG 2018 deutlich. Darin kritisiert die WG im Vorwort:

"Die Stadt hat zwar eine neuen Flächennutzungsplan verabschiedet, baureife Flächen sind hieraus aber noch nicht hervorgegangen. Es mangelt an Bebauungsplänen und erschlossenen Baugrundstücken. Ausgerechnet in dieser Situation stellt der Rat der Stadt Göttingen mit einer Stimme Mehrheit (CDU und Grüne) potenzielle Bauflächen der Genossenschaft unter Landschaftsschutz ... Diese restriktive Baulandpolitik in unserer Stadt begräbt 
jegliche Hoffnung auf einen ausgeglichenen Wohnungsmarkt in der Zukunft. ...Gewinnorientierte Vermieter und Verkäufer befinden sich in einer Art 'Goldgräberstimmung' ...".

Seit kurzem (2017) scheint die Stadt ihre Aktivitäten im Bau- und Planungsdezernat verstärkt zu haben.

2017 ist nach 5jähriger Bearbeitungszeit ein neuer Flächennutzungsplan (FNP) in Kraft getreten. Er ersetzt den vorherigen aus dem Jahr 1975 und konzipiert die Stadtentwicklung bis 2030. Teil des aktuellen FNPs ist ein umfangreiches Wohnbaulandkonzept, einschließlich von grundstücksgenauen Karten zu Baulücken und möglichen Wohnbaugebieten (Baulandkataster) (abrufbar auf der Seite der Stadt). Grundlage für die Abschätzung des Flächenbedarfs bis 2030 ist das GEWOS-Gutachten (2016) mit leichten Abänderungen.

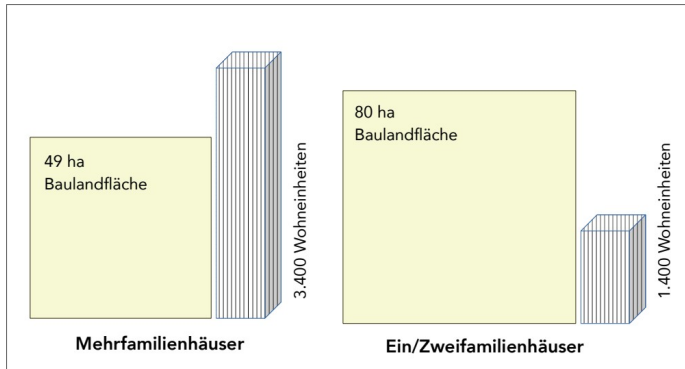

Abb. 64: Wohn- und Baulandbedarf bis 2030 (FNP) Planungsgrundlage
Der FNP (2017) geht davon aus, dass bis 203049 ha für rd. 3.400 Wohneinheiten in Mehrfamilienhäusern und 80 ha (!) für rd. 1.400 Ein/Zweifamilienhäuser erforderlich sind. Sie sind aus planerischer Sicht auch realisierbar; die Standorte dieser Flächen wie auch potenziell weitere für ein Baulandmanagement sind in einer Karte festgehalten.

Im August 2019 berichtet die Stadt, für wie viele Wohneinheiten (einschließlich Ein/ Zweifamilienhäuser) jüngst und demnächst Baurecht geschaffen wurde bzw. werden soll:

$\begin{array}{ll}2017 & 340 \text { WE } 3 \text { „Flächen” } \\ 2018 & \text { 200 WE 1 „Flächen” } \\ 2019 & 505 \text { WE } 8 \text { „Flächen” } \\ \text { geplant: } & \\ \begin{array}{l}2020 \\ \text { in Arbeit } \\ \text { ab } 2019\end{array} & \text { 1860 WE } 9 \text { „Flächen” } \\ & 550 \text { WE } 2 \text { „Flächen”. }\end{array}$

Das erscheint viel. Doch ob und wann die Flächrn bebaut werden, hängt von Grundeigentumsverhältnissen, Investitionsabsichten und der Schaffung von Baurecht, d.h. der Verabschiedung von Bebauungsplänen, $a b$. Dies kann bei Einsprüchen von Betroffenen oder mangelnden Personalkapazitäten der städtischen Verwaltung Jahre in Anspruch nehmen. Gute Planung funktioniert langfristig. Sie muss daher frühzeitig beginnen.

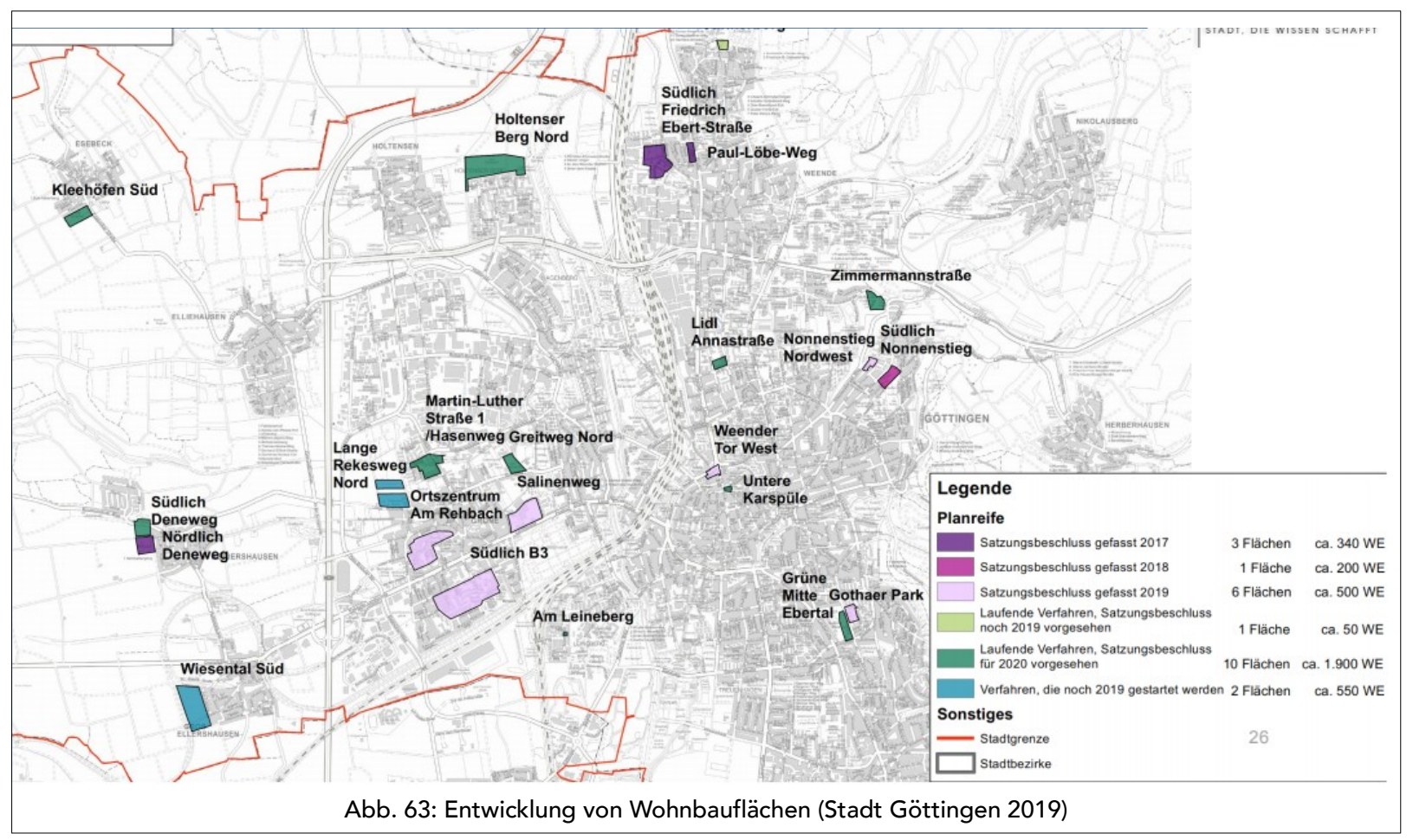




\section{Proteste}

\section{PROTEST UND WIDERSTAND (1)}

G öttingen ist nicht Berlin. Proteste von Mietern gibt es aber auch hier. Die Wohnungsnot der Studierenden (Wohnrauminitiative Göttingen, Rote Straße), die Unterbringung von Geflüchteten (Fridtjof-Nansen-Haus), die Auseinandersetzung mit Immobilienkonzernen (Vonovia, Grone und Adler Real Estate) und das Vorgehen von Projektentwicklern und Investoren (IWF, Zimmermannstraße, UM13, OM10) sind es vor allem, die in den letzten 10 Jahren Widerstand hervorgerufen haben. 2019 hat sich aus diesen Initiativen und weiteren Unterstützern ein Göttinger Bündnis „Gutes Wohnen für alle" gebildet.

Diese Proteste und Initiativen werden im Folgenden kurz dargestellt. Der Überblick beansprucht nicht, vollständig zu sein. Es mag noch weitere Proteste geben. Und es hat sie auch vor 2010 schon gegeben z.B. im „Blümchenviertel”/ Weststadt.

\section{Wohnrauminitiative Göttingen}

Die Ankündigung von Mieterhöhungen durch das Studentenwerk und einer ,Umstrukturierung der Wohnungsangebote', d.h. Schließung von kleinen studentischen Wohnheimen, führt im Sommer 2012 zur Grün-

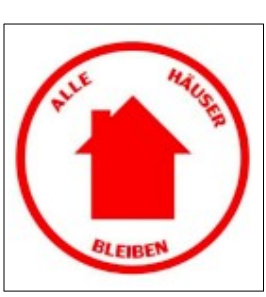
dung der Wohnrauminitiative (ein Vorläufer war die Here-to-stay Kampagne 2008-2012). Die Wohnrauminitiative sieht 27 Wohnhäuser in ihrer Existenz bedroht - vor allem am Kreuzbergring, in der Goßlerstraße, Bühlstraße, Geiststraße und Roten Straße. Das Studentenwerk widerspricht dieser Darstellung, auch weil ihr manche der genannten Häuser nicht gehören, und fordert vom Land Niedersachsen bessere Finanzierungskonditionen, um mehr Wohnheimplätze errichten zu können. Doch das Land gewährt keine weiteren Förderungen. Mit der steigenden Zahl von Studierenden in Göttingen (ab 2012) wächst der Mangel an Wohnraum und mit ihm die Mietpreise.

Die Wohnrauminitiative Göttingen protestiert immer wieder mit Aktionen, Vorträgen und Veranstaltungen gegen Wohnraummangel, Verdrängung und Gentrifizierung.

Im Januar 2013 wird die leer stehende Geiststraße 10ehemals HNO-Klinik und danach Wohnheim bis 2010besetzt. Die Universitätsleitung lässt räumen. Im Sommer 2014, als AStA und Universität dringend Wohnraum für Studierende suchen, steht das Gebäude Geiststraße noch immer leer und wird unter dem Mot- to „Bezahlbarer Wohnraum für alle!” „wieder von Aktivistinnen und Aktivisten begangen" ${ }^{50}$

Auch an anderen Stellen kommt es zu Auseinandersetzungen der Wohnrauminitiative mit dem Studentenwerk wegen Mieterhöhungen und Angriffen auf die Selbstverwaltung. Das Studentenwerk klagt über fehlende staatliche Zuschüsse und Kommunikationsstörungen, die Initiative über die Androhung mietrechtlicher Schritte und Abmahnungen wegen des Anbringens von Transparenten. Es geht um die Häuser Rosenbach 2/4 und Humboldtallee 9.

Zu Wintersemesterbeginn 2014 führt der Wohnungsmangel dazu, dass Stadt und Studentenwerk die Voigtschule als Notunterkunft (mit Feldbetten) anbieten. Die Wohnrauminitiative bietet ein Notzeltlager für wohnungslose Erstsemester*innen in der Humboldtallee 9 an. Am 25.10.2014 protestieren die Initiative und viele andere: „Für das Recht auf Stadt und bezahlbare Wohnungen!Gentrifizierung, Verdrängung, Widerstand". Zu Beginn des Wintersemesters 2015 mietet das Studentenwerk Zimmer im Best Western Hotel an, um wohnungslose Studierende temporär unterzubringen. Die Auseinandersetzungen der Wohnrauminitiative mit dem Geschäftsführer des Studentenwerks gehen unvermindert weiter, auch gerichtlich.

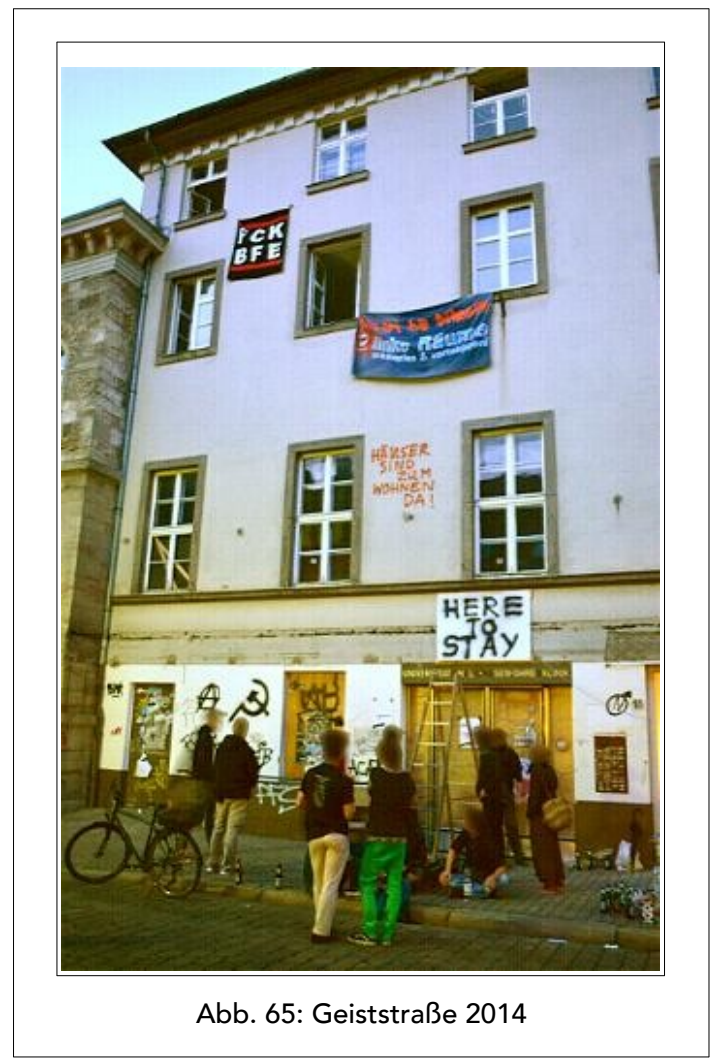




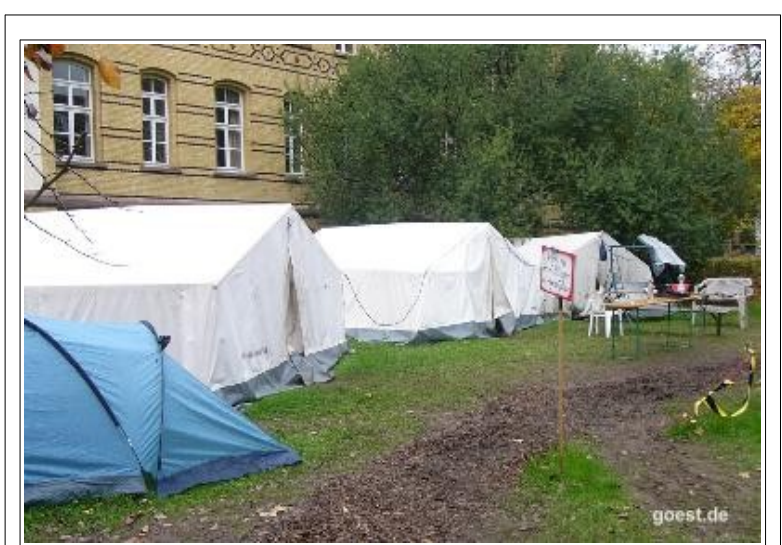

Abb. 66: Zeltlager Humboldtallee 9.Oktober 2014

Im Sommer 2016 drohen erneut Mieterhöhungen in den Wohnheimen des Studentenwerks. Auch die SPD findet das unsozial, allerdings nur die Ortsgruppe Weende; die SPD der Landesregierung sieht keine Notwendigkeit vermehrter finanzieller Zuschüsse.

Die Proteste gegen Mieterhöhungen des Studentenwerks und um die Beibehaltung der Kollektivmietverträge (Gosslerstraße 17/17a) gehen Anfang 2017 weiter. Anwälte werden eingeschaltet. Das Studentenwerk spricht (April 2017) fristlose Kündigungen aus. Der Widerstand findet bundesweites Medienecho. Allmählich laufen Gespräche zwischen Initiative und Studentenwerk an. Im Dezember 2018 wird Gosslerstraße 17/17a vom Studentenwerk an einen von der Bewohnergemeinschaft gegründeten gemeinnützigen Verein „Verein zur Förderung von Bildung, Kultur und studentischem Leben" verkauft.

Das Studentenwerk setzt den Verkauf kleinerer Wohnheime an Bewohnergemeinschaften fort (s. Rote Strasse). Die Wohnrauminitiative bleibt weiter aktiv gegen Wohnungsnot (Besetzung Fridtjof-Nansen-Haus, Unterbringung von Geflüchteten), Mietenwahnsinn (u.a. Unterstützung von INGrone), Gentrifizierung (z.B. Unterstützung Waageplatz und OM10), sber auch gegen faschistische Attacken.

\section{Rote Straße}

Es gibt einen langen Konflikt zwischen den Bewohnern der Roten Straße und dem Vermieter Studentenwerk Göttingen. Dem Studentenwerk war die Sanierung der denkmalsgeschützten Wohnheime Rote Straße 1-5/

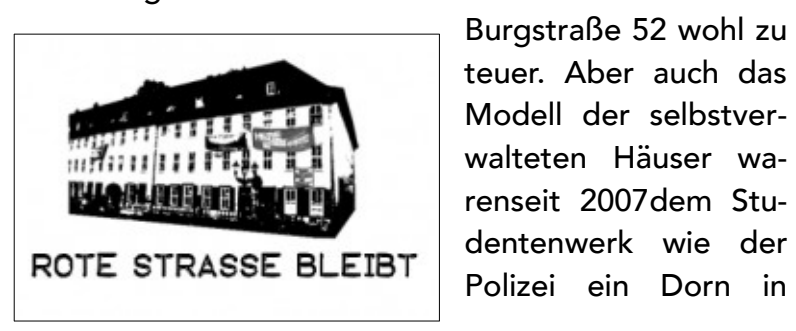

Auge. Ab 2015 schwelt der Streit zwischen Bewohner*innen und Studentenwerk, wer die aufgelaufenen Sanierungskosten („Sanierungsstau“) zu tragen habe. Die Bewohner verweigern "drastische" Mieterhöhungen. Im November 2017 laden die Bewohner Bauschutt in der Zentralmensa ab, um auf den baulichen Missstand der Häuser und Wohnungen aufmerksam zu machen. Das Studentenwerk bekennt sich dann Anfang 2018 zu seiner Instandhaltungspflicht.

Im April 2018 kommt es zu einer Demo in der Innenstadt gegen soziale Verdrängung, das Studentenwerk solle seiner - zugesagten - Instandsetzungspflicht

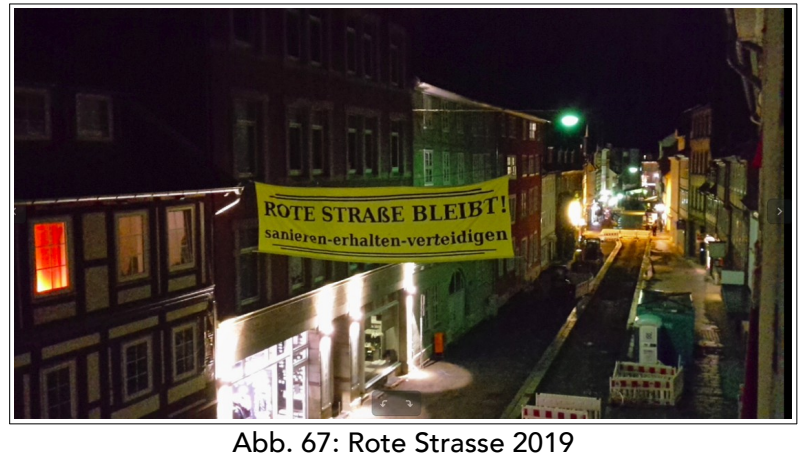

nachkommen. Das Studentenwerk bietet die Sanierung an, jedoch zu neuen Mietvertragskonditionen (Mietsteigerung $+160 \%$, Staffelmiete). Die Bewohner wehren sich gegen die Beendigung des Kollektivmietvertrages. Es kommt dann doch zu einer Einigung. Die Sanierung beginnt Mai 2019.

\section{Fridtjof-Nansen-Haus}

Im Mai 2018 zieht der Mieter Goethe-Institut endgültig aus der um 1900 erbauten Villa des Tuchmacherfabrikanten Levin aus. Seit den 1930er Jahren ist die Stadt Eigentümerin der inzwischen denkmalgeschützten Villa im Ostviertel einschließlich des $\mathrm{rd}$. 6.000 qm großen, parkähnlichen Grundstücks. Die Stadt plant (2018) den Verkauf der Immobilie. Ende April 2018 wird der seit 2 Jahren leer stehende Wohnheimtrakt besetzt, um den Verkauf zu stoppen und stattdessen dort Wohnraum für Geflüchtete zu schaffen, die - so die Initiative -

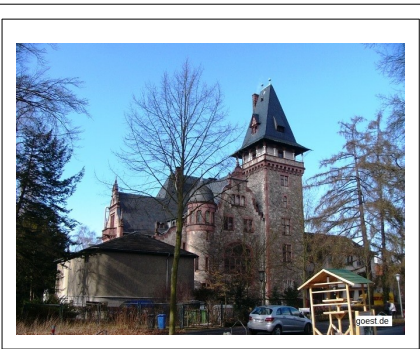

Abb. 68: "Levinsche Villa"

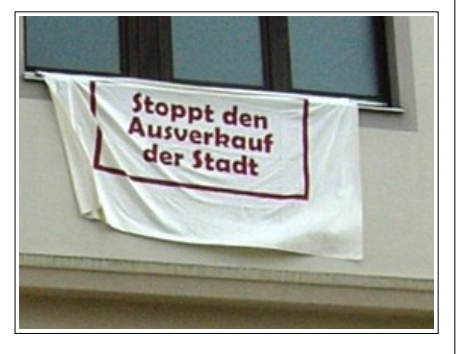




\section{Proteste}

\section{PROTEST UND WIDERSTAND (2)}

menschenunwürdig auf der Siekhöhe untergebracht seien.

Die Besetzung wird Anfang Mai durch die Polizei beendet. Es entwickelt sich in der Öffentlichkeit wie im Stadtrat eine heftige Diskussion über die schon 2017 von der Stadt geäußerten Verkaufsabsichten. Im Juni 2018 dürfen zwei potentielle Investoren im Bauausschuss ihre Nutzungspläne vorstellen: der Verlag Hogrefe und Herr Rafie Elizei, dieses Mal mit der im Januar 2018 gegründeten EBR Immobilien Invest $\mathrm{GmbH}$. Anträge von den GöLinken und Piraten, städtische Grundstücke nicht zu verkaufen und Wohnungslösungen zu suchen, werden von SPD/Grünen/FDP und CDU abgelehnt mit den Argumenten „nicht sanierungsfähig, Sanierung zu teuer, Verkaufserlöse werden für Investitionen in Kitas und Schulen benötigt" (Bauausschußsitzung 7.6.2018). „Weder sei eine Nutzung als Städtisches Archiv, noch als bezahlbarer Wohnraum realistisch.” (SPD) „Das Haus käme in gute Hände und werde sicherlich zu einem Schmuckstück in der Stadt." (Grüne) - (Ratssitzung vom 15.6.2018).

Diese "guten Hände" sind dann der Hogrefe Verlag, der die Immobilien im Jahr 2018 von der Stadt kauft. Die Geflüchteten sind bis Mitte 2019 noch in der Notunterkunft, der fensterlosen Lagerhalle auf der Siekhöhe, untergebracht.

\section{BI Nonnenstieg}

Als Reaktion auf den IWF-Siegerentwurf 2012 gründet sich im November 2012 die Bürgerinitiative Pro Nonnenstieg, um eine Verbesserung der Planung zu erreichen. Sie fordert und erarbeitet Vorschläge für eine weniger massive Bebauung sowie den Erhalt der Grünflächen. Im Sommer 2013 kommt es zu etlichen Bürgerversammlungen. Im Dezember 2013 wird die Auslegung des Bebauungsplanes beschlossen. Gegen den am 16.4.2014 erneut ausgelegten Bebauungsplan

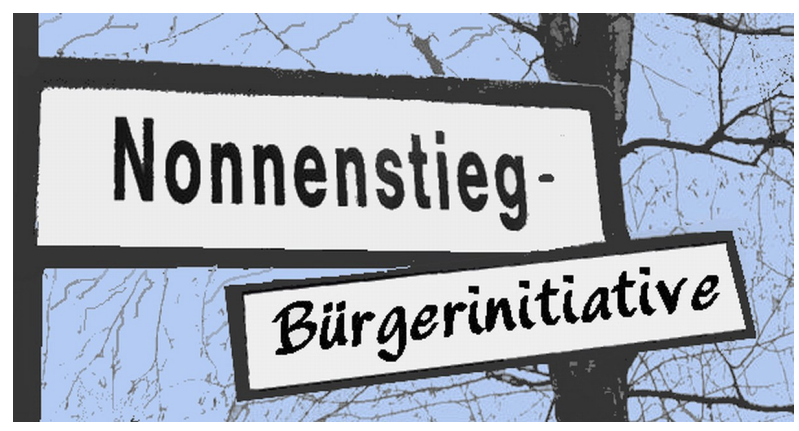

bringt die $\mathrm{BI}$ auf 160 Seiten 76 Einwände und 34 Anregungen vor. Im Oktober 2014 werden diese und einige hundert weitere Einwände (insgesamt rd. 1.000) von der Stadtverwaltung zurückgewiesen (bis auf einen). Im November 2014 vertagt der Bauausschuss den IWF-Plan. Die BI startet sein Bürgerbegehren zum Schutz des Waldes auf dem IWF-Gelände.

In der Äußerung des Oberbürgermeisters im Januar 2015, dass eine „angebotsorientierte Planung zu mehr Erfolg führen wird als eine investorengesteuerte Stadtplanung" (goest 9.1.15.), sieht die Bl eine "Kehrtwende der Stadtpolitik". Die Bauplanung wird zunächst auf Eis gelegt, das IWF wird Unterkunft für Geflüchtete. Die Wiederaufnahme der Bebauungsplanung im Herbst 2017 mobilisiert die BI Pro Nonnenstieg erneut. Sie kritisiert weiterhin die zwar geänderte, aber aus ihrer Sicht immer noch zu hohe und zu dichte Bebauung. Auch mit einem ,Einwohnerantrag' im April 2018 mit 2.803 Unterschriften kann sie ihr Anliegen nicht durchsetzen. Ende 2019 beginnt der Abriss der IWF-Gebäude.

\section{Zimmermannstraße I}

Kurz vor Weihnachten 2017 informiert der Vermieter Schneider seine Mieter in der Zimmermannstraße 5864 darüber, dass ab 15.1.18 "Sanierungs/Reparaturarbeiten" in Küchen und Bädern ausgeführt werden, und zwar gleichzeitig in allen Wohnungen - im Winter. Für die Mieter werden als Ersatz zwei Container aufgestellt. Mieter beschweren sich über unzumutbare Zustände, wenden sich hilfesuchend an den Ortsverband Weende der SPD. Namen sickern offenbar durch. Die Rechtsanwältin des Vermieters droht mit Kündigungen. Der Vermieter beschwert sich darüber, dass Mieter an die Öffentlichkeit gehen und sieht darin eine Rufschädigung. Die Klagen der Mieter führen zu kontroversen Debatten im Rat (Bauausschuss) der Stadt. CDU-Vertreter kritisieren die "gefährliche Polemik gegen Miethaie" angesichts eines doch „offensichtlichen Nicht-Problems". Die Piraten sehen einen Amtsmissbrauch, denn die Rechtsanwältin ist auch Ratsvorsitzende und baupolitische Sprecherin der SPD. Die Politikerin und Rechtsanwältin sieht keinen Interessenkonflikt. Die SPD auch nicht. Die Anwältin ist bis heute Mitglied im Bauausschuss und dessen stellvertretende Vorsitzende. Es gibt Aufregung über den Politikbetrieb, über Filz und politische Moral. Weniger skandalös erscheinen dagegen die Spielräume und Unsicher- 


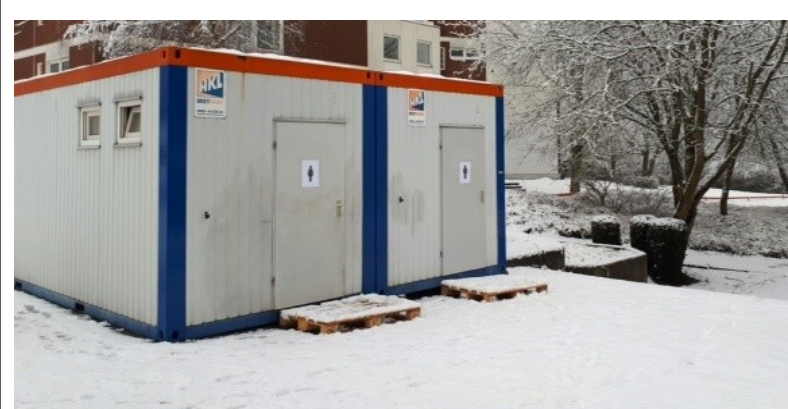

Abb. 69: Container - Ersatz für Bäder - Zimmermannstrasse Januar 2018

heiten im Rechtsschutz der Mieter. Besteht nicht der eigentliche Skandal darin, wie der soziale Rechtsstaat das Vertragsverhältnis Vermieter-Mieter zugunsten der Eigentümer gestaltet?

\section{Zimmermannstraße II}

In etwa zur gleichen Zeit, Ende 2017/Anfang 2018 ergibt sich am östlichen Ende der Zimmermannstraße überraschend die Möglichkeit, ein 0,4 ha großes Grundstück zu erwerben. Allerdings darf nach dem FNP dort nicht gebaut werden - es ist Landschaftsschutzgebiet und wichtige Kaltluftschneise. Stadtverwaltung und Politiker sehen den gerade (2017) beschlossen FNP aber als ,nicht in Stein gemeißelt' an. Die Bürgerinitiative Nonnenstieg versucht die Aufhebung des Landschaftsschutzes an der Stelle zu verhindern und verweist auf die Argumente der Stadtpolitik, mit denen diese kurz zuvor das Landschaftsschutzgebiet ausgewiesen hatte. Im Februar 2018 erwirbt ein Göttingen Immobilienunternehmer das Grundstück, die Stadt Göttingen überbietend, und will dort „20 bis 30" Mietwohnungen bauen.

\section{GroneSüd/Mitte}

In Grone protestieren der Runde Tisch Grone und der Verein INGrone (Verein für Interkulturelle Nachbarschaft in Grone) im Sommer 2015 gegen den Leerstand von rd. 80 Wohnungen bei der Westgrund AG angesichts von Wohnungsmangel und schlechter Unterbringung von Geflüchteten. Im Herbst 2016 kommt es zu einer Vereinbarung zwischen Stadt und dem neuen Eigentümer Adler Real Estate AG, 50 Wohnungen mit städtischen Zuschüssen zu renovieren und über Belegrechte zu vermieten. Die höheren Mieten in den renovierten Wohnungen nutzt ARE, um Mieterhöhungen auch in unrenovierten Wohnungen durchzusetzen. Zudem gibt es falsche Nebenkostenabrechnungen. Im Februar 2017 organisiert der Verein INGrone eine Bür- gerversammlung im Nachbarschaftszentrum Grone, um über ein gemeinsames Vorgehen gegen ARE zu beraten.

Am 26. Oktober 2017 stellen Stadtverwaltung und Adler Real Estate die Modernisierungs- und Aufstockungspläne im Ortsrat Grone vor. Die ARE geht von einer Mieterhöhung von mind. 2,59 $€ / \mathrm{m}^{2}$ aus - bei einem Durchschnittsniveau von $5 € / \mathrm{m}^{2}$ ein Plus von mehr als $50 \%$. Einen Monat später beschließt die Stadtverwaltung, für die Gebiete Bebauungspläne aufzustellen. Am 25.11.2017 lädt der Verein INGrone die betroffenen Mieter in das Nachbarschaftszentrum ein, um gemeinsam zu be-

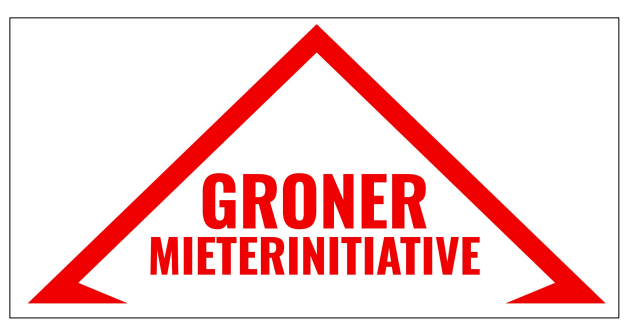
sprechen, wie auf die Pläne von Adler zu reagieren sei. Es bildet sich die Groner Mieterini, die sich für den Erhalt bezahlbarer Mieten einsetzt - mit Flugblättern, weiteren Versammlungen im Nachbarschaftszentrum (u.a. wieder wegen falscher Nebenkostenabrechnungen im Februar 2018 mit über 70 Mieter*innen und im Januar 2019), mit Initiativen im Ortsrat Grone wie z.B. Anträgen auf eine Voruntersuchung für eine mögliche soziale Erhaltungssatzung, mit Kritik am Städtebaulichen Vertrag, Demonstrationen vor dem Rathaus gegen die Verabschiedung der Bebauungspläne, u.a.m.

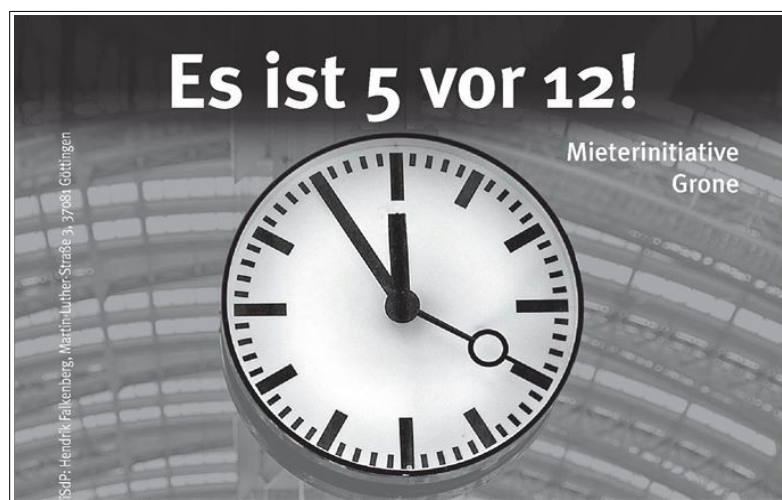

17. Mai: Der Rat entscheidet über unsere Mieterhöhungen Wir wehren uns!

Am Freitag, 17. Mai, wird der Rat über den Bebauungsplan in Grone-Süd und Grone-Nord beschlieBen. Sie haben uns nicht gefragt, aber sie entscheiden über unsere Mieterhöhungen! Wenn sie de B.Plan ablehnen würden, wird die ADLER AG auf die Modernisierungen verzichten; es rentiert sich Lasst uns den Mitgliede

Freitag, 17. Mai: Kundgebung vor dem Rathaus Ratssitzung, 13.30 Uhr, Neues Rathaus

Die letzte Möglichkeit, den Ratsmitgliedern zu zeigen, was WIR von IHREN Beschlüssen halten

(anschließend - 14.15 Uhr - gehen wir in die Ratssitzung):

„Bezahlbaren“ Wohnraum erhalten (max. 5,60-7,00 Euro/qm) Wohnraum durch kommunale Gesellschaften Keine Rendite mit unserer Miete

Aktionäre wollen Rendite, kein bezahlbares Wohnen Stoppt den Mietenwahnsinn 


\section{PROTEST UND WIDERSTAND (3)}

2018 veröffentlicht der Verein INGrone Hilfen und Handreichungen über die Rechte von Mietern. Im Januar 2019 gibt er ein längeres Papier heraus, dass die Praktiken und Strukturen des Adler Real Estate -Konzerns analysiert.

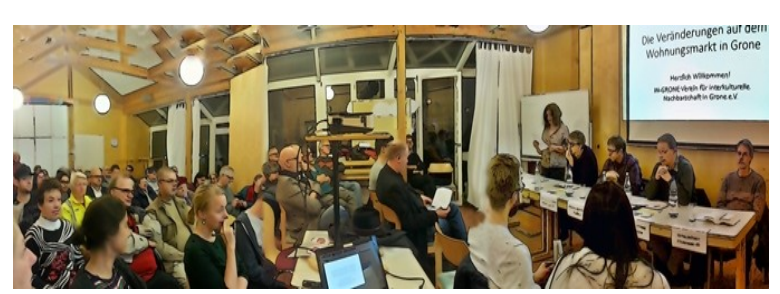

Abb. 70: Mieter*innenversammlung in Grone Nov. 2017

\section{Vonovia}

Schon kurz nachdem aus der Deutschen Annington und der GAGFA die Vonovia wird (2015) und die ersten Nebenkostenabrechnungen der Vonovia eintreffen, setzen sich Mieter im Bereich der Königsberger Straße zusammen, um sich gegenseitig zu unterstützen und fehlerhaften Nebenabrechnungen zu widersprechen (2016/17). Sie richten ein Beratungsbüro ein, verteilen Flyer und organisieren Vortrags- und Diskussionsveranstaltungen. Vonovia-Mieter aus anderen Stadtteilen, besonders Grone, werden auf diese Aktivitäten aufmerksam und schließen sich der Mieterinitiative an (2018). Akribisch und mit großem Einsatz - bis hin zu rechtlichen Schritten - kontrollieren und kritisieren vor allem Mieterinnen aus der „Eisenbahnersiedlung" die Nebenkosten- wie Modernisierungsabrechnungen. Sie finden doppelt abgerechnete neue Haustüren, abgerechnete Kosten für nicht stattgefundene

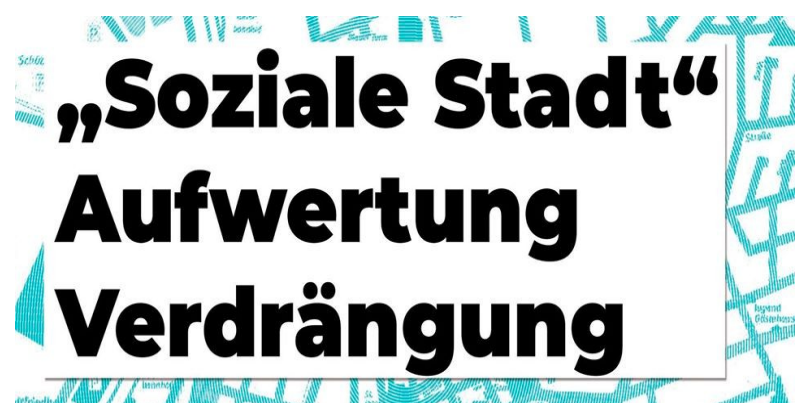

\section{Was macht das mit unseren Mieten?}

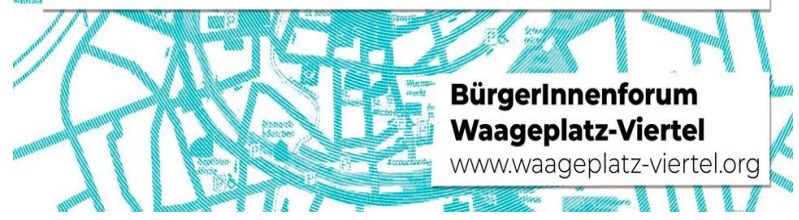

Winterdienste oder für den Schnitt einer Hecke, die längst gerodet und durch einen Drahtzaun ersetzt war, oder für neuen Sand für einen Kinderspielplatz, obwohl in der Sandkiste seit Monaten ,Unkraut' wuchs usw. Die Mieterinnen kartieren mit großen Zeitaufwand, wo es in Göttingen noch weitere Mietwohnungsbestände von Vonovia gibt, um auch dort Flyer zu verteilen und zu mobilisieren. Eine Antrag auf (geringe) finanzielle Unterstützung, um den Beratungs-Laden aufrecht erhalten zu können, lehnt die Stadtverwaltung ab (2019). Das regelmäßige Treffen der Mieterinitiative und der rege Austausch über die Abrechnungspraktiken der Vonovia hat zu Erfolgen geführt. Dort wo widersprochen wurde, konnten Erstattungen ungerechtfertigter und überhöhter Nebenkostenzahlungen erreicht werden. Seit 2020 erhält die Mieterinitiative auch Unterstützung durch den Mieterverein, der ebenfalls und öffentlich gegen die Nebenkostenabrechnungen der Vonovia mobilisiert ( $\rightarrow$ Kap. 11).

\section{Th OM10}

Im November 2015 besetzen Aktivist*innen in der Innenstadt die Obere-Masch-Straße 10/10a, um gegen Leerstand vorzugehen und Solidarität mit Geflüchteten zu praktizieren. Die "Instandbenutzer*innen" richten die ehemaligen Büros als Wohnräume her. Es finden zahlreiche Versammlungen und Kulturveranstaltungen statt. Nach einjährigen Verhandlungen und

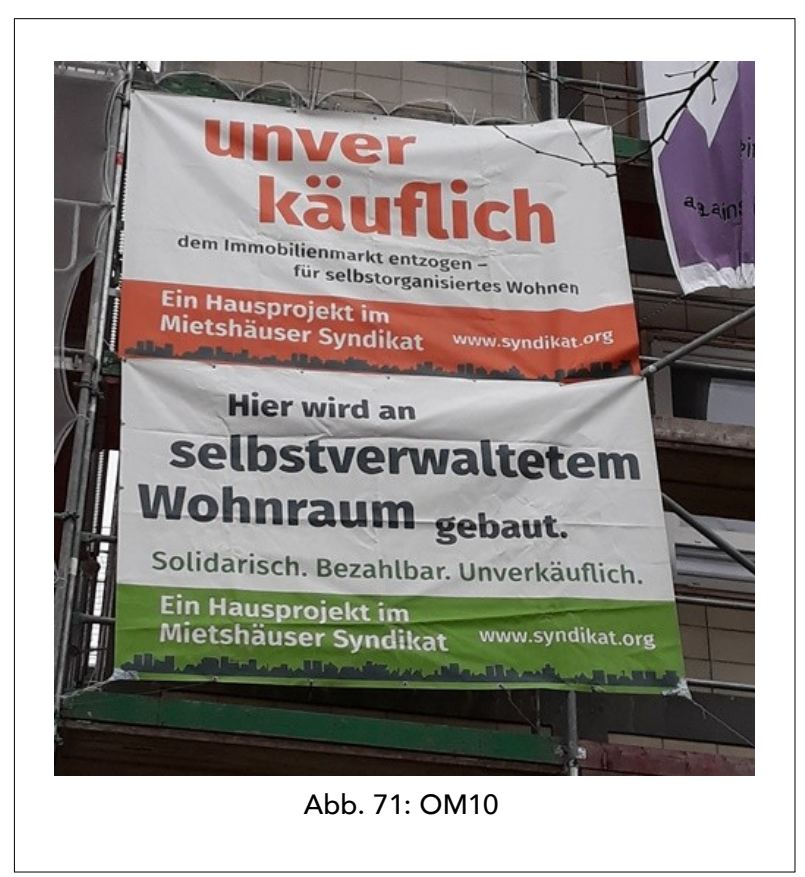


breiter öffentlicher Unterstützung für die Besetzung verkauft der DGB 2017 das Haus an die Besetzer*innen/Bewohner*innen/Nutzer*innen. Ende 2018 tritt die GmbH OM 10 dem Mietshäuser-Syndikat bei.

So wird dauerhaft günstiger, selbstverwalteter Wohnraum geschaffen. Gleichzeit wird das mit der OM10 neu entstandene politische und kulturelle Zentrum auch langfristig erhalten. Es bietet Räume für Vernetzung und Aktion und für eine offene Mieter-Erstberatung.

\section{U UM13 / Waageplatz / Gotmar- straße 9}

Seit Anfang 2018 setzt sich das Bürger ${ }^{\star}$ innenforum Waageplatzviertel gegen eine städtische Planung ein, von der sie eine Gentrifizierung der nordwestlichen Innenstadt und damit den Verlust von weiterem bezahlbarem Wohnraum befürchtet. Jeden ersten Mittwoch im Monat bietet das Bürger*innenforum in der OM10 eine Offene Mietberatung an, eine kostenfreie anwaltliche Erstberatung mit Mieter*innencafé. In der Unteren-Masch-Straße 13 droht genau das, Verdrängung und Verlust von bezahlbarem Wohnraum, nachdem der Investor Coreo AG das Haus gekauft hat und saniert.

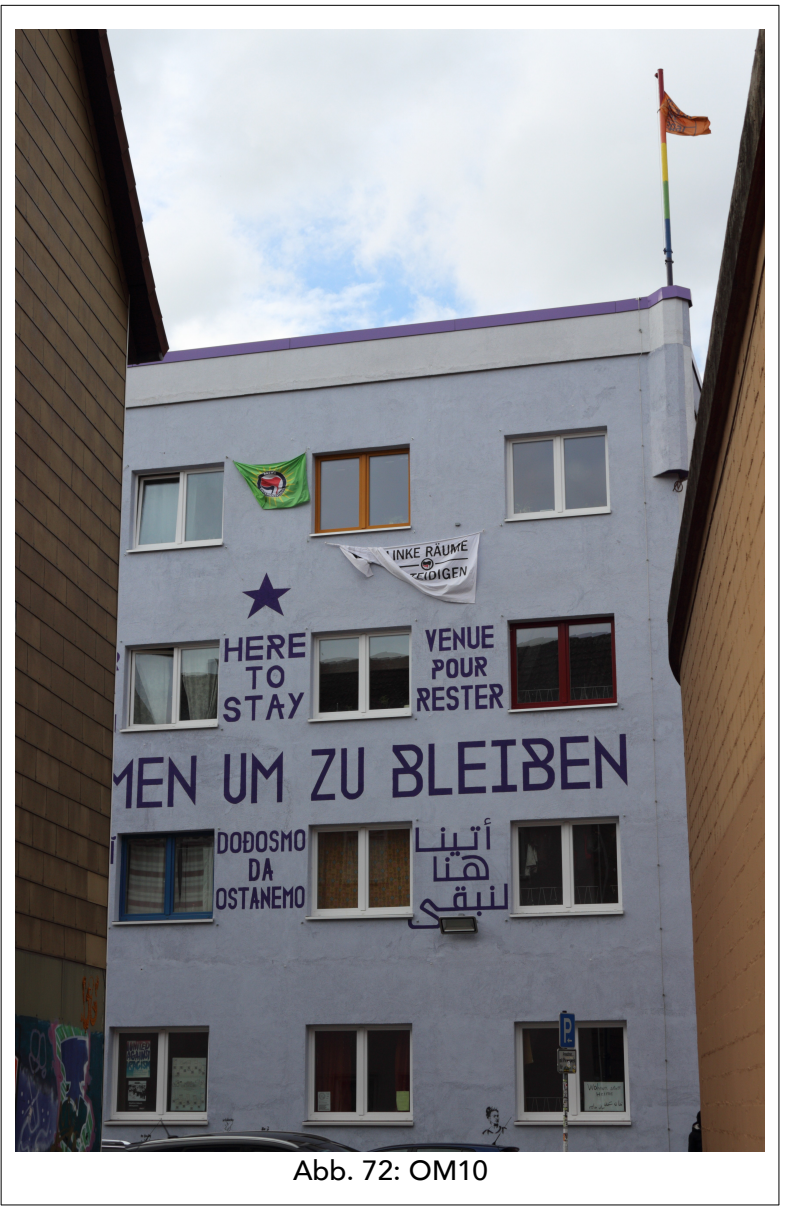

Die langjährigen Mieter*innen der preisgünstigen Wohnungen wehren sich seit Mitte 2019 gegen die Entmietung.

\section{UM13:}

"Kleine Fische gegen Miethaie - Bewohner*inneninitiative Untere Masch 13 gegen Coreo".

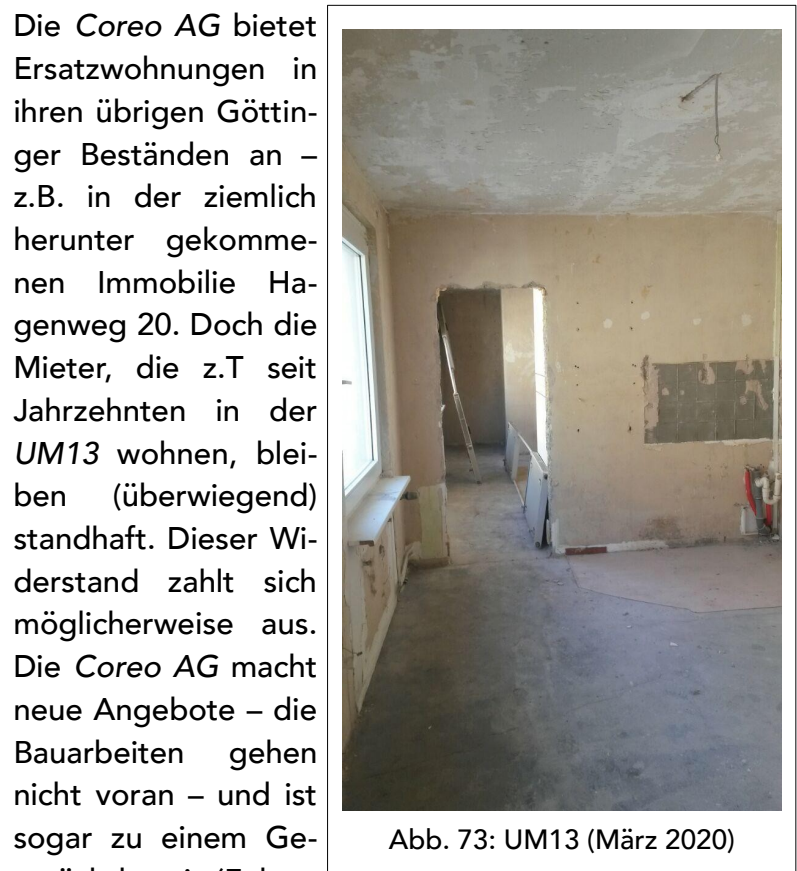

ar 2020). Es bleibt abzuwarten, ob die Angebote eine Schadensbegrenzung für die Mieter bewirken oder ob sie nicht nur taktische Winkelzüge sind.

Die Stadtverwaltung zeigt Mitgefühl $($ „,..., dass es immer schwieriger für Menschen mit schmalem Geldbeutel werde, angemessenen Wohnraum zu finden." GT 14.8.2019), sieht aber keine Möglichkeit, einzugreifen, weil es ein privatrechtliches Verhältnis zwischen dem Vermieter und jedem einzelnen Mieter sei. Auch eine

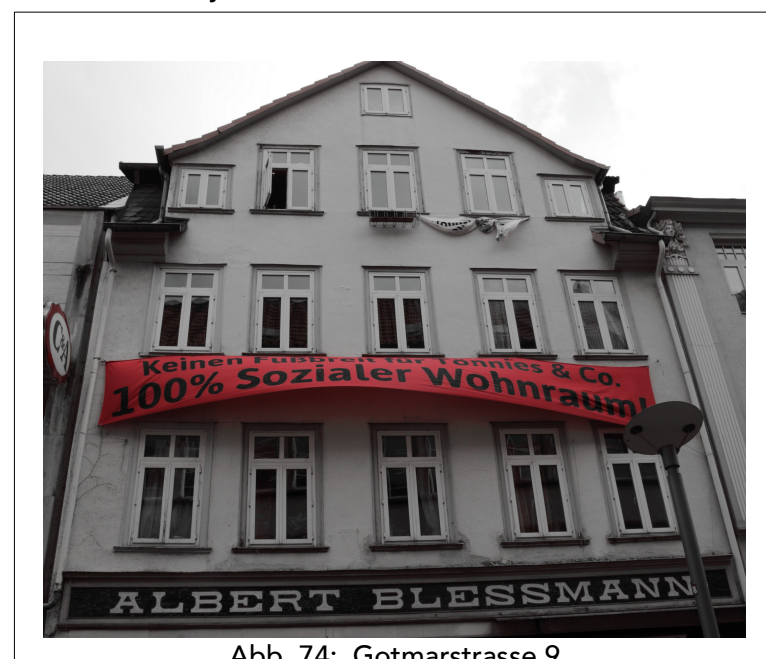

Abb. 74: Gotmarstrasse 9 


\section{Proteste}

\section{PROTEST UND WIDERSTAND (4)}

zumindest moralische Unterstützung durch Rat und Parteien gibt es nicht. Inzwischen arbeiten die Handwerker im Haus. Heizung und Wasser fallen manchmal aus, vom Baulärm ganz zu schweigen.

Auch Mietern in der Gotmarstraße 9 droht seit Sommer 2019 der Verlust ihrer preisgünstigen Wohnungen, nachdem die Sparkasse Göttingen die Immobilie an den Investor HT Group, Tochter der Hansa Invest, verkauft hat. Die HT Group plant dort hochwertiges, teures Wohnen und Geschäfte.

\section{Bündnis "Gutes Wohnen für alle”}

Dieses Bündnis hat sich 2019 im Zuge des bundesweiten Aktionsbündnisses „Mietenwahnsinn stopppen!” aus Mieter *inneninitiativen, Sozialverbänden, Gewerkschaften sowie mietenpolitischen Akteur*innen gebildet.

Das Bündnis trifft sich monatlich im OM10, um Aktivisten zu vernetzen, Informationen auszutauschen, Aktionen zu planen und durchzuführen.

„Wir setzen uns für eine Wende in der Wohnungspolitik ein, die nicht länger die Renditeinteressen der Aktionär*innen wahrt, sondern sich daran orientiert, allen Menschen gutes Wohnen zu ermöglichen. Das Bündnis sieht Investoren und die Stadt in der Pflicht, endlich Konsequenzen zu ziehen und Taten für ein Recht auf gutes Wohnen folgen zu lassen."

(guteswohnenfueralle@riseup.net)

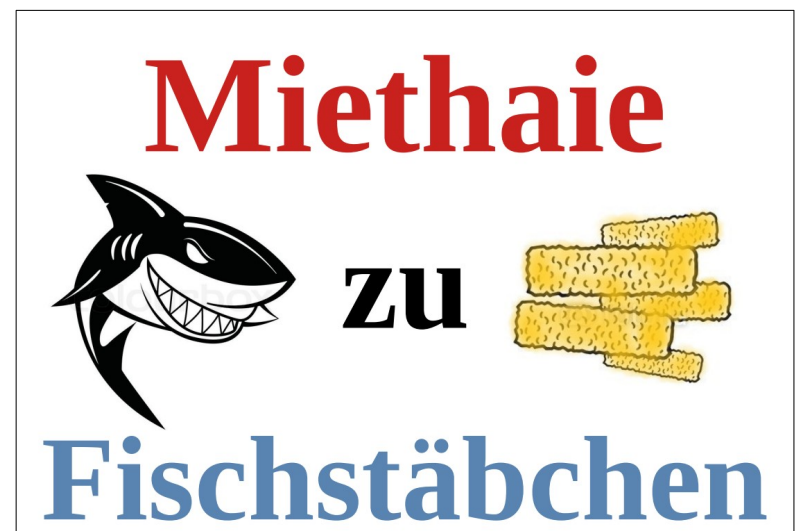

Abb. 75: Transparent der Groner Mieterini zur Demo: " Radtour durch das Miethaifischbecken" (März 2020)
Forderungen zum Housing Action Day 28.3.2020 :

"1. Ausbau von öffentlich/genossenschaftlich verwaltetem Wohnungsbau. Boden und Wohnungsbestände ankaufen und dem privaten Markt entziehen. Kein Verkauf von städtischem und öffentlichem Eigentum.

2. Erhalt und Ausbau von sozialem Wohnraum in allen Stadtviertel auch im Bestand.

3. Für eine Stadtpolitik im Interesse der Stadtbewohner*innen. Stadtpolitik gegen die Interessen von profitorientierten Immobilienkonzernen (z.B. Adler, Vonvia, Coreo und Bassil).

4. Konsequente Unterstützung der Stadt von Leistungsbezieher*innen für ihr Recht auf gutes Wohnen (Quadratmeterpreise, Wohnstandard, keine Sammelunterkünfte.

5. Für ein einklagbares Recht auf Wohnen, Wohnungslosigkeit beenden.

6. Leistbarer Wohnraum für Alle. Durchsetzung eines Mietendeckels.

7. Leerstand zu Wohnraum. Spekulation bekämpfen, Demokratisierung fördern. Wohnen für Menschen statt für Profite.

Für einen radikalen Kurswechsel in Politik und Wirtschaft: Für einen solidarische und ökologische Stadtentwicklung." 


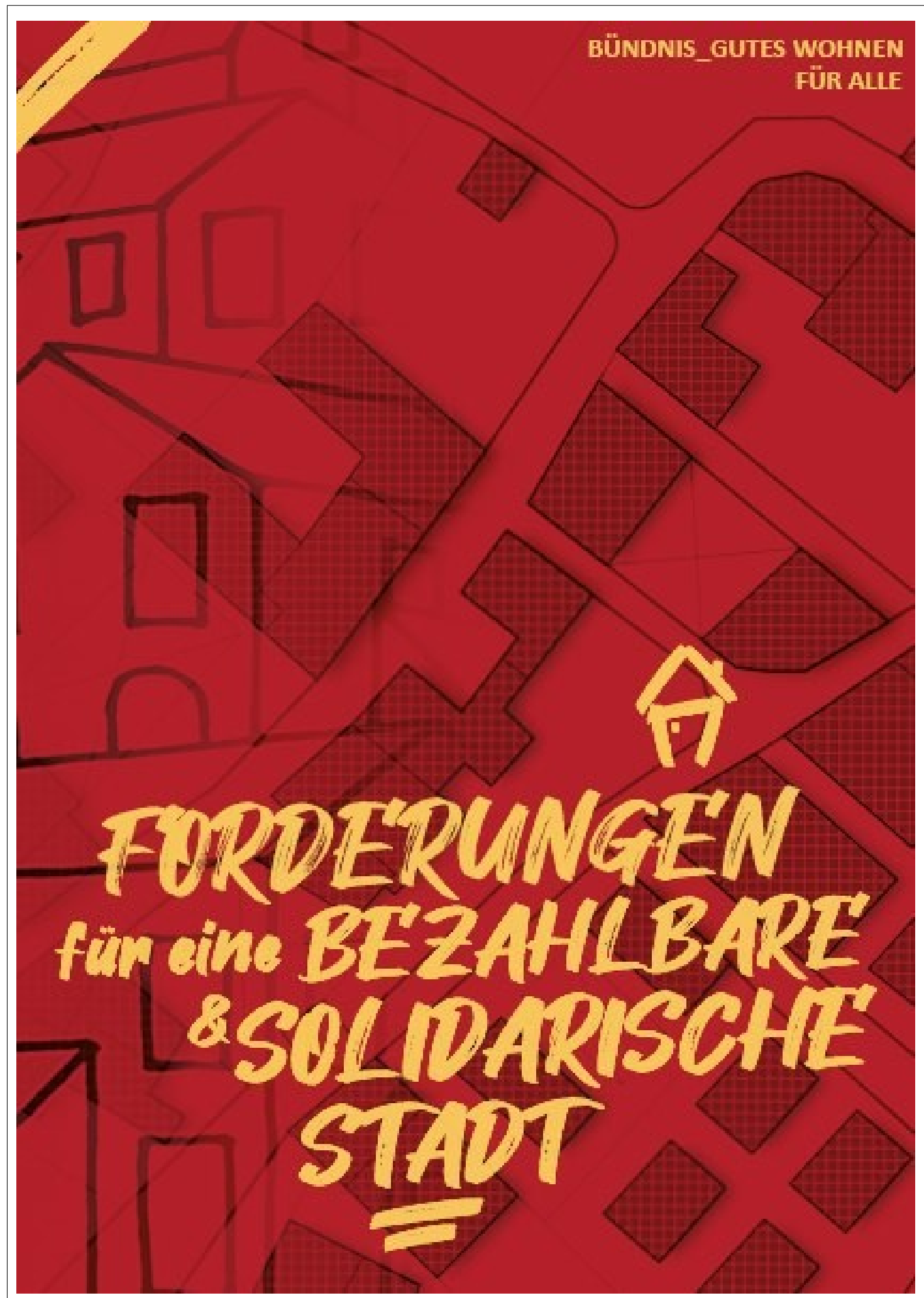

Abb. 76: Plakat des Göttinger Bündnis zum Housing Action Day 2020 
Abb. 77: Standorte öffentlicher und genossenschaftlicher Wohnungsunternehmen

\section{Objekte in öffentlicher oder genossenschaftlicher Trägerschaft im Stadtgebiet Göttingen}

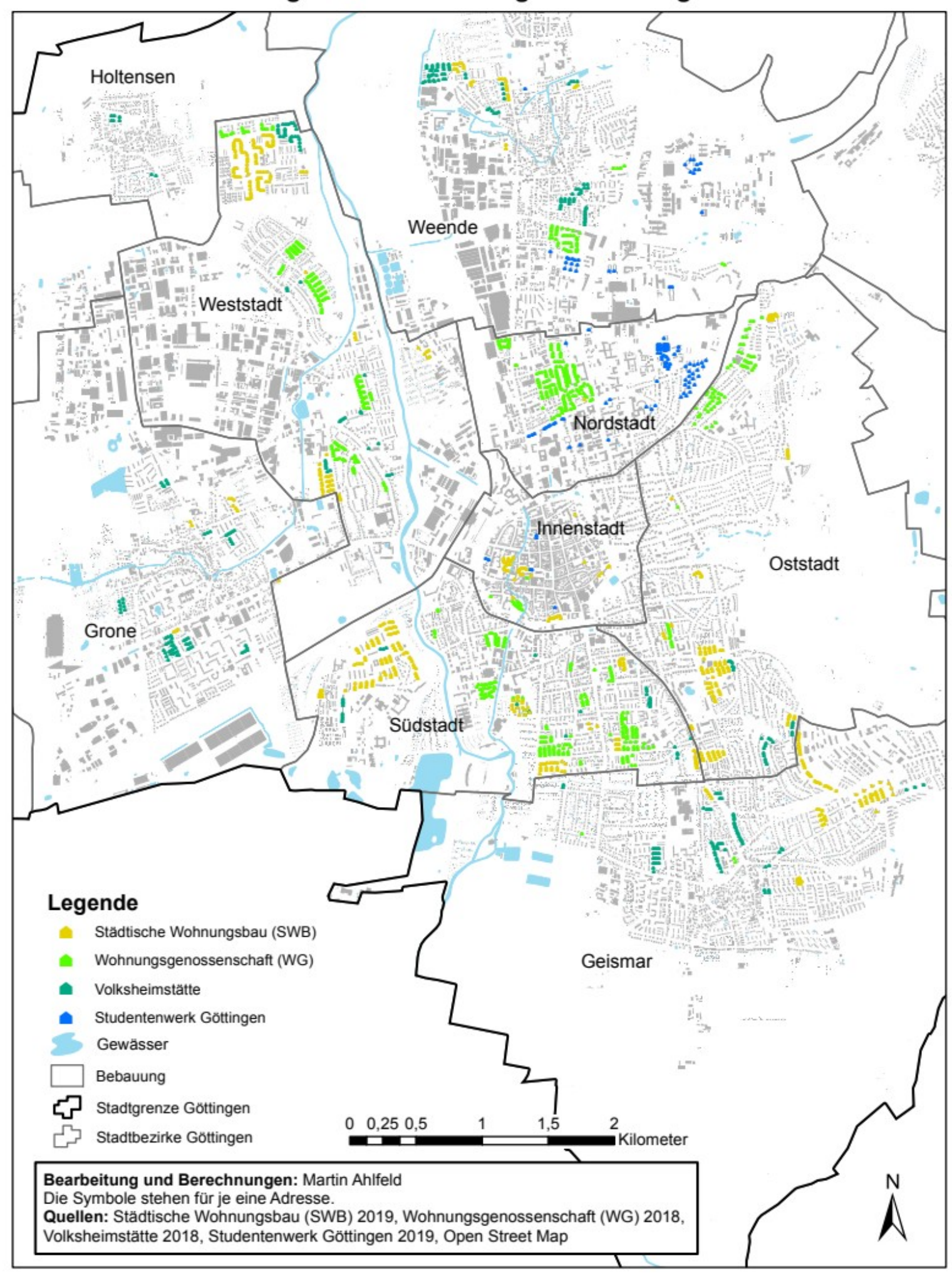




\section{Eine grundlegend neue Wohnungspolitik ist notwendig}

\section{MIETERSCHUTZ - MIETERSYNDIKAT}

$\mathrm{M}$ ietwohnungen sind Eigentum und Geschäftsmittel des Vermieters. Der Vermieter hat rechtlich gesehen die Freiheit, wie er mit seinem Eigentum verfährt. Es hat sich jedoch gezeigt, dass diese Freiheit nicht so genutzt wird, dass die gesellschaftliche und volkswirtschaftliche Funktion der notwendigen Versorgung mit Wohnraum ausreichend gewährleistet ist. Im Vertragsverhältnis Vermieter-Mieter ist der Mieter in doppelter Weise benachteiligt: sein Einkommen und somit seine Mietzahlungsfähigkeit ist sehr begrenzt und zum anderen hat er rechtlich keinen Anspruch auf eine Wohnung, während dem Vermieter (Grundeigentümer) ein Monopol am Standort, am Grundstück, gewährt ist. Das führt zwangsläufig zu zahlreichen zivilrechtlichen Konflikten zwischen Vermieter und Mieter. Und diese können für die gesamtgesellschaftliche Entwicklung und besonders für das Wirtschaftswachstum hinderlich bis kontraproduktiv sein. Die Beispiele dafür sind zahlreich: die Wohnungsfrage in der BRD Ende der 1960er/ 1970er Jahre, die Wohnungsfrage im Deutschen Reich Ende des 19. Jh., die Wohnungsfrage in England Mitte des 19.Jh.um nur einige zu nennen.

BGB § 903 Befugnisse des Eigentümers: „Der Eigentümer einer Sache kann, soweit nicht das Gesetz oder Rechte Dritter entgegenstehen, mit der Sache nach Belieben verfahren und andere von jeder Einwirkung ausschließen."

Um Mieter in der Auseinandersetzung mit dem Vermieter zu stärken, um das Vertragsverhältnis überhaupt funktionsfähig zu machen, sind über das allgemeine Vertragsrecht im Bürgerlichen Gesetzbuch (BGB) hinaus Mieterschutzgesetze eingerichtet worden: ein Kündigungsschutz in Deutschland seit den 1920er Jahren, ein soziales Wohnraummietrecht seit 1960, Regulierungen zur Miethöhe seit Mitte der 1970er Jahre. Immer wieder wurde das Mietrecht angepasst und reformiert, zuletzt 2001 und seitdem:

2013 Mietrechtsänderungsgesetz (u.a. Änderungen bei Kündigungsschutz und Modernisierungsumlage).

2015 Mietpreisbremse in „angespannten Wohnungsmärkten"Göttingen gehört dazu

2019 Modernisierungsumlage wurde von $11 \%$ auf $8 \%$ gesenkt, eine Kappungsgrenze eingeführt, die Mietpreisbremse verschärft.

Hat man als Mieter ein Problem mit dem Vermieter, muss man prüfen, ob die Forderungen berechtigt sind, ob und wie sie durch einen Paragraphen (oder durch ein Gericht) anerkannt werden. Das Mietrecht ist kompliziert und manchmal nicht präzise, daher verunsichert es viele.

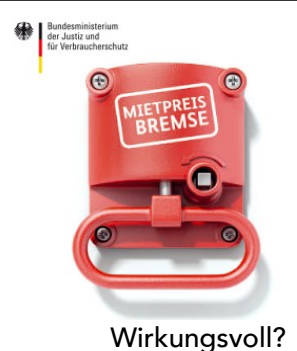

In Göttingen fehlt ein Mietspiegel. Göttingen ist eine der ganz wenigen Großstädte in Deutschland ohne Mietspiegel. Die SPD Göttingen lehnt ihn ab, weil ein Mietspiegel Mieterhöhungen begünstige.

Wissenschaftliche Belege gibt es dafür nicht.

Manche Mietervereine haben ausführliche Internetseiten, die hier Erste Hilfe leisten.

z.B. der Berliner Mieterverein https://www.berliner-mieterverein.de/

Seit kurzem auch der Göttinger Mieterverein https://www.mieterverein-goettingen.de

Oft jedoch benötigt man eine konkrete, auf den jeweiligen Fall bezogene Rechtsberatung.

In Göttingen gibt esneben zahlreichen Anwälten

OM10offene Mieterberatung (https://waageplatz-viertel.org/index.php/categor y/bezahlbare_mieten/)

Asta Uni Göttingen (https://asta.uni-goettingen.de/rechtsberatung/),

Tafel Göttingen (https://www.tafelgoettingen.org/rechtsberatung)

Mieterverein Göttingen (https://www.mieterverein-goettingen.de)

Menschen mit geringem Einkommen können im Amtsgericht (relativ unkompliziert) Kostenübernahmen für eine Rechtsberatung und evtl. Prozesskostenhilfe beantragen (Formulare u.a. zu Beratungshilfe und Prozesskosten: https:// justizportal.niedersachsen.de/startseite/buergers ervice/formulare_und_hilfen/) 


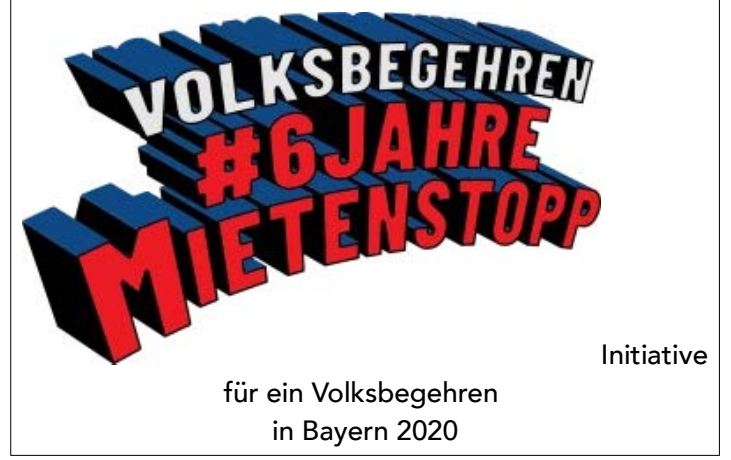

\section{Mieterinitiativen}

Es gibt Mieterinitiativen, in denen betroffene Mieter sich gegenseitig informieren, helfen und unterstützen, ihre Rechte wahrzunehmen z.B. im Umgang mit Nebenkostenabrechnungen. Mieterinitiativen zu organisieren und darin mitzuarbeiten, ist wichtig, um Anliegen und Forderungen gegenüber Vermietern wie Politik nachdrücklich vorzubringen und durchzusetzen.

In Göttingen hat die Stadtverwaltung ein Projekt auf den Weg gebracht, dass bei der Gründung von Mieterinitiativen beraten soll. Das klingt gut. $\mathrm{Ob}$ es Mietern und bestehenden Initiativen helfen wird, bleibt abzuwarten. Eingebunden und gefragt waren die bestehenden Initiativen bei der Planung des Projektes nicht.

Welche Mieterinis es gibt, kann man beim Bündnis „Gutes Wohnen für alle" erfahren.

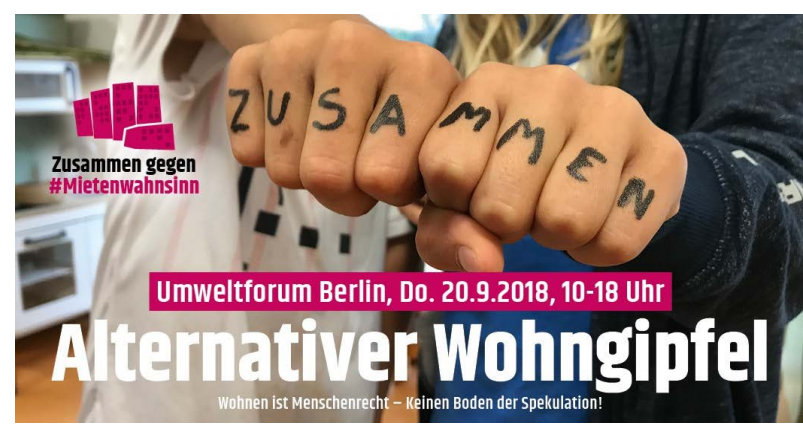

\section{Mieterschutz - anders und effektiver}

Es gibt seit einigen Jahren auch einen anderen Versuch, den Mieterschutz zu verbessern, indem die Eigentumsfrage anders gelöst wird - über das Mietshäuser Syndikat. Das Syndikat ist eine Rechtskonstruktion, die sicherstellt, dass ein Mietshaus im Eigentum der darin wohnenden Mieter bleibt und nicht weiterverkauft werden kann, also das Mietshaus auf Dauer dem Immobilienmarkt entzogen bleibt.

\section{Mietshäuser Syndikat}

Das Mietshäuser Syndikat ist eine 1992 von Hausbesetzern in Freiburg im Breisgau gegründete, koopera- tive, nicht kommerzielle Beteiligungsgesellschaft. Sie unterstützt Hausprojekte durch eine besondere rechtliche Konstruktion. Die Häuser, oft Wohnprojekte, werden Eigentum einer eigens dafür gegründeten $\mathrm{GmbH}$. Diese $\mathrm{GmbH}$ gehört dem Hausverein (den Mietern) und der Beteiligungsgesellschaft des Syndikats; beide sind zu gleichen Teilen stimmberechtigt. Dadurch kann der Hausverein, der eigenverantwortlich das Haus verwaltet und bewirtschaftet, das Haus allein also nicht verkaufen. Die Beteiligungsgesellschaft wiederum wird kontrolliert von allen Hausvereinen im Syndikat.

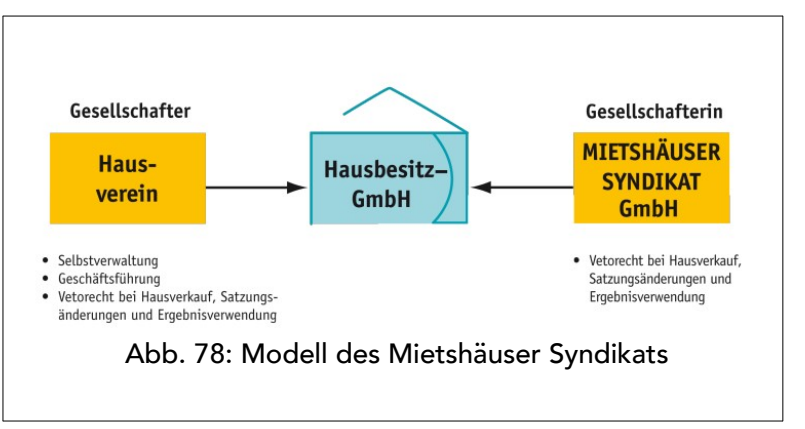

Das Mietshäuser Syndikat beteiligt sich nicht finanziell an den stets sozialverträglichen Hausprojekten, die Finanzierung müssen diese jeweils selbst organisieren. Weil es den Hausvereinen in der Regel an Eigenkapital mangelt und dadurch ihr Zugang zu Bankkrediten erschwert ist, sind sie vielfach auf Direktkredite angewiesen und das bedeutet, auf Kreditgeber, die nicht auf hohe Rendite spekulieren. Es gibt zudem einen vom Syndikat eingerichteten Solidarfonds, dem alle Hausvereine verpflichtend angehören. Über den unterstützen sich die Hausvereine gegenseitig und solidarisch. Inzwischen gibt es mindestens 153 Hausprojekte quer über Deutschland verteilt, zwei davon in Göttingen: die OM10"seit dem 13.12.2018 durch das Syndikat entprivatisiert, $442 \mathrm{~m}^{2}$ Wohnraum für 20 Personen, 346 $\mathrm{m}^{2}$ Gemeinschaftsfläche, Kleinstgewerbe, usw." und ein Miethaus in der Südstadt. (https://www.syndikat.org).

In Göttingen werden weitere ähnliche Projekte diskutiert und zu realisieren versucht. Mengenmäßig schafft diese Initiative nicht den benötigten bezahlbaren Wohnraum. Aber -

Der Grundgedanke der "Entprivatisierung" von Immobilien ist ein wichtiger Ansatz, den Mieterschutz zu verbessern, Mieter vor Mieterhöhungen und Kündigungen zu schützen. 


\section{Eine grundlegend neue Wohnungspolitik ist notwendig}

\section{REKOMMUNALISIERUNG}

$\mathrm{D}$

ass der "Markt" nicht ausreichend bezahlbare Wohnungen schafft, ist ja nicht erst seit den letzten Jahren bekannt. Die „Wohnungsfrage" reicht bis weit ins 19. Jahrhundert zurück. Der kommunale Wohnungsbau (und früher auch der Werkswohnungsbau) galt immer als eine notwendige Ergänzung des „Marktes”. Gegenwärtig wird vermehrt eine Rekommunalisierung gefordert, eine Ausweitung des kommunalen Wohnungsbaus, der vor rd. 20 Jahren eingefroren und für überflüssig erklärt wurde.

Die Stadt Göttingen betreibt seit 1960 Wohnungsbau über die Städtische Wohnungsbau GmbH (SWB). Die stadteigene $\mathrm{GmbH}$ hat in den 1960er und 1970er Jahren umfangreichen, modernen, meist öffentlich geförderten Wohnungsneubau betriebenim Ebertal, auf dem Leineberg, dem Holtenser Berg, in Geismar. Viele Sozialbindungen sind in den letzten Jahren aber ausgelaufen oder werden demnächst auslaufen. Im Wohnungsbestand der SWB ist daher der Anteil „frei finanzierter" Wohnungen von 55\% (2008) auf rd. 63\% (2018) gestiegen.

Die durchschnittliche Nettokaltmiete (aller Wohnungen der SWB) hat sich von $4,48 € / \mathrm{m}^{2}$ (2008) über $4,94 € / \mathrm{m}^{2}$ (2012) auf 5,16 €/m² (2018) erhöht. Bei neuen Wohnungen von hochwertigem Standard liegt die Miete teilweise bei 9 bis $10 € / \mathrm{m}^{2}$. Die niedrige Durchschnittsmiete zeigt jedoch, dass es unter den 4.687 Wohnungen (2018) noch sehr viele, nicht sozial gebundene mit Mieten unter $6 € / \mathrm{m}^{2}$ geben muss.

Der Wohnungsbestand ist in gutem Zustand. Die SWB investiert viel in die Modernisierung der Gebäude, aber auch in die Instandsetzungen von Wohnungen und Pflege des Wohnumfeldes. Sie achtet darauf, bei

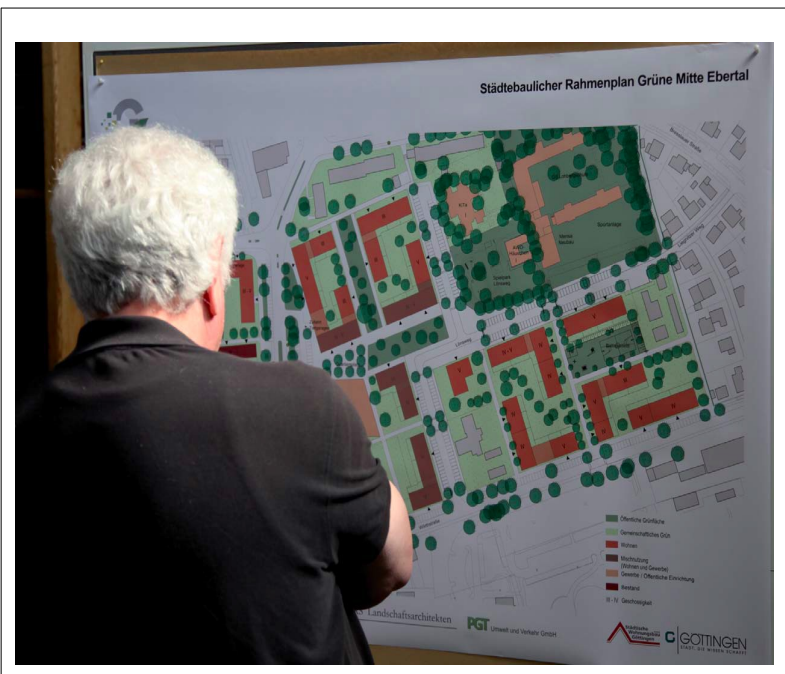

Abb. 79: SWB - Grüne Mitte Ebertal 2019 umfangreichen Maßnahmen Mieter nicht zu verdrängen, sondern im Quartier eine andere Wohnung zur Verfügung zu stellen. Sie führt dies in Absprache mit Mietern durch, die auch in die Planung einbezogen werden wie es auch beim aktuellen Projekt "Grüne Mitte Ebertal" zu sehen ist.

Die Nachfrage nach Wohnungen der SWB ist entsprechend groß und die Leerstandsquote mit 0,3\% sehr gering (2018).

Es gibt Mieterbeiräte, drei Mieterbüros im Stadtteil (Leineberg, Holtenser Berg, Ebertal). Die SWB beteiligt sich an der Einrichtung eines Nachbarschaftszentrums auf dem Holtenser Berg.

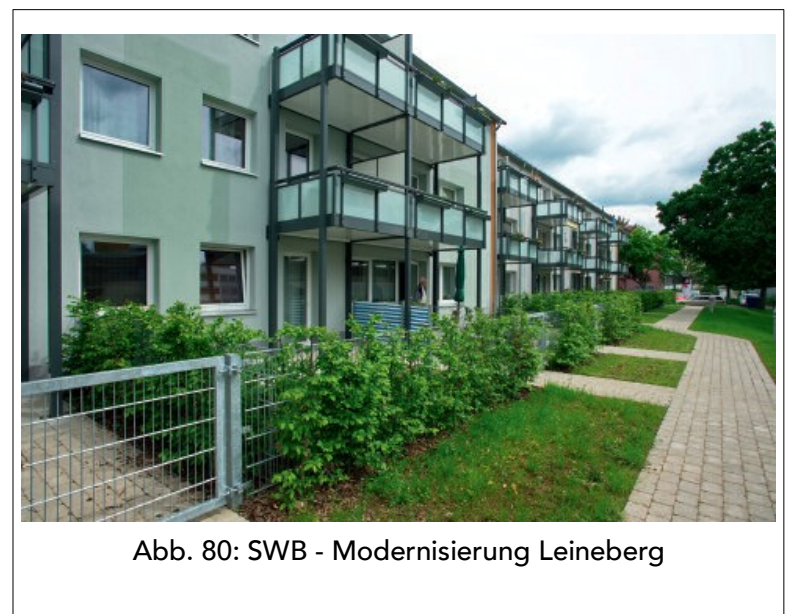

Es lassen sich noch weitere positive Tätigkeiten der SWB aufzählen (Mietergärten, Spielplatz- und Freiflächengestaltung, sozialpolitische Eigenverpflichtungen, Berücksichtigung ästhetischer Ansprüche beim Neubau).

Bei alledem wirtschaftet die SWB wie ein „normales” Unternehmen d.h auf Rentabilität verpflichtet. Sie hat in den vergangenen 10 Jahren ihren Eigentümern, der Stadt Göttingen und der Sparkasse Göttingen, zuverlässig jährliche Gewinne zwischen 2 und 3 Millionen Euro beschert.

Das erweckt den Eindruck, dass eine ordentliche, bezahlbare Wohnungsversorgung mit einer privatwirtschaftlichen Organisationsform, durch den "Markt", möglich ist. Doch dieser Eindruck trügt. Denn Unternehmen wie die SWB oder auch Wohnungsgenossenschaften folgen einem anderen Unternehmensziel (oder sollten es), nämlich nicht dem der Gewinnmaximierung, der Ausnutzung aller Marktmöglichkeiten und gesetzlich eingeräumten Freiheiten, das eingesetzte Geld zu vermehren. 
Es liegt die Frage nahe, warum angesichts der Knappheit an bezahlbarem Wohnraum eine kommunale Wohnungsbaugesellschaft wie die SWB nicht viel mehr Wohnungen baut. Immer wieder hat es dazu auch im Rat der Stadt entsprechende Anträge gegeben (etwa auf Kapitalaufstockung). Es ist - so scheint es - die SWB selbst, die bremst. Angeführt werden verschiednen Begründungen:

Es fehle schlichtweg an Personal / Fachkräften (die SWB hat rd. 40 Beschäftigte, vor 2017 waren es rd. 30).

Es fehle an schnell kopierbaren Planungs"modulen"; früher habe die NILEG gute Wohnungs- und Gebäudeentwürfe geliefert, die zügig und mit relativ geringem Arbeitsaufwand hätten übernommen werden können.

Inzwischen sei die Bauwirtschaft so ausgelastet, das Neubau nur verzögert und deutlich teurer möglich sei (Baukosten $2700 €$ /qm, 2200 E/qm).

Manchmal fehle es auch an Bauland / Baurecht.

Der große Zusatzbedarf an bezahlbarem Wohnraum (in Göttingen) sei erst vor 4-5 Jahren deutlich geworden.

Mit solch einem Bündel von Argumenten, die hier auch nicht im Einzelnen überprüft werden können, wird auf widrige Umstände verwiesen. Diese - und nicht eine Unternehmensstrategie - seien verantwortlich dafür, dass die SWB nicht mehr bezahlbare Wohnungen gebaut oder ältere Bestände gekauft und saniert habe.

Doch dies wäre noch genauer zu prüfen: Welche Unternehmensstrategie verfolgt die SWB? Welche Strategie wollen ihre Eigentümer, vor allem die Stadtregierung?

Die Tatsache, dass eine Wohnbaugesellschaft sich in kommunalem Besitz befindet, bedeutet nicht automatisch, dass sie gut für bezahlbaren Wohnraum arbeitet. Es kann sein, dass kommunale Wohnbaugesellschaften ihren Wohnungsbestand nicht pflegen, weil der Eigentümer, die Kommune, finanzielle oder andere Mittel verweigert. Oder - als entgegengesetzte Variante dass die Wohnbaugesellschaft vor allem schöne Wohnungen zu bauen hat, dafür aber eher wenige. Weil die kommunalen Wohnbaugesellschaften Instrument der kommunalen Politik sind, ist ihre Unternehmensstrategie auch Spiegel der wechselnden Interessen von Parteien und Verwaltung.

Vor mehr als 10 Jahren gab es Bestrebungen, die SWB zu verkaufen („privatisieren”), die CDU konnten sich damit jedoch nicht durchsetzen. Die Erweiterung der SWB durch den Aufkauf der damals noch günstigen Altbestände von Baubecon oder Gagfah-alt war der Stadtregierung damals allerdings zur risikoreich. Die Mahnung der SWB - in den Geschäftsberichten zwischen 2008 und 2015 immer wiederes gebe einen
Fehlbedarf an bezahlbaren Wohnraum in Göttingen, gerade auch als Folge von Hartz IV, ignorierte die Stadtregierung weitgehend. Zwar hat die SWB ihr Neubauvolumen in den letzten 10 Jahren gegenüber den Jahren davor verdoppelt - aber das ist absolut gesehen nicht so viel. Laut Statistik (Gösis) besitzt die SWB 2018183 Mietwohnungen mehr als 2008.

Aus Geschäftsberichten der SWB :

2008: „Gleichzeitig ist am Mietmarkt festzustellen, dass die Nachfrage nach preiswertem Wohnraum weiterhin zunimmt. Diese Entwicklung war bereits der Wohnungsmarktbeobachtung 2005 zu entnehmen. Die Auswirkungen der Hartz IV-Reform tragen weiterhin dazu bei,.."

2011: "Während das Angebot im Bereich des höherpreisigen Mietwohnungsbestandes eine ausreichende Auswahl bietet, ist eine stetig steigende Nachfrage nach preiswertem Wohnraum am Göttinger Mietmarkt festzustellen. Die drastische Einschränkung der staatlichen Förderung, die zum Erliegen des sozialen Wohnungsbaus führt, trägt dazu wesentlich bei. Die Auswirkungen der Hartz IV-Reform verstärken die Nachfrage nach Wohnraum im unteren Preissegment."

2013: „Der Wohnungsmarkt in Göttingen ist angespannt, was sich am deutlichsten an der großen Nachfrage nach bezahlbarem Wohnraum zeigt. "

Dass die von rot-grün unter Schröder intensivierte neoliberale Soziale Marktwirtschaft Strukturen geschaffen hat, die den kommunalen bzw. insgesamt den öffentlichen Wohnungsbau behindert und diskreditiert haben, ist unbestritten. Dass diese Strukturen so nachhaltig wirken und zählebig und starr einer Ausweitung des kommunalen Wohnungsbaus entgegen stehen, mag manche überraschen.

Es steht ausser Frage, dass es eine Rekommunalisierung der Wohnungsversorgung, einen größeren Umfang von gutem, bezahlbaren Wohnraum durch kommunalen Wohnungsbaugesellschaften braucht. Aber außer mehr Mittel (Geld, Boden, Personal) braucht es offensichtlich auch andere Kontroll- und Mitsprachemöglichkeiten als die bisherigen, von (Partei)Politik geprägten. Wie diese gestaltet werden sollten, muss in einer breiten und intensiven Diskussion über Vergesellschaftung des Wohnungsbaus geklärt werden. 


\section{Eine grundlegend neue Wohnungspolitik ist notwendig}

\section{NEUE GEMEINNÜTZIGKEIT - LANDESWOHNUNGSBAUGESELLSCHAFT}

$\mathrm{D}$ ie bisherige Wohnungspolitik führt spätestens seit Aufgabe der Wohnungsgemeinnützigkeit 1990 in eine Sackgasse. Die Politik gesteht das indirekt ein, wenn sie von "der sozialen Frage unserer Zeit" spricht (Seehofer wie auch die SPD 2018). Doch befristete Sonderabschreibungen und erhöhte Fördermittel reichen nicht. Ein nur an Rendite ausgerichteter, privat organisierter Wohnungsmarkt leistet erkennbar keine Wohnungsversorgung bezahlbar und für alle ausreichend. Strukturelle Lösungen sind notwendig.

Zwei derartige, am Gemeinwohl ausgerichtete Reformansätze zur Wohnungspolitik sollen hier angeführt werden: neue Gemeinnützigkeit und öffentlicher Wohnungsbau.

\section{Neue Wohnungs-Gemeinnützigkeit}

Von vielen wird die Wiedereinführung der Gemeinnützigkeit gefordert. Sie sehen in diesem Instrument eine aus gesamtwirtschaftlicher Sicht sehr effektive staatliche Intervention. Die Grünen und Die Linke haben dazu schon entsprechende Anträge im Bundestag gestellt, bisher erfolglos.

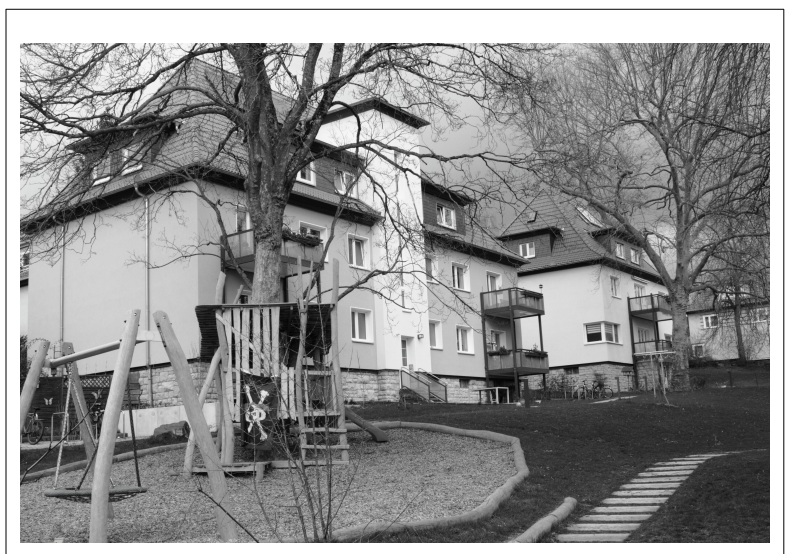

Abb. 81: Wohnungsgenossenschaft- Modernisierung Nonnenstieg

Gemeinnützige Wohnungsunternehmen sind keine Erfindungen des Staates oder seiner Kommunen. Wohnreformer haben sie Mitte des 19.Jahrhunderts entwickelt. Ihr Ziel war es, Wohnungen für sozial benachteiligte Haushalte zu errichten. Gemeinnützige Wohnungsunternehmen sollten daher nicht nach dem Gewinn-, sondern dem Kostendeckungsprinzip arbeiten, sich auf den Wohnungsbau beschränken und Dividendenausschüttungen begrenzen.
In Göttingen wurde 1878 als erste die Gemeinnützige Baugesellschaft gegründet, sie baute am Egelsberg. 1889 kam der Göttinger Spar- und Bau-Verein dazu, 1944 umgewandelt in Wohnungsgenossenschaft e.G.m.b.H. Göttingen ${ }^{51}$. 1948 wurde die Volksheimstätte eG gegründet und 1960 von der Stadt Göttingen und der Niedersächsischen Heimstätte die Städtische Wohnungsbau mbH (seit 1963 Städtische Wohnungsbau $\mathrm{GmbH}$ )

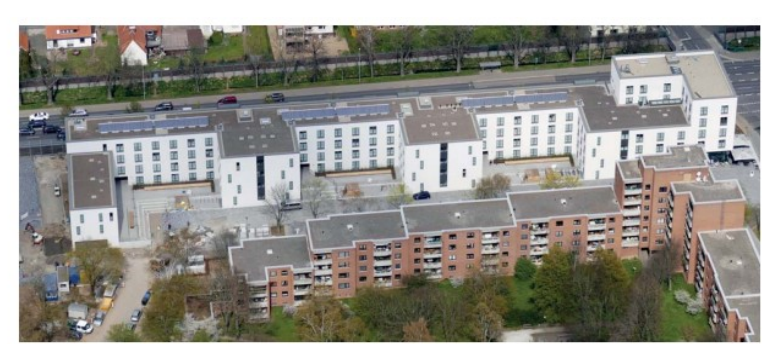

Abb. 82: Wohnungsgenossenschaft - Neubau Adam-vonTrott-Weg

Die Neue Wohnungsgemeinnützigkeit (NWG) will ein Wohnungsmarktsegment wieder einrichten, in dem für die Unternehmen gilt, ihr Handeln an den Aufwendungskosten und nicht am Gewinn zu orientieren. Sie sollen einer Gewinnbeschränkung unterliegen und von Steuernder Gewerbe-, Körperschafts-, Grund- und Grunderwerbssteuer - befreit oder zumindest entlastet werden. Erwirtschaftete Überschüsse sollen als revolvierender Fonds wieder investiert werden. Neu ist der Vorschlag, die NWG in dem Auftrag sozialer Wohnraumversorgung konkret auf eine einkommensorientierte Mietgestaltung - Begrenzung der Mietbelastungsquoteund die Versorgung bestimmter Mietergruppen festzulegen. Neu ist auch die Forderung, die befristete Sozialbindung bei öffentlich geförderten Wohnungen aufzuheben und die Miethöhe bei steigenden Einkommen über eine Mietbelastungsquote anzupassen. Neu ist ebenfalls, Mieter*innen über eine Mietermitbestimmung deutlich mehr Mitbestimmungsund Kontrollrechte einzuräumen.

Es liegen sehr detaillierte Konzeptionen vor. Sie prüfen die Durchsetzbarkeit (Vereinbarkeit mit EU-Recht z.B.) und diskutieren mögliche negative Effekte (z.B. Segregation). DieLinken haben schon 2016 einen entsprechenden Antrag im Bundestag eingebracht, Bündnis90/DieGrünen jüngst (Februar 2020) erneut einen Antrag gestellt. Doch der Bundesverband deutscher Wohnungs- und Immobilienunternehmen (GdW) und 
andere stehen dem kritisch gegenüber. Vielleicht weil sie an angespannten Wohnungsmärkten interessiert sind? So wird im Deutschen Institut für Urbanistik (difu) vermutet ${ }^{52}$.

\section{Landeswohnungsbaugesellschaft ${ }^{53}$}

Der DGB Niedersachsen hat Anfang 2019 eine neue soziale Wohnungspolitik vorgeschlagen, um bezahlbaren Wohnraum dauerhaft und ausreichend zu sichern. Zum einen (Säule 1) soll die Förderung des sozialen Wohnungsbaus geändert werden, so dass deutlich mehr gebaut und die zeitlich befristete Mietpreisbindung in eine dauerhafte umgewandelt wird. Zum anderen (Säule 2) soll die öffentliche Hand - das Land - selbst Wohnungsbau betreiben. Zur Ergänzung und Unterstützung des kommunalen Wohnungsbaus soll als „elementare Säule” eine Landeswohnungsbaugesellschaft gegründet werden, die bis 2030 mindestens 40.000 Wohnungen in "angespannten Wohnungsmärkten" Niedersachsens baut. Das Besondere daran ist nicht nur die Zielsetzung, gute Wohnungen für untere und mittlere Einkommen zu schaffen bei einer Mietbelastungsquote von höchstens $25 \%$. Es ist die rechtliche und wirtschaftliche Konstruktion:

- Die Gesellschaft soll eigenständig sein, und zwar in der Rechtsform einer Anstalt öffentlichen Rechts (AöR), die über Verwaltungsrat und Fachbeirat politisch direkter zu steuern sei als eine $\mathrm{GmbH}$.

- Ihr Eigentum soll unveräußerlich sein (In der Verfassung verankertes Verbot der Privatisierung von Wohnungsbeständen).

- Die Anteilseigner der Gesellschaft verzichten auf Gewinnausschüttungen, stattdessen Reinvestition in Modernisierung und Neubau und somit Aufbau eines öffentlichen Vermögens (öffentliche Gelder für öffentliche Vermögen).

- Das Anfangskapital kommt aus den Landeshaushaltsmitteln, Investitionskredite werden bei der (öffentlichen) $\mathrm{N}$-Bank aufgenommen.

- Mietermitbestimmung durch Mieterbeiräte.

- In sozialer, baulicher und ästhetischer Hinsicht handelt die Landeswohnbaugesellschaft gemeinwohlorientiert (Stadtrendite statt Aktionärsrendite).

Das DGB-Papier enthält noch weitere Vorschläge. Es sind Vorschläge, über die sicher noch diskutiert werden muss. So ist zu überlegen, ob Wohnungsbau und Wohnungsbewirtschaftung organisatorisch nicht getrennt werden sollten; letztere braucht eine eher lokale/regionale Form und Mitwirkung. Eine Landeswohnungsbaugesellschaft könnte - in Anlehnung an die Tätigkeiten der früheren landeseigenen NILEGPlanungs"module" (für Geschosswohnungsbau und Wohnquartiere) entwerfen und die kommunalen Woh-
DGB-Vorschlag zur niedersächsischen Wohnungspolitik

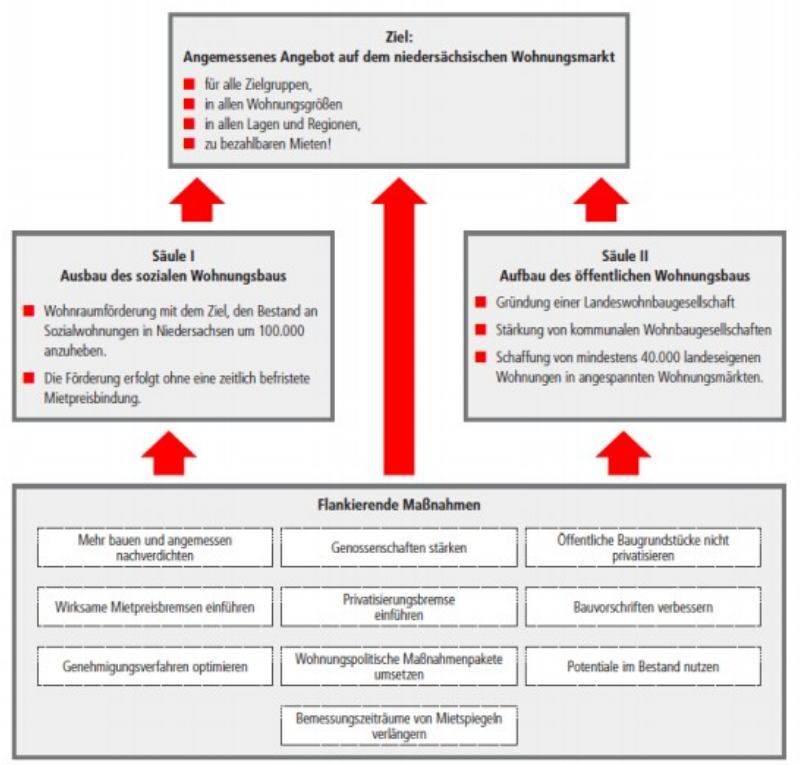

Abb. 83: Vorschlag des DGB Niedersachsen für eine neue Wohnungspolitik (2019)

nungsbaugesellschaften auf diese Weise unterstützen und beschleunigen. Zu diskutieren ist auch Frage, wie eine Landeswohnungsbaugesellschaft kontrolliert werden sollte, um Entwicklungen wie bei der Neuen Heimat zu verhindern.

Der DGB-Vorschlag will und kann ein produktiver Anstoss sein zu einer Strategiediskussion über die Struktur und Funktionsweise eines neuen gemeinnützigen Wohnungsmarktsegments.

In der letzten Zeit wird oft ein gemeinnütziger oder gemeinwohlorientierten Wohnungsbau gefordert. Die Forderung kritisiert die herrschende Wohnungsbaupolitik, die ihrerseits in Anspruch nimmt, dass sie im Sinne des Allgemeinwohls handelt. Offenbar wird unter dem Begriff Allgemeinwohl ganz Unterschiedliches, vielleicht sogar Unvereinbares, verstanden. Um das zu prüfen, sollte geklärt werden, welchen Inhalt das Allgemeinwohl hat, das die Politik meint und durchsetzt, und welchen Bedingungen das Wohlergehen aller darin unterworfen wird. 


\section{Eine grundlegend neue Wohnungspolitik ist notwendig \\ 30 SOZIALES BODENRECHT, ÖFFENTLICHES GRUNDEIGENTUM}

D ie hohen Bodenpreise und der Mangel an Bauland werden immer wieder als zentrale Hindernisse für bezahlbares Wohnen angeführt: Es braucht einen anderen Umgang mit Grund und Boden. An Vorschlägen mangelt es nicht. ${ }^{54} \mathrm{Die}$ meisten sind sich darin einig, dass das vom Staat eingerichtete Verfügungsmonopol über das private Grundeigentum stärker beschränkt werden muss. Mit den bestehenden Möglichkeiten des Baugesetzbuches und des Steuerrechts lassen sich Stadtentwicklung und besonders Wohnungsversorgung nicht ausreichend steuern.

\section{Privates Grundeigentum regulieren}

Steuerliche Sonderregeln abschaffen

Die Grunderwerbssteuer (GrESt) von 3,5\% bis 6,5\% (je nach Bundesland) entfällt bei so genannten share deals, wenn also nur $94,9 \%$ der Anteile an der bodenbesitzenden Personen- oder Kapitalgesellschaft gekauft werden und die restlichen $5,1 \%$ erst nach 5 Jahren; Veräußerungsgewinne aus dem Verkauf von Grund und Boden bleiben steuerfrei (statt Steuersatz von $30 \%$ ), wenn sie innerhalb von vier Jahren in den Kauf von Grund und Boden, Gebäuden oder ,Aufwuchs' reinvestiert werden (§ 6b EStG)

\section{Planungswertausgleich}

Der Wert eines Grundstücks kann erheblich steigen, wenn die Stadtplanung eine intensivere, ertragreichere Nutzung ermöglicht (siehe das Beispiel IWF $\rightarrow$ Kap. 9). Die Abschöpfung einer solchen planungsinduzierten Bodenpreissteigerung durch die Kommune ist immer wieder in der Diskussion. Sie wie auch Modelle einer Bodenwertzuwachssteuer werden vor allem immer dann besonders laut gefordert, wenn Städte rasch wachsen und umgebaut werden müssen, aber Bodenspekulation die stadtplanerische Gestaltung der Wachstumsprozesse preislich verhindert oder zeitlich verzögert. Gehen Wirtschaftswachstum und Stadtwachstum wieder zurück, schrumpft auch der Ruf nach Reformen. Und sollte es in der Zwischenzeit tatsächlich zu rechtlich geregelten Interventionsmöglichkeiten gekommen sein - wie z.B. im Städtebauförderungsgesetz von 1971 - , werden sie nicht bzw. nur in Ausnahmefällen genutzt.

Aktuell können Kommunen so etwas wie einen Planungswertausgleich nur mit dem schwachen Instrument einer privatrechtlichen Vereinbarung (wie Städte- baulicher Vertrag) versuchen durchzusetzen. In bebauten Gebieten ohne Bebauungsplan (Baurecht nach $\S$ 34 BauGB) ist es bislang kaum möglich, weshalb hier die Bodenspekulation besonders blüht; auch die allgemeine Bodenspekulation wird mit diesem Instrument nicht eingedämmt.

Bau- und Mietpreise steigen über jedes Maß, zuerst aber über das, das dem sozialen Wohnungsbau gesetzt ist. Während oder weil 800000 Familien in der Bundesrepublik noch immer keine menschenwürdige, eigene Wohnung besitzen, treibt die Bodenspekulation ihre Blüten. ... Dem Grundgesetz, das die soziale Bindung von Grund und Boden postuliert, ist Hohn gesprochen worden. Und das wird weiter geschehen, wenn mit dem unvermehrbaren Gut Boden weiter gehandelt werden kann wie mit jeder anderen Ware."

(DIE ZEIT vom 9.10.1970)

Bodenwertzuwachssteuer, Bodensteuer, Bodenwertsteuer, Ertragswertverfahren, Grundsteuer $C$

Zur Zähmung des privaten Grundeigentums, zur Regulierung seiner Freiheiten so, dass es das gesamtwirtschaftliche Wachstum nicht unnötig behindert, sind schon zahlreiche Modelle der Besteuerung diskutiert und probiert worden. Das reicht von der schon Ende des 19.Jh. entwickelten Bodenwertsteuer über die Wiedereinführung der Grundsteuer $C$ (auf unbebautes Land mit Baurecht, sie gab es sie bereits kurz in den 1960er Jahren) bis hin zum Ertragswertverfahren der aktuellen Grundsteuerreform. Die meisten dieser Modelle wurden bald wieder abgeschafft: Die gewünschten sozialpolitischen Steuerungseffekte waren gering und der Aufwand für die Erhebung und Rechtssicherheit meist sehr gross. Die Funktion von Boden als profitable Kapitalanlage und Spekulationsobjekt wird durch steuerliche Reformen ohnehin nicht beseitig ${ }^{55}$, im günstigsten Fall gedämpft.

\section{Öffentliches Grundeigentum schaffen}

\section{Ausweitung des kommunalen Vorkaufsrechts}

Das bestehende Instrument Vorkaufsrecht ist in seiner rechtlichen wie finanziellen Handhabung wenig tauglich. Notwendig ist zumindest ein preislimitiertes Vorkaufsrecht, bei dem sich der zu zahlende Kaufpreis 
nicht am Marktpreis, sondern allenfalls am Ertragswert orientiert. Eine derartige Refom könnte vorteilhaft sein zur Schaffung oder Erhaltung bezahlbaren Wohnraums sowie für eine kommunale Politik der Bodenbevorratung. Im Rahmen der bestehenden Regulierung könnte auch an anderen Stellschrauben gedreht werden: Verlängerung der Erwerbsfristen, die Möglichkeit einer Bauverpflichtung mit Fristsetzung für Nachverdichtung und Innenentwicklungso Vorschläge des Deutschen Städtetages (2017) und des Deutschen Instituts für Urbanistik (difu) (2017) ${ }^{56}$ - bis hin zu einem gesetzlich gesicherten Vorkaufsrecht für alle Hausgemeinschaften (Mietersyndikat $\rightarrow$ Kap. 27)

\section{Erbbaurecht und Konzeptvergabe}

Der Vorschlag: Grundstücke in öffentlicher Hand sollen nicht verkauft, sondern es sollen nur Erbbaurechte vergeben werden (vor allem im Bereich Wohnen). Kommunen könnten damit weitreichenden Einfluss auf die Nutzung des Grundstücks nehmen und im Erbbauvertrag umfangreiche Auflagen festlegen. Die Konzeptvergabe von Nutzungsrechten - statt nach Höchstpreisen - soll bodenpreissteigernde Wirkungen eindämmen. Nur die Verbindung von Erbbaurecht und Konzeptvergabe sichere die soziale Bodennutzung, so der Deutsche Städtetag (2017).

\section{Bodenfonds}

Weitergehend ist der Vorschlag, einen kommunalen bzw. öffentlichem Bodenfonds einzurichten. Der Fonds kauft Grundtücke, vor allem im Hinblick auf bezahlbares Wohnen und Errichtung sozialer Infrastruktur, und übernimmt auch die Aufgabe der Erschließung. Dadurch wird eine strategische Entwicklung der Stadt erleichtert und kostengünstiger (s. Beispiel Ulm). Mögliche Gewinne des Fonds werden wieder angelegt (revolvierender Fonds). Der Fonds handelt auch interkommunal und sollte außerhalb des kommunalen Haushalts angesiedelt sein mit einer Anschubfinanzierung durch Bund/Land.

\section{Bodenräte}

Es braucht eine andere Kontroll- und Lenkungsinstanz für öffentliches Grundeigentum als die gegenwärtige. Sie sollte aus Mieterräten, Nachbarschaft, kommunalen Vertretern, kommunalen wie gemeinwohlorientierten Wohnungsbauunternehmen, u.a. zusammengesetzt sein und eine kollektive Form zur Sicherung der Interessen vieler Akteuere und zur Verhinderung von Privatisierungen und unsozialen Mietsteigerungen haben.

Gegen derartige Vorschläge gibt es heftigen neoliberalen Gegenwind:
„Es hat einen Grund, dass noch keine demokratische Gesellschaft Grund und Boden in öffentliches Eigentum überführt hat. Der Markt ist unabdingbar, um mit der fundamentalen Knappheit des Bodens umzugehen. Das Gemeinwohl ist ein hehres Ziel, aber ein schlechter Massstab."

Nikolas Piper (Leiter Ressort Wirtschaft der Süddeutschen Zeitung) SZ vom 28.8.2018

Die Knappheit an Boden wird hier in einen quasi natürlichen, unveränderbaren Sachverhalt, einen „Sachzwang", verwandelt, der dann angeblich nur durch privates Eigentum gut bewirtschaftet kann. Eine typische neoliberale Behauptung zur Rechtfertigung des "Marktes", die unterschlägt, dass die Knappheit eine gesellschaftlich und politisch hergestellte ist.

Viele der angeführten Reformvorschläge sind, wie angedeutet, nicht neu. Sie begleiten die Stadtentwicklung seit über 150 Jahren. In Phasen, in denen Städte rasch wachsen, werden die negativen Wirkungen des Privateigentums an Grund und Boden besonders deutlich und entsprechend der Ruf nach Reformen lauter. Lässt der Wachstumsdruck nach, versenken Grundeigentümer und Politiker die Reformideen wieder. Man denke nur an die Zeit Ende 1960er/Mitte 1970er Jahre und den Kampf der SPD gegen Bodenspekulation. Und das "Vergessen" aller Reformideen ab Mitte der 1970er Jahre - bis heute.

Warum ist das so? Weil es um etwas Grundsätzliches geht. Der bloße Gedanke an Eigentumsbeschränkung, stösst auf massive Gegenmacht, weil er das Fundament des Kapitalismus zersetzt (Hubeli 2020). Das Privateigentum ist so unbedingt und prinzipiell aufrechtzuerhalten, dass die "Leistungsgesellschaft" sogar leistungslose (Grund)Renteneinkommen, selbst wenn sie zu Lasten anderer gesellschaftlicher Gruppen gehen, schützt und rechtfertigt. Auch die (meisten) Bodenreformvorschläge respektieren und wollen das Privateigentum und den "freien Markt”, wenn sie fordern, die private Verfügungsmacht über den Boden zu stutzen. Die Reformen sind ein Versuch der Zähmung, der sich selbst zur Daueraufgabe erklärt. Seit über 150 Jahren.

Um diese „Daueraufgabe” zu überwinden, muss auch grundsätzlich darüber nachgedacht werden: Kann es mit Privateigentum an Grund und Boden in der gegenwärtigen Form überhaupt ein Ende der Wohnungsfrage geben? 


\section{QUELLEN UND LITERATUR}

\section{Abbildungen}

DGB 2019: Abb. 82.

Mietshäuser Syndikat: Abb. 77.

Stadt Göttingen: Abb. 28, 49-51, 63.

Städtische Wohnungsbau, Geschäftsberichte: Abb. 78, 79.

Wohnungsgenossenschaft, Geschäftsberichte: Abb. 81.

www.goest.de : Abb. 27, 65-70.

Alle übrigen Abbildungen von den Autoren.

\section{Anmerkungen}

(nächste Seite) 
1 Die GEWOS geht in einem Gutachten (GEWOS 2013) davon aus, dass der Ersatzbedarf in Göttingen 160 Wohneinheiten pro Jahr beträgt. Ein hoher Anteil der neu erstellten Wohnungen wäre danach Ersatzbedarf und keine Bestandserweiterung.

2 GEWOS 2013: Wohnbauflächenbedarfsprognose Göttingen 2025. p. 53.

3 Die Mietangebote wurden in den Portalen immoscout24 und immonet erhoben. Mietverträge, die nicht über diese Portale vermittelt wurden, sind also nicht erfasst. Es ist davon auszugehen, dass die nicht inserierten Mietverträge etwas günstiger sind. Da hier insbesondere der zeitliche Vergleich von Interesse ist, ist diese Verzerrung für den hiesigen Zweck von minderem Interesse.

4 LuXemburg 2/2019: Das Geschäftsmodell beruht auf der Enteignung der MieterInnen - Interview mit Knut Unger. In: Schöner Wohnen, Zeitschrift hrsg, von Rosa-Luxemburg-Stiftung, S. 20-25 (https://www.zeitschriftluxemburg.de/schoener-wohnen-luxemburg-2_2019/).

5 Unger, Knut 2018: Mieterhöhungsmaschinen. Zur Finanzialisierung und Industrialisierung der unternehmerischen Wohnungswirtschaft. In: Prokla 191, 218, S. $211 \mathrm{f}$.

Kofner , S. 2012: Aktuelle Geschäftsmodelle von Finanzinvestoren im Themenfeld Wohnungswirtschaftlicher Wandel und neue Finanzinvestoren. NRW Landtag 16/375, S. $265 \mathrm{ff}$.

6 Handelsblatt vom 18.2.2020: „Immer mehr Investoren lehnen Milliarden-Fusion am Wohnungsmarkt ab”.

7 ausführlich: Belina, Bernd 2015: Miete. In: Historisch-Kritisches Wörterbuch des Marxismus, Bd. 9/I, S. 858-870.

8 Statistisches Bundesamt 2018, Pressemitteilung vom 5.12.2019. Der Anteil der Wohnungsgenossenschaften am Mietwohnungsbestand betrug 23\% und der von öffentlichen und kommunalen Wohnungsunternehmen $4 \%$.

9 https://investoren.vonovia.de/websites/vonovia/German/2050/aktionaersstruktur.html; 19.12.19

${ }^{10}$ Quelle: http://mieteraktionärin.de/wohin-fliessen-die-mieten-der-vonovia-1/\#more-201; 19.12.2019; vgl auch: Unger, Knut: Der Konflikt mit der Vonovia spitzt sich zu. (= Rosa-Luxemburg-Stiftung, Standpunkte 3/2019).

${ }^{11}$ Garcia-Landa, A, / Trautvetter, Ch. 2019: Wem zahle ich eigentlich Miete? Den finanzialisierten Immobilienmarkt verstehen - Ein Recherchehandbich für Mieter*innen. Berlin www.rosalux.de.

${ }^{12}$ ARE: Finanzbericht 2. Quartal 2018, S. $18 \mathrm{f}$.

${ }^{13}$ Ganz anders dazu heißt es im Geschäftsbericht der ARE für 2018: „Als professioneller Vermieter stellt ADLER routinemäßig sicher, dass die entsprechenden Vorschriften zum Brandschutz in allen Objekten des Konzerns eingehalten werden. Gleichwohl wurden alle Property-Manager wiederholt für das Thema sensibilisiert und beauftragt, alle einschlägigen Maßnahmen zur Brandverhütung und Bekämpfung sorgfältig zu überprüfen, bei Bedarf auch in Zusammenarbeit mit den für den Brandschutz zuständigen Behörden."

${ }^{14}$ Mitteilung der ARE am 27.12.2017 (http://www.dgap.de/dgap/News/corporate/adler-real-estate-neuesfuehrungsteam-steuert-wachstum-und-wertsteigerung/?newsID=1045323; 25.11.2018)

15 „Die Bewertung von Immobilien ist ein zentrales Thema bei Immobilienaktiengesellschaften. ... Die Bewertung wird im Wesentlichen durch die Parameter Diskontierungs-/Kapitalisierungszins, Marktmiete und Leerstand beeinflusst." ( Adler Real Estate: Jahresabschluß 2018, S. 62)

${ }^{16}$ Der Geschäftsführer Rafie Elizei ist laut ww.goest.de „in vielfältiger Weise geschäftlich mit der Sparkasse Göttingen verbunden". Zu den Aktivitäten: RegJo Nr. 25/2015, vgl. auch https://stadtentwicklunggoettingen.wordpress.com/2019/01/25/marktgesteuerte-stadtentwicklung-und-ihrepolitische-durchsetzung-zum-teil-verkauf-des-iwf-gelaendes-an-wertgrund/\#more-1254

${ }^{17}$ GBC AG 2018: Researchstudie Coreo AG, S. 25. Online verfügbar unter: https://www.coreo.de/fileadmin/Investor_Relations/Aktie/Research/2018_11_30_GBC_CoreoResearch.pdf. Zum Share Deal vgl. Coreo AG 2018: Geschäftsbericht 2018, S. 26. Online verfügbar unter: https://www.coreo.de/fileadmin/Investor_Relations/Finanzberichte/2018/2018_Coreo_Konzern_GB_DE_layouted. pdf. Sämtliche Internseiten für diesen Artikel wurden zuletzt am 01.02.2020 abgerufen.

${ }^{18}$ Coreo AG 2018: Wertpapierprospekt vom 26. November 2018, S. 72. Online verfügbar unter: https://www.coreo.de/fileadmin/Investor_Relations/Aktie/2018/WPP/2018_11_26_Coreo_Prospekt.pdf.

${ }^{19}$ Ebd., S. 59.

${ }^{20}$ GBC AG 2018, S. 7.

21 Ebd., S. 25.

22 Coreo AG 2019: Coreo verkauft Teil des Göttinger Portfolios. Pressemitteilung. Online verfügbar unter: http://n.eqs.com/c/fncls.ssp?u=RAVXYWYUNQ.

${ }^{23}$ Vgl. untere masch 13 2019: Die UM13 ist noch da! Video (02:58 Minuten). Online verfügbar unter: https://vimeo.com/354194208. 
24 Huber, Sascha 2019: Coreo AG. Interview mit Vorstandschef Marin Marinov und Finanzchef Felix Krekel. 16. Januar 2019. Online verfügbar unter: https://www.finanztrends.info/coreo-ag-interview-mit-vorstandschef-marinmarinov-und-finanzchef-felix-krekel/. Zur Fläche vgl. Coreo AG: Portfolio. Online verfügbar unter https://www.coreo.de.

${ }^{25}$ Coreo AG: Aktionärsstruktur. Grafik auf https://www.coreo.de.

26 Siehe SRC 2019: Coreo AG. Online verfügbar unter: http://www.src-research.de/uploads/tx_studien/Coreo_21November2019.pdf.

27 Huber 2019.

${ }^{28}$ https://www.boerse-muenchen.de/Anleihe/DE000A2LQE54.

29 GBC AG 2018, S. 6.

30 SRC 2019, S. 3.

${ }^{31}$ Coreo AG 2018, S. 102, S. 118.

32 "Our strategy is to own for generations and create scale effects and efficiencies (buy \& hold), and therefore different from a financial investor with a limited investment horizon (buy \& sell)." (Vonovia 2020: Investor Presentation January 2020.)

33 Johannisstrasse, $120 \mathrm{qm}, \quad 16,70 € / \mathrm{m}^{2}$ Johannisstrasse, $47 \mathrm{qm}, \quad 15,95 € / \mathrm{m}^{2}$ Mauerstrasse, $50 \mathrm{qm}, \quad 15,80 € / \mathrm{m}^{2}$ Bürgerstrasse, $25 \mathrm{qm}, \quad 17,60 € / \mathrm{m}^{2}$ Obere Masch Strasse, 20 qm, 17,25 €/m² Abgerufen von Immobilienscout24; 7.3.2020.

${ }^{34} 2019$ von Wertgrund und HANSAINVEST übernommen, heisst jetzt WohnSelect Kapitalverwaltungsgesellschaft $\mathrm{mbH}$.

${ }^{35}$ In wenigen Fällen können auch Sozialleistungsbezieher Wohngeld erhalten.

${ }^{36}$ Hubert, F. / Tomann, H. 1991: Der Erwerb von Belegungsrechten im Wohnungsbestand - eine ökonomische Wirkungsanalyse. Gutachten für das BMBau

${ }^{37}$ Antrag der B'90/Die Grünen-Ratsfraktion betr. "Wohnungsbau jetzt! - Aber wirklich." vom 01.12.2016 sowie Ergänzungsantrag der SPD-Fraktion vom 16.12.2016 (als Ratsvorlage am 27.1.2017)

${ }^{38}$ s. GEWOS 2017: Analyse und Prognose der sozialen Wohnraumversorgung in der Stadt Göttingen.

${ }^{39}$ https://stadtentwicklunggoettingen.wordpress.com/2020/01/04/zur-kritik-des-kommunalen-handlungskonzepteszur-schaffung-und-sicherung-von-bezahlbarem-wohnen/

${ }^{40}$ Prognos 2019: Wer baut Deutschland? Studien zum Wohnungsbautag 2019. Prognos AG Berlin.

${ }^{41}$ Ebd.

${ }^{42}$ Krummacher, Michael 1081: Wohnungspolitik in der BRD. In: Prokla 45, S. 99.

${ }^{43}$ DIW 2018 : Grabka, Markus M.; Goebel, Jan: Einkommensverteilung in Deutschland: Realeinkommen sind seit 1991 gestiegen, aber mehr Menschen beziehen Niedrigeinkommen. In: DIW-Wochenberichte 21, 2018.

${ }^{44}$ GEWOS 2017: Analyse und Prognose der sozialen Wohnraumversorgung in der Stadt Göttingen.

${ }^{45}$ Zur Kritik: Frieling, H.-D. Von 2020: Göttingen - Kommunales Handlungskonzept zur Schaffung und Sicherung von bezahlbarem Wohnraum in Göttingen. (https://stadtentwicklunggoettingen.wordpress.com/2020/01/04/zur-kritikdes-kommunalen-handlungskonzeptes-zur-schaffung-und-sicherung-von-bezahlbarem-wohnen/)

${ }^{46}$ Landeshauptstadt München 2019: Münchner Jahreswirtschaftsbericht 2019. S. 70.

${ }^{47}$ Detaillierte Untersuchung dazu: Klinge, Tobias J. 2015,: Der Göttinger Bodenmarkt im Zuge der Wirtschafts- und Finanzkrise. Eine GIS-gestützte empirische Untersuchung anhand von Bodenrichtwerten. Bachelorarbeit Geographie, Univ. Göttingen.

${ }^{48}$ Fehlberg/Mießner 2015.

${ }^{49}$ DGB-Bezirk Niedersachsen - Bremen - Sachsen-Anhalt 2019: Bezahlbarer Wohnraum für alle! Schritte aus der Wohnungskrise in Niedersachsen. S.28 (http://www.niedersachsen.dgb.de)

${ }^{50} \mathrm{http}: / / g o e s t . d e / s t u d e n t e n h e i m e . h t m$

${ }^{51}$ Zur Geschichte der Göttinger Wohnungsgenossen sehr informativ die Festschrift der Wohnungsgenossenschaft "1891-2016. 125 Jahre Wohnungsgenossenschaft eG Göttingen" (www.wg-goe.de).

52 Nach Holm Andrej; Horlitz, Sabine; Jensen, Inga 2017: Neue Wohnungsgemeinnützigkeit. Voraussetzungen, Modelle und erwartete Effekte. Rosa-Luxemburg-Stiftung, Studien 5/2071, S. 5. 
${ }^{53}$ https://niedersachsen.dgb.de/presse/++co++cd92e15a-22f6-11e9-877b-52540088cada

${ }^{54}$ Eine ausführliche und kritische Übersicht geben: Heinz, Werner; Belina, Bernd : Die kommunale Bodenfrage. In: Studien 2/2019 der Rosa-Luxemburg-Stiftung, 2019. Dort auch die Quellenangaben zu den verschiedenen Vorschlägen.

${ }^{55}$ Das haben schon Brede, Helmut; Dietrich, Barbara; Kohaupt, Dietrich: Politische Ökonomie des Bodens und Wohnungsfrage. Frankfurt a.M. 1976 gezeigt.

${ }^{56}$ DStGB (Deutscher Städte- und Gemeindebund) 2018: Bezahlbaren Wohnraum schaffen. Kommunale Instrumente der Baulandmobilisierung. Dokumentation Nr. 47.

Deutscher Städtetag 2017: Neuausrichtung der Wohnungs- und Baulandpolitik. Positionspapier des Deutschen Städtetages,. Berlin/Köln 2017.

difu (Deutsches Institut für Urbanistik) 2017: Bodenpolitische Agenda 2020-2030. Warum wir für eine nachhaltige und sozial gerechte Stadtentwicklungs- und Wohnungspolitik eine andere Bodenpolitik brauchen. Berlin 2017. 


\section{LITERATUR}

Belina, Bernd 2015: Miete. In: Historisch-Kritisches Wörterbuch des Marxismus, Bd. 9/I, S. 858-870.

Deutscher Städtetag 2017: Neuausrichtung der Wohnungs- und Baulandpolitik. Positionspapier des Deutschen Städtetages,. Berlin/Köln 2017.

DBG (DGB-Bezirk Niedersachsen-Bremen-Sachsen-Anhalt) 2019: Bezahlbarer Wohnraum für alle! Schritte aus der Wohnungskrise in Niedersachsen. www.niedersachsen.dgb.de.

difu (Deutsches Institut für Urbanistik) 2017: Bodenpolitische Agenda 2020-2030. Warum wir für eine nachhaltige und sozial gerechte Stadtentwicklungs- und Wohnungspolitik eine andere Bodenpolitik brauchen. Berlin 2017.

DIW (Deutsches Institut für Wirtschaftsforschung) 2018 : Grabka, Markus M.; Goebel, Jan: Einkommensverteilung in Deutschland: Realeinkommen sind seit 1991 gestiegen, aber mehr Menschen beziehen Niedrigeinkommen . In: DIW-Wochenberichte 21, 2018

Fehlberg, T. / Mießner, M. (2015): Mietpreissteigerungen und Wohnungsengpässe abseits der Ballungsräume. Investitionen in B-Lagen und Regionalzentren - das Beispiel Göttingen. In: sublurban. zeitschrift für kritische stadtforschung. 3. Jg., H. 1, S. 25-44 (URL: http://www.zeitschrift-suburban.de/sys/index.php/suburban/article/view/167).

Frieling, H.-D. von 2014: Wohnraum. In: Belina, Bernd / Nauman, Matthias / Strüver,; Anke (Hrsg.): Handbuch Kritische Stadtgeographie. Münster: Westfälisches Dampfboot, S. 141-146.

Frieling, H.-D. von 2020: Göttingen - Kommunales Handlungskonzept zur Schaffung und Sicherung von bezahlbarem Wohnraum in Göttingen.

https://stadtentwicklunggoettingen.wordpress.com/2020/01/04/zur-kritik-des-kommunalenhandlungskonzeptes-zur-schaffung-und-sicherung-von-bezahlbarem-wohnen/

Frieling, H.-D. von: Armut und Agenda 2010 in Göttingen. Ein kritischer Armuts- und Reichtumsbericht. Geographisches Institut der Georg-August Universität, Abteilung Humangeographie Göttingen, PURL: http://resolver.sub.uni-goettingen.de/purl/?webdoc-2098.

GEWOS 2013: Wohnbauflächenbedarfsprognose Göttingen 2025.

GEWOS 2016: Wohnraumbedarfsprognose Göttingen 2030.

GEWOS 2017: Analyse und Prognose der sozialen Wohnraumversorgung in der Stadt Göttingen.

Heinz, Werner / Belina, Bernd 2019: Die kommunale Bodenfrage. In: Studien 2/2019 der Rosa-LuxemburgStiftung, 2019.

Holm, A. / Horlitz, S. / Jensen. I. 2017: Neue Wohnungsgemeinnützigkeit. Voraussetzungen, Modelle und erwartete Effekte. (=Studien 5/2017) Rosa-Luxemnurg-Stiftung.

Hubeli, Ernst 2020: Die neue Krise der Städte. Zur Wohnungsfrage im 21. Jahrhundert. Rotpunktverlag, Zürich.

INGrone (Verein für interkulturelle Nachbarschaft in Grone e.V.) 2019: Göttingen Grone - Objekt spekulierender Immobiliengesellschaften. Manuskript, Januar 2019.

Junker, Stephan 2018: Wohnverhältnisse in Deutschland. Mietbelastung, soziale Ungleichheit und Armut Kurzgutachten im Auftrag des Sozialverband Deutschland e. V. (sovd.de)

Marlow, R. /Mießner, M. 2019: Immobilieninvestitionen und Verdrängung in Universitätsstädten. Das Beispiel Göttingen. In: Forum Wissenschaft, 36. Jg., H. 2, S. 12-15. 
(https://stadtentwicklunggoettingen.wordpress.com/2019/12/04/mietpreisentwicklung-2019/\#more1288.)

Mießner, M. 2017: Studentische Wohnungen als Anlageobjekte. Zu den sozialräumlichen Implikationen einer Investitionsstrategie in der Universitätsstadt Göttingen. In: RaumPlanung - Fachzeitschrift für räumliche Planung und Forschung, H. 1, S. 46-51.

Mießner, M. 2019: Studentifizierung in Göttingen. Ein Beispiel für sozialräumliche Verdrängung in deutschen Universitätsstädten. In: Geographische Rundschau 10/2019, S. 22-27.

Mießner, M. / Klinge, T. J. 2017: Sozialräumliche Segregation in der Universitätsstadt Göttingen. Verdrängungsprozesse im Spannungsfeld von Investorenstrategien und sozial gerechter Wohnraumversorgung. In: Dittrich, C. / Harteisen, U. / Reeh, T. (Hg.): Land und Stadt: Lebenswelten und planerische Praxis. Göttinger Geographische Abhandlungen, Bd. 121). Göttingen, S. 117-140.

Pestel Institut/ ARGE// eV 2018: Das Baujahr im Fakten-Check.

Stadt Göttingen 2018: Göttinger Bündnis für bezahlbares Wohnen. Gemeinsames Bekenntnis zur Schaffung von neuem, insbesondere bezahlbarem Wohnraum in Göttingen. Laufzeit: 2018 - 2030. Broschüre 9 Seiten.

Stadt Göttingen 2018: Kommunales Handlungskonzept zur Schaffung und Sicherung von bezahlbarem Wohnraum in Göttingen.

Stadt Göttingen 2019: Kommunales Handlungskonzept - Monitoring für das Jahr 2018. Foliensatz vorgestellt im Ausschuss für Soziales, Integration, Gesundheit und Wohnungsbau am 13.08.2019.

GAG 2019: Grundstücksmarktbericht 2019. Northeim: Landesamt fur Geoinformation und Landesvermessung Niedersachsen (LGLN) Regionaldirektion Northeim.

\section{Autoren}

Hans-Dieter von Frieling, geb. 1945, Dr., ist Wirtschaftsgeograph, ehemaliger wissenschaftlicher Mitarbeiter am Geographisches Institut der Georg-August-Universität Göttingen. Forschungsgebiete: Politische Ökonomie der Stadt- und Regionalentwicklung, sozialräumliche Ungleichheit in der Stadt, Entwicklung von Armut und Wohnungsversorgung..

Michael Mießner, geb. 1985, Dr., ist wissenschaftlicher Mitarbeiter am Institut für Geographie der Technischen Universität Dresden. Er lehrt und forscht zu regionaler und ländlicher Entwicklung, zu Immobilienmärkten abseits der Großstädte sowie zur Raumordnungspolitik Deutschlands.

Robin Marlow, studiert Kulturanthropologie an der Georg-August-Universität Göttingen und arbeitet zu Prozessen der Göttinger Stadtentwicklung und des Wohnungsmarktes. 
Impressum:

Dr. Michael Mießner, TU Dresden, Institut für Geographie Helmholtzstr. 10, 01069 Dresden

humangeo@mailbox.tu-dresden.de 